Organizadores Márcio Minto Fabricio Rosaria Ono

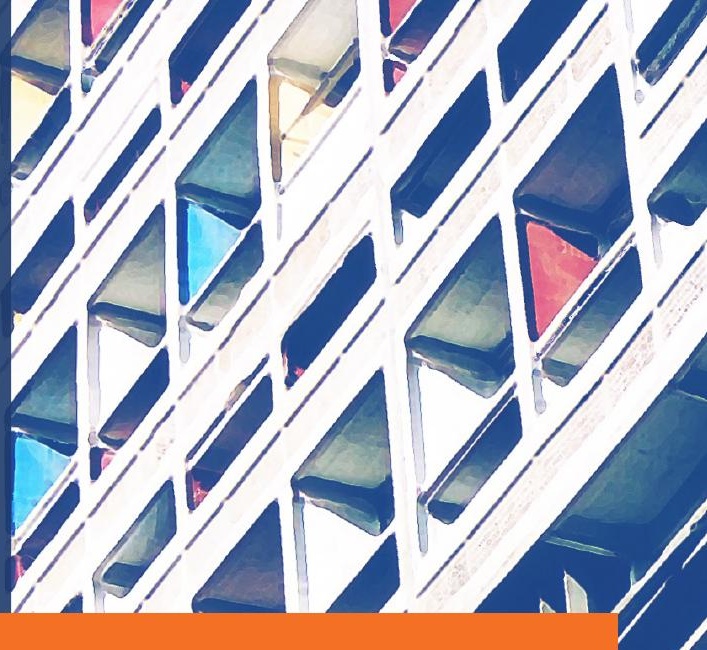

Avaliação de Desempenho de Tecnologias Construtivas Inovadoras

Manutenção e

Percepção dos Usuários

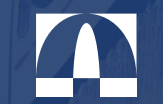

casonsoges

antac

$a^{N} A$ A

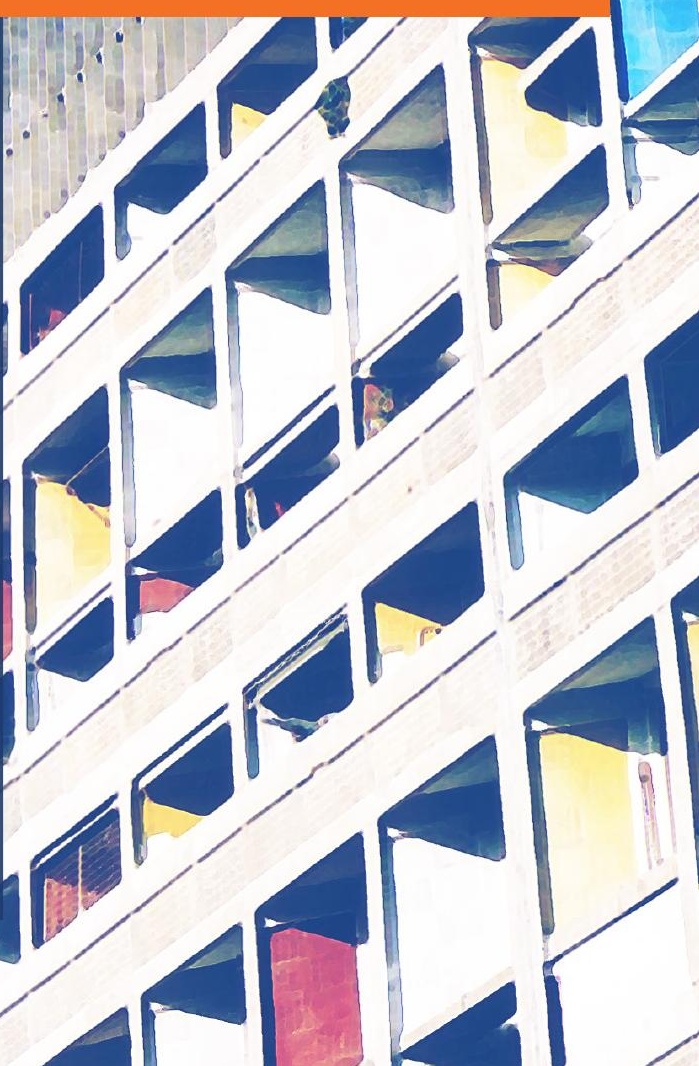




\author{
Organizadores \\ Márcio Minto Fabricio \\ Rosaria Ono
}

\title{
Avaliação de Desempenho de Tecnologias Construtivas Inovadoras
}

Manutenção e Percepção dos Usuários

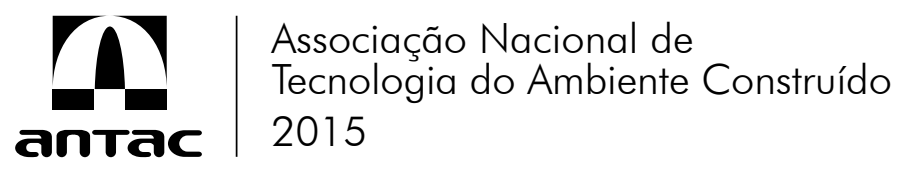


Ficha catalográfica preparada pelo Serviço de Biblioteca "Prof. Dr. Sergio Rodrigues Fontes" da EESC/USP

\author{
A945 \\ Avaliação de desempenho de tecnologias \\ construtivas inovadoras [recurso eletrônico] : \\ manutenção e percepção dos usuários / \\ organizadores: Márcio Minto Fabrício, Rosaria \\ Ono. -- [Porto Alegre] : ANTAC, 2015. \\ 1 livro eletrônico \\ ISBN 978-85-89478-42-7 \\ 1. Desempenho. 2. Inovação tecnológica. 3. SINAT \\ - Sistema Nacional de Avaliações. 4 Habitabilidade. \\ 5. Manutenção Predial. 6. Sistemas Construtivos. \\ I. Fabricio, Márcio Minto. II. Ono, Rosaria.
}

DOI: 10.4322/978-85-89478-42-7

A distribuição é gratuita, não sendo permitida a sua venda. 


\section{Agradecimentos}

À Finep: Inovação e Pesquisa, pelo suporte à rede de pesquisa

Desenvolvimento de métodos e metodologias para avaliação de desempenho de tecnologias inovadoras no âmbito do Sistema Nacional de Avaliação Técnica INOVATEC/Finep e pelo apoio financeiro dado à publicação deste livro.

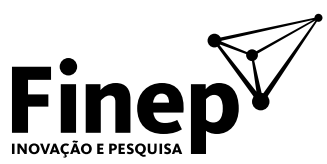

Ministério da Ciência, Tecnologia e Inovação

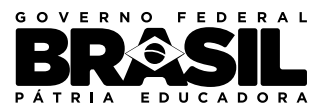





\section{Autores e Colaboradores}

\section{Alexsandra Rocha Meira}

Graduação em Engenharia Civil pela Universidade Federal da Paraíba (1993), mestrado em Engenharia de Produção pela Universidade Federal da Paraíba (1996) e doutorado em Engenharia de Produção pela Universidade Federal de Santa Catarina (2002). Atualmente é professora titular do Instituto Federal de Educação, Ciência e Tecnologia da Paraíba.

\section{Claudia de Andrade Oliveira}

Graduação em Engenharia Civil pela Escola de Engenharia de Lins, mestrado e doutorado em Engenharia de Construção Civil e Urbana pela Escola Politécnica da Universidade de São Paulo. Atualmente é professora doutora da Faculdade de Arquitetura e Urbanismo da Universidade de São Paulo.

\section{Cláudio Vicente Mitidieri Filho}

Graduação em Engenharia Civil pela Universidade de São Paulo (1980), mestrado em Engenharia Civil pela Universidade de São Paulo (1988) e doutorado em Engenharia Civil pela Universidade de São Paulo (1998). Atualmente é pesquisador sênior do Instituto de Pesquisas Tecnológicas do Estado de São Paulo, especialista em Sistemas Construtivos e Desempenho de Edificações Habitacionais e docente do Mestrado Profissional em Habitação do Instituto de Pesquisas Tecnológicas do Estado de São Paulo. 


\section{Dimas de Assis Albuquerque Teixeira}

Graduação em Construção de Edifícios pelo Instituto Federal de Educação, Ciência e Tecnologia da Paraíba (2014). Atualmente é prestador de serviço da Secretaria de Planejamento da Prefeitura Municipal de João Pessoa (PB).

\section{Fabiana Lopes de Oliveira}

Graduação em Engenharia Civil pela Universidade Estadual do Maranhão (1993), mestrado em Engenharia Civil pela Universidade de São Paulo (1996), doutorado em Engenharia Civil pela Universidade de São Paulo (2001), pós-doutorado pela Universidade de São Paulo (2003). Atualmente é professora doutora da Universidade de São Paulo.

\section{Luis Carlos Bonin}

Graduação em Engenharia Civil pela Universidade Católica de Pelotas (1983), mestrado em Engenharia pela Universidade Federal do Rio Grande do Sul (1987). Atualmente é Professor Assistente da Universidade Federal do Rio Grande do Sul. Tem experiência na área de Engenharia Civil, com ênfase em Construção Civil. Atuando principalmente nos seguintes temas: Planejamento, Produção de Edificações.

\section{Gibson Rocha Meira}

Graduação em Engenharia Civil pela Universidade Federal da Paraíba (1989), mestrado em Engenharia de Produção pela Universidade Federal da Paraíba (1995) e doutorado em Engenharia Civil pela Universidade Federal de Santa Catarina (2004), e pelo Instituto de Ciencias de la Construcción Eduardo Torroja, Espanha. Atualmente é professor titular do Instituto Federal de Educação, Ciência e Tecnologia da Paraíba, professor do Programa de Pós-graduação em Engenharia Urbana e Ambiental da UFPB e colaborador no Programa de Pós-graduação em Engenharia Civil da UFPE.

\section{Iara Del' Arco Sanches}

Graduação em Arquitetura e Urbanismo pela Universidade Estadual de Londrina (2004) e mestrado em Arquitetura e Urbanismo pela Universidade de São Paulo (2011).

\section{Karin M. S. Chvatal}

Graduação em Engenharia Civil pela Universidade Estadual de Campinas. Mestrado em Engenharia Civil pela Universidade Estadual de Campinas. Doutorado em Engenharia Civil pela Faculdade de Engenharia da Universidade do Porto. Atualmente é professora doutora da Universidade de São Paulo. 


\section{Khaled Ghoubar}

Graduação em Arquitetura e Urbanismo pela Universidade de São Paulo (1973), mestrado em Arquitetura e Urbanismo pela Universidade de São Paulo (1980), doutorado em Arquitetura e Urbanismo pela Universidade de São Paulo (1987), livre-docência pela Universidade de São Paulo (2000). Atualmente é professor titular da Universidade de São Paulo.

\section{Lucia Zanin Shimbo}

Doutorado em Arquitetura e Urbanismo pela Universidade de São Paulo, Pós-doutorado pela Universidade de São Paulo. Atualmente, é docente da Universidade de São Paulo.

\section{Luciano Ferreti}

Graduação em Arquitetura pela Universidade Guarulhos (1983), Mestrado em Arquitetura e Urbanismo pela Universidade de São Paulo (2008). Atualmente é doutorando no Programa de Pós-Graduação da Faculdade de Arquitetura e Urbanismo da Universidade de São Paulo (desde 2014).

\section{Maisa Beatriz M. Fausto da Silva}

Graduação em Construção de Edifícios pelo Instituto Federal de Educação, Ciência e Tecnologia da Paraíba (2012). Atualmente é bolsista do Instituto Federal de Educação, Ciência e Tecnologia da Paraíba.

\section{Marcio Minto Fabricio}

Graduação em Engenharia Civil pela Universidade Federal de São Carlos (1993), mestrado em Arquitetura e Urbanismo pela Universidade de São Paulo (1996), doutorado em Engenharia pela Universidade de São Paulo (2002), livre-docência em Arquitetura, Urbanismo e Tecnologia pela Universidade de São Paulo (2008). Atualmente é professor da Universidade de São Paulo.

\section{Marina Estela Martins}

Graduação em Engenharia Civil pela Escola de Engenharia de São Carlos.

\section{Miguel Antonio Buzzar}

Graduação em Arquitetura e Urbanismo pela Universidade de São Paulo (1980), mestrado em Estruturas Ambientais Urbanas pela Universidade de São Paulo (1996) e doutorado em Estruturas Ambientais Urbanas pela Universidade de São Paulo (2002). Atualmente é professor associado da Universidade de São Paulo. 


\section{Nelma Mirian Chagas de Araújo}

Graduação em Engenharia Civil pela Universidade Federal da Paraíba (1989), mestrado em Engenharia de Produção pela Universidade Federal da Paraíba (1998) e doutorado em Engenharia de Produção pela Universidade Federal da Paraíba (2002).

\section{Rosa Carolina Abrahão Amancio}

Graduação em Arquitetura e Urbanismo pela Universidade Tuiuti do Paraná, especialização em Gestão e Tecnologia de Sistemas Construtivos de Edificações pela Universidade Federal de São Carlos, mestrado em Construção Civil pela Universidade Federal do Paraná.

\section{Rosaria Ono}

Graduação em Arquitetura e Urbanismo pela Universidade de São Paulo (1987), mestrado em Engenharia pela Nagoya University (1991) e doutorado em Arquitetura e Urbanismo pela Universidade de São Paulo (1997). Atualmente é professora titular da Universidade de São Paulo.

\section{Sheila W. Ornstein}

Doutorado em Arquitetura e Urbanismo pela Universidade de São Paulo (1988). Atualmente é professora titular da Universidade de São Paulo e Diretora do Museu Paulista da Universidade de São Paulo.

\section{Victor F. Roriz}

Graduação em Engenharia Mecânica pela Universidade Federal de Uberlândia (2002), mestrado em Construção Civil pela Universidade Federal de São Carlos (2007), doutorado em Engenharia Civil, Arquitetura e Urbanismo pela Universidade Estadual de Campinas (2011) e pós-doutorado pelo Instituto de Arquitetura e Urbanismo pela Universidade de São Paulo (2013). Atualmente é colaborador da Universidade de São Paulo, professor da Faculdades Dom Pedro II, revisor de periódico da Ambiente Construído (Online) e pesquisador do Instituto de Arquitetura e Urbanismo da Universidade de São Paulo.

\section{Walter José Ferreira Galvão}

Graduação em Arquitetura e Urbanismo pela Faculdade de Belas Artes de São Paulo (1990), especialização em Conforto Ambiental e Conservação de Energia pela Universidade de São Paulo (2001), mestrado em Arquitetura pela Universidade de São Paulo (2007) e doutorado em Arquitetura pela Universidade de São Paulo (2012). Atualmente é docente na Faculdade de Arquitetura e Urbanismo da UNINOVE. 


\section{Apresentação da ANTAC Gestão 2015-2016}

Fundada em 1987, a ANTAC (Associação Nacional de Tecnologia do Ambiente Construído) é uma associação técnico-científica, de caráter multidisciplinar, que reúne pesquisadores e técnicos envolvidos com a produção e transferência de conhecimentos na área de tecnologia do ambiente construído. Esta área integra profissionais das mais diversas especialidades, tais como Engenheiros, Arquitetos, Físicos, Químicos e Sociólogos, que atuam em Construção Civil, Tecnologia de Arquitetura e Habitação. Embora constituída majoritariamente por pesquisadores e docentes vinculados a universidades e institutos de pesquisa, a Associação conta também com inúmeros associados vinculados a órgãos públicos e empresas privadas.

Para acompanhar e contribuir no desenvolvimento científico e tecnológico da construção civil, a ANTAC congrega seus associados em grupos de trabaIho (GTs), que organizam discussões mais aprofundadas e específicas de cada área. Seus membros promovem publicações e participam de workshops, encontros, projetos e revisões de normas.

A ANTAC executa atividades como: a publicação da Revista Ambiente Construído integrada a biblioteca eletrônica de periódicos científicos Scielo; a participação nos fóruns de discussão sobre o tema da Ciência, Tecnologia \& Inovação (C,T\&l) no Ambiente Construído nas instâncias governamentais e junto às entidades ligadas aos agentes privados da cadeia produtiva; a discussão e formulação políticas de C,T\&l para o Ambiente Construído com tais agentes; o estabelecimento de formas de interação com as agências de fomento à pesquisa em tecnologia do ambiente construído; aproximações temáticas e busca de atuações conjuntas com Associações afins; a promoção de eventos direcionados à comunidade de C,T\&l e 
com impacto nos setores produtivos da construção civil e finalmente a modernização das relações da entidade com seus grupos de trabalho, em particular para a realização dos eventos e edição de livros.

Os livros que compõem a Coleção ANTAC são uma iniciativa da associação no âmbito da edição de livro compilando contribuições científicas de Redes Cooperativas de Pesquisa coordenadas e/ou com a participação de pesquisadores associados. Assim como a edição de livros de conteúdos acadêmicos desenvolvidos por pesquisadores ativos nos grupos de trabalho da ANTAC na área de tecnologia do ambiente construído.

O livro em questão - Coleção ANTAC: Rede Cooperativa de Pesquisa INOVATEC/Finep - trata do primeiro volume de apresentação dos resultados de pesquisa da Rede Cooperativa que aborda o desempenho e a avaliação de desempenho em sistemas construtivos inovadores no Âmbito do SiNAT - Sistema Nacional de Avaliações Técnicas.

ANTAC Gestão 2015-2016

Regina C. Ruschel, UNICAMP, Presidente ANTAC

José de Paula Barros Neto, UFC, Vice-presidente ANTAC

Eduardo Luis Isatto, UFRGS, Diretor Financeiro ANTAC

Paulo Roberto Pereira Andery, UFMG, Diretor Administrativo ANTAC

Alex Abiko, USP, Diretor de Relações Inter-institucionais ANTAC

Aldomar Pedrini, UFRN, Diretor de Divulgação ANTAC 


\section{Prefácio}

\section{Luis Carlos Bonin}

A implantação do Sistema Nacional de Avaliação Técnica - SiNAT, em 2007, para avaliar novos produtos utilizados nos processos de construção e a publicação da revisão da NBR 15575 - Edificações habitacionais: Desempenho, em 2013, que estabelece os requisitos e critérios de desempenho que se aplicam às edificações habitacionais, resultaram na criação de um novo cenário tecnológico para o setor de produção de edificações da construção civil brasileira.

Este novo cenário, por um lado, propiciou uma oportunidade para o desenvolvimento porque definiu objetivamente um referencial para a inovação e estimulou a melhoria contínua da qualidade do ambiente construído. Além disso, ao definir este referencial, permitiu a diferenciação entre os produtores de edificações capazes ou não de cumprir os requisitos e critérios formulados, melhorando assim a competição no setor.

Por outro lado, ele significou um grande desafio pois, apesar de resultar de estudos e experiências tecnológicas já discutidas em instituições brasileiras há mais de três décadas e em instituições estrangeiras há muito mais tempo, ele se estabeleceu antes de a cultura da comunidade técnica nacional ter evoluído para se apropriar do conteúdo e dos objetivos tanto do SiNAT quanto da NBR 15575. Não surpreende, portanto, a existência de lacunas de conhecimento a serem preenchidas em futuras revisões da NBR 15575 ou da documentação técnica operacional do SiNAT.

Acentua este desafio a carência de infraestrutura tecnológica voltada especificamente ao atendimento das necessidades da construção civil brasileira, principalmente de laboratórios de ensaios e testes e de uma interação mais intensa entre as instituições de ensino e pesquisa e as empresas produtoras atuantes na 
fabricação de produtos para a construção, na elaboração de projetos, na execução dos serviços de construção nos canteiros de obras ou na manutenção do ambiente construído.

Esta publicação apresenta uma parte dos resultados obtidos por uma rede de pesquisa que envolveu a participação de dez instituições tecnológicas brasileiras selecionadas no edital 07/2009 da Finep - Inovação e Pesquisa - com o objetivo de aprofundar o conhecimento sobre critérios de desempenho e desenvolver novos métodos de avaliação que possam ser utilizados no aperfeiçoamento da NBR 15575 e subsidiar a elaboração de novas diretrizes de avaliação de produtos de construção inovadores no SiNAT.

Alguns dos capítulos desta publicação apresentam e discutem ferramentas de trabalho elaboradas para imediata utilização na avaliação de produtos de construção inovadores no âmbito do SiNAT. Sua divulgação numa versão resumida nesta publicação e em maiores detalhes nos relatórios de resultados disponibilizados no site da rede INOVATEC, representa uma efetiva contribuição para superar o desafio citado.

Outros capítulos propõem uma reflexão consistentemente embasada sobre temas relacionados ao conteúdo da NBR 15575 ou da documentação de referência do SiNAT, ampliando o domínio destes temas e preparando o caminho para seu futuro aperfeiçoamento.

Evidentemente não existia nas atividades dos pesquisadores participantes da rede INOVATEC a pretensão de preencher todas as lacunas de conhecimento existentes na NBR 15575 ou revisar todos os procedimentos operacionais do SiNAT, mas sim contribuir topicamente na superação de algumas das limitações ora existentes. Este objetivo foi, sem dúvida alguma, atingido. 


\section{Sumário}

1. A Rede INOVATEC/Finep: sua contribuição

ao SiNAT/PBQP-Habitat e à norma brasileira NBR 155751

Márcio Minto Fabricio

Rosaria Ono

2. 0 sistema brasileiro de avaliação técnica de produtos inovadores para a Construção Civil ${ }^{I}$

Rosa Carolina Abrahão Amancio

Márcio Minto Fabricio

Cláudio Vicente Mitidieri Filho

Rosaria Ono

3. Avaliação técnica do produto de construção

inovador: contexto brasileiro e internacional

Rosa Carolina Abrahão Amancio

Márcio Minto Fabricio

4. Procedimentos para a avaliação de desempenho de sistemas construtivos inovadores em uso com vistas ao atendimento à NBR 15575:2013

Rosaria Ono

Fabiana L. Oliveira

Sheila W. Ornstein

Walter J. F. Galvão

Khaled Ghoubar 
5. Avaliação do desempenho térmico de habitações segundo a ABNT NBR 15575

Karin M. S. Chvatal

Victor F. Roriz

6. A questão da manutenção de

sistemas construtivos inovadores

para habitação

Lucia Zanin Shimbo

Marina Estela Martins

7. Avaliação da manutenibilidade em sistemas construtivos inovadores

lara Del'Arco Sanches

Márcio Minto Fabrício

Miguel A. Buzzar

8. Contribuição ao estudo sobre uso e manutenção de sistemas construtivos inovadores: Light steel framing e paredes de concreto com formas de PVC incorporadas

Claudia de Andrade Oliveira

Luciano Ferreti

9. Custos de manutenção efetivos e potenciais:

um estudo em habitações de interesse social com sistema construtivo inovador

Maisa Beatriz M. Fausto da Silva

Dimas de Assis Albuquerque Teixeira

Alexsandra Rocha Meira

Nelma Mirian Chagas de Araúio

Gibson Rocha Meira 


\section{Cap. 1}

A Rede INOVATEC/Finep: sua contribuição ao SiNAT/PBQP-Habitat e à norma brasileira NBR 15575

\author{
Márcio Minto Fabricio \\ Rosaria Ono
}

A Rede de Pesquisa "Desenvolvimento de métodos e metodologias para avaliação de desempenho de tecnologias inovadoras no âmbito do Sistema Nacional de Avaliação Técnica", Rede INOVATEC, foi implementada em 2011 pelo edital $n^{\circ}$ 07/2009 da Finep - Inovação e Pesquisa. A proposta da rede era desenvolver e aprimorar critérios de desempenho e novos métodos de avaliação relativos à durabilidade e à vida útil de projeto de produtos e sistemas construtivos inovadores, que possam subsidiar futuras diretrizes SiNAT (Sistema Nacional de Aprovações Técnicas) dentro do PBQP-H (Programa Brasileiro de Qualidade e Produtividade do Habitat), considerando os aperfeiçoamentos demandados pela nova norma NBR 15575: Edifícios Habitacionais - Desempenho (ABNT, 2013). Assim, a rede tinha como missão propor adequações dos métodos e critérios do SiNAT à nova Norma, bem como considerar a aceitação dos usuários às tecnologias inovadoras.

A rede INOVATEC/Finep foi estruturada em seis subprojetos que tratam de áreas temáticas diferentes. São elas:

i. Gestão: responsável por gerir e estimular a articulação da rede;

ii. Durabilidade: encarregado de avaliar a durabilidade de materiais, componentes e elementos construtivos inovadores;

iii. Ambiental: responsável pela avaliação ambiental de produtos e sistemas construtivos inovadores; 
iv. SiNAT: encarregado de contribuir com o aperfeiçoamento da NBR 15575 e do SiNAT;

v. Uso e Manutenção: responsável por elaborar manuais para avaliação de desempenho do usuário para gestão da qualidade do projeto e de tecnologias construtivas inovadoras;

vi. Estrutura: encarregado de definir procedimentos para avaliação estrutural de sistemas inovadores.

Desde o início, privilegiou-se o desenvolvimento de métodos de avaliação que permitissem considerar os impactos de uso e de manutenção de tecnologias inovadoras junto à população atendida por programas habitacionais como - Minha Casa, Minha Vida.

Como resultado do projeto foram elaboradas propostas de critérios e métodos para avaliação de desempenho, incluindo os requisitos de durabilidade, sustentabilidade, habitabilidade, adequação ao uso e aceitação pelo usuário dos produtos e sistemas construtivos inovadores.

Dentro deste contexto, a presente coletânea reúne contribuições de parte dos pesquisadores participantes da rede que trabalharam especificamente nos subprojetos "SiNAT" e "Uso e Manutenção", provenientes das seguintes instituições: IFPB - Instituto Federal de Educação Ciência e Tecnologia da Paraíba; USP/FAU - Faculdade de Arquitetura e Urbanismo da Universidade de São Paulo; USP/ IAU - Instituto de Arquitetura e Urbanismo da Universidade de São Paulo e do IPT - Instituto de Pesquisa Tecnológicas do Estado de São Paulo.

São encartados nove capítulos de diferentes autores, sendo que, neste capítulo 1, além de se realizar uma breve apresentação e contextualização da Rede INOVATEC/Finep, apresenta-se uma descrição sucinta dos conteúdos abordados neste volume. Os dois capítulos seguintes fazem parte do subprojeto "SiNAT", iniciando com o capítulo 2 que realiza uma introdução ao SiNAT (Sistema Nacional de Aprovações Técnicas) e à sua estrutura de funcionamento, dentro do PBQP-H (Programa Brasileiro de Qualidade e Produtividade do Habitat) do Ministério das Cidades. O objetivo deste é contextualizar o panorama em que se faz a inserção das atividades da Rede INOVATEC/Finep.

O terceiro capítulo aborda a estrutura e o funcionamento do SiNAT sob o ponto de vista dos sistemas análogos de avaliação técnica de produtos inovadores para construção civil existentes em outros países, ressaltando suas semeIhanças e diferenças, considerando possibilidades de aprimoramentos futuros do sistema vigente.

Do capítulo 4 em diante, as questões e os temas tratados, pertencentes ao subprojeto "Uso e Manutenção", consideram preocupações com questões de uso e manutenção de sistemas construtivos inovadores e também das formas de avaliação do seu desempenho em uso.

Assim, no capítulo 4, é proposto um conjunto de procedimentos para avaliação de desempenho em uso de sistemas construtivos inovadores, 


\section{A Rede INOVATEC/Finep: sua contribuição ao SiNAT/PBQP-Habitat e à norma brasileira NBR 15575}

considerando tanto o ponto de vista técnico como o do usuário e seu nível de satisfação com o edifício. Propõe-se um conjunto de instrumentos que possam subsidiar aprimoramentos dessas habitações que empregam sistemas construtivos inovadores tanto na fase de projeto e construção, como também no seu uso e manutenção.

O capítulo 5, por sua vez, trata da análise de um requisito específico de desempenho das habitações - o desempenho térmico - trazendo uma leitura crítica dos critérios de avaliação deste requisito da norma NBR 15575, sua relação com a norma NBR 15220 - Desempenho térmico de edificações e com a RTQ-R - Regulamento técnico da qualidade para o nível de eficiência energética em edificações residenciais, assim como apresenta propostas para o seu aprimoramento.

No capítulo 6, o tema tratado é a manutenção de sistemas construtivos inovadores sob o ponto de vista da disponibilidade e da qualificação de sua mão-de-obra, uma vez que sistemas construtivos não-convencionais exigem cuidados diversos dos usuais e, por vezes, procedimentos, materiais e equipamentos especializados. Apresenta-se, neste capítulo, resultados de pesquisa realizada sobre este enfoque num empreendimento, por meio de coleta de informações de múltiplas fontes, de sujeitos participantes do processo de construção, uso e manutenção das habitações.

O capítulo 7 apresenta, inicialmente, uma discussão conceitual sobre a manutenção no processo de produção industrial e destaca, em seguida, a importância da manutenibilidade, analisando a evolução deste tema no contexto do SiNAT e das normas brasileiras de manutenção, NBR 5674, e de desempenho em edifícios habitacionais, NBR 15575. Como resultado da pesquisa, um método de avaliação da qualidade das informações para manutenção e a facilidade de manutenção por parte do usuário, assim como da prestação de serviços de assistência técnica é proposta, considerando todas as partes envolvidas no processo.

No capítulo 8, a manutenção é abordada por meio de uma pesquisa exploratória de campo, com a observação crítica de edificações habitacionais construídas com o emprego de sistemas construtivos inovadores, dentro do contexto do SiNAT. A pesquisa incluiu também a compreensão de sistemas construtivos inovadores pelo usuário-morador e de sua interação com o mesmo, sob o ponto de vista de sua satisfação no uso e manutenção. A pesquisa exploratória foi realizada sobre empreendimentos construídos com o emprego de dois diferentes sistemas construtivos inovadores.

Já o capítulo 9 apresenta uma discussão sobre os custos da manutenção em habitações de interesse social em sistema construtivo inovador, ponderando sobre os desafios da manutenção neste tipo de edificação. Para a compreensão dos custos envolvidos, a pesquisa propõe um método de avaliação da estimativa destes custos ao longo do tempo e apresenta os resultados obtidos por meio de um estudo de caso envolvendo dez unidades habitacionais de um empreendimento já implantado e ocupado há mais de 10 anos. 
Os capítulos que constituem este volume apresentam as contribuições resultantes das pesquisas encerradas por uma parte dos pesquisadores e instituições envolvidos na rede INOVATEC/Finep. Está prevista a publicação de um segundo volume, resultante da finalização do projeto da rede, envolvendo ainda os demais subprojetos da rede, a saber: Durabilidade, Ambiental e Estrutura. 


\section{Cap.

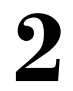

O sistema brasileiro de avaliação técnica de produtos inovadores para a Construção Civil ${ }^{I}$

\author{
Rosa Carolina Abrahão Amancio \\ Márcio Minto Fabricio \\ Cláudio Vicente Mitidieri Filho \\ Rosaria Ono
}

I $O$ presente capítulo apresenta uma revisão e atualização do texto apresentado originalmente como trabalho publicado nos anais das Jornadas LNEC: Engenharia para sociedade - investigação e inovação - Cidades e Desenvolvimento, 2012, Lisboa (AMAN$\mathrm{CIO}$; FABRICIO; MITIDIERI FILHO, 2012).
O setor da Construção Civil brasileira é formado por uma série de agentes com diferentes graus de complexidade, relacionados a produtos diversificados e com processos tecnológicos variados, que se adequam a diferentes tipos de demanda (MELLO; AMORIM, 2009). O setor abriga desde grandes indústrias, como cimento, siderurgia e química, até uma série de microempresas de serviços de baixo conteúdo tecnológico. Assim, pode-se afirmar que uma das características marcantes da Construção Civil é a heterogeneidade (MELLO; AMORIM, 2009).

No final dos anos 1980 e em meio a um ambiente competitivo, os indivíduos vinculados à Construção Civil brasileira perceberam que o crescimento do setor dependia do comprometimento dos profissionais com a qualidade, produtividade e com a inovação tecnológica (CASTRO, 1999). Neste contexto, os produtos inovadores são fundamentais para intensificar a competitividade da Construção. No entanto, a resistência à sua implementação no mercado é uma barreira que pode ser reduzida, especialmente com a elucidação das características técnicas do produto, obtidas por meio da Avaliação Técnica.

O produto inovador, ou uma inovação tecnológica, é entendido como um produto que ainda não possui normas técnicas que especifiquem suas características ou que definam procedimentos de projeto e execução. No Brasil, a elaboração de diretrizes de avaliação técnica e as próprias 
avaliações técnicas de produtos inovadores devem ser alinhadas à ABNT NBR 15575:2013 - Edificações Habitacionais - Desempenho (ABNT, 2013), que define os requisitos e critérios de desempenho para o edifício habitacional como um todo e para seus sistemas, com base nas exigências dos usuários. De maneira geral, a norma de desempenho é estabelecida com base nas respostas que a edificação ou seus sistemas devem apresentar, independentemente dos materiais constituintes, quando submetidos a determinadas condições de exposição, considerando seu uso. Como a ABNT NBR 15575:2013 não menciona materiais, componentes ou produtos específicos e nem traz referências de desempenho particulares para tais produtos, há necessidade da elaboração de diretrizes para avaliação técnica, particularizadas ou adaptadas para uma família de produtos, considerando seu uso na construção e as regiões de aplicação, particularmente quando se trata da exigência de durabilidade.

O significado de desempenho pode ser abrangente, pois está basicamente relacionado às exigências dos usuários, porém, está sendo entendido como comportamento em uso. A tradução das necessidades ou das exigências dos usuários em requisitos e critérios de desempenho relativos à segurança, à habitabilidade, à funcionalidade e à durabilidade, que possam ser mensurados de maneira objetiva, é um desafio desta norma técnica. Esta metodologia de avaliação de desempenho é considerada e, particularmente com a definição de métodos de avaliação padronizados, a norma fornece as ferramentas necessárias para a previsão ou avaliação do comportamento provável ou potencial de um determinado sistema.

O conceito de produtos inovadores adotado neste livro é, portanto, o de materiais de construção, componentes, elementos, sistemas e processos construtivos que não possuem normas técnicas brasileiras harmonizadas, de caráter prescritivo (BRASIL, 2007). No Brasil, o sistema responsável pela avaliação técnica de produtos de construção inovadores é o SiNAT, Sistema Nacional de Avaliação Técnica de Produtos Inovadores, que está vinculado ao Programa Brasileiro da Qualidade e Produtividade do Habitat (PBQP-H), subordinado ao Ministério das Cidades.

\section{O SiNAT - Sistema Nacional de Avaliação Técnica}

A criação do SiNAT é resultado da mobilização da comunidade técnica brasileira na elaboração de um suporte ao funcionamento de procedimentos de avaliação de produtos de construção inovadores (BRASIL, 2007a); em outras palavras, é o ambiente que abriga a inovação tecnológica na construção civil, seja destinada a obras de infraestrutura ou de edificações habitacionais. Um de seus objetivos é garantir a implementação de produtos inovadores no setor, suprindo provisoriamente as lacunas das normas técnicas prescritivas, por meio da elaboração de Diretrizes técnicas comuns de avaliação aplicadas a famílias de produtos. O outro objetivo é conceder DATecs, Documentos de Avaliação Técnica, relacionados com a respectiva diretriz, aplicados a produtos 
e empresas específicas (BRASIL, 2007b; MITIDIERI FILHO, 2011). O principal estímulo para uma empresa buscar o DATec é a confiabilidade quanto ao desempenho do produto (LOTURCO, 2008).

Para a concessão do DATec é necessário que o produto avaliado atenda a critérios mínimos de desempenho previamente estabelecidos em uma diretriz de avaliação técnica harmonizada, verificados por meio de ensaios e análises que compreendem a caracterização dos materiais e componentes que o integram e a verificação do seu desempenho potencial. Segundo Loturco (2008), os ensaios de desempenho são referentes a: (i) desempenho estrutural; (ii) estanqueidade à água; (iii) segurança ao fogo; (iv) desempenho térmico; (v) desempenho acústico; (vi) durabilidade, entre outros. É necessário também que haja uma sistemática de controle e de assistência técnica, por parte do produtor, que mantenha o produto nas condições que foi previamente avaliado.

Para a concessão do DATec, seguem-se os seguintes passos (Figura 1): (i) entrada com pedido de avaliação técnica do produto inovador em uma Instituição Técnica Avaliadora, ITA, autorizada a participar do SiNAT; (ii) elaboração de diretriz para avaliação técnica para a família do produto, caso ainda não exista; (iii) análise e harmonização da diretriz nas instâncias do SiNAT, quais sejam o Comitê Técnico e a Comissão Nacional, e publicação da diretriz; (iv) realização de avaliação técnica, com análises e ensaios, pela ITA e elaboração do RTA, Relatório Técnico de Avaliação; (v) introdução de modificações ou promoção de adequações necessárias no produto, pelo produtor, caso a avaliação técnica indique tal necessidade, e reavaliação pela ITA, caso necessário; (vi) realização, pela ITA, de auditoria técnica inicial no processo de fabricação ou produção, e na instalação ou execução do produto; (vii) introdução pelo produtor de adequações no processo de controle da qualidade e de assistência técnica, caso necessário, em razão dos resultados da auditoria técnica inicial, e realização de nova auditoria técnica pela ITA, caso necessário; (viii) elaboração de minuta do DATec, pela ITA, e encaminhamento à Secretaria Geral do SiNAT; (ix) análise da minuta e harmonização pelo Comitê Técnico do SiNAT; $(x)$ reformulação do DATec, pela ITA, caso exigido pelo Comitê Técnico; (xi) análise da minuta de DATec pela Comissão Nacional do SiNAT e introdução, pela ITA, de eventuais adequações solicitadas; (xii) concessão pela CN-SiNAT e publicação do DATec pela SG-SiNAT (BRASIL, 2007a).

A concessão do DATec acontece por meio de um processo com procedimentos de avaliação e de apreciação padronizados, o que faz com que os resultados provenientes de diferentes Instituições sejam harmonizados e publicados de forma homogênea.

\section{Diretriz SiNAT}

É o documento que contém as diretrizes para avaliação técnica de uma determinada família de produtos inovadores. Nela constam os requisitos, os 


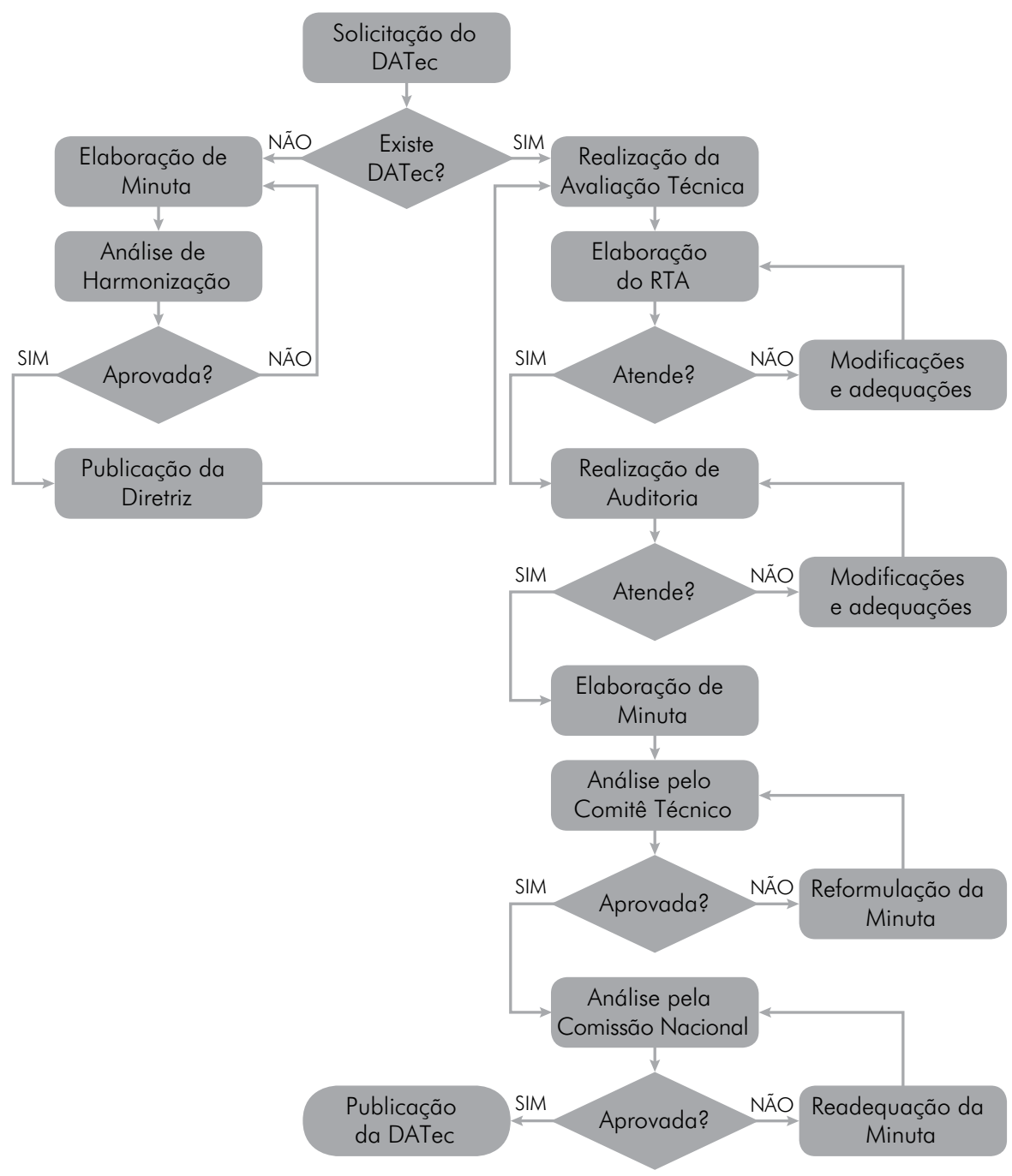

Figura 1. Caminho para concessão do DATec no SiNAT

critérios de desempenho e os métodos de avaliação que devem ser adotados na avaliação técnica dos produtos (BRASIL, 2007a). A Diretriz SiNAT é um documento de referência para a elaboração da avaliação técnica.

Geralmente uma ITA é responsável pela iniciativa de propor uma minuta de Diretriz ao SiNAT, em razão de necessidades de um setor específico, porém podem também ser de iniciativa de comissões ou grupos técnicos especializados. A ITA é um instituto de pesquisa, um laboratório ou uma instituição autorizada a participar do SiNAT pela Comissão Nacional, segundo critérios predefinidos, 
apta a realizar avaliações técnicas de produtos inovadores (BRASIL, 2007a), podendo esta autorização ser limitada a determinadas famílias de produtos.

Na realidade, as ITAs propõem minutas de diretrizes de avaliação técnica e tais diretrizes são harmonizadas num Comitê Técnico, aprovadas pela Comissão Nacional e publicadas. Da mesma forma, as ITAs propõem minutas de DATecs específicos para produtos e fabricantes, que são harmonizados num Comitê Técnico, aprovados pela Comissão Nacional e, finalmente, publicados. A Figura 2 apresenta a estrutura geral do SiNAT (MITIDIERI FILHO, 201 1).

A Diretriz SiNAT é divida em seis partes, são elas: (i) introdução; (ii) caracterização do produto; (iii) requisitos e critérios de desempenho; (iv) métodos de avaliação; (v) análise global do desempenho do produto; (vi) controle da qualidade na fabricação, montagem e instalação (BRASIL, 2011).

Sua introdução contém o objeto da diretriz, isto é, a família de produtos a que a diretriz se refere, trata do campo de aplicação do produto, trata da terminologia, que é a descrição ou definição dos termos utilizados na diretriz, e citação dos documentos técnicos complementares. Na segunda parte da diretriz, caracteriza-se o produto, isto é, são apresentadas as principais características dos materiais e componentes que formam o objeto da diretriz.

Na terceira parte da diretriz, apresentam-se os requisitos e critérios de desempenho para o produto: (i) desempenho estrutural; (ii) segurança contra incêndio; (iii) estanqueidade à água; (iv) desempenho térmico; (v) desempenho acústico; (vi) durabilidade e manutenibilidade e/ou demais requisitos e critérios

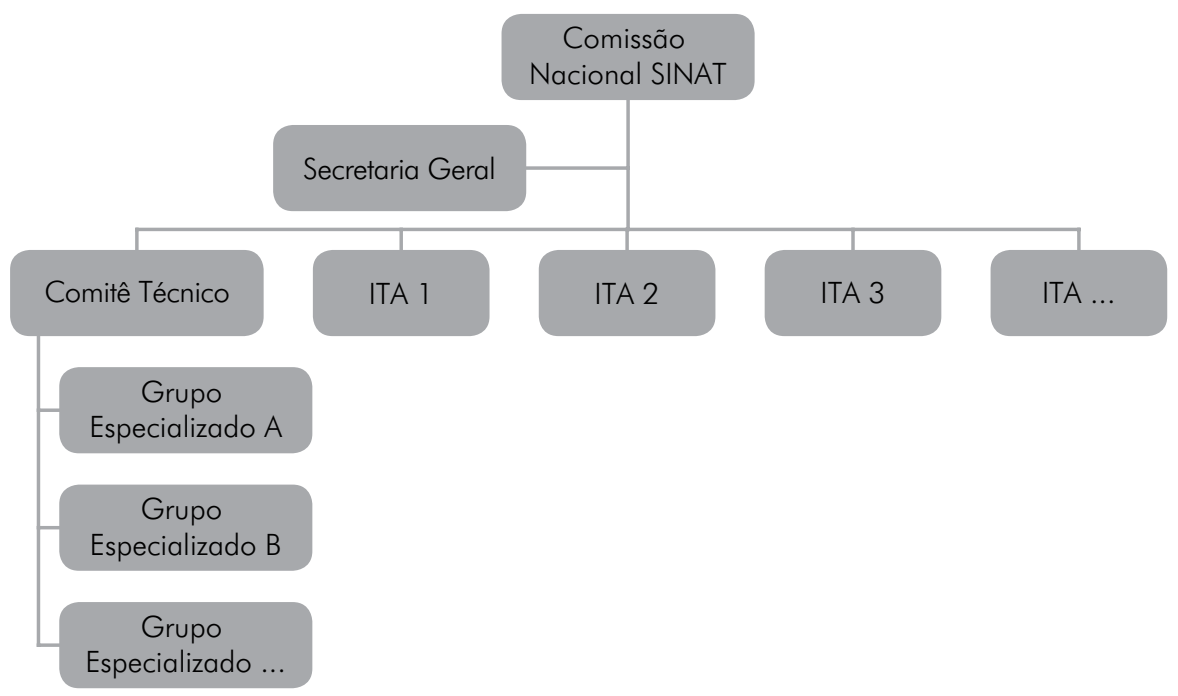

Fonte: Regimento geral do SiNAT. Acessado em 5/1/2015

Figura 2. Estrutura geral do SiNAT 
aplicáveis ao produto. A quarta parte da diretriz contém os métodos de avaliação, vinculados aos critérios de desempenho, como ensaios, análises, cálculos, inspeções ou medições.

A quinta parte da diretriz apresenta a necessidade de se consolidar a análise global de desempenho do produto, organizando as informações e os dados técnicos num RTA, no qual é sintetizado o desempenho global do produto de acordo com os resultados obtidos na avaliação técnica, considerando os ensaios e as análises realizadas. A sexta parte da diretriz apresenta instruções de como fazer o controle da qualidade da fabricação e da montagem ou instalação do produto, controle este passível de auditoria técnica prévia à concessão do DATec e de auditorias técnicas periódicas, em geral a cada seis meses, após concessão do DATec.

\section{DATec - Documento de Avaliação Técnica}

DATec é o documento que sintetiza os resultados da avaliação técnica de um produto (BRASIL, 2007a). É proposto por uma ITA autorizada a participar no SiNAT, com base em uma Diretriz SiNAT. O DATec é discutido e harmonizado nas duas instâncias do SiNAT, ou seja, no seu Comitê Técnico e na Comissão Nacional, última instância deliberativa, a qual autoriza a concessão.

Para a concessão do DATec é necessário primeiramente haver uma Diretriz SiNAT relativa à família que contemple o produto alvo da avaliação técnica. Na sequência, é preciso realizar a avaliação do produto com base no conceito de desempenho, auditar o controle da qualidade exercido pelo produtor e elaborar o DATec.

Por fim, após a concessão do DATec, são realizadas auditorias técnicas periódicas, incluindo ensaios, análises, vistorias técnicas e auditorias no processo e no produto, considerando o controle da qualidade adotado pelo produtor e os parâmetros definidos tanto no DATec, quanto na Diretriz.

Tanto a lista das ITAs designadas, como dos DATecs concedidos e em vigor estão disponíveis na página eletrônica do SiNAT no Ministério das Cidades.

\section{Considerações finais}

O Sistema Nacional de Avaliação Técnica (SiNAT), criado em 2007, representou um importante passo para introdução de inovações tecnológicas no setor de construção civil brasileiro, que conviveu durante anos com a introdução de produtos e sistemas construtivos pouco padronizados, e por vezes pouco ensaiados e testados, passou a contar com procedimentos sistematizados e formais para introdução de inovações tecnológicas no mercado nacional de construção.

Ao estabelecer mecanismos institucionais que contemplam diretrizes e critérios técnicos para análise de produtos e sistemas de construção inovadores, 
- SiNAT busca garantir critérios mínimos de desempenho dos produtos homologados. Também ajuda a romper as barreiras e desconfianças quanto à novos produtos e sistemas, favorecendo a introdução de inovações no mercado de construção.

As avaliações técnicas divulgadas por meio dos DATecs são formatadas para comunicar a adequação do produto ao uso pretendido, conforme a Diretriz de avaliação técnica de referência. As DATecs não têm força de norma técnica ABNT (embora na prática possa servir como referência para proposição de uma nova norma) ou regulamentação exigidas no setor de construção, mas são referências fundamentais para acesso à financiamentos públicos federais dentro dos programas habitacionais brasileiros. Por exemplo, para financiar um produto de construção inovador pela Caixa Econômica Federal é necessária a verificação prévia de desempenho provável e, preferencialmente, a apresentação do correspondente DATec, que contém as informações fornecidas pela avaliação técnica.

Embora represente um passo importante para aprimorar e controlar o processo de introdução de inovações técnicas nos produtos e sistemas construtivos, o SiNAT ainda enfrenta importantes desafios para se consolidar. Hoje, de acordo com o dados divulgados no web site do PBQP- $\mathrm{H}^{\prime}$, estão disponíveis de forma aberta onze diretrizes SiNAT e vinte e quatro DATecs, o que pode ser considerado um número ainda pequeno frente ao porte e complexidade do setor de construção civil brasileiro. Outro desafio importante é consolidar uma rede de ITAs (Instituição Técnica Avaliadora) em todo o território nacional, com condições técnicas para atender as demandas do setor.

Por fim, o SiNAT e as diretrizes técnicas devem sempre ser atualizadas para não se tornarem obsoletas. Como as diretrizes e as avaliações técnicas são elaboradas com base no conceito de desempenho, é fundamental a interação do sistema com a NBR 15575 (MITIDIERI FILHO, $2011)$. Desta forma, sempre que a norma for revisada, será necessário verificar a compatibilidade das Diretrizes SiNAT com a mesma, e vice-versa, alterando o que for preciso ou adotando-se as informações mais atuais.
$1<$ http://pbqp-h.cidades.gov.br/projetos sinat.php> 


\section{Referências}

AMANCIO R. C. A. ; FABRICIO, M. M. ; MITIDIERI FILHO, C. V. Avaliações técnicas de produtos de construção inovadores no Brasil. In: JORNADAS LNEC: Engenharia para sociedade: investigação e inovação: cidades e desenvolvimento, 2012, Lisboa. Cidade e Desenvolvimento, 2012. [S.n.t.]. p. 1-7.

ABNT - ASSOCIAÇÃO BRASILEIRA DE NORMAS TÉCNICAS. NBR 15575:2013

desempenho de edificações habitacionais. Rio de Janeiro, 2013.

BRASIL. Ministério das Cidades. Portaria n 345, de 3 de agosto de 2007. Regimento geral do Sistema Nacional de Avaliações Técnicas (SINAT) de produtos inovadores. Diário Oficial da União, Brasília, DF, Seção 1, n. 155, 13 de agosto de 2007.

BRASIL. Ministério das Cidades. Programa Brasileiro de Qualidade e Produtividade do Habitat. Sistema Nacional de Avaliações - SINAT. Disponível em: <http://pbqp-h. cidades.gov.br/projetos_sinat.php>. Acesso em: 29 fev. 2012.

BRASIL. Ministério das Cidades. Sistema Nacional de Avaliações Técnicas. Diretriz Sinat N. 001, revisão 02: diretriz para avaliação técnica de sistemas construtivos em paredes de concreto armado moldadas no local. Brasília, DF: Ministério das Cidades, 2011 . Disponível em:<http://pbqp-h.cidades.gov.br/projetos_sinat.php>. Acesso em: 28 maio 2012.

CASTRO, J. A. Invento \& inovação tecnológica: produtos e patentes na construção. São Paulo: Annablume, 1999.

LOTURCO, B. Excelência atestada. Téchne. São Paulo, n. 136, jul 2008. Disponível em: <http://techne.pini.com.br/engenharia-civil/136/artigo285436-1.aspx>. Acesso em: 14 dez. 2011.

MELLO, L. C. B. B.; AMORIM, S. R. L. O subsetor de edificações da construção civil no Brasil: uma análise comparativa em relação à União Europeia e aos Estados Unidos. Production, São Paulo, v. 19, n.2, p. 388-399, 2009. Disponível em: <http://www.scielo. $\mathrm{br} /$ scielo.php? script $=$ sci_abstract\&pid $=$ S0103-65132009000200013\&lng $=$ pt\&nrm $=$ iss o\&tlng $=$ pt $>$. Acesso em: 21 maio 2012.

MITIDIERI FILHO, C. V. Inovações e SiNAT. Notícias da Construção, São Paulo, v. 8, n. 107 , p. 44-45, dez. 2011. 


\section{Cap.

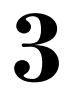

Avaliação técnica do produto de construção inovador: contexto brasileiro e internacional

\author{
Rosa Carolina Abrahão Amancio \\ Márcio Minto Fabricio
}

Apesar de ser conhecidamente um setor tradicionalista e, por vezes, retrógrado em termos de materiais e processos, a Construção Civil tem buscado soluções e respostas para um melhor desempenho de forma a atender às exigências de qualidade e segurança nas edificações, beneficiando-se, aos poucos, dos produtos de construção inovadores.

Neste trabalho, considera-se produto inovador aquele que não possui norma harmonizada e que entra no mercado por meio de um apoio técnico consolidado (AMANCIO et al., 2012). O apoio dito comprova o desempenho do produto ao uso pretendido e é evidenciado por meio da avaliação técnica, após ser submetido a diversos testes, ensaios e análises de desempenho geral e individual de seus componentes. A avaliação técnica é um documento elaborado por organismos de avaliação especializados. Ela é o veículo para a homologação dos produtos e sistemas construtivos inovadores.

No Brasil, a prática de avaliação técnica para homologação de produtos de construção é recente, o organismo avaliador responsável pelo processo é o SiNAT, Sistema Nacional de Avaliação Técnica, que foi aprovado pelo CTECH, Comitê Nacional de Desenvolvimento Tecnológico da Habitação em 2007, sendo operacionalizado efetivamente em 2008 (AMANCIO et al., 2012).

Mundialmente, especialmente na Europa, essa prática existe há tempos. Desde os anos 1980, existem regulamentações comuns aos países europeus, que determinam critérios para a homologação de produtos de construção inovadores. 
Para alinhar a homologação de produtos de diversos países, foi criada uma rede mundial de organismos avaliadores, a Federação Mundial das Organizações de Avaliação Técnica, WFTAO, World Federation of Technical Assessment Organisations (AMANCIO; FABRICIO, 2012). Em função da diversidade de normas de construção e de métodos de avaliação em vigor mundialmente, a rede tem o intuito de desenvolver entre os membros: (i) a troca de informações e experiências sobre o escopo e os procedimentos utilizados nas avaliações técnicas; (ii) o entendimento comum dos requisitos das avaliações técnicas para minimizar a duplicação de esforços; (iii) a troca mútua de critérios de avaliação. A WFTAO conta com 24 organismos de avaliação técnica de 22 países membros, entre eles: (i) vários países europeus; (ii) Estados Unidos; (iii) Nova Zelândia; (iv) África do Sul; (v) Brasil; e (vi) Canadá. As características gerais dos organismos avaliadores serão detalhados na sequência.

Este trabalho é parte das atividades elaboradas pelas metas físicas 53 e 54, do Subprojeto 4 - SiNAT, pelo projeto INOVATEC/Finep. O projeto é composto por nove instituições brasileiras e é apoiado pela Finep - Inovação e Pesquisa. Seu intuito é subsidiar futuras diretrizes SiNAT, com base na ABNT NBR 15575, em vigor em 2013.

\section{Método de pesquisa}

O trabalho foi elaborado com base em revisão da literatura sobre: produtos inovadores, avaliação técnica de produtos de construção inovadores e organismos de avaliação. O objetivo é levantar os principais organismos de avaliação em âmbito internacional e entender como acontece a homologação, em termos da análise dos documentos de avaliação técnicas. Para tanto, foram delineadas algumas particularidades dos organismos avaliadores, como forma de contextualizá-los melhor, assim como foi elaborado um Relatório Comparativo dos documentos de avaliação técnica nacional e internacionais. Foram elencados e descritos os tópicos do DATec, Documento de Avaliação Técnica, documento nacional do SiNAT e comparados com os tópicos de avaliações técnicas internacionais.

Este trabalho é parte de uma pesquisa extensa. Os resultados na íntegra foram entregues no formato de Relatório Técnico à Finep. $O$ dito relatório é composto pela descrição detalhada dos tópicos de todas as avaliações técnicas analisadas. Neste capítulo do livro INOVATEC/Finep, somente será apresentada a estrutura do DATec e, já na sequência, a análise comparativa dele com as avaliações técnicas internacionais. $O$ conteúdo da análise foi destacado conforme apresenta diferença em relação ao documento nacional. As Avaliações Técnicas internacionais estudadas foram:

- ETA - European Technical Assessment (Dinamarca, Finlândia, França, Itália, Polônia, Portugal, Espanha, Reino Unido e Alemanha);

- Technical Assessment (Austrália);

- Evaluation Report (Canadá); 
- BRANZ Appraised (Nova Zelândia);

- Agrément (África do Sul); e

- Evaluation Report (Estados Unidos).

Para a análise, optou-se por verificar entre dois ou quatro documentos de avaliação por país. Esse critério de seleção possibilita detectar, se for o caso, qualquer diferença nos tópicos das avaliações técnicas. $O$ principal objetivo do Relatório Comparativo foi identificar os tópicos avaliados internacionalmente que não correspondem ao nacional.

\section{Organismos de avaliação técnica}

Os organismos de avaliação técnicas são institutos e laboratórios que, muitas vezes trabalham com pesquisa, avaliação técnica e controle de qualidade. Seus serviços são fruto da aptidão e do conhecimento de uma série de profissionais, peritos em diversas áreas. Eles são responsáveis, entre outras coisas, por homologar os produtos inovadores.

De acordo com Loturco (2011), homologação é a comprovação e a divulgação das características e propriedades de determinado objeto, tal objeto pode ser um produto de construção. De maneira geral, as homologações não podem ser aceitas como regulamentação, elas são documentos para consulta que possuem informações extremamente relevantes sobre o objeto homologado (AMANCIO et al., 2012).

A homologação pode ser uma ferramenta indispensável para o produto inovador, uma vez que confere credibilidade ao produto e ao fabricante, já que é emitida de acordo com avaliação técnica que comprova o desempenho do produto analisado. Na sequência serão apresentados os organismos de avaliação técnica de vários países, inclusive do Brasil.

\section{Europa - diversos organismos avaliadores: ETA-Danmark, VTT, CSTB, ICITE, ITB, LNEC, IETcc, BBA, DIBt}

Cada país europeu possui um ou mais organismos avaliadores, porém a avaliação técnica europeia é elaborada por meio da mesma normativa, que é única aos países pertencentes à Comunidade Europeia. Essa normativa é que define a estrutura geral do documento de avaliação técnica europeu, a ETA, European Technical Assessment (Avaliação Técnica Europeia). Sua estrutura foi definida inicialmente pela DCP, Diretiva de Produtos de Construção, Council Directive 89/106/EEC, de 1988, e complementada pela Council Directive 93/68/ EEC, de 1993 (LNEC, 2010).

Após vinte anos de existência da DCP, a Comissão Europeia apresentou uma proposta para sua substituição. A DCP foi revogada dando lugar ao RPC, Regulamento (UE) N. 305/2011 do Parlamento Europeu e do Conselho de 9 de março de 2011, em vigor desde Julho de 2013. O RPC, da mesma 
forma que o DCP, estabelece condições harmonizadas para a comercialização dos produtos de construção. $O$ novo regulamento entrou em vigor com o argumento de tornar menos oneroso e mais rápido o processo de obtenção de uma Avaliação Técnica, especialmente por reduzir as cargas administrativas para pequenas empresas (MARTíN, 2013). De acordo com a Comissão Europeia, ele deve simplificar o quadro existente e melhorar a transparência e a eficácia das medidas em vigor.

A solicitação de uma ETA deve ser realizada pelo detentor do produto, fabricante ou requerente autorizado, para um Organismo de Avaliação Técnica, Technical Assessment Bodies (TABs), membro da Organização Europeia de Avaliação Técnica, European Organisation for Technical Assessment (EOTA) e aprovado pela Comissão Europeia.

O processo da obtenção da ETA inicia-se com um formulário que deve ser acompanhado pela descrição do produto, especificações, projetos e relatórios de ensaios, explicando detalhadamente o objeto do pedido e apresentando a sua finalidade em termos de uso (CE, 1994). Depois disso é preciso preparar um Documento de Avaliação Europeu, European Assessment Documents (EAD), que estabelece critérios de avaliação detalhados para elaboração da ETA (BBA, 2013), caso já não exista um EAD para o produto em questão. Na sequência, o TAB responsável elabora o programa de trabalho da ETA, que contém: (a) informações sobre o produto fornecidas pelo fabricante; (b) visitas na fábrica do produto; (c) testes de desempenho; (d) consulta de especialistas e (e) pesquisa com usuário e especificadores do produto. Após a finalização do documento, ele deve ser aprovado pelo fabricante, pela EOTA, pela Comissão Europeia e por especialistas.

A ETA é válida nos 28 Estados-membros europeus (países) e também pode ser reconhecida em países que possuem um acordo de reconhecimento mútuo com a Comunidade Europeia (CE). A ETA é a base para a Declaração de Desempenho, Declaration of Performance (DoP), que é de responsabilidade do fabricante. Ela também é o veículo para aquisição da marcação $C E$, selo que possibilita o comércio comum de produtos nos Estados-membros da Comunidade Europeia.

\section{ICC-EC Evaluation service (Estados Unidos)}

Nos Estados Unidos, a homologação de produtos inovadores é conseguida após elaboração do Evaluation Report (Relatório de Avaliação). Nesse documento, a avaliação de desempenho é elaborada com base nos critérios de aceitação do ICC-ES e com base nos códigos para avaliação por tipo de produto, que são: (i) códigos internacionais; (ii) códigos nacionais; (iii) códigos padrões; (iv) códigos uniformes; (v) outros códigos designados pelo ICC-ES (ICC-ES, 2013). No geral, as regulamentações utilizadas para fundamentar o Evaluation Report são o Código Internacional de Construção, International Building Code (IBC), e o Código Residencial Internacional, International Residential Code (IRC).

Para adquirir uma avaliação técnica americana, o requerente precisa apresentar projetos, detalhes, cálculos e demais dados que complementem a 
descrição do produto, fundamentando sua performance e atestando a conformidade com os códigos e critérios estabelecidos pelo ICC-ES. Todo material deve ser assinado por profissionais responsáveis. Os laboratórios que fazem os ensaios devem atender à norma ISO/IEC 17025 de Requerimentos gerais para Laboratórios de Ensaio e Calibração e serem credenciados pela IAS, International Accreditation Service.

\section{BRANZ - Building Research New Zeland (Nova Zelândia)}

$\mathrm{Na}$ BRANZ, para verificar o desempenho de um produto tanto com relação aos aspectos gerais, quanto específicos, solicita-se o BRANZ Appraisal. $O$ processo de avaliação de produtos tem duração variável, o período é entre 6 a 12 meses. A avaliação neozelandesa é embasada no Código de Construção da Nova Zelândia, New Zealand Building Code (NZBC), e contém os seguintes passos: (i) aplicação; (ii) plano de avaliação; (iii) contrato de avaliação; (iv) avaliação do produto, contendo todas as informações necessárias, inspeção da qualidade e revisão da literatura técnica; (v) emissão da avaliação formal e (vi) revalidação, por meio de revisão permanente (BRANZ, 2013).

As revisões da BRANZ Appraisal incluem visitas na fábrica do produto. Normalmente, a periodicidade é de uma vez ao ano, porém no caso de produtos mais complexos elas podem ocorrer com mais frequência. Os usuários do BRANZ Appraisal recebem atualizações pelo site e pela revista BRANZ build magazine.

\section{ASA - Agrément South Africa (África do Sul)}

A ASA é responsável pela emissão do Agrément para os produtos de construção inovadores certificados na África do Sul. O Agrément é elaborado com base no conceito de desempenho acordado pela Agrément South Africa (ASA), que aborda: (a) critérios de desempenho estabelecidos por especialistas para as áreas referentes ao desempenho adequado do produto; (b) métodos de ensaio ou avaliação adequados para aferir o desempenho do produto; (c) avaliação do desempenho real do produto em conformidade com os métodos estabelecidos; (d) aceitação da Agrément em função da avaliação do desempenho medido ou avaliado para os critérios estabelecidos (ASA, 2013).

Para adquirir um Agrément procede-se com: (i) aplicação; (ii) pagamentos de taxas; (iii) parecer de peritos sobre o produto; (iv) contrato de serviço; (v) definição do critério de avaliação; (vi) testes e avaliações; (vii) consulta a peritos externos a ASA; (viii) controle de qualidade e inspeções; (ix) finalização do certificado e envio para o cliente; $(x)$ revisão pelo Comitê Técnico; (xi) aprovação e publicação; (xii) após Agrément é solicitado ao fabricante a requisição do certificado de manutenção. 


\section{SiNAT - Sistema Nacional de Avaliação Técnica (Brasil)}

O órgão que representa o Brasil na WFTAO é o IPT, Instituto de Pesquisa Tecnológica. No entanto, a avaliação de produtos e sistemas construtivos inovadores passou a ser responsabilidade do SiNAT (BRASIL, 2013).

O SiNAT está vinculado ao Programa Brasileiro de Qualidade e Produtividade do Habitat (PBQP-H). Seu documento de avaliação é o DATec - Documento de Avaliação Técnica, cuja concessão acontece com base em diretrizes e avaliações técnicas emitidas pelas ITA, Instituições Técnicas Avaliadoras. As ITAs são responsáveis pelos procedimentos técnicos que atestam o desempenho de diversos produtos (BRASIL, 2007). Os passos para adquirir o DATec são (AMANClO et al., 2012): (i) aplicação; (ii) elaboração de diretriz para avaliação; (iii) publicação da diretriz; (iv) ensaios técnicos; (v) elaboração do DATec; (vi) publicação do DATec. As diretrizes e as avaliações técnicas do SiNAT são elaboradas com base no conceito de desempenho da norma brasileira de desempenho, ABNT NBR 15575 - Edificações habitacionais - Desempenho (ABNT, 2013).

\section{CCMC - Canadian Construction Materials Centre (Canadá)}

No Canadá, a NRC Construction por meio do CCMC, fornece o serviço de avaliação de produtos de construção inovadores e não-padronizados nos termos do Código de Construção, Building Code. O documento canadense é a Evaluation Report, sua aquisição contém os seguintes passos (CCMC, 2013): (i) aplicação; (ii) comprovação da legitimidade da inovação; (iii) Escopo e Plano de Avaliação; (iv) Guia Técnico (critérios técnicos de avaliação); (v) testes laboratoriais terceirizados; (vi) avaliação dos resultados e opiniões; (vii) Evaluation Report.

\section{Avaliação técnica: contexto internacional e brasileiro}

As avaliações técnicas têm o intuito de demonstrar a conformidade do produto avaliado aos requisitos preestabelecidos. Entre os requisitos avaliados estão os requisitos essenciais ou exigências com relação ao desempenho de um produto em específico, que são definidos de acordo com normativas e/ou diretrizes, designadas por famílias de produtos.

Para ser homologado, o produto inovador deve estar de acordo com os requisitos mínimos solicitados, tendo que comprovar seu desempenho por meio de testes, ensaios, ou qualquer outra evidência capaz de sustentar sua performance. Em vários países, assim como no Brasil, a homologação de produtos de construção inovadores almeja preencher as lacunas da normalização técnica prescritiva (SiNAT, 2013). Isso faz do organismo avaliador uma infraestrutura fundamental para o desenvolvimento tecnológico da Construção Civil. 
Na Europa, para que os produtos inovadores sejam comercializados nos países pertencentes ao comum acordo de comércio no território europeu é necessário que possuam o selo da marcação CE. A aquisição do selo somente é permitida ao produto com desempenho comprovado por meio da Avaliação Técnica Europeia ETA. Assim como os países europeus, outros países ao redor do mundo também assumiram o compromisso de homologar seus produtos de construção inovadores.

\section{Análise comparativa das avaliações técnicas}

A partir da análise identificou-se um padrão bem definido nas avaliações técnicas em âmbito mundial, o que significa que não houve grandes diferenças em termos de tópicos avaliados. Sabe-se que toda avaliação técnica é elaborada para um produto em específico, de modo que algumas especificidades inerentes a ele são necessariamente detalhadas e acrescentadas como informações fundamentais. No entanto, a característica geral dos documentos analisados para todos os casos foi a mesma.

\section{Estrutura do DATec - Documento de Avaliação Técnica}

1. Descrição do produto: descrição do produto, incluindo composição física (tipos de materiais), dimensões, resistência, aplicação e uso. Nesse espaço, comentam-se as informações que são fornecidas no projeto, assim como as características que devem ser definidas antes da aplicação por especialistas. Neste trecho, citam-se alguns detaIhes que não foram contemplados na avaliação técnica e também citam quais são os produtos (que não tem caráter inovador) e não foram avaliados porque têm normas prescritivas já definidas para serem seguidas.

1.1. Condições e limitações de uso: limitações do produto quanto ao uso (especialmente referente ao que não pode ser executado). Nessa parte, comentase que determinadas alterações só podem ser executadas com a aprovação do fabricante do produto. Também comenta-se sobre as condições específicas para efetuar intervenções (quando necessário, determina-se a visualização do Manual do Proprietário para informações detalhadas).

2. Diretriz para avaliação técnica: aqui cita-se a Diretriz SiNAT (documento elaborado por especialistas que determina os tópicos que devem ser avaliados) utilizada na orientação da avaliação técnica.

3. Informações e dados técnicos: descrição dos materiais que compõem o produto: especificações, detalhes construtivos, principais componentes, elementos, equipamentos e procedimento de execução. Os itens listados nos dados técnicos detalham as caraterísticas dos materiais incorporados no produto e sua função no todo. Quando possível, apresentam-se ilustrações do produto.

3.1. Especificações e detalhes construtivos: descreve tudo o que é necessário para que o produto seja executado corretamente.

3.2. Procedimentos de execução: descreve a sequência de montagem (ou sequência construtiva, no caso de um sistema construtivo), até que o produto esteja em condições de uso. 
4. Avaliação Técnica: cita a Diretriz SiNAT de referência e os tópicos que precisam ser avaliados, comentando, algumas vezes, os índices de desempenho (ou outros índices) que precisam ser atendidos. Nesta etapa, são apresentados os resultados que comprovam a conformidade do produto às exigências estabelecidas por um grupo de especialistas, que constam na Diretriz de referência. Normalmente, a avaliação técnica deve comprovar:
a. o desempenho estrutural;
b. a estanqueidade à água;
c. o desempenho térmico;
d. o desempenho acústico;
e. a durabilidade e a manutenibilidade;
f. a segurança ao fogo.

5. Controle da qualidade: critério para verificação da qualidade, descrição de como é elaborado o processo de avaliação e controle da qualidade (citam-se as ferramentas utilizadas para avaliação e o nome da empresa certificadora, quando existente) e citação a respeito de quanto em quanto tempo faz-se as auditorias. Neste espaço, citam-se os tipos de verificações que são elaboradas, como: auditorias técnicas no processo produtivo; verificação das certificações que a empresa possui; referência à resistência técnica e ao desempenho do produto e comenta o período das avaliações periódicas (auditorias técnicas) do DATec.

6. Fontes de informação: comenta-se as principais referências utilizadas para elaboração do documento, divididos em: (i) documentos da empresa; (ii) DATec; (iii) Relatórios Técnicos; (iv) referências normativas. Os documentos comumente citados são: documentos da empresa; relatórios técnicos, de ensaio, de inspeção e outros; projetos; procedimentos de execução; fichas de verificação de materiais e serviços; manual de uso e ocupação; referências normativas entre outros. Se o produto já possuía DATec, isso no caso de uma renovação, o documento deve ser citado neste trecho do documento.

7. Condições de emissão do DATec: pré-requisitos para manter o DATec em vigor conforme o regimento do SINAT (cita o artigo de referência no regimento). Neste capítulo, citam-se os tópicos que são de responsabilidade do fabricante para que o produto se mantenha em conformidade com a avaliação do DATec.

Na sequência, comparam-se os tópicos do DATec com os tópicos das avaliações técnicas internacionais.

\section{Relatório comparativo}

De maneira geral, a comparação entre a estrutura do DATec e as estruturas das avaliações técnicas internacionais apontou mais semelhanças do que diferenças em termos de tópicos avaliados. Na sequência, segue a descrição detaIhada da análise comparativa, de acordo com o formato de tópicos do DATec.

\section{Descrição do produto}

No DATec, a descrição do produto inclui composição física (tipos de materiais), dimensões, resistência, aplicação e uso. Nela comentam-se as 
informações que são fornecidas pelo projeto, assim como as características que devem ser definidas antes do manuseio do produto por especialistas. Neste tópico, também são citados alguns detalhes que não foram contemplados na avaliação técnica. Por vezes, citam-se alguns produtos que não foram avaliados (por não possuírem caráter inovador) e que possuem normas prescritivas já definidas para serem seguidas.

Dentro do DATec, no subitem condições e limitações de uso, especifica-se, especialmente, o que não pode ser feito com o produto. Comenta-se que determinadas alterações só podem ser executadas com a aprovação do fabricante. Também comenta-se sobre as condições específicas para efetuar intervenções (quando necessário, é determinada a visualização do Manual do Proprietário para informações detalhadas).

Todas as Avaliações Técnicas analisadas dispõem de um tópico de descrição do produto e de informações sobre as condições e limitações de uso, exceto a Technical Assessment (Austrália), que, apesar de ter um tópico de descrição do produto, não fornece informações sobre as condições e limitações de uso.

\section{Diretriz para avaliação técnica}

Nesse tópico, o DATec comenta a Diretriz SiNAT, utilizada como referência. A diretriz é um documento, elaborado por especialistas (ITA), que determina os critérios de avaliação do produto (BRASIL, 2007). Ela não é um documento de uso comum a todas as Avaliações Técnicas internacionais. O Evaluation Report, do CCMC (Canadá), por exemplo, faz a avaliação técnica baseando-se em normas de construção canadenses e em códigos pertinentes ao produto. O CCMC examina o produto e define quais provas técnicas serão exigidas, essas provas são fundamentadas em códigos (regulamentos) que o produto deve atender.

O documento africano Agrément não é elaborado com base em uma Diretriz para avaliação técnica. Ele é baseado na norma de construção nacional, na ISO e em outras regulamentações pertinentes, como as referentes ao sistema de gerenciamento de qualidade. Alguns Agrément também utilizam informações de outros materiais de referência mundiais, como avaliações técnicas já publicadas por instituições vinculadas a WFTAO e a UEAtc - The European Union of Agrément. O Evaluation Report, que é a avaliação americana, é elaborado com base no código de construção nacional, no código residencial nacional e em outros códigos vigentes nos Estados Unidos.

\section{Informações e dados técnicos}

As informações e dados técnicos do DATec apresentam a descrição dos materiais que compõem o produto: especificações, detalhes construtivos, principais componentes, elementos, equipamentos e procedimento de execução. Os itens dos dados técnicos detalham as caraterísticas dos materiais incorporados e sua função no todo. Quando possível, apresentam-se ilustrações do produto. 
Esse tópico possui os subitens: (i) especificações e detalhes construtivos: descreve tudo o que é necessário para que o produto seja executado corretamente; (ii) procedimentos de execução: descreve a sequência de montagem (ou sequência construtiva, no caso de um sistema construtivo), até que o produto esteja em condições de uso. Todas Avaliações Técnicas analisadas possuem um tópico semelhante.

\section{Avaliação Técnica}

No item Avaliação Técnica do DATec, cita-se a Diretriz SiNAT utilizada, assim como os tópicos que precisam ser avaliados comentando, algumas vezes, os índices de desempenho (ou outros índices) que precisam ser atendidos. Nesta etapa, são apresentados os resultados que comprovam a conformidade do produto às exigências estabelecidas, informações essas requisitadas pela Diretriz de referência. De maneira geral, o produto deve comprovar e apresentar, por meio do DATec, o seguinte: (i) desempenho estrutural; (ii) estanqueidade à água; (iii) desempenho térmico; (iv) desempenho acústico; (v) durabilidade e a manutenibilidade; (vi) segurança ao fogo.

Todas as avaliações técnicas analisadas descrevem o desempenho do produto em seus documentos. Normalmente, o que deve ser analisado é definido de acordo com o produto. As ETAs (avaliações europeias) devem atender aos requisitos básicos de construção (de acordo com o novo Regulamento (UE) n 305/2011): (i) resistência mecânica e estabilidade; (ii) segurança em caso de fogo; (iii) higiene, saúde e meio ambiente; (iv) segurança em uso; (v) proteção contra ruído, (vi) economia de energia e retenção de calor; (vii) uso sustentável dos recursos naturais.

\section{Controle de qualidade}

No item Controle da qualidade, define-se o critério para verificação da qualidade, que trata da descrição do processo de avaliação e do controle da qualidade (ferramentas utilizadas para avaliação e o nome da empresa certificadora, quando é o caso), também é comentado sobre a periodicidade das auditorias. Neste espaço, citam-se os tipos de verificações que são elaboradas, como: (i) auditorias técnicas no processo produtivo; (ii) certificações da empresa; (iii) comprovações da resistência técnica e desempenho do produto; (iv) periodicidade das auditorias técnicas do DATec.

$\mathrm{Na}$ Technical Assessment (Austrália), comenta-se que o produto é elaborado com sistema de gerenciamento de qualidade, no entanto não há detalhes sobre o controle de qualidade. $\bigcirc$ Evaluation Report (Canadá) não contém informações sobre controle de qualidade.

\section{Fontes de informações}

Nesse item, comentam-se as principais referências utilizadas para elaboração da avaliação técnica são elas: (i) documentos da empresa; (ii) DATec; 
(iii) relatórios técnicos; (iv) referências normativas. Os documentos comumente citados são: (i) documentos da empresa; (ii) relatórios técnicos, de ensaio, de inspeção e outros; (iii) projetos; procedimentos de execução; (iv) fichas de verificação de materiais e serviços; (v) manual de uso e ocupação; (vi) referências normativas entre outros. No caso do documento já possuir DATec, isto é, quando se fizer necessário uma renovação, o DATec deve ser citado.

Todas as avaliações técnicas analisadas comentam sobre as principais fontes de informações utilizadas, no entanto, não comentam necessariamente sobre documentos de empresas ou relatórios técnicos.

\section{Condições de emissão do DATec}

Nesse item, são estabelecidos os pré-requisitos para manter o DATec em vigor conforme o regimento do SiNAT (no DATec é citado o artigo de referência no regimento). Nesse espaço apresentam-se os tópicos de responsabilidade do fabricante para que o produto mantenha a conformidade com o DATec.

Todas avaliações técnicas analisadas contém informações semelhantes ou equivalentes sobre o que deve ser considerado para manter o documento de avaliação técnica em vigor.

\section{Diferenças pontuais das Avaliações técnicas internacionais com o DATec}

As avaliações técnicas internacionais possuem tanto tópicos semelhantes aos do DATec, quanto tópicos que não possuem qualquer informação equivalente. Segue abaixo os exemplos de tópicos que não são encontrados no DATec.

\section{Technical Assessment (Austrália)}

Na Technical Assessment (Austrália) os tópicos diferentes são:

CSIRO Appraisal: trata-se de uma página que explica a Appraisal no âmbito da CSIRO e quais os certificados ou avaliações técnicas são emitidos pelo órgão. Nessa página também são apresentados os integrantes do Comitê Técnico Consultivo e dos Comitês Revisores Regionais (que participam da elaboração da avaliação).

Ficha da CSIRO Appraisal: ficha da Appraisal contém 14 itens (lado esquerdo da página): (a) Organismo de origem; (b) Unidade organizacional; (c) Tipo do documento; (d) Número do Documento; (e) Título e subtítulo; (f) Autor(es); (g) Órgão que está publicando e o local de publicação (cidade); (h) Referências da publicação; (i) Data (mês e ano); (i) Número de páginas e formato; (k) Preço; (l) Notas suplementares; (m) Palavras- chaves; (n) Abstract (Lado direito da página): (a) Número de indexação; (b) Número do arquivo; (c) Autoridade liberadora; (d) Endereço para contato; (e) Status do documento (rascunho, provisório, final); ( $f$ ) Status do documento (sem restrições, confidencial, classificado); (g) Documentos para elaboração do contrato (número do contrato, nome dos consultores e endereço); (h) Documentos relacionados; (i) Outras informaç̃̃es adicionais. 


\section{Evaluation Report (Canadá)}

Última Página -: possui informações do titular do relatório, endereço, telefone, endereço da fabrica. Explica o Evaluation Report no âmbito do CCMC e um parágrafo reafirmando que a validade do Evaluation Report depende da conformidade do produto aos requisitos apresentados neste documento.

\section{ETA - European Technical Assessment (países europeus)}

As ETA (europeias) contém os seguintes tópicos diferentes:

Indicações ao(s) fabricante(s) -: neste espaço são feitas considerações no que diz respeito à embalagem, transporte, armazenamento e uso, manutenção e reparo, quando necessário.

As ETA consideram essencial a avaliação dos seguintes temas: (i) higiene, saúde e meio ambiente; (ii) segurança em uso; (iii) economia de energia e retenção de calor; (iv) proteção contra ruído.

\section{Considerações finais}

A pesquisa alcançou informações detalhadas dos organismos avaliadores, assim como dos passos necessários para a aquisição da avaliação técnica em âmbito nacional e internacional. No contexto brasileiro, foi apresentado, com minúcia, os tópicos que compõem o DATec. A verificação da estrutura do DATec propiciou uma análise comparativa entre a avaliação técnica nacional com documentos correspondentes de vários países. Foi identificada grande semelhança entre os documentos analisados, mostrando um alinhamento de estrutura documental e de conteúdo sobre o tema em âmbito internacional.

Mesmo os documentos de países mais experientes nas práticas de avaliação e homologação não apresentam diferenças significativas quando comparados ao DATec. Muito porque o DATec, junto ao SiNAT, foi inspirado nesses padrões, usando como parâmetros, especialmente, os documentos de avaliação europeus. É importante destacar que todos os documentos de avaliação analisados evidenciam as bases legais utilizadas, os tópicos avaliados para a comprovação de desempenho e possuem critérios para verificação da qualidade do produto. Certamente existem diferenciações nas regulamentações que fundamentam os documentos de avaliação, já que essas são elaboradas pelos países para seu próprio uso. A maior evidência nesse sentido foi o acréscimo de mais um requisito básico para construção pelo RPC para a ETA, que é o uso sustentável dos recursos naturais, pelo qual o produto avaliado deve demonstrar desempenho. Não houve esse tipo de comprovação nas análises dessa pesquisa em função da não obrigatoriedade momentânea do requisito citado.

No Brasil, a prática de homologação de produtos de construção inovadores é recente, visto que somente foi oficializada, junto ao setor, com a criação do $\mathrm{SiNAT}$. De qualquer forma, os procedimentos funcionais e técnicos que têm sido 
vivenciados já suscitam avaliação e propostas de incrementos. O SiNAT, como qualquer sistema em andamento, necessita ser observado, para garantir que suas premissas sejam atendidas e que as demandas do setor, do mercado e dos usuários possam ser consideradas e supridas.

De qualquer forma, a formação de uma estrutura coesa no que concerne aos organismos avaliadores e às avaliações técnicas, em termos de critérios e processos de avaliação, é um processo que acontece lentamente e o bônus é adquirido pela prática, que vem com o tempo de atuação. Em outros países, sobretudo os europeus, os padrões de análise já foram há tempos determinados por regulamentações específicas e, tem sido aprimorados diante de observações e de demandas.

O mais importante é que a aquisição da Avaliação Técnica pode ser a meIhor maneira de introduzir inovação no mercado. Na Europa, por exemplo, a ETA é pré-requisito para comercialização de produtos de construção inovadores no mercado comum europeu e item obrigatório para obtenção da marcação CE. No Brasil, para financiar um sistema construtivo inovador pela Caixa Econômica Federal, é necessário obter a comprovação de desempenho, assim como as demais informações fornecidas pela avaliação técnica. 


\section{Referências}

AGRÉMENT SOUTH AFRICA. The certification process. Pretoria, 2010. Disponível em: <http://www.agrement.co.za/uploads/cms/documents/Certification_process_x.PDF>. Acesso em: 13 maio 2013.

AMANCIO, R. C. A.; FABRICIO, M. M. Produtos de construção inovadores: análise da avaliação de órgãos homologadores internacionais. In: ENTAC - ENCONTRO NACIONAL DE TECNOLOGIA DO AMBIENTE CONSTRUÍDO, 14., 2012, Juiz de Fora. Anais... Juiz de Fora: UFJF, 2012.

AMANCIO, R. C. A.; FABRICIO, M. M.; MITIDIERI FILHO, C. V. Avaliações técnicas de produtos de construção inovadores no Brasil. In: JORNADAS ENGENHARIA PARA A SOCIEDADE, Lisboa, 2012. Anais... Lisboa: [s.n.], 2012.

BBA - BRITISH BOARD OF AGRÉMENT. Watford, 2013. Disponível em: <http://www. bbacerts.co.uk>. Acesso em: 7 ago. 2013.

BRANZ - BUILDING RESEARCH OF THE NEW ZELAND. Appraisal process. Porirua City, 2013. Disponível em: http://www.branz.co.nz/cms_display.php? sn=32\&st=1\&pg=9614. Acesso em: 15 jul. 2013.

BRASIL. Ministério das Cidades. Portaria n³45, de 3 de agosto de 2007. Regimento geral do Sistema Nacional de Avaliações Técnicas (SINAT) de produtos inovadores. Diário Oficial da União, Brasília, DF, Seção 1, n. 155, 13 de agosto de 2007.

BRASIL. Ministério das Cidades. Programa Brasileiro de Qualidade e Produtividade do Habitat. Sistema Nacional de Avaliações - SINAT. Disponível em: <http://pbqp-h.cidades. gov.br/projetos_sinat.php>. Acesso em: 15 set. 2013.

CCMC - CANADIAN CONSTRUCTION MATERIALS CENTRE. CCMC evaluation process. Otawwa, 2013. Disponível em: <http://www.nrc-cnrc.gc.ca/eng/solutions/advisory/ccmc/ evaluation_process.html>. Acesso em: 15 jan. 2013.

CE - COMUNIDADES EUROPEIAS. Decisão da Comissão de 17 de Janeiro de 1994 relativa às regras processuais comuns para as aprovações técnicas europeias (94/23/CE). Jornal Oficial das Comunidades Européias, 20 jan. 194, n. L 17, p.34-40. Disponível em: < http://eur-lex.europa.eu/legal-content/PT/TXT/ PDF/?uri=OJ:L:1994:017:FULL\&from=PT > . Acesso em: 14 maio 2012.

CSIRO - COMMONWEALTH SCIENTIFIC AND INDUSTRIAL RESEARCH ORGANISATION. Clayton South, 2013. Disponível em: <http://www.csiro.au/en/Portals/About-CSIRO. aspx>. Acesso em: 10 jan. 2013.

ETA-DANMARK. Nordhavn, 2013. Disponível em: <http://www.etadanmark.dk/en>. Acesso em: 6 set. 2013.

ICC - INTERNATIONAL CODE COUNCIL. Washington, 2013. Disponível em: <http:// www.iccsafe.org/Pages/default.aspx>. Acesso em: 26 set. 2013.

ICC-ES - ICC EVALUATION SERVICE. Application information and rules of procedure. Estados Unidos. Disponível em: <http://www.icc-es.org/Applications/>. Acesso em: 16 mar. 2013.

LNEC - LABORATÓRIO NACIONAL DE ENGENHARIA CIVIL. Relatório de actividades do Laboratório Nacional de Engenharia Civil, I.P. no ano de 2010. [S.I.], 2011 . Disponível em: <http://www.Inec.pt/documentos/relatorios/relatorio_activ_2010.pdf>. Acesso em: 20 nov. 2011.

LOTURCO, B. Excelência atestada. Téchne, São Paulo, n. 136, jul 2008. Disponível em: <http:// techne.pini.com.br/engenharia-civil/136/artigo285436-1.aspx>. Acesso em: 14 dez. 2011.

MARTÍN, R. F. Principios y técnicas de la calidad y su gestión en edificación. Madrid, Escuela Técnica Superior de Edificación, Universidad Politécnica de Madrid; 2006. 


\section{Cap. 4}

\section{Procedimentos para a avaliação de desempenho de sistemas construtivos inovadores em uso com vistas ao atendimento à NBR 15575:2013}

\author{
Rosaria Ono \\ Fabiana L. Oliveira \\ Sheila W. Ornstein \\ Walter J. F. Galvão \\ Khaled Ghoubar
}

\section{Introdução}

Para a realização de uma Avaliação Pós-Ocupação (APO), são utilizados múltiplos instrumentos relacionados aos usuários e aos especialistas com conhecimento em áreas específicas. Essa avaliação consiste em verificar se as condições do ambiente em uso são satisfatórias quanto ao desempenho do ambiente construído do ponto de vista dos seus usuários. A partir do cruzamento comparativo entre as considerações dos especialistas e as ponderações dos usuários são formulados diagnósticos que fundamentam, em curto prazo, as recomendações para melhorias e intervenções na edificação em uso. Se aplicada em edificações semelhantes e de modo sistêmico, a APO pode contribuir - de modo realimentador - a médio e longo prazo, para a composição de bancos de dados que abriguem aspectos positivos que podem ser reproduzidos em edificações semelhantes e também aspectos negativos que devem ser evitados em futuros projetos. Os resultados das APOs podem ainda contribuir no aperfeiçoamento de normas de desempenho para avaliação de sistemas construtivos nas etapas de projeto, construção, uso, operação e manutenção de edificações (PREISER, VISCHER, 2005; FINCH, 2012).

As exigências funcionais de uma habitação são de: segurança, saúde, higiene e conforto e adequação ao uso (PEDRO, 2011 1). Logo, o desenvolvimento de projeto 
de novas edificações deve abranger diversas avaliações de modo a conduzir a uma solução ótima de projeto, construção, uso e manutenção, especialmente quando da análise de desempenho de sistemas construtivos inovadores, isto é, de sistemas pouco ou nada conhecidos.

Os sistemas construtivos são considerados "inovadores", por definição normativa, quando não existem normas brasileiras específicas que determinem sua forma de construção e avaliação e, por consequência, não apresentem critérios preestabelecidos para a avaliação de sua conformidade.

Neste contexto, é muito importante o desenvolvimento de métodos para avaliação em uso de edifícios habitacionais com sistemas construtivos inovadores, visando à identificação de fatores que podem ser aprimorados no próprio sistema ou nos procedimentos específicos de manutenção durante o uso (VOORDT; WEGEN, 2005; VILLA; ORNSTEIN, 2013).

Neste projeto, foi elaborado um procedimento que pudesse ser adotado para avaliação de qualquer sistema construtivo, portanto, com base nos requisitos e critérios de desempenho definido na norma brasileira NBR 15575 (ABNT, 2013; Câmara Brasileira da Indústria da Construção, 2013).

A norma NBR 15575:2013 foi utilizada como um guia orientativo também das exigências dos usuários, buscando-se, adicionalmente, as demais normas nela citadas que devem ser consultadas para definição dos requisitos e critérios de avaliação de desempenho de diversos aspectos da edificação. A adoção de parâmetros normativos para avaliação de sistemas construtivos inovadores tem como objetivo garantir maior aceitação pela sociedade e a segurança adequada ao usuário, em concordância com o Código de Defesa do Consumidor (BRASIL, 1990), além disso, critérios normativos mínimos devem sempre ser respeitados nas edificações.

Todos os instrumentos foram desenvolvidos estruturados sobre os temas a saber: desempenho acústico; desempenho térmico; desempenho luminoso; funcionalidade; acessibilidade; segurança contra incêndios; segurança no uso; durabilidade, vida útil e desempenho estrutural.

\section{Métodos e Técnicas}

Uma diretriz importante que permeou todo o desenvolvimento dos instrumentos foi a obtenção de instrumentos eficazes, porém de aplicação rápida e de baixo custo.

Considerando-se os métodos e as técnicas da Avaliação Pós-Ocupação, inicialmente foram estabelecidos os tipos de instrumento a serem utilizados na coleta de dados, a saber:

- Instrumento para coleta de dados sobre a satisfação do morador com a edificação e o sistema construtivo inovador (dados quali-quantitativos por amostragem);

- Instrumento para coleta de informações de pessoa-chave - no caso, o síndico ou zelador - quando se tratar de unidades habitacionais agregadas em forma de condomínio (informações qualitativas); 


\section{Procedimentos para a avaliação de desempenho de sistemas construtivos inovadores em uso com vistas ao atendimento à NBR 15575:2013}

- Instrumento para avaliação do desempenho físico de sistema construtivo inovador, por meio de verificação técnica de documentações que compõem o projeto (verificação qualitativa) e da verificação em uso, na obra (verificação quali-quantitativa).

Estabeleceu-se que a aplicação dos instrumentos e sua análise para elaboração do relatório sobre o desempenho do sistema construtivo inovador deveriam ser conduzidas por uma equipe técnica com conhecimentos sólidos na área de arquitetura e engenharia civil, cuja avaliação de competência é de responsabilidade de uma instituição avaliadora. É importante que os aplicadores tenham domínio sobre os requisitos e critérios de desempenho e, caso necessário, sejam submetidos a treinamentos de capacitação para a realização da avaliação.

Esses profissionais devem estar aptos a realizar avaliações precisas para gerar relatórios técnicos ricos em informações relevantes ao processo de avaliação de um sistema construtivo inovador.

Os procedimentos desta Avaliação Pós-Ocupação foram desenvolvidos após período de levantamento dos vários instrumentos existentes a fim de que fosse realizada a seleção daqueles mais adequados à situação. Ao final, foi proposto um conjunto de quatro instrumentos de coleta de dados, envolvendo dois grupos de agentes, conforme apresentado a seguir, na Figura.

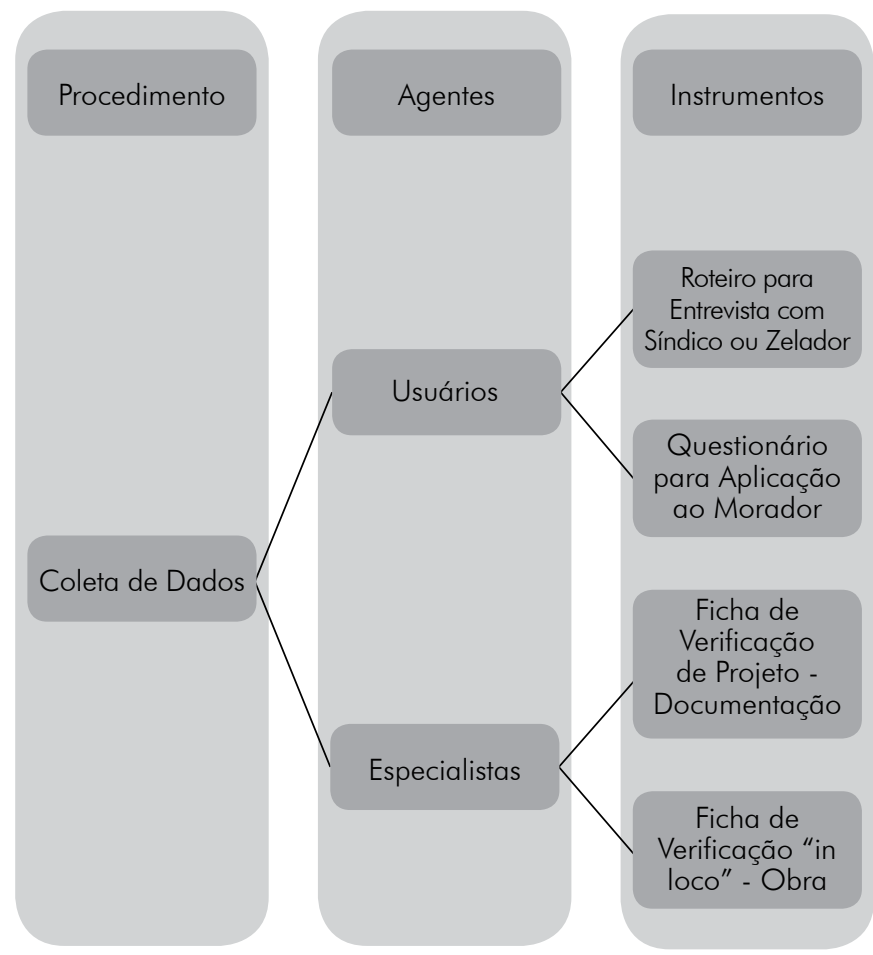

Figura. Estrutura dos Procedimentos de Avaliação e seus Instrumentos 
Os quatro instrumentos resultantes desta pesquisa foram elaborados e testados em dois momentos de seu desenvolvimento: em campo e em dois diferentes empreendimentos habitacionais constituídos de sistemas construtivos inovadores.

A APO se vale de múltiplos métodos para compor a avaliação, portanto, é importante que os quatro instrumentos sejam aplicados em sua plenitude, para garantir uma avaliação equilibrada, com dados provenientes dos diferentes métodos e fontes que se completam.

Os agentes envolvidos podem ser divididos em dois grandes grupos: os usuários (moradores) do empreendimento e os especialistas, dos quais podem ser obtidos diferentes tipos de informações, por meio dos quatro instrumentos propostos e a seguir descritos.

\section{Roteiro para entrevista com síndico ou zelador}

O roteiro de entrevista semiestruturada foi formulado com a finalidade de balizar a obtenção de informações sobre o desempenho em uso do sistema construtivo em habitações agrupadas em condomínios residenciais horizontais ou verticais, onde o empreendimento em estudo apresenta forma de administração condominial. Considera-se essencial, neste caso, o depoimento desta(s) pessoa(s)-chave para compreensão da estrutura do condomínio, assim como das principais questões que envolvem o empreendimento no seu dia-a-dia. Caso não exista a estrutura condominial, porém, identifica-se uma liderança comunitária, por exemplo, e esta também pode ser objeto da entrevista. Este instrumento deve ser preferencialmente aplicado antes dos demais, pois pode subsidiar a equipe técnica com informações importantes para a condução da avaliação em questão.

\section{Questionário de satisfação do morador}

Este instrumento tem como objetivo a obtenção de dados dos moradores de unidades habitacionais e de como estes avaliam o desempenho de sua habitação e do sistema construtivo inovador de sua edificação. $O$ morador é o principal agente indicador de pontos relevantes (positivos e negativos) ao desempenho da edificação em uso. Além disso, ele pode apontar questões que os técnicos talvez não consigam constatar facilmente ou que passem despercebidas numa visita técnica, principalmente quanto aos requisitos de conforto.

\section{Fichas de verificação}

As fichas de verificação foram elaboradas para uso pelos técnicos (especialistas) para avaliação do desempenho das edificações, consistindo em dois tipos:

a. Verificação de projeto - Documentação;

b. Verificação "in loco" - Obra. 


\section{Procedimentos para a avaliação de desempenho de sistemas construtivos inovadores em uso com vistas ao atendimento à NBR 15575:2013}

O objetivo das fichas de verificação é observar e registrar os diversos aspectos que influem na qualidade e segurança de uma edificação e, para tanto, compõem-se de fichas com temas agrupados em oito itens já citados anteriormente.

Esse instrumento apresenta requisitos de atendimento obrigatório e facultativo. Os requisitos obrigatórios têm origem em exigências mínimas estabelecidas por normas da Associação Brasileira de Normas Técnicas (ABNT), enquanto que o atendimento dos requisitos facultativos é apenas recomendado neste procedimento, em conformidade com as boas práticas para garantia da qualidade de projeto e de construção.

Para cada requisito ou critério elencado nas fichas existem os campos de preenchimento referentes ao que foi constatado em: atende, não atende, não se aplica e não verificado. As alternativas devem ser assinaladas (apenas uma opção para cada requisito) nas seguintes condições de classificação:

$\rightarrow$ Atende - Quando o indicador objeto da questão é atendido plenamente;

$\rightarrow$ Não atende - Quando o atendimento do indicador objeto da questão é parcial ou não é atendido;

$\rightarrow$ Não se aplica - Quando o indicador objeto da questão inexiste na unidade ou edifício avaliado, portanto, não é aplicável;

$\rightarrow$ Não verificado - Quando, por algum motivo, não foram aplicados os métodos necessários para verificação do atendimento, ou não, do indicador objeto da questão.

Foi elaborada uma tabela com toda a referência normativa que indica a(s) norma(s) técnica(s) na(s) qual(is) cada requisito foi embasado, respectivamente, para verificação de projeto como para verificação "in loco".

Ao fim das fichas, há espaço para comentários adicionais, para que o avaliador possa registrar questões que considerou importante ou que justifiquem a alternativa selecionada.

Abaixo do espaço para comentários adicionais apresenta-se uma planilha para preenchimento do número de frequências de atendimento dos critérios, obrigatório ou facultativo.

\section{Ficha de verificação de projeto - Documentação}

O objetivo deste instrumento é verificar os diversos aspectos que afetam a qualidade e segurança de uma edificação e que podem ser avaliados a partir da análise da documentação técnica disponível. Deverá ser feita uma análise para cada tipologia (com plantas diferentes ou dimensões diferentes) do sistema construtivo inovador, caso exista mais de uma. 


\section{Ficha de verificação "in loco" - Obra}

O objetivo desse instrumento é a verificação "in loco" dos diversos aspectos de desempenho de uma edificação, por meio de visitas técnicas às unidades residenciais segundo um critério estatístico de amostragem preestabelecido. Constam nestas fichas os aspectos que complementam aqueles observados na verificação de projeto, ou seja, por análise de documentação, e aqueles que devem ser obrigatoriamente conferidos no local.

\section{Da Aplicação dos Instrumentos Propostos}

Para cada um dos instrumentos propostos são apresentados, a seguir, conteúdos explicativos sobre:

- Pré-requisitos para aplicação do instrumento;

- Forma de aplicação do instrumento;

- Tratamento dos dados coletados.

\section{Roteiro para entrevista com síndico / zelador}

O roteiro de entrevista semiestruturada é composto de dois blocos. $\bigcirc$ primeiro, menor, busca caracterizar o perfil do entrevistado. $O$ segundo aborda questões diretamente relacionadas ao desempenho técnico das áreas comuns das edificações, do ponto de vista de sua relação com o sistema construtivo e da facilidade de manutenção, assim como aquelas do ponto de vista das reclamações dos moradores.

A pessoa a ser entrevistada deve ser, preferencialmente, o responsável legal (síndico) do condomínio ou a pessoa que é acionada pelos moradores para solucionar problemas no dia-a-dia do condomínio (zelador).

Este instrumento está voltado a obter informações dos agentes que estão diretamente envolvidos no dia-a-dia da gestão de condomínios residenciais e que, em função do trabalho que realizam, são detentores de informações muito relevantes à configuração de um panorama sobre o desempenho das edificações do condomínio em uso.

O entrevistador deve conhecer o teor de todos os itens do roteiro e estar apto a esclarecer sobre qualquer um dos seus itens, caso o entrevistado não o compreenda.

O agendamento prévio da entrevista é importante para garantir a presença do entrevistado e que esta seja realizada com tempo suficiente para se obter o maior número de informações possíveis. É também interessante que esta entrevista ocorra em período anterior à aplicação da Ficha de verificação "in loco" - Obra, pois as informações obtidas podem ser úteis na detecção ou identificação de inconformidades na obra.

entrevistador deve registrar as informações fornecidas em um suporte à parte, garantindo a preservação dos dados para posterior análise. 


\section{Procedimentos para a avaliação de desempenho de sistemas construtivos inovadores em uso com vistas ao atendimento à NBR 15575:2013}

Ao realizar a entrevista com base no roteiro, o entrevistador pode fazer perguntas adicionais e complementares às questões iniciais, quando achar pertinente.

Ao final, o entrevistador deve elaborar e apresentar um relatório destacando os dados qualitativos mais relevantes obtidos, seguindo a ordem dos itens propostos no roteiro de entrevista semiestruturada.

\section{Questionário de satisfação do morador}

As questões estão agrupadas em três grandes blocos no questionário, a saber:

- Caracterização do usuário (com o objetivo de se obter um perfil dos usuários);

- Interface do morador com a sua moradia (com questões que, após a tabulação das respostas, resultam em um panorama das habitações, sendo possível identificar alguns problemas e, mais tarde, analisá-los para um diagnóstico mais preciso);

- Interface usuário com o sistema construtivo inovador (com questões voltadas aos aspectos de identificação da inovação construtiva pelo usuário).

Em geral, para cada pergunta do questionário, o usuário deve assinalar apenas uma opção (resposta). No final do questionário, há espaço para comentários e observações.

Informações prévias devem ser obtidas sobre o número total de unidades habitacionais do empreendimento, por tipologia, e sua distribuição (planta de implantação) para dar subsídio à definição do tamanho da amostra a ser coletada, assim como a forma de distribuição dos questionários no conjunto habitacional.

Outra etapa prévia importante é o de planejamento, que envolve a negociação com o representante do condomínio (síndico) ou líder comunitário, para:

- Ampla divulgação desta atividade aos moradores, visando à conscientização da importância de sua participação;

- Viabilizar a entrega dos questionários aos moradores (forma e prazo);

- Garantir a coleta dos questionários preenchidos (forma e prazo).

No caso do questionário a ser preenchido eletronicamente (uma alternativa em estudo), não se dispensa a negociação com o condomínio para viabilizar o acesso eletrônico aos moradores.

Após a coleta dos questionários preenchidos, o número total deve ser registrado e os seguintes aspectos devem ser verificados, antes de proceder à tabulação das respostas:

- Se todas as questões foram respondidas;

- Se as respostas estão legíveis, claramente registradas e que as palavras utilizadas sejam compreensíveis;

- Se não há erros de unidade, no caso de dados quantitativos;

- Se há consistência nas informações, ou seja, coerência entre respostas a diferentes questões. 
Os questionários que não atendam aos aspectos acima listados devem ser descartados. As respostas dos questionários considerados válidos devem ser tabuladas para análise qualitativa dos dados.

Um relatório deve ser elaborado, apresentando os resultados da tabulação dos dados, com comentários da análise das questões de maior relevância, do ponto de vista da equipe técnica, para avaliação de desempenho do sistema construtivo em questão.

O cruzamento das respostas obtidas nesse instrumento com as obtidas através dos outros instrumentos que compõem os procedimentos de avaliação aqui proposto deve fornecer dados sobre a correlação entre o nível de satisfação do usuário com o sistema construtivo que compõe sua habitação e os aspectos técnicos que justificam o seu desempenho.

\section{Ficha de verificação de projeto - Documentação}

Este instrumento é um roteiro de verificação documental e é composto por oito temas, totalizando oito fichas a serem preenchidas.

Em cada uma das fichas, de acordo com o tema, são elencados os requisitos e critérios a serem verificados pelo profissional responsável.

Para aplicação deste instrumento, é necessária a obtenção dos documentos técnicos abaixo elencados, a ser fornecido pelo empreendedor / construtor das habitações empregando o sistema construtivo inovador:

- Plantas e cortes de todos os projetos executivos, inclusive os complementares;

- Plantas e cortes do projeto aprovado pelo Corpo de Bombeiros;

- Plantas e cortes do projeto aprovado na Prefeitura;

- Memorial descritivo do projeto;

- Certificados de avaliação de desempenho dos componentes construtivos, tais como o comportamento ao fogo dos materiais especificados para acabamento de piso, parede e forro; resistência ao fogo dos componentes do sistema construtivo (piso/parede/cobertura);

- Características técnicas dos materiais e componentes construtivos, como transmitância térmica, índice de redução sonoro ponderado e capacidade térmica, calor específico, densidade superficial de massa, dentre outros;

- Documentação de aprovação do sistema construtivo, quando inovador (por exemplo, DATec/SiNAT);

- Planilhas de custos do empreendimento.

A análise da documentação deve ser realizada por profissionais capacitados para avaliação técnica das documentações acima relacionadas.

As fichas de verificação possuem a apresentação gráfica que pode ser vista no Quadro. 


\section{Procedimentos para a avaliação de desempenho de sistemas construtivos inovadores em uso com vistas ao atendimento à NBR 15575:2013}

Nesta estrutura, apresentam-se nas colunas da esquerda para a direita: na primeira coluna, os critérios; na segunda coluna, o seu nível de importância e a avaliação do atendimento do requisito de acordo com a classificação definida neste procedimento. Ao final dos requisitos a serem avaliados, há espaço para comentários adicionais ou complementares aos requisitos e/ou croquis que possam auxiliar no entendimento quando necessário.

O instrumento deve ser aplicado por tipologia de edificação e unidade habitacional do empreendimento. Assim, se houver mais do que uma tipologia, deverá haver o número correspondente de fichas de avaliação.

Tendo caráter expedito, este instrumento deve servir para identificar possíveis inconformidades com base na verificação de documentações técnicas disponíveis. No caso de, durante a verificação, serem encontradas inconformidades devido à falta de documentação, o responsável deve requerer a documentação faltante ao solicitante da avaliação. Caso não sejam sanadas, as inconformidades consideradas graves devem ser apontadas no relatório final.

A elaboração do relatório a partir da aplicação das fichas para verificação de projeto por meio de documentação deve fornecer conclusões tanto de caráter geral, sobre a edificação como um todo, quanto sobre os pontos específicos detectados na tabulação e na análise dos dados.

A partir da leitura dos resultados será possível indicar a necessidade de esclarecimentos técnicos sobre questões específicas e, em alguns casos, a necessidade de análise mais profunda a ser realizada por especialista ou mesmo a complementação de dados por outros instrumentos que compõem este procedimento de avaliação. Tem um papel importante de complementação de informações a Ficha de verificação "in loco"- Obra a ser realizada após a aplicação do presente instrumento.

A informação gerada após a análise da documentação deve, posteriormente, compor o relatório final, a ser elaborado considerando o conjunto de dados obtidos por meio do conjunto de instrumentos propostos por este procedimento.

\section{Ficha de verificação "in loco" - Obra}

Para um melhor resultado recomenda-se o estudo prévio da(s) planta(s)-tipo da unidade(s) habitacional(is) a ser(em) vistoriada(s). Detalhes de projeto do sistema construtivo em questão e conteúdo do memorial descritivo também devem ser conhecidos previamente à visita técnica.

Um estudo prévio permitirá uma melhor compreensão dos aspectos a serem verificados nas unidades habitacionais e contribuirá para uma inspeção mais precisa, com preenchimento mais apurado do instrumento.

Preferencialmente, as inspeções prediais devem ser precedidas da avaliação por meio das "fichas de verificação de projeto - documentação", para prévia identificação de questões relevantes ao processo de avaliação e melhor conhecimento do empreendimento a ser inspecionado. 
Quadro. Modelo da ficha de verificação

\begin{tabular}{|c|c|c|c|c|c|c|c|c|}
\hline \multicolumn{9}{|c|}{ 1. Desempenho XXXX } \\
\hline \multirow[t]{2}{*}{ Critérios } & \multirow{2}{*}{$\begin{array}{l}\text { Nível de } \\
\text { importância }\end{array}$} & \multicolumn{7}{|c|}{ Classificação } \\
\hline & & \multicolumn{2}{|c|}{ Atende } & Não atende & \multicolumn{2}{|c|}{ Não se aplica } & \multicolumn{2}{|c|}{ Não verificado } \\
\hline$\ldots \ldots \ldots$ & Obrigatório & & & & & & & \\
\hline$\ldots \ldots \ldots$ & Facultativo & & & & & & & \\
\hline$\ldots \ldots \ldots$ & Obrigatório & & & & & & & \\
\hline \multicolumn{9}{|c|}{ Comentários adicionais: } \\
\hline \multirow[t]{2}{*}{ Respostas } & \multicolumn{8}{|c|}{ Classificação } \\
\hline & & Atende & Nã & tende & aplica & Não & erificado & $\%$ \\
\hline \multicolumn{9}{|c|}{$\begin{array}{l}\text { Obrigatório } \\
\text { (valor absoluto e \%) }\end{array}$} \\
\hline \multicolumn{9}{|c|}{$\begin{array}{l}\text { Facultativo } \\
\text { (valor absoluto e \%) }\end{array}$} \\
\hline Totais (valor & ssoluto e \%) & & & & & & & \\
\hline
\end{tabular}

A verificação "in loco" da obra deve ser realizada por profissionais capacitados e devidamente treinados na realização dos procedimentos aqui apresentados.

Este instrumento é um roteiro com itens a serem verificados na obra composto também por oito temas. Os temas foram divididos em itens a serem verificados nas áreas internas e externas à unidade habitacional, totalizando 16 fichas. As fichas referentes à verificação na obra abordam os seguintes temas: Conforto Acústico; Conforto Térmico; Conforto Luminoso; Funcionalidade; Acessibilidade; Segurança contra Incêndio; Segurança no Uso; Durabilidade, Vida Útil e Segurança Estrutural.

Em cada uma das fichas, de acordo com o tema, são elencados os requisitos e critérios a serem verificados pelo profissional responsável pela visita técnica.

As Fichas de verificação "in loco" possuem apresentação gráfica muito semelhante às Fichas de verificação de projeto e incluem os requisitos e critérios apresentados nas fichas de verificação, que são aqueles definidos nas normas da Associação Brasileira de Normas Técnicas (ABNT). O nível de importância também foi baseado nos requisitos apresentados nos documentos de referência mencionados e, para cada requisito ou critério elencado nas fichas, existem os campos de preenchimento referentes ao verificado no local (classificação) em: atende, não atende, não se aplica e não verificado, idêntico às fichas de verificação de projeto. 


\section{Procedimentos para a avaliação de desempenho de sistemas construtivos inovadores em uso com vistas ao atendimento à NBR 15575:2013}

As vistas técnicas devem ser realizadas para verificação tanto das áreas internas como externas das unidades habitacionais, objetivando a verificação do desempenho em uso dos componentes do sistema construtivo inovador.

Para efetuar a vistoria, o profissional deve estar capacitado para avaliação em conformidade com o conteúdo das seguintes normas, no mínimo: NBR 9050 (ABNT, 2004), NBR 9077 (ABNT, 2001), NBR 5674 (ABNT, 2012), NBR 15575 (ABNT, 2013).

Por ser realizada de maneira expedita, esta verificação deve ser entendida como meio para identificação de possíveis problemas de maior gravidade. No caso em que, em uma vistoria forem encontradas inconformidades, e se estas forem definidas como "críticas" perante os olhos do vistoriador, deve-se recomendar uma segunda avaliação, a ser realizada por especialista na área.

Os resultados tabulados de toda a amostra de unidades inspecionadas devem gerar dados totalizados referentes à frequência de atendimento de requisitos, de locais de ocorrências encontradas, e detalhes específicos de alguns itens, quando necessário.

A elaboração do relatório a partir da aplicação das fichas de verificação "in loco" deve fornecer resultados tanto de caráter geral, sobre a edificação como um todo, quanto sobre os pontos específicos detectados na tabulação e na análise dos resultados de todas as unidades habitacionais verificadas.

Os resultados obtidos com a aplicação desta ficha devem apresentar:

- A frequência com que os requisitos das normas estão sendo atendidos nas edificações visitadas;

- Os locais de maior incidência de ocorrências de não conformidades;

- A necessidade ou não de vistoria e análise posterior de pontos específicos a serem executados por especialista;

- O estado geral das condições de uso dos itens, das unidades habitacionais e das áreas comuns das edificações como um todo;

- Eventuais ações de melhoria.

Também devem ser incluídas no relatório as fotografias registradas no ato das visitas técnicas, quando estas puderem embasar ou reforçar observações realizadas durante essas visitas.

As informações obtidas por meio deste procedimento deve, posteriormente, compor o relatório final a ser elaborado considerando o conjunto de dados obtidos por meio dos demais instrumentos.

\section{Diretrizes para elaboração do relatório final}

Para elaboração do relatório final devem ser utilizados os resultados obtidos em todos os instrumentos. Com relação às fichas de inspeção, no caso de critérios 
obrigatórios, o não atendimento da maioria dos requisitos resulta em uma avaliação negativa e, analogamente, quanto mais próximo de 100\%, melhor a avaliação do sistema construtivo inovador. No caso de resultados que diferem de 100\%, devem ser apontados e detalhados os itens que não se enquadraram nos critérios apresentados, especificando (ou não) a necessidade de contar com um especialista para uma avaliação mais completa e detalhada de determinado item.

No caso de critérios facultativos, quanto maior a porcentagem de 'atende', melhor a avaliação do sistema construtivo inovador. Desconformidades também devem ser incluídas no relatório, mas esses critérios não são considerados críticos para o desempenho do sistema.

O relatório deve conter as seguintes partes:

- Introdução: deve apresentar o assunto e o objetivo do documento e especificar o sistema construtivo e os dados da edificação avaliada;

- Relatório Geral: deve apresentar os resultados quantitativos obtidos nas fichas de inspeção, sendo interessante a utilização de gráficos para melhor ilustrar os dados. É importante que se aponte as não conformidades encontradas e que os aspectos técnicos mais importantes sejam detalhados.

- Recomendações: devem ser apresentadas sugestões e/ou críticas em relação às características observadas e apontadas no item anterior. Nessa parte, deve-se apontar a necessidade de avaliação específica por técnicos especialistas e a possibilidade de interdição caso considere, mesmo com avaliação preliminar, que as irregularidades encontradas apresentem riscos aos moradores.

- Anexos: devem ser incluídas fotografias, documentos ou informações técnicas que contribuam com o embasamento do relatório e das sugestões apresentadas nesse documento.

\section{Considerações finais}

A proposta de um conjunto de instrumentos para avaliação de desempenho de sistemas construtivos inovadores em uso teve, como principal parâmetro, o usuário. O nível de satisfação do usuário com o desempenho do sistema construtivo não depende somente das características técnicas do próprio sistema construtivo - muitas vezes restritivas no que se refere à flexibilidade, facilidade de manutenção, etc. - mas também em função do nível socioeconômico, das condições da moradia anterior e de vários outros fatores que o levaram a ocupar aquela habitação. Por outro lado, conhecer, de forma sistêmica, as necessidades e os níveis de satisfação dos usuários é fundamental no processo de gestão da qualidade do projeto. Em particular, no caso daqueles sistemas ainda não normatizados no país, é importante considerar a redução de riscos no uso e de preconceitos emanados do desconhecimento do usuário morador em relação ao sistema construtivo, além da relevância da realimentação do processo de projeto com informações sobre o desempenho no decorrer do uso, tanto do ponto de vista dos especialistas, como dos usuários do espaço. 


\section{Procedimentos para a avaliação de desempenho de sistemas construtivos inovadores em uso com vistas ao atendimento à NBR 15575:2013}

Sendo assim, o conjunto de métodos e técnicas aqui proposto, com base nos requisitos e critérios de desempenho exigidos pela norma brasileira NBR 15575 (ABNT, 2013) - que passou a vigorar a partir de 19 de julho de 2013 -, teve como objetivo contribuir para o aprimoramento do desempenho de sistemas construtivos inovadores.

Esta pesquisa deve prosseguir com o desenvolvimento e o aperfeiçoamento dos instrumentos para uso em plataforma digital, por meio de questionários eletrônicos que possam ser preenchidos on-line, via web, e fichas de verificação igualmente em formato eletrônico, que possam ser manuseadas e preenchidas em tablets.

Os instrumentos podem ser aplicados também na avaliação de desempenho de empreendimentos construídos com sistemas construtivos tradicionais, pois está fundamentada na norma brasileira com base em desempenho (ABNT, 2013), podendo contribuir para a melhoria da qualidade dos projetos habitacionais como um todo. 


\section{Referências}

ABNT - ASSOCIAÇÃO BRASILEIRA DE NORMAS TÉCNICAS. NBR 5674: manutenção de edificações - Requisitos para o sistema de gestão de manutenção. Rio de Janeiro: 2012. . NBR 9050: acessibilidade a edificações, mobiliário, espaços e equipamentos urbanos. Rio de Janeiro: 2004. . NBR 9077: saída de emergência em edifícios. Rio de Janeiro: 2001. Janeiro, 2013. . NBR 15575: edifícios habitacionais - desempenho: partes 1 a 6. Rio de

BRASIL. Lei 8078, de 11 de setembro de 1990. Código e defesa do consumidor. Disponível em: <http://www.idec.org.br/consultas/codigo-de-defesa-do-consumidor>. Acesso em: 12 jan. 2014).

CÂMARA BRASILEIRA DA INDÚSTRIA DA CONSTRUÇÃO. Desempenho de edificações habitacionais: guia orientativo para atendimento à norma ABNT NBR 15575/2013. Fortaleza, 2013.

FINCH, E. (Ed.). Facilities change management. West Sussex: Wiley-Blackwell, 2012.

PEDRO, J. B. Método de avaliação das necessidades de reabilitação: desenvolvimento e aplicação experimental. Lisboa: Laboratório Nacional de Engenharia Civil, 2011.

PREISER, W. F. E.; VISCHER, J. C. (Eds.). Assessing building performance. Oxford: Elsevier, 2005.

VILLA, S. B.; ORNSTEIN, S. W. (Orgs.). Qualidade ambiental na habitação: avaliação pós-ocupação. São Paulo: Oficina de Textos, 2013.

VOORDT, T. J. M.; WEGEN, H. B. R. Architecture in use: an introduction to the programming, design and evaluation of buildings. Oxford: Architectural, 2005. 


\section{Cap. 5}

Avaliação do desempenho térmico de habitações segundo a ABNT NBR 15575

\author{
Karin M. S. Chvatal \\ Victor F. Roriz
}

\section{Introdução}

A Norma brasileira ABNT NBR 15575: Edificações habitacionais - Desempenho (ABNT, 2013) estabelece um conjunto de exigências (tanto qualitativas, quanto quantitativas) para que se garanta o adequado desempenho das habitações. Esse desempenho é considerado em relação às necessidades do usuário, as quais, por sua vez, traduzem-se nos seguintes aspectos: segurança, habitabilidade e sustentabilidade. Essa não é uma norma prescritiva, ou seja, não indica como o edifício deve ser construído, mas sim o que ele deve atender para que tenha o desempenho desejado, independente do seu sistema construtivo.

Neste capítulo são apresentadas as exigências da ABNT NBR 15575 quanto ao desempenho térmico. $O$ método de avaliação proposto pela Norma é descrito de forma didática para profissionais e estudantes do setor da construção civil, ao mesmo tempo em que são indicadas algumas de suas limitações, observadas tanto pelos autores deste texto quanto por outros especialistas na área.

A Norma é composta por seis partes. Na primeira parte, são estabelecidas as exigências de desempenho com relação aos aspectos acima citados, considerando-se o edifício como um todo. As partes seguintes possuem o mesmo tipo de abordagem, mas com exigências específicas para os sistemas que compõem a edificação: sistemas estruturais 
(parte 2), sistemas de pisos (parte 3), sistemas de vedações verticais internas e externas (parte 4), sistemas de coberturas (parte 5) e sistemas hidrossanitários (parte 6). O texto da Norma refere-se a habitações sem limitação no número de pavimentos, salvo quando mencionado o contrário (ou seja, as exigências relativas somente a habitações com até cinco pavimentos são expressamente indicadas).

O desempenho térmico das habitações é tratado nas seguintes partes da Norma:

- Parte 1. Requisitos Gerais. Descreve o método de avaliação do desempenho térmico.

- Parte 4. Requisitos para os sistemas de vedações verticais internas e externas. Apresenta os requisitos de desempenho térmico para as vedações verticais externas.

- Parte 5. Requisitos para os sistemas de coberturas. Apresenta os requisitos de desempenho térmico para as coberturas.

\section{Normas e regulamento nacionais sobre o desempenho térmico e energético de habitações}

Em 2005, foi publicada a primeira norma nacional que trata do desempenho térmico de habitações, a ABNT NBR 15220 - Desempenho térmico de edificações (ABNT, 2005). Ela trata especificamente sobre esse assunto na sua Parte 3, se restringindo a habitações unifamiliares de interesse social (Parte 3 - Zoneamento bioclimático brasileiro e diretrizes construtivas para habitações unifamiliares de interesse social). O país é dividido em oito zonas bioclimáticas e são indicadas recomendações para o projeto em cada uma delas. Essas recomendações se referem a valores-limite para as propriedades termofísicas das vedações, tamanho mínimo das aberturas para ventilação, necessidade ou não de sombreamento e indicação de estratégias de condicionamento térmico passivo.

Logo após, em 2008, foi publicada a ABNT NBR 15575. Esta Norma causou um grande impacto no setor da construção civil, que não se considerava preparado para absorver as mudanças que ela impunha. Com isso, solicitouse sua revisão e seguiu-se um período de discussões, no qual o texto original sofreu modificações, até resultar na versão atual, publicada em 19/02/2013 e válida desde 19/07/2013.

Paralelamente ao desenvolvimento da ABNT NBR 15575, surgiu o RTQ-R, Regulamento técnico da qualidade para o nível de eficiência energética em edificações residenciais, publicado em 2010 e atualizado em 2012, e voltado a edificações uni e multifamiliares. Ele apresenta requisitos técnicos e métodos para a obtenção do nível de eficiência energética do edifício, o qual pode variar de $\mathrm{A}$ (mais eficiente) a $\mathrm{E}$ (menos eficiente). Essa informação permite a obtenção da Etiqueta Nacional de Conservação de Energia (ENCE) para a habitação. Essa etiqueta é, no momento, voluntária, mas deve se tornar obrigatória nos próximos anos. 


\section{Procedimentos para avaliação do desempenho térmico de habitações propostos pela ABNT NBR 15575}

\section{Esquema geral dos procedimentos}

Primeiramente, é mencionado que a edificação deve possuir características que estejam de acordo à zona bioclimática na qual ela se situa, conforme as recomendações da ABNT NBR 15220: Parte 3. É importante informar que a ABNT NBR 15220-3 foi redigida tendo em vista habitações unifamiliares de interesse social e que o zoneamento proposto por ela foi apropriado pela ABNT NBR 15575, por ser o único disponível no país na época. Essa adaptação implica em certas restrições, haja vista a ABNT NBR 15575 considerar qualquer tipo de habitação. No entanto, atualmente o zoneamento bioclimático encontra-se em processo de revisão e está sendo aperfeiçoado tendo em vista essas questões (RORIZ, 2012b).

Os procedimentos de avaliação do desempenho térmico de habitações descritos são os apresentados na Figura 1.

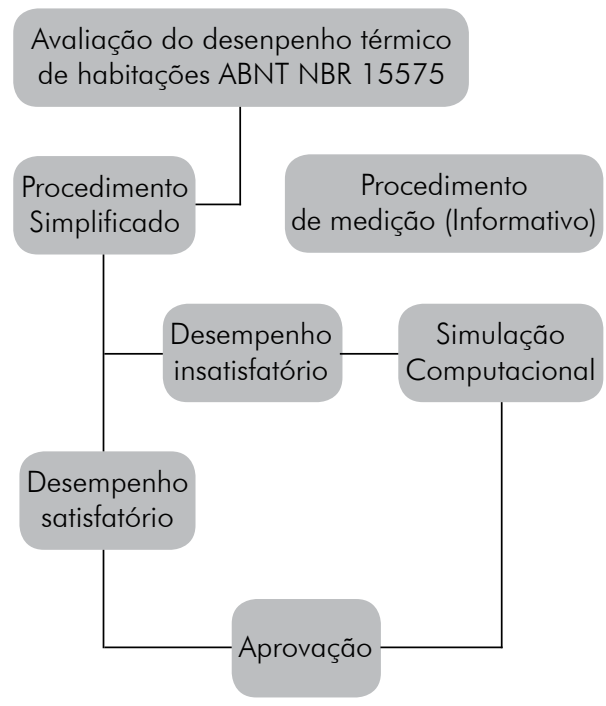

Figura 1. Esquema geral dos procedimentos para avaliação do desempenho térmico de habitações propostos pela ABNT NBR 15575

O primeiro passo é a aplicação do procedimento simplificado. Caso o desempenho resulte em insatisfatório, passa-se então ao método da simulação computacional. Entende-se que não há impedimento para a aplicação direta do método da simulação computacional, caso o usuário assim o deseje. Além 
${ }^{1}$ Área efetiva de abertura de ventilação do ambiente corresponde à área de abertura que permite a livre circulação de ar. disso, é apresentado um procedimento complementar, o procedimento 2 , que se refere a medição em edificações ou protótipos construídos. Este é considerado de caráter informativo e não se sobrepõe aos citados anteriormente, não sendo, portanto, tratado neste texto.

\section{Procedimento simplificado}

No procedimento simplificado, a envoltória (paredes exteriores e cobertura) deve atender às exigências especificadas nas partes 4 e 5 da Norma.

Uma dessas exigências refere-se às aberturas para ventilação das salas de estar e dormitórios: estas devem atender à legislação específica do local da obra (Código de Obras, Sanitários, ou outros). Caso não haja exigência legal, as porcentagens da Tabela 1 devem ser adotadas. Estas se referem à área efetiva de abertura' em relação à área de piso, a fim de que o desempenho mínimo seja atendido. Essas porcentagens também são em função do clima do local.

A fixação de áreas mínimas de abertura visa a garantir o desempenho térmico mínimo da habitação através da ventilação natural. No entanto, esse tipo de requisito pode não ser suficiente, pois uma ventilação eficiente ocorre em função também de outros fatores, como as condições de vento no local e a orientação das aberturas de entrada e saída em relação ao vento predominante. Além disso, em muitos casos, a legislação local restringe-se apenas a valores mínimos capazes de proporcionar uma ventilação higiênica, ligados à qualidade do ar e concentração de polventes e não a critérios de conforto. Uma possível melhoria na norma, indicada inclusive em versão anterior do mesmo documento, seria considerar que as referências da Tabela 1 , ou valores similares, fossem adotadas como mínimas admissíveis.

Tabela 1. Exigências da ABNT NBR 15575 para as aberturas para ventilação das salas de estar e dormitórios, segundo o procedimento simplificado

\begin{tabular}{lc}
\hline$A=$ área de abertura efetiva/ área do piso $\times 100(\%)$ \\
\hline $\begin{array}{lc}\text { Zonas bioclimáticas } 1 \text { a } 7 & \text { Zona bioclimática } 8 \\
A \geq 7 \% & \text { regiões nordeste e sudeste: } A \geq 8 \% \\
\text { região norte: } A \geq 12 \%\end{array}$ \\
Zonas 1 a 6: devem poder ser vedadas no período de frio
\end{tabular}

Fonte: adaptada de ABNT (2013). 
Outra exigência do procedimento simplificado referese a três propriedades termofísicas das paredes exteriores e da cobertura: transmitância térmica $(U)$, capacidade térmica $(C T)$ e absortância $(\alpha)^{2}$. A Tabela 2 sintetiza os valores limite de $\mathrm{U}, \mathrm{CT}$ e $\alpha$ indicados pela Norma, em função da zona bioclimática.

Quando se observa os limites estabelecidos pela ABNT NBR 15575, nota-se que a transmitância térmica $(U)$ é sempre limitada a valores máximos e que, quanto melhor o nível de desempenho, menor é esse limite. Outro ponto a ser notado é a relação entre $U$ e $\alpha$, que deve ser considerada em todos os climas mais quentes (zonas 3 a 8): para absortâncias mais altas, os valores limite de $U$ são menores. Quanto à capacidade térmica (CT) das paredes, exige-se o mínimo de $130 \mathrm{Kj} / \mathrm{m} 2 \mathrm{~K}$ em todo o país, exceto na zona 8 , de clima quente e úmido. Já para as coberturas, não há restrição.

Métodos simplificados, alternativos ao método computacional, facilitam a análise de habitações com características padronizadas. A simplicidade dessas edificações não justifica os recursos investidos em uma simulação computacional e, dessa forma, o seu desempenho pode ser obtido rapidamente. No entanto, o procedimento simplificado da ABNT NBR 15575 considera somente a envoltória opaca e requisitos mínimos para as aberturas, o que pode ser insuficiente para definir o desempenho da edificação.
${ }^{2}$ A ABNT NBR 15220: Parte 2 apresenta os métodos de cálculo de $\mathrm{U}$ e CT.

A transmitância térmica (U) é o fluxo de calor por metro quadrado e unidade de diferença de temperatura que atravessa um determinado fechamento, em regime estacionário.

A capacidade térmica (CT) é "a quantidade de calor necessária para variar em uma unidade a temperatura de um sistema" (ABNT NBR 15.220: Parte 1, 2005). A absortância $(\alpha)$ é o "quociente da taxa de radiação solar absorvida por uma superfície pela taxa de radiação solar incidente sobre esta mesma superfície" (ABNT NBR 15.220: Parte 1, 2005).

Tabela 2. Exigências para as propriedades termofísicas das paredes externas e da cobertura, prescritos pela ABNT NBR 15575

\begin{tabular}{|c|c|c|c|c|c|c|c|}
\hline & & & 7 & Zonas & 3 a 8 & & \\
\hline & & & & $\alpha \leq 0.6$ & $\alpha>0.6$ & & \\
\hline & $\mathrm{U}\left(\mathrm{W} / \mathrm{m}^{2} \cdot \mathrm{K}\right)$ & M & $\leq 2.5$ & $\leq 3.7$ & $\leq 2.5$ & & \\
\hline $\begin{array}{l}\text { (desempenho } \\
\text { mínimo/M) }\end{array}$ & $\mathrm{CT}\left(\mathrm{kJ} / \mathrm{m}^{2} . \mathrm{K}\right)$ & M & Zonas & 1 a $7: C T \geqq$ & 130 & & \\
\hline & & & & Zonas & 3 a 6 & Zonas & 7 e 8 \\
\hline $\begin{array}{l}\text { Coberturas } \\
\text { (desempenho }\end{array}$ & & & Zonas 1 e 2 & $\alpha \leq 0.6$ & $\alpha>0.6$ & $\alpha \leq 0.4$ & $\alpha>0.4$ \\
\hline mínimo/M, & $\mathrm{U}\left(\mathrm{W} / \mathrm{m}^{2} \cdot \mathrm{K}\right)$ & M & $\leq 2.3$ & $\leq 2.3$ & $\leq 1.5$ & $\leq 2.3 . \mathrm{FT}$ & $\leq 1.5 . \mathrm{FT}$ \\
\hline intermediário/l & & I & $\leq 1.5$ & $\leq 1.5$ & $\leq 1.0$ & $\leq 1.5 . \mathrm{FT}$ & $\leq 1.0 \mathrm{FT}$ \\
\hline & & S & $\leq 1.0$ & $\leq 1.0$ & $\leq 0.5$ & $\leq 1.0 \mathrm{FT}$ & $\leq 0.5 \mathrm{FT}$ \\
\hline
\end{tabular}

Fonte: adaptada de ABNT (2013).

O fator de transmitância, FT, é definido na NBR 15220-3. Ele é adimensional, e permite um valor-limite mais alto de $U$, caso o ático seja ventilado (somente para as zonas 7 e 8). Para coberturas não ventiladas, $\mathrm{FT}=1$. 
A temperatura interior é resultado da atuação de diversos elementos que proporcionam ganhos ou perdas de calor ao edifício: a envoltória opaca, as áreas envidraçadas, as aberturas, entre outros. A Norma deve incluir esses elementos em seu procedimento simplificado ou, caso não os inclua, ao menos delimitar a validade dos requisitos para edifícios com certas características (MARQUES; CHVATAL, 2013).

\section{Método de simulação computacional}

Neste método, cria-se um modelo digital, no qual a construção é submetida ao clima local, observa-se a evolução das temperaturas internas emuladas e comparam-se os valores máximos e mínimos atingidos a valores de referência. A avaliação de desempenho térmico por simulação, por ser um procedimento mais trabalhoso e especializado, exige mais tempo e preparo. São necessários especialistas que dominem não apenas os princípios relacionados à dinâmica dos fluxos de calor no edifício, mas também as ferramentas computacionais relacionadas.

\section{Programa de simulação}

O programa recomendado pela ABNT NBR 15575 para as simulações é o EnergyPlus (U.S. DEPARTMENT OF ENERGY, 2013). Ele foi desenvolvido pelo Departamento de Energia dos Estados Unidos e se difundiu entre os especialistas como uma ferramenta extremamente precisa e sofisticada para simulações do desempenho térmico e da eficiência energética de edificações. Ele tem a vantagem de ser gratuito e de apresentar todo o complexo modelo de cálculo utilizado, sendo alterado e revisado periodicamente. Por outro lado, tem uma interface pouco amigável e não intuitiva. Os dados de entrada são inseridos em um arquivo de texto e os de saída são apresentados em tabelas, sem nenhum processamento, ficando a cargo do usuário a análise e o pós-processamento.

Alternativamente, é possível utilizar outros programas de simulação dinâmica que sejam capazes de reproduzir os efeitos de inércia térmica, desde que validados através da ASHRAE Standard 140 (ASHRAE, 2011). Essa Norma especifica procedimentos que permitem o teste das capacidades técnicas e a faixa de aplicação dos programas de simulação de desempenho termoenergético de edificações.

\section{Dados climáticos}

Tal qual no procedimento simplificado, o primeiro passo é a identificação da Zona Bioclimática à qual a habitação pertence (conforme indicado na ABNT NBR 15220: Parte 3). Esta análise pode ser feita em observação a um mapa ou a uma lista apresentados no Anexo A da Parte 1 da ABNT NBR 15575. Uma dificuldade encontrada é que poucas cidades estão listadas nominalmente e a observação gráfica pode dar margem a uma interpretação equivocada. Uma 
opção é o uso de programas de auxílio, como o ZBBR (Roriz, 2004), que apresenta a classificação bioclimática de todos os municípios brasileiros.

A inserção dos dados climáticos referentes ao local no programa de simulação é de vital importância, pois possui um impacto significativo no desempenho. A Norma exige que as avaliações sejam feitas para o que denomina de dias típicos de projeto de verão e de inverno. Para as zonas bioclimáticas 1 a 5 , a avaliação deve ser feita para os dias típicos de projeto de verão e de inverno, enquanto para as zonas restantes é dispensada a avaliação de inverno.

Os dados climáticos referentes a esses dias, para vinte e seis capitais brasileiras, são apresentados no Anexo A da Parte 1. Além de se ter esse tipo de informação para poucas cidades, os dados fornecidos são insuficientes para a completa caracterização dos respectivos climas. $O$ programa de simulação exige variáveis adicionais, como a data desses dias típicos, dados relativos ao vento, à nebulosidade, entre outros. Alterações nesses dados impactam significativamente os resultados, conforme observaram Sorgato et al. (2013).

Com relação a outras cidades não contempladas nessas Tabelas, na Parte 1, item 11.2, é descrito: "na falta de dados para a cidade onde se encontra a habitação, recomenda-se utilizar os dados climáticos de uma cidade com características climáticas semelhantes e na mesma zona bioclimática brasileira (conforme a parte 3 da ABNT NBR 15220-3). NOTA: arquivos climáticos gerados por instituições de reconhecida capacitação técnica (universidades ou institutos de pesquisa) podem ser utilizados, desde que a fonte seja devidamente referenciada e os dados sejam de domínio público" (ABNT NBR 15575). Esse tipo de informação não é clara, dando margem a equívocos e diferenças significativas nas avaliações, afinal, qual é o critério para se considerar uma cidade com características climáticas semelhantes a outra? Somase a isso o fato de que não é apresentado o método para obtenção desses dias típicos de projeto, e há falta de dados climáticos confiáveis. Diversos especialistas alertam sobre este fato e se mobilizam para melhorar estas referências. Exemplo disso são as mesas redondas e apresentações ocorridas no último Encontro Nacional de Conforto no Ambiente Construído, ENCAC, em 2013 (ENCONTRO NACIONAL..., 2013).

Finalmente, questiona-se o fato da análise não ser feita utilizando-se dados climáticos anuais. Considera-se esse tipo de avaliação mais confiável por utilizar dados horários de um ano representativo do clima. Dessa forma, as variações climáticas e o comportamento do edifício frente a elas podem ser contemplados, o que não é possível quando se analisa apenas um dia. Esse ano representativo é obtido através da aplicação de métodos estatísticos em séries históricas de dados. Os resultados podem ser avaliados em função dos graus-hora de desconforto devido ao calor ou ao frio, ou aos graus-hora de resfriamento e de aquecimento, comparando-se com um projeto de referência, conforme considerado no RTQ-R. Recentemente, foram elaborados arquivos climáticos anuais, no formato para uso no EnergyPlus, de 411 cidades brasileiras, os quais encontram-se disponíveis gratuitamente (RORIZ, 2012A). 


\section{Modelo digital do edifício}

O modelo digital utilizado na simulação é uma descrição detalhada da construção, indicando a geometria de cada superfície (paredes, janelas, pisos, cobertura, etc.), bem como cada camada que a compõe. Por exemplo, descreve-se a geometria de uma parede e que esta é composta das camadas A, B e C. A descrição das camadas, por sua vez, é também um processo à parte, onde se especificam as propriedades termofísicas do material, como sua condutividade térmi$\mathrm{ca}$, calor específico, densidade, entre outras. A Norma exige que, para esta base de dados, devem-se utilizar preferencialmente referências das propriedades térmicas dos materiais obtidas em laboratórios reconhecidos, através de métodos normalizados. Em seguida, consulta-se o fabricante e, caso este não disponha das informações, pode-se adotar os dados das tabelas da ABNT NBR 15220. Num modelo digital de uma residência, todos os recintos são construídos virtualmente, sendo, portanto, simulado o desempenho, considerando as trocas térmicas entre todos os ambientes e avaliados os resultados das temperaturas dos ambientes de longa permanência (considerados pela Norma como os dormitórios e salas). No caso de empreendimentos com mais de uma unidade habitacional, considera-se que as mesmas condições de temperatura ocorram nas unidades e que, portanto, a troca de calor entre elas possa ser desprezada.

\section{Orientação solar}

A orientação do edifício pode ter grande influência nos fluxos de calor, especialmente no ganho de calor solar. A Norma exige que, para unidades habitacionais isoladas, deve-se simular na orientação de implantação. Caso essa orientação não esteja definida ou para conjuntos habitacionais e edifícios multipavimentos, deve-se simular na condição mais crítica do ponto de vista do desempenho térmico, que é indicada abaixo:

- Para conjuntos habitacionais e edifícios multipavimentos: (a) no caso de habitações térreas, selecionar uma unidade habitacional com o maior número de paredes expostas; (b) no caso de edifício multipavimentos, selecionar uma unidade do último andar, com a cobertura exposta.

- Tanto para habitações isoladas quanto para conjuntos habitacionais e edifícios multipavimentos, deve-se escolher um ambiente de maior permanência para ser analisado (salas ou dormitórios), desde que atenda às seguintes exigências:

- Simulação para o dia típico de projeto de verão: janela do dormitório ou da sala voltada, obrigatoriamente, para o oeste. A outra parede exposta voltada para o norte, caso possível.

- Simulação para o dia típico de projeto de inverno: janela do dormitório ou da sala voltada, obrigatoriamente, para o sul. A outra parede exposta voltada para o leste, caso possível.

Os critérios acima não necessariamente implicam nas situações com pior desempenho térmico. Como a simulação é executada somente para um dia, a 
orientação mais desfavorável dependerá da incidência solar nesse dia específico, a qual pode não ser representativa de todo o período de verão do local. Conforme já mencionado anteriormente, a inserção dessa informação no programa de simulação não é tratada pela Norma, ficando a critério do usuário. Sorgato et al. (2012) apontam para a complexidade desse tipo de recomendação. É citado o exemplo de Florianópolis, onde a orientação leste é mais crítica do que a oeste devido ao maior índice de nebulosidade do céu à tarde.

Também relacionado ao ganho solar e às janelas, é exigido que as paredes expostas e as janelas estejam desobstruídas, ou seja, que não existam edificações ou vegetação nas proximidades que modifiquem a incidência de sol e ou vento. A exceção, neste caso, é que, se a edificação apresentar dispositivo de sombreamento externo, como brises, marquises e beirais ou no caso de edificações de um mesmo complexo, isso deve ser considerado na simulação.

\section{Ventilação natural}

O cálculo da ventilação adotado pela ABNT NBR 15575 é extremamente simplificado. A Norma considera que existe uma taxa de ventilação em cada ambiente constante de uma renovação por hora (1 ren/hora). Ou seja, a cada hora, todo o ar do ambiente é trocado uma vez. Esta taxa de ventilação é da ordem de grandeza da infiltração (entrada de ar pelas frestas) que ocorre em um ambiente quando se tem janelas e portas fechadas. A Norma apresenta também a possibilidade de se considerar a taxa de 5 ren/hora (ver item Novas simulações). Ambas alternativas não representam condições realistas para a maioria dos casos em estudo. A correta avaliação do potencial de ventilação natural das edificações, entretanto, é tarefa difícil e de cálculo altamente complexo, o que inviabiliza atualmente sua exigência em um procedimento usual. Este ponto da norma ainda deve ser fruto de discussões para que seja aperfeiçoado tendo em vista essas limitações.

\section{Absortância das superfícies expostas}

Outro ponto bastante simplificado da Norma se refere à definição da absortância à radiação solar das superfícies expostas. A absortância é a variável que quantifica a porcentagem da energia que solar chega na superfície, a qual é absorvida e, portanto, torna-se calor instantaneamente. Segundo a Norma, ela deve ser definida conforme a cor das superfícies externas da cobertura e das paredes expostas e, em caso de não se ter esta informação, deve-se simular para três alternativas de paredes: cor clara (30\%), média (50\%) ou escura (70\%). Todavia, em muitos casos, esta observação é enganosa, pois uma cor tida como escura pode absorver menos radiação que outra superfície com cor mais clara, e vice-versa (DORNELLES, 2008; RORIZ; CARAM; RORIZ, 2011). Outra questão é a grande variação entre as graduações propostas, uma vez que esta variável tem grande influência nos resultados do modelo (DORNELLES; RORIZ; RORIZ, 2007). Existem algumas referências para esta variável, 
mas, devido ao dinamismo do mercado de tintas e da facilidade em se obter em laboratório estes valores, considera-se que esta deveria ser uma informação obrigatória, de fornecimento por parte dos fabricantes de tintas e texturas.

\section{Critérios para classificação do desempenho}

Os critérios adotados para avaliar os resultados das simulações são apresentados no Anexo E da ABNT NBR 15575 e reproduzidos nas Tabelas 3 e 4, que definem os níveis de desempenho térmico mínimo, intermediário ou superior da habitação. No caso do verão (Tabela 4), o desempenho é insuficiente sempre que a temperatura máxima do ar do ambiente analisado, no dia típico de projeto, for maior ou igual à temperatura máxima do ar exterior. Os desempenhos mínimo, intermediário e superior são alcançados quando a temperatura máxima do ar interior for menor que máxima externa, sendo que, quanto maior a diferença entre ambas, maior o nível de desempenho.

Tabela 3. Critério de avaliação de desempenho térmico para as condições de verão, de acordo com o método de simulação da ABNT NBR 15575

\begin{tabular}{|c|c|c|}
\hline \multirow{2}{*}{ Nível de desempenho } & \multicolumn{2}{|c|}{ Critério } \\
\hline & Zonas 1 a 7 & Zona 8 \\
\hline Insuficiente & $\mathrm{Ti}, \max >\mathrm{Te}, \max$ & $\mathrm{Ti}, \max >\mathrm{Te}, \max$ \\
\hline Mínimo & $\mathrm{Ti}, \max \leq \mathrm{Te}, \max$ & $\mathrm{Ti}, \max \leq \mathrm{Te}, \max$ \\
\hline Intermediário & $\mathrm{Ti}, \max \leq\left(\mathrm{Te}, \max -2^{\circ} \mathrm{C}\right)$ & $\mathrm{Ti}, \max \leq\left(\mathrm{Te}, \max -1^{\circ} \mathrm{C}\right)$ \\
\hline Superior & $\mathrm{Ti}, \max \leq\left(\mathrm{Te}, \max -4^{\circ} \mathrm{C}\right)$ & $\mathrm{Ti}, \max \leq\left(\mathrm{Te}, \max -2^{\circ} \mathrm{C}\right)$ \\
\hline
\end{tabular}

Fonte: adaptada de ABNT (2013).

Ti,max é o valor máximo diário da temperatura do ar no interior da edificação $\left({ }^{\circ} \mathrm{C}\right)$

Te,max é o valor máximo diário da temperatura do ar exterior à edificação $\left({ }^{\circ} \mathrm{C}\right)$

Tabela 4. Critério de avaliação de desempenho térmico para condições de inverno, de acordo com o método de simulação da ABNT NBR 15575

\begin{tabular}{|c|c|c|}
\hline \multirow{2}{*}{ Nível de desempenho } & \multicolumn{2}{|c|}{ Critério } \\
\hline & Zonas 1 a 5 & Zonas 6,7 e 8 \\
\hline Insuficiente & $\mathrm{Ti}, \min <\left(\mathrm{Te}, \min +3^{\circ} \mathrm{C}\right)$ & \multirow{4}{*}{$\begin{array}{l}\text { Nestas zonas, este critério não } \\
\text { precisa ser verificado. }\end{array}$} \\
\hline Mínimo & $\mathrm{Ti}, \min \geq\left(\mathrm{Te}, \min +3^{\circ} \mathrm{C}\right)$ & \\
\hline Intermediário & $\mathrm{Ti}, \min \geq\left(\mathrm{Te}, \min +5^{\circ} \mathrm{C}\right)$ & \\
\hline Superior & $\mathrm{Ti}, \min \geq\left(\mathrm{Te}, \min +7^{\circ} \mathrm{C}\right)$ & \\
\hline
\end{tabular}

Fonte: adaptada de ABNT (2013).

Ti,min é o valor mínimo diário da temperatura do ar no interior da edificação $\left({ }^{\circ} \mathrm{C}\right)$

Te,min é o valor mínimo diário da temperatura do ar exterior à edificação $\left({ }^{\circ} \mathrm{C}\right)$ 
Já no caso do inverno (Tabela 4), para o qual somente as zonas 1 a 5 são analisadas, o desempenho mínimo é atingido quando a temperatura interior mínima do ar no ambiente analisado for ao menos $3^{\circ} \mathrm{C}$ maior que a temperatura mínima do ar exterior. De forma análoga ao verão, quanto maior essa diferença, maior é o nível de desempenho.

Como exemplo de um possível resultado, apresenta-se a Figura 2. Consideramse condições de verão e que o clima da cidade de interesse, situado na zona bioclimática 4, seja tal que as temperaturas do ar exteriores ao edifício (dia típico de projeto) são as representadas pela curva que indica $T_{\text {ext }}$ (temperatura exterior). Após todo o processo de simulação, obtém-se a evolução da temperatura no dormitório 1 , representada como $T_{\text {dorm } 1}$. Como a temperatura máxima interna $\left(T_{i, m a x}\right)$ é inferior à máxima externa $\left(T_{e, \text { max }}\right)$, o desempenho mínimo é alcançado. $O$ nível de desempenho dependerá da diferença entre a $T_{i, \text { max }}$ e a $T_{e, \text { max }}$ conforme indicado na Tabela 4. Nesta situação, o nível de desempenho atingido para a habitação é o mínimo.

\section{Novas simulações}

Caso não tenha sido atingido o desempenho mínimo para o verão, a Norma prevê novas simulações, que devem considerar três possibilidades de alteração nos dados de entrada:

- Alteração na ventilação: aumento da taxa de ventilação para cinco renovações de ar por hora e janelas sem sombreamento;

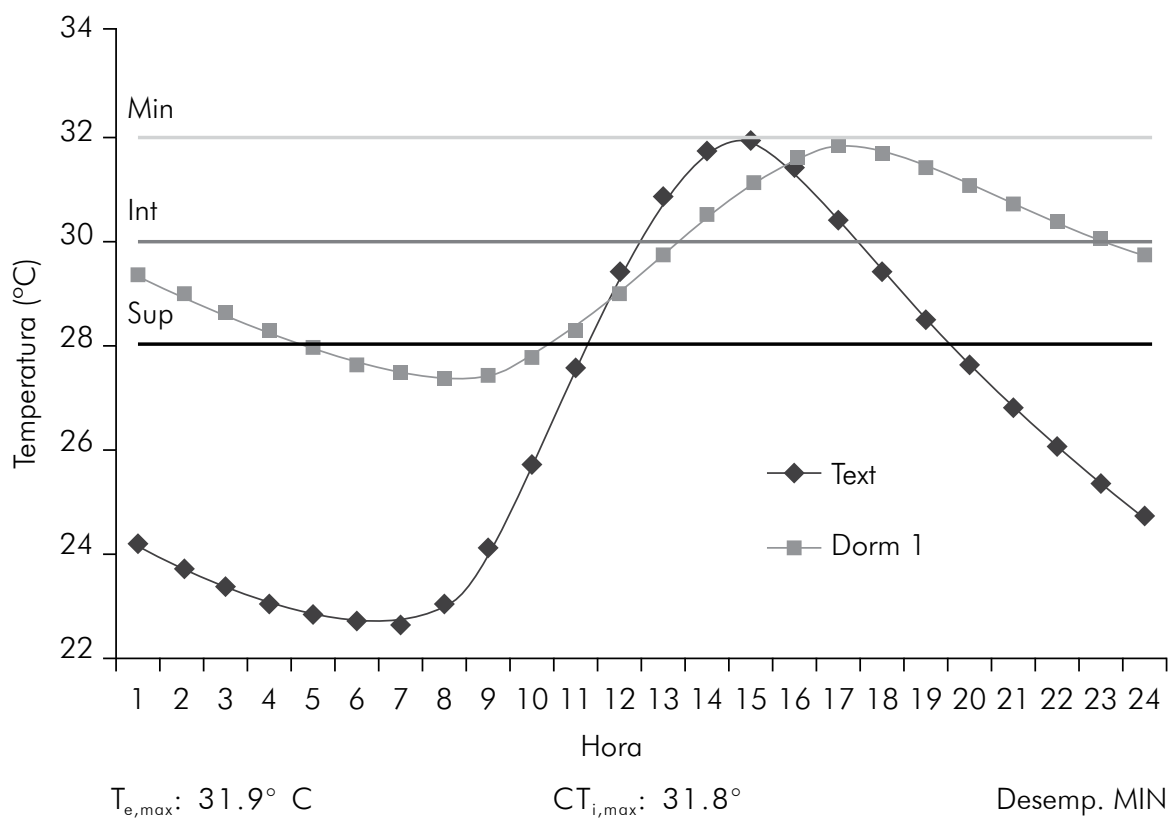

Figura 2. Exemplo de avaliação de desempenho de verão 
- Alteração no sombreamento: proteção solar externa ou interna com elemento que reduza no mínimo $50 \%$ da radiação solar direta que entra pelas janelas, mantendo-se a taxa de renovação do ar (1,0 ren/h);

- Alteração na ventilação e no sombreamento: as duas alterações anteriores combinadas (proteção solar mais janelas com sombreamento).

Acredita-se que uma habitação que não apresente o desempenho mínimo no verão, deve sofrer alterações consistentes no seu projeto, de modo que isso represente uma efetiva melhoria nas suas condições. A consideração da nova taxa de renovação de ar deve ser justificada e refletir mudanças reais nas condições de ventilação natural do edifício. Além disso, embora sejam tratadas da mesma forma na Norma, há diferenças significativas entre o comportamento de proteções solares externas ou internas. Proteções solares externas são muito mais eficientes, pois evitam a entrada de radiação solar direta antes da sua transmissão pela janela.

\section{Outras observações gerais}

Verifica-se que no método de simulação da ABNT NBR 15575, o edifício não é simulado em suas condições de utilização reais. Não são considerados os ganhos de calor internos devido à ocupação, equipamentos e iluminação artificial, e a modelagem da ventilação natural não corresponde ao que é usual (janelas abertas, ao menos no período quente). Isso pode implicar em análises equivocadas do desempenho, conforme também afirmam Sorgato, Melo e Lamberts (2013).

Também, em nenhum momento, a Norma faz referência à consideração de estratégias de condicionamento térmico passivo na simulação que, sabidamente, devem ser incentivadas, pois propiciam a melhora do desempenho sem gasto excessivo de energia.

Além disso, como o processo de simulação é extremamente complexo, muitas variáveis de entrada são necessárias e nem todas estão definidas no texto da Norma. Variáveis como a "Temperatura do Solo", por exemplo, podem ter um impacto extremamente significativo nos resultados da simulação. Seria recomendável que se exigisse do simulador a apresentação de certos dados quando da entrega da avaliação ou mesmo uma cópia do arquivo de entrada. Considera-se também imprescindível o treinamento obrigatório ou a certificação de agentes, de modo a fornecer o embasamento teórico correto para a modelagem no programa computacional.

Finalmente, atenta-se para a necessidade de uma maior coerência entre a ABNT NBR 15575, a ABNT NBR 15220 (ABNT, 2005) e o RTQ-R (INMETRO, 2012), conforme levantado por Loura, Assis e Bastos (2011). Esses autores encontraram algumas divergências entre a ABNT NBR 15575 e o RTQ-R, ao avaliarem a mesma habitação pelos dois métodos. Sabe-se que cada um desses documentos possui objetivos e escopos diferentes, mas é importante que haja coerência entre seus requisitos e métodos de avaliação. 


\section{Considerações finais}

A ABNT NBR 15575, com seu método de avaliação do desempenho térmico, a ABNT NBR 15220 e o RTQ-R, embora tenham sido instituídos no Brasil muitos anos após a implementação desses mesmos tipos de documentos em outros países, representam um avanço extremamente significativo no setor da construção civil. Por serem os primeiros documentos que tratam desse assunto no país, têm um caráter educativo, apresentando a construtores e consumidores critérios e métodos para melhoria do desempenho das edificações. Pelo mesmo motivo, é importante que se mantenha uma discussão constante sobre a sua aplicação e a viabilidade de seus métodos de cálculo, a fim de se garantir o seu aperfeiçoamento. É imprescindível que seja feito um esforço no sentido de tornar estas normas mais coerentes entre si e que elas representem as condições mínimas estabelecidas pela sociedade brasileira. Este texto procura contribuir com esse debate, trazendo questões referentes ao método de avaliação da ABNT NBR 15575 relativos ao desempenho térmico e sugestões para sua melhoria. 


\section{Referências}

ABNT - ASSOCIAÇÃO BRASILEIRA DE NORMAS TÉCNICAS. NBR 15220: desempenho térmico de edificações. Rio de Janeiro, 2005.

ABNT - ASSOCIAÇÃO BRASILEIRA DE NORMAS TÉCNICAS. NBR 15575: edificações habitacionais: desempenho. Rio de Janeiro, 2013.

ASHRAE - ASHRAE STANDING STANDARD PROJECT COMMITTEE 140. Standard method of test for the evaluation of building energy analysis computer programs. Atlanta: ASHRAE, 2011.

DORNELLES, K. A. Absortância solar de superfícies opacas: métodos de determinação e base de dados para tintas látex acrílica e PVA. 2008. (Tese de doutorado - Engenharia Civil) - Faculdade de Engenharia Civil, Arquitetura e Urbanismo da Universidade Estadual de Campinas, Campinas, 2008.

DORNELLES, K. A.; RORIZ, V.; RORIZ, M. Determination of the solar absorptance of opaque surfaces. In: INTERNATIONAL CONFERENCE ON PASSIVE AND LOW ENERGY ARCHITECTURE, 24., 2007, Singapore. Proceedings... [S.n.t.].

ENCONTRO NACIONAL DE CONFORTO NO AMBIENTE CONSTRUÍDO - ENCAC, 12.; ENCONTRO LATINOAMERICANO DE CONFORTO NO AMBIENTE CONSTRUÍDO, 8., 2013, Brasília, DF. Anais... Porto Alegre: ANTAC, 2013.

INMETRO - INSTITUTO NACIONAL DE METROLOGIA, NORMALIZAÇÃO E QUALIDADE INDUSTRIAL. RTQ-R - Regulamento técnico da qualidade para o nível de eficiência energética em edificações residenciais. Rio de Janeiro, 2012.

MARQUES, T. H. T.; CHVATAL, K. M. S. A review of the Brazilian NBR 15575 Norm: applying the simulation and simplified methods for evaluating a social house thermal performance. In: SYMPOSIUM ON SIMULATION FOR ARCHITECTURE AND URBAN DESIGN, 4., 2013, San Diego. Proceedings... [S.n.t.].

RORIZ, M. Arquivos climáticos de municípios brasileiros. São Carlos: Laboratório de Eficiência Energética em Edificações, 2012a.

RORIZ, M. Uma proposta de revisão do zoneamento bioclimático brasileiro. São Carlos: Laboratório de Eficiência Energética em Edificações, 2012b.

RORIZ, V. F.; CARAM, R.; RORIZ, M. Absortâncias e emitâncias efetivas de superfícies: um método para estimá-las e exemplos de suas importâncias. In: ENCONTRO NACIONAL DE CONFORTO NO AMBIENTE CONSTRUÍDO - ENCAC, 11 ., Búzios. Anais... Porto Alegre: ANTAC, 2011

RORIZ, M. ZBBR 1.1, Zoneamento Bioclimático do Brasil. Disponível em: Laboratório de Eficiência Energética em Edificações. ZBBR: zoneamento bioclimático do Brasil. São Carlos, 2004.

SORGATO, M. J.; MARINOSKI, D. L.; MELO, A. P.; LAMBERTS, R. Nota técnica referente à avaliação para a norma de desempenho NBR 15575 em consulta pública. Florianópolis: Laboratório de Eficiência Energética em Edificações, UFSC, 2012.

SORGATO, M. J.; MELO, A. P.; LAMBERTS, R. Análise do método de simulação de desempenho térmico da Norma NBR 15575. In: ENCONTRO NACIONAL DE CONFORTO NO AMBIENTE CONSTRUÍDO - ENCAC, 12., 2013, Brasília, DF. Anais... Belo Horizonte: UFMG, 2013.

U. S. DEPARTMENT OF ENERGY. EnergyPlus: building energy simulation software. Washington, 2013. 
Cap. 6

' Sobre o programa MCMV, há artigos publicados logo após seu lançamento, em 2009, como Rolnik e Nakano (2009) e Fix e Arantes (2009); e análises mais recentes sobre os resultados do programa, como em Moyses e Borges (201 1), Cardoso, Aragão e Araujo (2011) e Cardoso (2013).

\section{A questão da manutenção de sistemas construtivos inovadores para habitação}

\author{
Lucia Zanin Shimbo \\ Marina Estela Martins
}

\section{Introdução}

\section{Aumento das atividades da Construção Civil e produção em escala da habitação no Brasil}

A partir dos anos 2000, as dinâmicas da política habitacional, do mercado imobiliário e da construção civil se revelaram fortemente amarradas no Brasil, na perspectiva de desenvolvimento econômico colocada pelo governo federal. A relação entre política pública habitacional e produção privada de moradias se redesenhou com a entrada do capital financeiro nas grandes empresas construtoras e incorporadoras e com o aumento de recursos dos principais fundos do Sistema Financeiro da Habitação (SFH), o Fundo de Garantia do Tempo de Serviço (FGTS) e o Sistema Brasileiro de Poupança e Empréstimo (SBPE).

Para exemplificar, entre 2002 e 2012, o valor total anual contratado para habitação com recursos do FGTS foi multiplicado aproximadamente em 11 vezes, passando de aproximadamente R\$ 3 bilhões em 2002 para R\$ 34 bilhões em 2012; enquanto que, pelo SBPE, esse valor foi multiplicado por 45, passando de $R \$ 1,7$ bilhão para $R \$ 76$ bilhões, no mesmo período (CBIC, 2013). Aproveitando essa maciça oferta de financiamento aos consumidores, grandes empresas passaram a ofertar imóveis com valores de até $R \$ 200$ mil (ou, aproximadamente, U\$ $100 \mathrm{mil}$ ) dentro do segmento econômico, assim considerado pelo mercado imobiliário. 
${ }^{2}$ Ver: Carassus, 1987.

Em 2009, foi lançado o Programa "Minha Casa, Minha Vida" (PMCMV)', com o objetivo de produzir um milhão de unidades habitacionais e de alavancar a promoção de habitação orientada, principalmente para o segmento econômico, corroborando os vínculos entre Estado e empresas, já esboçados desde o início da década. Atualmente na sua segunda fase, que pretende produzir mais 2,4 milhões de unidades, o programa atendeu sua motivação primordial de fomentar, ainda mais, o setor da construção civil e o mercado imobiliário. Praticamente em todos os estados do país, o PMCMV incentivou a produção em escala da habitação, consolidando um mercado, propriamente dito, de habitação.

Além do aumento de recursos para financiamento habitacional, o setor da construção civil como um todo apresentou um crescimento contínuo entre 2007 e 2010: nesse período, o valor adicionado da atividade da construção foi praticamente dobrado, passando de $\mathrm{R} \$ 63$ bilhões, em 2007, para $R \$ 125$ bilhões em 2010. Em especial, as obras residenciais tiveram aumento na participação no total das incorporações, obras e/ou serviços da construção, passando de 15,1\%, em 2007, para 20,6\% em 2010 (IBGE, 2010).

Entretanto, esse crescimento da Construção Civil está restrito à produção de novas edificações e não é acompanhado por um incremento nos serviços de manutenção do estoque existente. Para exemplificar, dentro da modalidade "construção de edifícios", a participação dos serviços de reforma ou manutenção de edifícios residenciais é diminuta, em torno de $6 \%$, enquanto que a construção de edifícios residenciais abrange mais de 50\% (IBGE, 2010). Vale ressaltar que dentro desses $6 \%$ estão incluídos os serviços de reforma e não é possível identificar a porcentagem exata de participação específica dos serviços relacionados à manutenção dos edifícios.

\section{A questão da manutenção}

Além de apresentar uma ínfima participação no setor da construção, no Brasil, a questão da manutenção não é priorizada nas diretrizes dos programas habitacionais vigentes, que estão pautados em indicadores mais quantitativos do que qualitativos. No contexto europeu, Bougrain e Carassus (2003) inserem os serviços relacionados à manutenção do estoque existente de edificações no "sistema produtivo setorial" da construção, que seria o conjunto 
complexo e organizado de relações entre os atores (produtivos e institucionais) que participam da produção, da gestão de obras e dos serviços derivados dessas obras, ao longo do ciclo de vida das edificações.

Os autores criticam a noção de "setor" da construção civil, defendida nos anos 1980 pelo próprio Carassus ${ }^{2}$, pois se limita ao conjunto de empresas que tem como atividade principal a construção, a reforma e a manutenção de edificações, restringindo-se às empresas de construção em si. Assim como questionam a ideia de "ramo" (filière, apesar de não ter uma tradução exata para o português), pois analisa apenas os fluxos de produção das edificações, articulando-se as suas etapas: concepção, realização e recepção.

A novidade analítica trazida por Bougrain e Carassus (2003) é justamente incluir, entre os principais grupos de atividades da construção, a gestão contínua do estoque de edificações existentes. Os outros dois grupos seriam a atividade descontínua de idealização da operação, gestão do projeto e arranjo complexo de produção em determinado local (atividades de projeto/canteiro) e atividades de produção industrial e de distribuição de materiais, componentes etc.

Os autores enfatizam que a economia europeia não espera mais da construção um crescimento massivo dos estoques de edifícios e de infraestrutura, como ocorria no período do pós-guerra, mas sim uma otimização dos serviços oferecidos pelas e nas edificações, existentes ou a construir, que satisfaçam as exigências do desenvolvimento durável. Nesse contexto, os serviços de manutenção são de extrema importância, pois garantem a qualidade da construção durante sua vida útil e contribuem para o seu prolongamento, evitando assim que o imóvel seja descartado precocemente. Segundo Bougrain e Carassus (2003), as empresas não devem dialogar apenas com a fase de execução das obras, devem levar em consideração as verdadeiras necessidades do usuário final para que a funcionalidade da obra seja definida.

Nesse sentido, as inovações tecnológicas na construção civil precisam considerar os serviços que irão suportá-la durante a fase de uso e de operação da edificação. Ou seja, ao se conceber um sistema construtivo inovador, é necessário pensar em como serão prestados os serviços durante o uso do próprio sistema e se existe mão de obra capacitada para executá-los. Mais especificamente, a falta de um saber-fazer relacionado à manutenção de sistemas inovadores é um entrave muito grande à durabilidade das edificações ${ }^{3}$.
${ }^{3}$ No Brasil, o órgão responsável pela avaliação de novos sistemas construtivos e os produtos inovadores disponibilizados no mercado é o "Sistema Nacional de Avaliações Técnicas" (SiNAT) elaborado pelo Programa Brasileiro de Qualidade e Produtividade no Habitat (PBQP-H) do Ministério das Cidades, em 2007 (IFBQ, 2011). 
${ }^{4}$ A pesquisa intitulada "Caracterização e análise da mão de obra especializada na manutenção de sistemas construtivos inovadores" foi desenvolvida pela aluna Marina Estela Martins, entre julho de 2012 e marco de 2013, com bolsa de Iniciação Tecnológica Industrial (ITI-A), do $C N P q$, e vinculada ao "SUBPROJETO 5 - Procedimentos para avaliação de desempenho de sistemas construtivos inovadores [SiNAT] à luz da percepção do usuário", da Rede INOVATEC/ Finep. Agradecemos ao CNPq e, em especial, ao coordenador da Rede, o Prof. Marcio Minto Fabricio.
No atual contexto de crescimento da produção habitacional no Brasil, a alvenaria estrutural se destaca como principal sistema construtivo adotado, para a qual há um saber-fazer bastante disseminado na construção civil. Apesar dessa predominância da alvenaria, outros sistemas construtivos considerados inovadores estão sendo empregados - alguns deles, inclusive, em empreendimentos do PMCMV - tais como: paredes de concreto moldadas in loco, paredes em PVC+concreto, steel-frame, blocos de EPS, grandes painéis cerâmicos pré-fabricados (JetCasa), formas blanche, paredes pré-moldadas em concreto, entre outras (FERREIRA, 2012).

Nos casos dos empreendimentos habitacionais que adotam tais sistemas, como tratar a questão da manutenção tendo em vista que grande parte da mão de obra tradicional no Brasil não tem um saber-fazer relacionado à execução desses sistemas construtivos inovadores? Além disso, e ampliando a questão, como lidar com a manutenção de empreendimentos habitacionais, financiados por programas públicos de habitação, que utilizam sistemas construtivos inovadores, considerando também a faixa de renda dos moradores?

Essas são as principais questões que este artigo pretende senão responder, pelo menos apontar caminhos de análise acerca da manutenibilidade de sistemas construtivos inovadores para habitação. Nessa perspectiva, as estratégias de pesquisa qualitativa tornam-se importantes, na medida em que possibilitam o confronto de dados provenientes de diversas fontes (observação, entrevistas com moradores e com trabalhadores da construção civil etc.) e permitem captar as reais apropriações e motivações dos usuários.

Dessa forma, este artigo traz os resultados de uma pesquisa de iniciação científica ${ }^{4}$ que realizou um estudo de caso em um empreendimento habitacional que utilizou o sistema construtivo de paredes de concreto moldadas in loco.

\section{Objetivo e Métodos}

O objetivo principal da pesquisa era caracterizar e avaliar a disponibilidade de mão de obra especializada para manutenção de edificações com sistemas construtivos inovadores. Para tanto, foram desenvolvidas as seguintes estratégias metodológicas: (i) revisão da literatura nacional e internacional sobre o conceito de inovação tecnológica 
na construção civil e a questão da manutenção; (ii) pesquisa documental, envolvendo o estudo sobre as instituições homologadoras de produtos inovadores no Brasil (SiNAT); (iii) estudo de caso.

O estudo de caso envolveu as seguintes etapas: (i) leitura e análise do manual do proprietário do Empreendimento Estudado (EE) da Empresa Pesquisada (EP); (ii) elaboração de roteiros de entrevistas aos moradores e trabalhadores da construção civil; (iii) levantamento de campo no EE para observação e registro das alterações nas unidades habitacionais realizadas pelos moradores; (iv) entrevistas e conversas informais com moradores e trabaIhadores; (v) sistematização e análise dos dados obtidos.

O empreendimento estudado se localiza na cidade de São Carlos (SP), com um total de 596 unidades habitacionais, com áreas privativas de aproximadamente $41 \mathrm{~m}^{2}$, e financiamento dentro do PMCMV. Trata-se de um condomínio fechado, com apenas uma entrada e murado em todo seu perímetro, no qual 356 unidades foram destinadas à Faixa 2 do Programa e 240 unidades à Faixa $3^{5}$. A entrega das unidades foi feita a partir de dezembro de 2011 . A coleta de dados no empreendimento foi realizada em dezembro de 2012 e março de 2013, portanto, um ano depois da entrega.

O sistema construtivo é composto pelos seguintes subsistemas principais e materiais: (i) Fundação: tipo radier; (ii) Estrutura: paredes portantes de concreto armado moldado in loco; (iii) Cobertura: estrutura de alumínio e telha cerâmica.

Esse sistema é considerado inovador pelo Sistema $\mathrm{Na}$ cional de Avaliações Técnicas (SiNAT), apesar da empresa responsável pelo empreendimento não apresentar um Documento de Avaliação Técnica (DATec) específico - outras empresas apresentam DATecs para sistemas bastante semelhantes, ou seja, sistemas de vedação portante utilizando concreto moldado no local.

A empresa construtora responsável pelo EE vem empregando tal sistema construtivo em todos os seus empreendimentos, nas 55 cidades de 12 estados brasileiros onde atua, voltados para o segmento econômico do mercado. Com capital aberto desde janeiro de 2007, a companhia lançou, desde a sua fundação em 1983, mais de 60 mil unidades habitacionais ${ }^{6}$.
${ }^{5}$ Dados obtidos junto ao Ministério das Cidades: Base de dados da Chamada $\mathrm{MCTl} / \mathrm{CNPq} /$ MCIDADES n $n^{\circ} 11 / 2012$ (BRASIL, 2013). O PMCMV se apresenta formalmente como um único programa habitacional, mas se estrutura operacionalmente em linhas distintas, de acordo com faixa de renda dos beneficiários, origem dos recursos e instituição proponente. Tais linhas estão agrupadas em, basicamente, três faixas de renda familiar mensal: de 0 a 3 salários mínimos (SM), de 3 a 6 SMs e de 6 a 10 $\mathrm{SMs}$ - posteriormente, a referência deixou de ser o salário mínimo e passou a ter um valor fixo, ou seja, a primeira faixa compreende famílias com renda até $\mathrm{R} \$ 1.600,00$; a segunda, entre $R \$ 1.600,00 \mathrm{e}$ $\mathrm{R} \$ 3.100,00$; e a terceira entre R\$3.101,00 e $\mathrm{R} \$ 5.000,00$ (CIUFFOLINI; SHIMBO, 2013).

${ }^{6}$ Informações obtidas no site da construtora. 
${ }^{7}$ Disponivel em: http:// www.cidades.gov. $\mathrm{br} / \mathrm{pbqp}-\mathrm{h} /$ projetos sinat.php Acesso em: 16/08/2012.

${ }^{8}$ Manual do proprietário do $E E$, p. 2.

${ }^{9}$ Manual do proprietário do EE, p. 2 (grifo nosso).

\section{Resultados e discussão}

\section{Análise do manual do proprietário}

No processo de avaliação de um produto inovador realizado pelo SiNAT, a questão da manutenção está centrada no conteúdo do Manual de Operação, Uso e Manutenção (Manual do Proprietário), preparado pela empresa responsável para cada empreendimento e que é analisado para a emissão dos certificados. Como condição para emissão do DATec, a empresa se compromete a "manter assistência técnica, por meio de serviço de atendimento ao cliente" ${ }^{\prime 7}$.

Dessa forma, transfere-se toda a responsabilidade de manutenção e fornecimento de mão de obra para a empresa proponente, sem haver um detalhamento sobre a fiscalização em relação ao cumprimento dessa condição e sobre o período no qual a empresa deve se responsabilizar pela manutenção.

O Manual do Proprietário do empreendimento estudado tinha como objetivo principal:

[...] auxiliar os usuários na correta utilização e manutenção do imóvel, contendo as principais informações sobre o imóvel e seu uso, tais como características construtivas, materiais empregados, informações técnicas de projeto, cuidados necessários durante as operações de limpeza, manutenção e garantias ${ }^{8}$.

Além disso, destacava que:

Ao receber as chaves e tomar posse do imóvel, a responsabilidade pela conservação e manutenção periódica passa a ser do proprietário, independentemente das garantias legais que the são asseguradas.

[...] A EP compromete-se a executar, sem ônus ao adquirente, os serviços necessários desde que considerados de sua responsabilidade. Caso o serviço solicitado esteja por alguma razão fora das condições de garantia, será cobrada uma taxa de visita estabelecida pela central de relacionamento. Nessas circunstâncias as correções ficarão sob a responsabilidade do proprietário?.

Como pode ser visto nos trechos acima, não são especificados os aspectos que são de responsabilidade da 
empresa e tampouco são estabelecidos claramente quais são os direitos e deveres entre empresa e usuário. Outra questão que não é detalhada é quem pode realizar os serviços necessários: a empresa mediante pagamento ou o proprietário ele mesmo, com instruções que deveriam estar contidas no manual do usuário, ou ainda contratando alguém para realizar o serviço. Nesse último caso, a principal pergunta é quem seria esse profissional que precisaria ter, em tese, um conhecimento específico para trabalhar com um sistema construtivo não convencional. Não há uma lista que pudesse indicar tais profissionais, como ocorre, por exemplo, nos manuais de eletrodomésticos, que indicam a rede de estabelecimentos de assistência técnica.

Durante o levantamento de campo, foi possível observar que a empresa realiza alguns serviços de manutenção com sua equipe própria, mas, com bastante frequência, há dificuldade de contato entre moradores e a central de relacionamento e há demora no atendimento, fazendo com que grande parte dos moradores contrate individualmente trabalhadores autônomos para realizarem os serviços.

Entretanto, o usuário perde a garantia se o adquirente ou usuário realizar modificações no imóvel, alterando seu projeto original, ou contratar serviços de revisão, consertos ou reparos por pessoas não autorizadas pela incorporadora.

O que foi possível observar a partir das entrevistas com os moradores é que eles não têm conhecimento de que poderiam entrar em contato com a construtora para contratar mão de obra qualificada e autorizada para a realização de consertos e reparos. Esse fato se deve, sobretudo, à falta de leitura cuidadosa do Manual do Proprietário por grande parte dos moradores. Além disso, outro fator que pode influenciar na falta de atenção devida ao Manual é que a própria empresa instrui os moradores, ao receberem as unidades, a procurar a secretaria de obras da prefeitura caso desejem aprovar alguma obra de ampliação ou reforma na unidade, como se fosse uma obra qualquer.

O Manual apresentava também uma tabela contendo os sistemas e materiais empregados e seus respectivos prazos de garantia. Muitos moradores não tinham conhecimento sobre tais prazos, apenas tinham em mente que seu imóvel apresentava uma "cobertura" da empresa para serviços de manutenção durante cinco anos, caso não existissem modificações feitas por trabaIhadores particulares.

Além disso, havia outra tabela que indicava a periodicidade da realização de manutenção, descrevendo cada um dos itens a serem verificados (instalações elétricas e hidráulicas, cobertura, paredes, tetos, esquadrias, metais sanitários, pisos e azulejos) e uma breve descrição sobre a atividade de manutenção preventiva que deveria ser executada. Algumas atividades referem-se apenas à verificação e limpeza dos itens, porém, outras requisitam gastos com materiais e serviços, como a execução de nova pintura de paredes, tetos e esquadrias a cada dois anos - no caso das janelas, a recomendação é que seja feita anualmente. 


\section{Alterações nas unidades habitacionais e o problema da incompatibilidade dos sistemas adotados}

Apesar das recomendações contidas no Manual, mesmo com suas limitações já apontadas, a grande maioria das unidades habitacionais já havia passado por alguma alteração construtiva, um ano após a entrega das chaves. Durante as entrevistas com moradores, foi possível perceber que a totalidade dos contratos era feita informalmente entre morador e trabalhador autônomo, sem autorização da construtora e com profissionais sem treinamento para lidar com esse tipo de sistema construtivo inovador, porém com experiência na construção civil, como será discutido mais adiante. Em alguns casos, os próprios moradores realizavam algumas alterações, principalmente relacionadas aos serviços mais simples, como por exemplo, executar o muro externo, cimentar o piso externo, instalações elétricas e pequenos reparos.

Durante o levantamento de campo, foram identificadas quatro situações das unidades habitacionais, três delas relacionadas a algum tipo de alteração (ampliação da área útil, somente execução de muro externo e reforma interna) e uma sem alterações.

As ampliações tinham como objetivo aumentar a área útil da unidade. Segundo os moradores, a casa era muito pequena e não oferecia conforto suficiente para as atividades da família. Observou-se que todos que realizavam ampliação também construíam muro externo. $O$ cômodo mais aumentado foi a cozinha, separando o seu uso do da sala de estar - como previa o projeto original. Outra reforma frequente era da lavanderia, que era ampliada juntamente com a cozinha. Em segundo lugar, optava-se por fazer uma área de lazer, na maioria das vezes com churrasqueira. O terceiro cômodo mais construído foi um banheiro adicional. Pelo menos metade da área disponível nos fundos da casa, ou seja, o quintal (que no projeto era considerado como área permeável), foi utilizada para aumentar a área útil da unidade.

A reforma interna se caracterizava por uma pequena modificação como, por exemplo, troca de revestimento do banheiro, pintura interna etc.

Das 596 unidades do empreendimento, foi possível levantar a situação de 483 unidades, ou seja, $81 \%$ do total, devido às dificuldades de acesso a algumas delas, impedindo a observação adequada. Dessa amostra de 483 unidades, 200 unidades tinham passado por ampliação (ou seja, 41\%), 179 realizado apenas muro externo (37\%), 103 estavam sem alterações (21\%) e em apenas duas havia reforma interna (1\%). Isso significa que aproximadamente $80 \%$ das unidades analisadas apresentavam algum tipo de alteração.

O principal sistema construtivo utilizado nas ampliações era a estrutura em concreto armado com fechamento em alvenaria de bloco cerâmico. Nas conversas com os trabalhadores, a escolha desse método era justificada pelo fato de ser o mais conhecido, cuja técnica era dominada pelos trabalhadores. 
Embora as coberturas das unidades tivessem estrutura metálica, as ampliações apresentavam telhados com estrutura de madeira. Na maioria das vezes, a cobertura era construída pelo mesmo trabalhador que havia realizado a ampliação, incluindo os serviços de alvenaria, ou seja, ele executava serviços de pedreiro e de carpinteiro.

Ao final da ampliação, a unidade se transformava em um híbrido entre sistema construtivo inovador e sistema construtivo tradicional. A interface entre esses dois sistemas se tornava, portanto, uma questão fundamental para garantir a estabilidade e durabilidade da unidade habitacional.

A maioria dos trabalhadores afirmava que não havia influência entre os dois sistemas construtivos, uma vez que a ampliação é feita separadamente. Alguns trabalhadores diziam que apenas "encostavam" a estrutura da ampliação na estrutura inicial, unindo-as apenas com argamassa. Essa técnica é suscetível de rachaduras na interface das suas estruturas, o que pode levar a problemas como infiltrações e outras patologias decorrentes.

Outros trabalhadores afirmavam não estar carregando a estrutura original, mas faziam amarrações entre as estruturas com aço e argamassa. Essa técnica pode ser menos susceptível a rachaduras, porém corre-se o risco da ampliação transmitir esforços indevidos à estrutura original. Embora os trabalhadores fossem muito experientes, não havia uma análise estrutural prévia para se verificar a distribuição de forças envolvidas na ligação entre as estruturas.

Em relação ao perfil dos trabalhadores que realizavam os serviços de manutenção e de ampliação, no geral, tratava-se de uma mão de obra não especializada, sendo que cerca de metade dos entrevistados havia feito apenas um curso de instalações elétricas. Segundo muitos depoimentos, essa profissão se "aprende na prática" e não existe um curso no qual eles poderiam se especializar na profissão que já praticam há anos.

Foi possível entrevistar apenas um técnico da EP que estava realizando serviços de manutenção em uma unidade e seu perfil era muito parecido com o dos demais trabalhadores entrevistados. Ou seja, contava com muitos anos de experiência, mais de dez anos trabalhando na construção civil, entretanto essa era a primeira vez que trabalhava com esse tipo de sistema construtivo (parede de concreto moldado in loco).

\section{Considerações finais: o real enfrentamento da questão da manutenção}

O estudo de caso realizado revela questões importantes sobre a situação da manutenção de sistemas construtivos considerados inovadores para a habitação no contexto brasileiro, em que prevalecem sistemas convencionais, pautados numa produção manufatureira e numa mão de obra não especializada.

A primeira questão diz respeito à limitação do instrumento que orienta a manutenção desses sistemas. A questão da manutenção fica restrita ao 
conteúdo do Manual do Proprietário, durante a avaliação do sistema construtivo inovador. Entretanto, como o estudo de caso apontou, esse conteúdo é vago quanto à especificação das responsabilidades da empresa e não apresenta instruções detalhadas sobre a mão de obra especializada disponível para prestar serviços de assistência técnica e manutenção.

Ao mesmo tempo, e constituindo uma segunda questão, o Manual especifica atividades de verificação e de manutenção que, embora sejam fundamentais para garantir a durabilidade do sistema, muitas vezes podem ser incompatíveis com a renda do morador. É o caso, por exemplo, da recomendação de realização de nova pintura, a ser feita anualmente nas janelas e a cada dois anos nas paredes e tetos. $O$ custo da execução de pintura anual ou bianual é elevado, tendo em vista a renda das famílias enquadradas num programa habitacional.

Entretanto, a garantia de assistência técnica pela empresa, prevista no Manual, é válida apenas quando não há modificações realizadas pelo usuário. E aqui reside a terceira questão apontada pelos resultados do estudo de caso: aproximadamente $80 \%$ das unidades habitacionais analisadas haviam passado por algum tipo de alteração. Isso significa que a ampla maioria dos usuários perdeu a garantia da empresa e que, a partir daí, não se trata mais de um único sistema construtivo inovador, mas sim, de um sistema híbrido, contendo um inovador e um convencional, cujo comportamento estrutural e construtivo, e suas necessidades de manutenção, não estão previstos no projeto técnico ou no Manual. Nessa situação, os problemas relacionados à estabilidade estrutural e às patologias construtivas podem ser agravados, prejudicando a manutenção do sistema construtivo inovador.

Assim sendo, a quarta e última questão apontada pelo estudo de caso se refere à necessidade de se discutir o grau de responsabilidade da empresa quando há ampliação e reforma das unidades habitacionais. O processo de avaliação de produtos inovadores na construção civil não pode negligenciar essa real possibilidade: os usuários vão ampliar e reformar sua casa ao longo do tempo.

A questão reside, então, em primeiro lugar, na correta orientação para realizar tal ampliação, ou se utilizando do próprio sistema construtivo inovador ou se especificando a correta interface entre sistemas construtivos diferentes. Em segundo lugar, e talvez mais importante, na indicação de quem é a responsabilidade para oferecer tal orientação. Considerando a reprodução em escala de sistemas construtivos inovadores vinculados aos programas habitacionais atuais, certamente, a responsabilidade não pode ficar restrita ao morador. A produção de ampliações, muitas vezes, de forma irregular, pode acabar por resultar em novos empreendimentos autoconstruídos acoplados aos empreendimentos produzidos por grandes empresas. E, mais uma vez, a introdução de inovações tecnológicas na construção civil pode ser ofuscada diante da inexistência de garantias jurídicas e de serviços técnicos adequados à manutenção da habitação. 


\section{A questão da manutenção de sistemas construtivos inovadores para habitação}

\section{Referências}

BOUGRAIN, F.; CARASSUS, J. Bâtiment: de l'innovation de produit a l'innovation de service. Paris: PUCA, 2003.

BRASIL. Ministério das Cidades. Programa Brasileiro de Qualidade e Produtividade do Habitat. Sistema Nacional de Avaliações - SINAT. Disponível em: <http://pbqp-h. cidades.gov.br/projetos_sinat.php>. Acesso em: 1 jun. 2012.

BRASIL. Ministério das Cidades. Secretaria Nacional de Habitação. Base de dados PAC/ UAP - CHAMADA MCTI/CNPq/MCIDADES n 11/2012. Brasília: Ministério das Cidades, 2013. (mimeo).

CARASSUS, J. Économie de la filière construction. Paris: École Nationale des Ponts et Chaussées, 1987.

CARDOSO, A. L. O Programa Minha Casa, Minha Vida e seus efeitos territoriais. Rio de Janeiro: Letra Capital, 2013.

CARDOSO, A. L.; ARAGÃO, T. A., ARAUJO, F. S. Habitação de interesse social: política ou mercado? Reflexos sobre a construção do espaço metropolitano. In: ENCONTRO NACIONAL DA ANPUR, 14., 201 1, Rio de Janeiro. Anais... Rio de Janeiro: Anpur, 2011.

CBIC - CÂMARA BRASILEIRA DA INDÚSTRIA DA CONSTRUÇÃO. FGTS e SBPE:

financiamento habitacional. Brasília, DF, 2013. Disponível em: <http://www.cbicdados. com. br/menu/financiamento-habitacional/>. Acesso em: 1 out. 13.

CIUFFOLINI, M. A.; SHIMBO, L. Z. Políticas urbanas e habitacionais e seus efeitos sociais: um estudo do Programa 'Minha Casa, Minha Vida' no Brasil e na Argentina. In: BONELLI, M.G.; LANDA, M.D.V. Sociologia e mudança social no Brasil e na Argentina. São Carlos: Compacta, 2013.

FERREIRA, J. S. W. (Coord.). Produzir casas ou construir cidades? Desafios para um novo Brasil urbano: parâmetros de qualidade para a implementação de projetos habitacionais e urbanos. São Paulo: LABHAB; FUPAM, 2012.

FIX, M.; ARANTES, P. F. Como o governo Lula pretende resolver o problema da habitação: Alguns comentários sobre o pacote habitacional Minha Casa, Minha Vida. Correio da Cidadania. Disponível em: <http://www.correiocidadania.com.br>. Acesso em: 8 out. 2009.

IBGE - INSTITUTO BRASILEIRO DE GEOGRAFIA E ESTATÍSTICA. Diretoria de Pesquisas, Coordenação de Indústria. Pesquisa anual da indústria da construção. Rio de Janeiro, 2010. Disponível em: <http://www.ibge.gov.br/home/estatistica/economia/industria/ paic/2010/default.shtm>. Acesso em: 30 ago. 2012.

IFBQ - INSTITUTO FALCÃO BAUER DE QUALIDADE. São Paulo, 2012. Disponível em: <http://www.falcaobaver.com.br/html/index.asp>. Acesso em: 1 ago. 2012.

MOYSÉS, A.; BORGES, E. M. Retomada dos financiamentos públicos imobiliários e a produção para os setores populares: impactos na reconfiguração espacial da RM de Goiânia. In: ENCONTRO NACIONAL D A ANPUR, 1., 201 1, Rio de Janeiro. Anais... Rio de Janeiro: Anpur, 2011

ROLNIK, R.; NAKANO, K. As armadilhas do pacote habitacional. Le Monde Diplomatique Brasil, v. 2, n. 20, mar. 2009. 
Avaliação de Desempenho de Tecnologias Construtivas Inovadoras

\section{Bibliografia}

ABNT - Associação Brasileira de Normas Técnicas. NBR 5674: manutenção de edificações: procedimentos. Rio de Janeiro, 1999.

CASTRO, J. A. Invento \& inovação tecnológica: produtos e patentes na construção. São Paulo: Annablume, 1999.

SINDUSCON - PA - SINDICATO DA INDÚSTRIA DA CONSTRUÇÃO DO ESTADO DO PARÁ. Manual de garantias NBR 5674:99. Belém, 2010. Disponível em: <http://www. sindusconpa.org.br/arquivos/File/manual-de-garantias-r6.pdf>. Acesso em: 1 jun. 2012. 


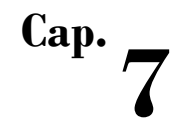

\title{
Avaliação da manutenibilidade em sistemas construtivos inovadores
}

\author{
Iara Del'Arco Sanches \\ Márcio Minto Fabrício \\ Miguel A. Buzzar
}

Muitos avanços e atividades desenvolvidas pelos setores industriais influenciaram a indústria da construção, sendo a absorção de conceitos de manutenção por esse setor um exemplo disso (SALERMO et al., 2005). Em uma definição ampla, manutenção consiste no ato ou efeito de manter, nas medidas necessárias à conservação ou permanência de alguma coisa ou de uma situação, em ordem (sistemas, coisas, etc.), os cuidados técnicos indispensáveis ao funcionamento regular e permanente (FERREIRA, 1986).

No panorama geral, a evolução dos sistemas de manutenção acompanhou a evolução industrial tecnológica. Essa evolução pode ser dividida no tempo em três gerações. A primeira geração diz respeito ao período até Segunda Guerra Mundial, quando a prevenção de falhas não era prioridade e os consertos eram executados à medida que as falhas aconteciam.

$\mathrm{Na}$ segunda geração, de 1950 até meados da década de 1970, as máquinas tornam-se mais complexas e em maior número, gerando uma maior dependência por parte da indústria. Neste período, adquire destaque o tempo de inatividade das máquinas levando à ideia de que falhas de equipamentos poderiam ser evitadas. A partir de 1960, o custo de manutenção também começou a aumentar drasticamente se comparado aos custos operacionais, levando ao crescimento de planejamento de manutenção e sistemas de controle.

A partir da metade da década de 1970, a terceira geração, o processo de mudança na indústria ganhou impulso ainda maior, 
as mudanças foram decorrentes de novas expectativas, novas pesquisas e novas técnicas. Fatores de segurança, qualidade na produtividade, consciência ambiental, ciclo de vida e maior eficácia de custos começaram a ser levados em consideração (MOUBRAY, 2000).

Assim a evolução do conceito de manutenção ocorreu de acordo com as mudanças sofridas na produção. Inicialmente a manutenção era vista como um mal necessário, acionada quando algo quebrava, que passou a ser tratada, em um segundo momento (segunda geração), como uma questão técnica, porém não integrada ao desenvolvimento de produtos. Depois da metade da década de 1970, a manutenção passou a ser vista não mais como uma função isolada do desenvolvimento de produtos, mas como uma aliada que vai ao encontro da produção podendo, inclusive, gerar lucro (WAEYENBERGH; PINTELON, 2002).

Mais especificamente, no contexto construção, a manutenção consiste no trabalho realizado para manter, restaurar e melhorar todas as partes de um edifício, seus subsistemas, serviços e arredores sustentando sua utilidade e valor (EL-HARAM; HORNER, 2002). Apesar do crescimento da importância da manutenção frente à sua interferência positiva, no cenário atual, muitas empresas consideram os fatores de manutenção como fatores de menor importância (ARIS, 2006). A falta de consideração aprofundada de fatores de manutenção interfere negativamente no ciclo de vida de uma edificação.

O ciclo de vida de uma edificação começa a ser determinado já no início da sua concepção. Cada uma das etapas do ciclo de vida tem sua parcela de influência na etapa de operação e uso e a consideração de fatores de manutenção durante todo o processo interfere na qualidade deste ciclo de vida. As decisões tomadas e as especificações originadas em cada etapa de projeto vão, em grande medida, determinar o desempenho e o grau de manutenibilidade de uma edificação assim como a demanda do tipo de serviços de manutenção para a etapa operação e uso.

A manutenibilidade consiste na maior ou menor facilidade de executar atividades de intervenção (ROSA, 2006). Essa facilidade de desempenhar serviços de manutenção, junto à transparência no que diz respeito às necessidades, prazos, tecnologia, materiais e procedimentos de manutenção para os usuários das edificações, é de fundamental importância para o ciclo de vida de uma edificação.

Com a adoção de tecnologias inovadoras, o tratamento dos conceitos de manutenção - no caso, a manutenibilidade destas tecnologias inovadoras torna-se algo ainda mais delicado. No cenário atual da construção, tecnologias inovadoras devem ser adotadas com objetivos que vão além da questão econômica. Elas devem proporcionar, sobretudo, benefícios para a etapa de uso da edificação proporcionando edificações de boa manutenibilidade e desempenho satisfatório. 


\section{Manutenção e a adoção de inovações tecnológicas}

Organizações diversas se utilizam de inovações tecnológicas como estratégias competitivas (TOLEDO; ABREU; JUNGLES, 2010). Diferentes segmentos de empresas engajam-se em atividades de inovações por vários motivos: melhoria de produtos, de eficiência, de qualidade ou capacidade de aprendizado e implementação de mudanças (OECD, 1997). No caso de um produto, a inovação consta da introdução de bem ou serviço (novo ou melhorado) em suas especificações técnicas, componentes, materiais e previsões de uso entre outras melhorias e características funcionais. Essas melhorias podem vir de uma única mudança considerável ou de várias mudanças que juntas representem mudanças significativas (OECD, 1997).

A manutenção predial, cujo objetivo primeiro é a preservação do edifício construído em condições semelhantes ao seu estado inicial (SEELEY, 1982), deve acompanhar o dinamismo do processo e das mudanças de necessidades, interesses e aspirações dos usuários junto ao desenvolvimento tecnológico e social (BONIN, 1998). Contudo, na Construção Civil, inovações tecnológicas são adotadas com o objetivo primeiro de reduzir custos de produção e agilizar o processo construtivo, obtendo melhorias globais como elevação de índices de produtividade, diminuição de desperdícios e de tempo (REZENDE; BARROS; ABIKO, 2002), deixando questões diretamente relacionadas à etapa de uso como desempenho e manutenção em segundo plano.

Em um cenário em que a busca por novas tecnologias visa, sobretudo, a economia, a manutenibilidade de edificações pode ser comprometida. Principalmente no caso de sistemas construtivos inovadores para os quais a manutenção demanda conhecimento, ferramentas e mão de obra específicos. O know-how dificilmente é dominado e, muitas vezes, não é acessível técnica ou financeiramente aos usuários. Nos casos de empreendimentos habitacionais de interesse social esse know-how foge do conhecimento do usuário e da realidade da infraestrutura regional a que ele pertence (SANCHES; FABRICIO; BUZZAR, 201?).

Mais precisamente nas habitações sociais, para que haja conscientização e entendimento por parte dos usuários de seu papel no desempenho e durabilidade de sua moradia, são necessários mudanças e aprimoramentos anteriores. Neste sentido, um dos aspectos a ser trabalhado é a consideração e a inserção de requisitos de manutenibilidade nos processos de avaliação e homologação de sistemas construtivos inovadores que objetivem melhorias na etapa de operação, uso e manutenção.

Práticas inovadoras são bem vindas e necessárias ao desenvolvimento da Construção Civil, principalmente no que diz respeito à construção habitacional de interesse social. A adoção dessas práticas deve buscar como resultados, além de um maior grau de industrialização e economia de recursos, a melhoria de desempenho e qualidade para etapa de uso das edificações. Para que isso ocorra faz-se necessário vencer barreiras tanto culturais, referentes a processos tradicionais, quanto governamentais, no que diz respeito a políticas de governo e incentivos, para que a 
'KELLETT, P. Tecnologia inapropriada? Experiências de vivienda social em Gran Brataña. Informes de La Construcción, v. 42, n. 409, sep./oct. 1990. Petter Kellett atua no Centre for Architectural Research and Development Overseas, da Universidade de New Castle Upon Tyne. Grã-Bretanha. adoção de novas tecnologias seja feita de modo adequado e fundamentado (SANCHES; FABRICIO; BUZZAR, 201?).

\section{Um breve histórico da adoção de inovações tecnológicas na Construção Civil}

As experiências com sistemas inovadores no passado repercutiram culturalmente em resistência institucional em abandonar padrões convencionais de construção (REZENDE; BARROS; ABIKO, 2002). A utilização de tecnologias não suficientemente desenvolvidas resultou em casos desastrosos. Experiências negativas tornaram o setor da Construção Civil menos receptivo a inovações tecnológicas repercutindo em progressiva desatualização tecnológica (KEMPTON; SYMS, 2009; GONÇALVES et al., 2003).

Os países europeus arrasados pela segunda guerra precisaram de soluções de reconstrução em períodos relativamente curtos, o que repercutiu no desenvolvimento de novos materiais, técnicas e sistemas construtivos de maior complexidade e fazendo com que a arte de construir se tornasse de difícil domínio. Essa necessidade de industrialização da construção pós-Segunda Grande Guerra começa a gerar uma consciência de avaliação de desempenho de soluções inovadoras (MITIDIERI FILHO, 1998).

No Reino Unido, habitações pré-fabricadas foram usadas durante períodos de alta demanda e também durante a erradicação de habitações subnormais da década de 1960. Por volta de um milhão de habitações pré-fabricadas foram construídas no século XX, muitas das quais foram projetadas para serem temporárias. No entanto, surgiram problemas devido à qualidade dos materiais de construção e da mão de obra desqualificada, levando a atitudes negativas com relação à pré-fabricação (PARLAMENTARY OFFICE OF SCIENCE..., 2003).

A desastrosa experiência na Inglaterra, quando várias habitações de um programa de construção de habitações pré-fabricadas para reconstrução pósSegunda Grande Guerra tiveram que ser demolidas, levou a conclusão que "não se pode empregar novas tecnologias, novos processos e sistemas de construção, sem antes ter ensaiado ou avaliado", gerando um ceticismo geral quanto ao emprego de novas tecnologias (KELLETT, 1990' apud MITIDIERI FILHO, 1998). 
A produção de habitação social inglesa tem se mostrado uma experiência contínua, mesmo após a adoção de políticas neo-liberais por parte do estado. Nesse sentido, guardadas as diferenças entre os contextos ingleses e britânicos, tal experiência constitui-se em uma referência importante para a discussão de políticas habitacionais e de também da adoção de práticas construtivas inovadoras.

A partir da década de 1970, surgiram novos sistemas construtivos mirando a racionalização e industrialização da construção em forma de alternativas a produtos e processos estabelecidos (GONÇALVES et al., 2003). Consequentemente, ao tempo que surgiam propostas de soluções inovadoras, surgiam também tentativas de solucionar problemas oriundos da falta de normalização. Mesmo o Banco Nacional de Habitação, cuja uma das suas marcas foi a resistência a adoção ou promoção de tecnologias construtivas não convencionais, investiu em pesquisas visando à elaboração de avaliação e critérios já no período final da existência deste órgão (IPT, 1981 apud GONÇALVES et al., 2003).

$\mathrm{Na}$ intenção de harmonizar as diversas referências desenvolvidas, a Caixa Econômica Federal, então sucessora do $\mathrm{BNH}$, como principal agente financeiro da política habitacional nacional, em conjunto com a Finep - Inovação e Pesquisa, financiou o projeto de pesquisa: Normas Técnicas para Avaliação de Sistemas Construtivos Inovadores para Habitações (GONÇALVES et al., 2003).

Ainda que de forma descontinuada, algumas iniciativas relativamente recentes, retomam o tema da qualidade na construção e da inserção de novas tecnologias (e sistemas) na construção civil. Dentro do Programa Brasileiro de Qualidade e Produtividade no Habitat (PBQP-H), foi criado o Sistema Nacional de Avaliação Técnica (SiNAT) com o objetivo de harmonizar requisitos, critérios e métodos para avaliação técnica de produtos inovadores no Brasil harmonizando procedimentos para a concessão dos documentos de avaliação técnica (MITIDIERI FILHO et al., 2007).

O SiNAT viabiliza processos para o monitoramento de obras através de atividades para atestar os serviços realizados e materiais empregados. Esse monitoramento é efetuado por instituições técnico-científicas (universidade ou instituto de pesquisa), com reconhecida competência.

Essas instituições desempenham avaliação técnica em uso (avaliação pós-ocupação), atividades de vistoria técnica, entrevistas com moradores e emissão de relatório comprovando o desempenho do sistema construtivo em uso e depois de decorrido prazo mínimo de 24 meses após o "habite-se" (FERNANDES, 2011).

Apesar dos recentes avanços na direção da harmonização de produtos e procedimentos inovadores, ainda existem diversas barreiras a se transpor. Alguns aspectos no setor da construção civil interferem na opção por adoção de tecnologias inovadoras, sendo que alguns dos principais fatores inibidores são externos ao ambiente da construção civil (TOLEDO; JUNGLES, 2010).

Mais adiante, discutiremos a questão da harmonização de sistemas de avaliação e a abordagem de parâmetros de manutenção por normas e documentos técnicos. 
${ }^{2}$ VARGAS, N. Organização do trabalho e capital: estudo da construção habitacional. Dissertação (mestrado em engenharia) - Coordenação de Programas em PósGraduação em engenharia. Rio de Janeiro: UFRJ, 1979.

OSEKI, J. H. Arquitetura em construção. 1983. Dissertação (mestrado) - Faculdade de Arquitetura e Urbanismo. São Paulo: USP, 1983. MARICATO, E. Indústria da construção e política habitacional. Tese (doutorado em Arquitetura) - Faculdade de Arquitetura e Urbanismo. São Paulo: USP, 1984. RIBEIRO, L.

C. Q. Dos cortiços aos condomínios fechados: as formas de produção da moradia na cidade do Rio de Janeiro. Rio de Janeiro: Civilização Brasileira, 1981.

${ }^{3}$ GIBSON, E. J. Developments in buiding maintenance - 1. London: Applied Science, 1979.

\section{Barreiras à adoção de tecnologias inovadoras}

Toledo e Jungles (2010) apresentam como forte aspecto a política econômica instável característica do país. Valença e Bonates (2010) reforçam a ideia de instabilidade apontando a sucessão de novas propostas e medidas por parte dos governos que acarretam em descontinuidade das políticas habitacionais.

Para Moraes e Santana (2003), a descontinuidade de programas habitacionais, assim como mudanças de posturas relacionadas à habitação, ocasionaram a perda de informações e prejuízos diversos.

A dissociação entre a questão habitacional e política realça como os governos lidam com a questão no presente assim como o fizeram no passado. Muito do quadro observado é devido à falta de planejamento adequado associado ao uso de fundos do governo seguindo uma lógica mais afeita à dimensão políitico-econômica do que à social (VALENÇA; BONATES, 2010).

Rezende et al. (2002) sistematizam, a partir de suas diversas referências ${ }^{2}$, algumas características específicas do setor da construção que dificultam sua evolução tecnológica. Entre outras características estão: variabilidade de construções; longo período para retorno do investimento inicial; grande número de agentes da cadeia produtiva somado à falta de uma coordenação; além da baixa exigência dos clientes.

A sazonalidade das vendas, a baixa qualificação de operários e subcontratados, a baixa remuneração de profissionais, além do baixo nível de detalhamento dos projetos, também são aspectos do setor apontados por Toledo e Jungles (2010).

Decisões de projeto equivocadas compõe um horizonte recorrente evidenciado em: falha ao segzuir critérios estabelecidos de projeto na escolha de sistemas estruturais e seleção de materiais; uso de novos materiais ou formas inovadoras de construção que não tenham sido devidamente testados; avaliação errônea de condições climáticas sob as quais os materiais têm que atuar; comunicação pobre entre diferentes membros de equipes de projeto e construção (GIBSON, $1979^{3}$ apud AL-HAMAD; ASSAF; AL-SHIHAH, 1997).

A natureza única de empreendimentos e sua vida útil longa acarretam em responsabilidades aos seus agentes, 
repercutindo na opção por tecnologias mais estabelecidas e conhecidas (TOLEDO et al., 2010). Os autores ainda acrescentam aspectos como a dependência entre empresas diferentes que atuam no processo de uma mesma construção. A dependência de outros setores industriais e sua evolução no que diz respeito a inovações também interfere e influencia na opção por adoção de tecnologias inovadoras.

Kempton (2010), através de uma pesquisa de avaliação qualitativa baseada em questionário, pôde concluir que, no geral, existe uma visão negativa das tecnologias construtivas inovadoras e sua viabilidade de manutenção no futuro. Os altos custos de implementação de tecnologias construtivas inovadoras é uma das maiores barreiras, especialmente porque construtores e empreiteiros são principalmente preocupados em obter lucros (KEMPTON; SYMS, 2009).

Apesar de alguns argumentos alegando que tecnologias construtivas inovadoras são menos caras do que métodos tradicionais, fontes da indústria indicam aumentos de custos. As razões para os custos mais altos são difíceis de discernir, talvez porque alguns dos benefícios do uso não sejam obviamente refletidos nas contas de projeto, como melhoria na qualidade de habitação (PARLAMENTARY OFFICE OF SCIENCE..., 2003).

\section{Facilitadores à adoção de tecnologias inovadoras}

Uma maior exigência por parte dos consumidores são algumas transformações indutoras de inovações no contexto atual. Além disso, a adoção de novas tecnologias faz do mercado algo mais competitivo no sentido de obter diminuição de custos e visar aumento dos lucros. A influência do setor de construção pesada e industrial que traz procedimentos organizacionais e tecnologias mais estruturadas, assim como o surgimento de mão de obra mais exigente e organizada através de sindicatos, também colaboram para adoção de tecnologias inovadoras (REZENDE et al., 2002).

Rezende et al. (2002) ainda apontam dentro do contexto das habitações populares, a introdução de inovações tecnológicas repercutindo em aumento de produtividade e melhoria da qualidade, além de reduzir custos de produção.

No que diz respeito à ação governamental, Rezende et al. (2002) apresentam fatores que contribuiriam com a adoção de novas tecnologias: a liberação de recursos para empreendimentos que empreguem novas tecnologias, o incentivo às inovações tecnológicas e recursos para instituições de pesquisa voltadas para o desenvolvimento da construção civil.

No âmbito da habitação social, o governo do Reino Unido (RU) tem incentivado o uso de $\mathrm{TCl}$, alegando viabilizar uma mudança de patamar na indústria da construção ajudando a contribuir quantitativa e qualitativamente. Entre os benefícios em potencial: construção mais rápida, redução no consumo de energias e diminuição de desperdício de materiais (PARLAMENTARY OFFICE OF SCIENCE..., 2003). 
${ }^{4}$ SLAUGHTER, E. S. Models of construction innovation. Journal of Construction Engineering and Management, v. 124, n. 30, p. $226-$ $31,1998$.
No Reino Unido, as principais vantagens dos MMC ou $\mathrm{TCl}$ apontadas pelo Parliamentary Office of Science and Technology são: habitações com essas tecnologias apresentam menos defeitos e podem ser construídas mais rapidamente; podem ser mais eficientes energeticamente; envolver menos transporte de materiais e produzir menos lixo. No âmbito social, o Governo do $\mathrm{RU}$ alega que as habitações com $\mathrm{TCl}$ podem apresentar menos acidentes e um menor impacto nos residentes locais durante as construções (traduzido e adaptado de PARLAMENTARY OFFICE OF SCIENCE..., 2003).

Dentro das tecnologias, algumas características podem contribuir com sua adoção como: a facilidade de adaptação às "condições locais"; como também elenca Slaughter (1998 apud Rezende et al., 2002): o tempo de implantação da tecnologia (quanto menor, mais fácil de ser adota$\mathrm{da}$; as necessidades de mudanças quando menos radicais sem modificar toda a estrutura produtiva apresentam maior chance de sucesso e quanto menor o volume de recursos necessários, mas fácil a sua introdução.

\section{Abordagem de fatores ligados à manutenção e harmonização de parâmetros para avaliação de sistemas construtivos inovadores}

Recentemente, tanto a norma de Manutenção (ABNT, 2012), quanto a norma de Desempenho (ABNT, 2013) passaram por revisão. Com isso, as alterações feitas já contribuíram para o processo de inserção de fatores de manutenção na avaliação de sistemas construtivos.

Ao observarmos os documentos técnicos de avaliação emitidos por instituições técnicas avaliadoras vinculadas ao SiNAT, desde o primeiro até os mais atuais, é possível ver uma sutil evolução na abordagem de assuntos relacionados a manutenibilidade e consideração da etapa de uso através de referências ao manual do usuário e afins.

Contudo, ainda que se tenha observado um maior cuidado com questões relacionadas à manutenibilidade das edificações, através de pesquisa, foi possível observar que no geral essa abordagem ainda é muito superficial. Documentos técnicos e normas adotados como parâmetros são 
exemplos da necessidade de se evoluir nesse aspecto, principalmente no que diz respeito ao usuário.

O SiNAT (Sistema Nacional de Avaliação Técnica) é um sistema proposto para avaliar produtos não abrangidos por normas técnicas prescritivas e suprir lacunas existentes na normalização técnica prescritiva (BRASIL, 2012). Instituições técnicas avaliadoras vinculadas ao SiNAT são as responsáveis pela avaliação e homologação de sistemas construtivos inovadores. Essas instituições trabalham sem padronização de parâmetros ou modo de operação padrão, trabalhando cada uma independentemente da outra.

Neste contexto, foi desenvolvida uma metodologia de avaliação que visa a contribuir com a homogeneização do processo de avaliação de sistemas construtivos inovadores, propondo uma sistematização de parâmetros e critérios de manutenibilidade com foco no usuário.

\section{Metodologia de avaliação de sistemas construtivos inovadores proposta ao SiNAT}

A adoção de sistemas construtivos inovadores em edificações, principalmente no caso de habitações sociais, deve ter por objetivo mais do que economia de tempo, recursos e melhorias no processo construtivo. No que diz respeito ao usuário e a sua relação com o edifício, os sistemas construtivos inovadores devem considerar a etapa de operação, uso e manutenção de forma a proporcionar desempenho satisfatório e atendimento aos requisitos do usuário (SANCHES et al., 201?).

O desenvolvimento de sistemas construtivos inovadores deve almejar a construção de moradias a custo acessível; o emprego de novos materiais ótima qualidade e com grande durabilidade; o desenvolvimento de tecnologias com empregos de componentes construtivos simples com caráter industrial, de fácil montagem e com possibilidade de ampliação da usa planta original; a redução de impacto ambiental (redução de desperdício e entulho; reaproveitamento de materiais; redução de insumos naturais, redução de consumo energético) e a produção de moradia agradável no que diz respeito à aparência, conservação, limpeza, aceitação, conforto térmico, acústico e estanqueidade (KLEIN; KLEIN; LIMA, 2004).

No Brasil, soluções inovadoras diversas são introduzidas no mercado objetivando sanar a questão do déficit habitacional no país, contudo nem todas as soluções atendem a requisitos mínimos essenciais para oferta de moradias de qualidade e acessíveis (KLEIN; KLEIN; LIMA, 2004).

No caso de edifícios residenciais, o desempenho deveria ser avaliado continuamente e gerido em conformidade. A avaliação de desempenho é necessária para minimizar demandas por reconstrução ou reforma assim como servir como medida fundamental para assegurar a longevidade de edifícios (KIM et al., 2004).

A avaliação de desempenho deveria ser sistemática e com uma gama de indicadores de desempenho. Sendo esses indicadores são sinais ou marcadores 
que apontam para uma condição a ser medida, a fim de avaliar as qualidades específicas e desempenhos.

O conhecimento dos serviços essenciais aos usuários dá base para definir prioridades nas políticas de manutenção. Para tanto, é necessário explorar a percepção que os usuários têm da importância de serviços de manutenção e descobrir quais serviços de manutenção em particular são essenciais para inquilinos assim como fez Mossel e Jansen (2010).

Para sistemas construtivos inovadores, por se tratarem de novas tecnologias e, portanto, desconhecidas, torna-se fundamental um maior cuidado com fatores ligados à operação, uso e manutenção. Devem-se disponibilizar adequadamente informações de como proceder em situações diversas, por exemplo, como funcionam as diversas interfaces do produto inovador, seja com as instalações elétricas, hidráulicas e caixilhos ou como proceder ao executar reformas, ampliações e melhorias, como acessar mão de obra capacitada para lidar com essa nova tecnologia e material compatível com a inovação, etc.

Devem-se analisar características como a disponibilidade ou disponibilização pelos produtores da tecnologia ou know-how necessários para gestão do sistema assim como assistência técnica para a etapa de uso. Os materiais necessários para limpeza, operação e manutenção, se há disponibilidade no mercado ou se são disponibilizados pelos produtores. Se a mão de obra para os trabalhos de manutenção precisa ser especializada ou não, se o produtor capacita funcionários de empreendimentos ou não.

Deve-se analisar se o sistema construtivo inovador permite interface com outros sistemas construtivos e como elas acontecem. Se o sistema é viável economicamente e fisicamente no que fiz respeito à facilidade de execução de trabalhos de manutenção, etc.

Com esta ideia, foi desenvolvida uma pesquisa com o intuito de sistematizar e apresentar requisitos de manutenção como forma de proposta de avaliação para homologação de sistemas construtivos inovadores.

\section{Desenvolvimento da metodologia de avaliação}

O método de pesquisa utilizado para desenvolver essa metodologia de pesquisa propositiva baseou-se nas etapas de pesquisa do Design Science Research ou Constructive Research. São características deste método o foco em problemas relevantes ao campo não acadêmico com a produção e teste de soluções inovadoras com a cooperação entre pesquisadores e profissionais da área para construção de um conhecimento teórico prévio com especial atenção à retroalimentação de dados (LUKKA, 2003).

A primeira etapa diz respeito à identificação do problema. Através de pesquisa foi verificada a abordagem superficial de aspectos de manutenção em normas e procedimentos de avaliação e homologação de sistemas construtivos 
inovadores. Outro problema identificado foi a também superficial consideração de requisitos do usuário com relação à etapa de operação, uso e manutenção.

O fundamento teórico para a construção da metodologia partiu do levantamento para discussão de requisitos, critérios e indicadores de desempenho e manutenção, encontrados em diferentes fontes nacionais e internacionais. Diretrizes e documentos de avaliação técnica internacionais, assim como diretrizes SiNAT e normas brasileiras ajudaram a balizar os critérios de avaliação. Entre outras, estão as normas da ABNT NBR 15575:2013 (Desempenho), NBR 5674:2012 (Manutenção) e a NBR 14037:2011 (Manual de operação, uso e manutenção).

No cenário internacional, buscou-se embasamento em diretrizes e documentos de avaliação técnica de instituições de referência na homologação de produtos inovadores. Como exemplo, a WFTAO (World Federation of Technical Assessment Organization) e seus países membros como França (através do CSTB - Centre Cientifique et Technique du Bâtiment), Portugal (através do LNEC - Laboratório Nacional de Engenharia Civil), Dinamarca (através do European Technical Approval - Danmark), Nova Zelandia (através do BRANZ) e Canadá (pelo Institute for Research in Construction, National Research Council) além de metodologias de avaliação de desempenho desenvolvidas pela comunidade acadêmica.

A segunda etapa do método de pesquisa diz respeito à obtenção da compreensão teórica sobre o tópico. Para tanto, foi feito levantamento para discussão de requisitos, critérios e indicadores de desempenho e manutenção a partir de normas e órgãos homologadores nacionais e internacionais para sistemas construtivos inovadores.

A partir da análise das normas vigentes, principalmente as normas de Desempenho (ABNT, 2013), Manual do Usuário (ABNT, 2011) e de Manutenção (ABNT, 2012) foram levantados indicadores a serem utilizados na metodologia de avaliação.

A terceira etapa dentro do método Design Science Research é relacionada à concepção e desenvolvimento de solução. No caso desta pesquisa, foram desenvolvidos instrumentos de avaliação da manutenibilidade de sistemas construtivos inovadores (questionário ao usuário, entrevista com síndico/zelador, entrevista com profissional de assistência técnica, roteiro de análise de documentos técnicos e roteiro de inspeção predial).

A quarta etapa é a etapa de testes e avaliação da solução. A metodologia de avaliação proposta passou por avaliações internas e externas. Em um primeiro momento, os instrumentos foram submetidos a dois exercícios de aplicação (pré-testes) para que tivessem sua aplicabilidade e conteúdo testados. Esses testes foram realizados tanto pela equipe que elaborou os instrumentos quanto por pessoas fora desse processo. Em um segundo momento, foi realizado workshop com especialistas da área de manutenção como professores universitários e membros de Instituto de Engenharia e de instituição técnica avaliadora. 
A quinta etapa diz respeito à revisão da solução. Os instrumentos e toda a metodologia foram revisados e validados a partir das atividades de pré-teste e das considerações, sugestões e correções vindas dos especialistas durante o workshop.

A sexta etapa refere-se à conclusão com relação ao que foi proposto e seu emprego. No caso dessa metodologia proposta, para sua consolidação final, faz-se necessária a adoção desta metodologia de avaliação por parte de instituições técnicas avaliadoras para que assim o instrumento passe por uma segunda validação externa, desta vem em campo.

\section{Instrumentos de avaliação}

Os instrumentos elaborados para a metodologia de avaliação devem ser aplicados em momentos diferentes. Primeiro em uma etapa que antecede a emissão do documento técnico de avaliação (DATec) emitido pela instituição técnica avaliadora vinculada ao SiNAT e, em um segundo momento, após a emissão deste documento.

No momento anterior à emissão do DATec deve-se fazer um estudo aprofundado dos documentos técnicos disponíveis para aplicação do primeiro instrumento (roteiro de avaliação de documentos técnicos) assim como para preparação para aplicação dos instrumentos da segunda etapa (pós-DATec).

Em um segundo momento, após a emissão do DATec, os instrumentos que devem ser aplicados são: questionário com usuário; entrevista com síndico/zelador; entrevista com profissional de assistência técnica e, por último, o roteiro de inspeção para avaliação da manutenção da unidade habitacional.

Os diferentes instrumentos ajudam a configurar um panorama a partir de pontos de vista diferentes, ou seja, profissionais da área da construção (instituições avaliadoras), profissionais representantes dos empreendedores (assistência técnica) e aqueles a quem se destinam as edificações, os usuários (moradores das unidades habitacionais).

A ordem sugerida para aplicação dos instrumentos também contribui para um embasamento prévio. Com informações a partir de documentos técnicos e de pessoas chave no processo (síndicos, zeladores, profissional de assistência técnica, usuário) a aplicação do ultimo instrumento pode se tornar muito mais rica e minuciosa sabendo-se de antemão de algumas questões apontadas por essas pessoas chave.

Os instrumentos devem ser aplicados por profissionais especialistas com experiência comprovada na área. Esses especialistas são de escolha e responsabilidade das Instituições Técnicas de Avaliação (ITAs) e devem estar aptos a realizarem avaliações precisas para gerarem laudos técnicos ricos em informações relevantes ao processo de avaliação de um produto/sistema construtivo inovador.

Os dados encontrados devem ser trabalhados de forma a configurar um laudo técnico com as características encontradas no que se refere à manutenibilidade do sistema construtivo inovador avaliado. 
Esse laudo técnico deve ser constituído de cinco partes. A primeira é a Introdução, na qual o sistema é especificado e são apresentados os dados da edificação avaliada. Em seguida, vem o Laudo Geral, onde se deve fazer uso de resultados quantitativos com gráficos percentuais gerais e, nesta parte, ainda deve-se informar inconformidades e detalhar pontos técnicos que o avaliador julgar necessário.

O próximo item do laudo técnico diz respeito à Conclusão. Na Conclusão deve-se informar se a avaliação realizada considera o sistema em questão aprovado ou reprovado de acordo com a avaliação percentual dos resultados obtidos referentes às normas vigentes e, em alguns casos, aprovado com ressalvas, em que se deve especificar em nota o motivo da exceção, assim como informar se considera o objeto em questão flexível e adaptável com um bom grau de manutenibilidade.

Outra parte importante do laudo técnico é a referente a recomendações. Nesta parte, são apresentadas sugestões e opiniões técnicas que visam à preservação de padrões pré-estabelecidos para desenvolvimento das atividades na edificação com qualidade e segurança. Nesta parte, se pode fazer referência à adequação das irregularidades, necessidade de paralisação de atividades de acordo com a funcionalidade do edifício e a necessidade de novas avaliações.

Os instrumentos da metodologia de avaliação proposta e seus manuais completos estão disponíveis no site: http://www.iau.usp.br/inovatec/.

\section{Questionário ao usuário}

Instrumento elaborado em conjunto com a equipe de pesquisadores da FAU/USP que tem como objetivo coletar dados com os usuários das unidades habitacionais com relação a sua avaliação e convivência com o sistema construtivo inovador no que diz respeito à manutenibilidade, desempenho da habitação e do sistema construtivo inovador adotado.

O questionário pode ser aplicado em forma de entrevista com a ação de um profissional ou remotamente, uma vez que esse instrumento foi elaborado para ser "autoexplicativo", ficando o tipo de aplicação a critério da instituição técnica avaliadora diante das condições e características encontradas em cada caso.

As questões do instrumento estão apresentadas em três grandes blocos. $\bigcirc$ primeiro bloco remete à caracterização do usuário, o segundo aborda a interface usuário-moradia e, por fim, a parte que aborda a interface usuário-sistema construtivo inovador.

O cruzamento das respostas obtidas com este e os demais instrumentos que compõem os procedimentos de avaliação propostos devem fornecer dados sobre a correlação entre o nível de satisfação do usuário com o sistema construtivo que compõe sua habitação e os aspectos técnicos que justificam o seu desempenho. 


\section{Roteiro de entrevista com síndico ou zelador}

Este instrumento consiste em um roteiro de entrevista semiestruturado que tem por objetivo balizar a obtenção de informações sobre o desempenho em uso do sistema construtivo inovador em habitações agrupadas em condomínios.

A entrevista é dirigida preferencialmente ao indivíduo acionado pelos moradores para solucionar problemas no dia-a-dia do condomínio (síndicos ou zeladores). São os agentes diretamente envolvidos no dia-a-dia da gestão de condomínios residenciais e que, em função do trabalho que realizam, são detentores de informações muito relevantes à configuração de um panorama sobre o desempenho das edificações do condomínio em uso. As perguntas abordam questões relacionadas ao nível de satisfação dos usuários, aspectos relacionados à manutenção e manual do usuário e outros aspectos gerais.

\section{Roteiro de entrevista com profissional prestador de assistência técnica}

Este roteiro busca complementar as informações relacionadas à manutenção e à assistência técnica prestada durante o tempo de garantia do empreendimento, assim como informações a respeito das solicitações dos usuários.

roteiro aborda questões referentes à prestação de assistência técnica, capacitação de mão de obra para prestação desse serviço, identificação de demanda de serviços não planejados, sistema de armazenamento de informações, qualidade de acesso às instalações, reservatórios e coberturas para realização de manutenção e inspeções, o caráter das intervenções de manutenção e acesso ao material de manutenção.

\section{Roteiro de inspeção para avaliação da manutenção da unidade habitacional}

$\bigcirc$ instrumento consiste em um roteiro cujo objetivo é detectar falhas e anomalias de responsabilidade técnica direta dos empreendedores e as falhas referentes a procedimentos equivocados de manutenção e, a partir daí, julgar o grau de manutenibilidade do sistema construtivo inovador.

instrumento é um roteiro com itens a serem inspecionados e é composto por 16 fichas - 11 fichas abordam os sistemas, itens ou instalações a serem verificados no interior da unidade habitacional e 5 abordam sistemas, itens ou instalações a serem verificados nas áreas externas à unidade habitacional.

As fichas referentes à inspeção de áreas internas da unidade habitacional são direcionadas: a paredes e painéis de vedação; a estruturas; à pintura; ao revestimento de piso; ao revestimento de parede; à pintura e estrutura do forro; 
Quadro 1. Recorte do roteiro de inspeção para avaliação da manutenção da unidade habitacional

\begin{tabular}{|c|c|}
\hline Elétricas & \\
\hline $\begin{array}{l}\text { 10.1 Não há peças } \\
\text { defeituosas }\end{array}$ & $\begin{array}{l}\square \text { A } \square \text { NA } \square \text { NSA } \square \text { NV } \\
\square \text { Sala } \square \text { Cozinha e área de serviço } \square \text { Banheiros } \square \text { Dormitórios } \\
\text { Grau de risco: } \square \text { Crítico } \square \text { Regular } \square \text { Mínimo } \square \text { NSA } \\
\text { Fotografias e observações: }\end{array}$ \\
\hline $\begin{array}{l}\text { 10.2 Quadro de } \\
\text { distribuição com todos os } \\
\text { disjuntores }\end{array}$ & $\begin{array}{l}\square \text { A } \square \text { NA } \square \text { NSA } \square \text { NV } \\
\square \text { Sala } \square \text { Cozinha e área de serviço } \square \text { Banheiros } \square \text { Dormitórios } \\
\text { Grau de risco: } \square \text { Crítico } \square \text { Regular } \square \text { Mínimo } \square \text { NSA } \\
\text { Fotografias e observações: }\end{array}$ \\
\hline $\begin{array}{l}\text { 10.3 Dispositivos de } \\
\text { acionamento estão } \\
\text { funcionando (testar } \\
\text { dispositivos - ligar e desligar) }\end{array}$ & $\begin{array}{l}\square \text { A } \square \text { NA } \square \text { NSA } \square \text { NV } \\
\square \text { Sala } \square \text { Cozinha e área de serviço } \square \text { Banheiros } \square \text { Dormitórios } \\
\text { Grau de risco: } \square \text { Crítico } \square \text { Regular } \square \text { Mínimo } \square \text { NSA } \\
\text { Fotografias e observações: }\end{array}$ \\
\hline $\begin{array}{l}\text { 10.4 Não há tomadas de } \\
\text { piso sem tampa }\end{array}$ & $\begin{array}{l}\square \text { A } \square \text { NA } \square \text { NSA } \square \text { NV } \\
\square \text { Sala } \square \text { Cozinha e área de serviço } \square \text { Banheiros } \square \text { Dormitórios } \\
\text { Grau de risco: } \square \text { Crítico } \square \text { Regular } \square \text { Mínimo } \square \text { NSA } \\
\text { Fotografias e observações: }\end{array}$ \\
\hline $\begin{array}{l}10.5 \text { Não há uso de } \\
\text { benjamins e réguas }\end{array}$ & $\begin{array}{l}\square \text { A } \square \text { NA } \square \text { NSA } \square \text { NV } \\
\square \text { Sala } \square \text { Cozinha e área de serviço } \square \text { Banheiros } \square \text { Dormitórios } \\
\text { Grau de risco: } \square \text { Crítico } \square \text { Regular } \square \text { Mínimo } \square \text { NSA } \\
\text { Fotografias e observações: }\end{array}$ \\
\hline $\begin{array}{l}10.6 \text { Não há fiação } \\
\text { aparente }\end{array}$ & $\begin{array}{l}\square \text { A } \square \text { NA } \square \text { NSA } \square \text { NV } \\
\square \text { Sala } \square \text { Cozinha e área de serviço } \square \text { Banheiros } \square \text { Dormitórios } \\
\text { Grau de risco: } \square \text { Crítico } \square \text { Regular } \square \text { Mínimo } \square \text { NSA } \\
\text { Fotografias e observações: }\end{array}$ \\
\hline $\begin{array}{l}\text { 10.7 Não há sinais de } \\
\text { infiltração }\end{array}$ & $\begin{array}{l}\square \text { A } \square \text { NA } \square \text { NSA } \square \text { NV } \\
\square \text { Sala } \square \text { Cozinha e área de serviço } \square \text { Banheiros } \square \text { Dormitórios } \\
\text { Grau de risco: } \square \text { Crítico } \square \text { Regular } \square \text { Mínimo } \square \text { NSA } \\
\text { Fotografias e observações: }\end{array}$ \\
\hline $\begin{array}{l}\text { 10.8 Há facilidade de } \\
\text { acesso com segurança } \\
\text { para manutenção e } \\
\text { limpeza e inspeção }\end{array}$ & $\begin{array}{l}\square \text { A } \square \text { NA } \square \text { NSA } \square \text { NV } \\
\square \text { Sala } \square \text { Cozinha e área de serviço } \square \text { Banheiros } \square \text { Dormitórios } \\
\text { Grau de risco: } \square \text { Crítico } \square \text { Regular } \square \text { Mínimo } \square \text { NSA } \\
\text { Fotografias e observações: }\end{array}$ \\
\hline $\begin{array}{l}10.9 \bigcirc \text { quadro de } \\
\text { distribuição está } \\
\text { identificado }\end{array}$ & $\begin{array}{l}\square \text { A } \square \text { NA } \square \text { NSA } \square \text { NV } \\
\square \text { Sala } \square \text { Cozinha e área de serviço } \square \text { Banheiros } \square \text { Dormitórios } \\
\text { Grau de risco: } \square \text { Crítico } \square \text { Regular } \square \text { Mínimo } \square \text { NSA } \\
\text { Fotografias e observações: }\end{array}$ \\
\hline $\begin{array}{l}\text { 10.10 Estado de } \\
\text { conservação }\end{array}$ & $\square$ Ótimo $\square$ Normal $\square$ Deficiente $\square$ Inexistente $\square$ NSA/NV \\
\hline
\end{tabular}


a esquadrias; à vidraçaria; a instalações elétricas; a instalações de telefonia, à televisão e internet; a instalações hidrossanitárias e a instalações de gás.

As fichas referentes à inspeção de áreas externas da unidade habitacional abordam questões relacionadas: à cobertura; à pavimentação (calçadas e acessos internos ao lote); a fachadas; a instalações de gás e outros diversos como caixa d'água, caixa de gordura, para-raios e aterramentos SPDA.

Em cada uma das fichas, de acordo com o tema (paredes/painéis de vedação, estruturas, pintura e revestimento de piso e parede, etc.) são elencados requisitos a serem verificados pelo profissional responsável pela inspeção.

Para melhor aplicação do instrumento, foi elaborado um manual de aplicação e preenchimento. O documento informa objetivo do instrumento, os pré-requisitos necessários à sua aplicação, o perfil do profissional que aplicará o instrumento, os termos e definições utilizados, a forma de aplicação e preenchimento do instrumento, a forma como os dados devem ser tratados, diretrizes para elaboração de laudo técnico e referências das normas das quais os requisitos foram retirados.

É importante ressaltar aqui que os itens dispostos no roteiro de inspeção foram retirados das normas da Associação Brasileira de Normas Técnicas, em especial da norma de desempenho NBR 15575:2013.

\section{Roteiro de avaliação da manutenibilidade do sistema construtivo inovador com base em análise de documentação técnica}

Este instrumento tem por objetivo principal detectar irregularidades e inconsistências segundo as normas e a partir de requisitos obrigatórios e facultativos, julgar o grau de manutenibilidade do sistema construtivo inovador em avaliação.

$O$ instrumento é constituído por um roteiro com itens referentes à documentação técnica cujos conteúdos devem ser analisados. Ele está dividido em três partes que dizem respeito aos documentos técnicos a serem avaliados como o Manual de Operação, Uso e Manutenção, o Modelo de Programa de Manutenção e a documentação técnica pertinente (projetos executivos, projetos de impermeabilização, memorial descritivo, normas pertinentes, etc.). Embora o programa de manutenção deva ser abordado no manual de operação, uso e manutenção, nas fichas do roteiro de avaliação o modelo de programa de manutenção foi separado da ficha do manual para facilitar a avaliação dividindo as informações em fichas complementares entre si.

As três fichas para avaliação apresentam em sua estrutura, da esquerda para a direita, cinco campos: requisitos a serem avaliados; caráter desses requisitos (facultativo ou obrigatório); campo para avaliação do atendimento aos requisitos (atende, não atende, não se aplica e não verificado); campo para classificação da informação, quando o requisito é atendido (atendimento 
Quadro 2. Estrutura da ficha de avaliação de documentos técnicos

\begin{tabular}{|c|c|c|c|c|c|c|c|c|}
\hline \multirow[t]{2}{*}{ Requisitos } & \multirow{2}{*}{$\begin{array}{l}\text { Caráter do } \\
\text { requisito }\end{array}$} & \multicolumn{4}{|c|}{ Atendimento aos requisitos } & \multicolumn{2}{|c|}{$\begin{array}{l}\text { Qualidade da } \\
\text { informação }\end{array}$} & \multirow{2}{*}{$\begin{array}{c}\text { Observações } \\
\text { complementares }\end{array}$} \\
\hline & & A & NA & NSA & NV & AS & $\mathrm{Al}$ & \\
\hline 01 & Obrigatório & $\square$ & $\square$ & $\square$ & $\square$ & $\square$ & $\square$ & $\begin{array}{c}\text { (a serem inseridas pelo } \\
\text { avaliador) }\end{array}$ \\
\hline 02 & Obrigatório & $\square$ & $\square$ & $\square$ & $\square$ & $\square$ & $\square$ & $\begin{array}{c}\text { (a serem inseridas pelo } \\
\text { avaliador) }\end{array}$ \\
\hline 03 & Facultativo & $\square$ & $\square$ & $\square$ & $\square$ & $\square$ & $\square$ & $\begin{array}{c}\text { (a serem inseridas pelo } \\
\text { avaliador) }\end{array}$ \\
\hline
\end{tabular}

satisfatório; ou atendimento insatisfatório); e campo para inserção de observações pertinentes à avaliação e que ajudem a justificar as alternativas escolhidas.

Os requisitos apresentados no decorrer das fichas foram retirados de normas da Associação Brasileira de Normas Técnicas (ABNT), de diretrizes do Sistema Nacional de Avaliação Técnica (SiNAT) e dos conceitos de Flexibilidade e Adaptabilidade propostos nesta metodologia de avaliação.

Os requisitos obrigatórios são os aqueles extraídos das normas da ABNT, nos casos em que são apresentados como dever ou obrigação, e os requisitos facultativos são os requisitos fundamentados nos conceitos de Flexibilidade e Adaptabilidade propostos ou os extraídos das normas nos casos em que são apresentados como não obrigatórios.

No manual do instrumento, que segue a mesma estrutura do manual do roteiro de inspeção discutido anteriormente, são apresentados os conceitos de Flexibilidade e Adaptabilidade, de onde o requisito facultativo tem embasamento e que foram propostos como requisitos a serem inseridos no processo de homologação de sistemas construtivos inovadores.

\section{Requisito: Flexibilidade}

A primeira parte da Norma de Desempenho NBR 15575 (ABNT, 2013) aborda como requisito, no item 16 - Funcionalidade e Acessibilidade, a possibilidade de ampliação da unidade habitacional recorrendo-se apenas a recursos regionais. A norma refere-se a unidades habitacionais térreas e assobradadas denominadas habitações de caráter evolutivo. Essas habitações são comercializadas já com previsão de ampliações.

Baseado em parte neste texto da norma e principalmente nas características que concedem a habitação um caráter evolutivo, propõe-se a criação de um requisito. Esse requisito, Flexibilidade, deve ser de caráter facultativo e seu atendimento significará que o sistema construtivo inovador avaliado é um sistema flexível cujas características devem: permitir ou prever a realização de reformas e modificações; permitir ou prever a realização de ampliações; oferecer 
informações de segurança para realização de atividades de operação, uso e manutenção em caso de reformas, modificações e ampliações; fornecer informações sobre infraestrutura material, tanto inovadora quanto convencional que seja compatível com o sistema construtivo inovador; fornecer informações sobre infraestrutura técnica necessária, tanto inovadora quanto convencional compatível com o sistema construtivo inovador.

Assim, na avaliação final de um sistema construtivo inovador, o bom resultado relacionado aos critérios de flexibilidade conferirá a ele a classificação de sistema construtivo flexível, ou seja, atende a necessidades mutáveis dos usuários, cabendo aqui unidades habitacionais térreas e em edifícios de apartamentos.

Para atender a esse requisito completamente, o incorporador ou o construtor deverá anexar ao manual do usuário os detalhes necessários para realização das alterações nas construções como: tecnologia construtiva a ser utilizada, mão de obra a ser empregada, materiais necessários (descrição e quando for o caso fornecedores), detalhes construtivos, informações de segurança para realização das alterações (ABNT, 2013).

\section{Requisito: Adaptabilidade}

Ainda com base no texto apresentado pela norma sobre habitações de caráter evolutivo, o requisito Adaptabilidade diz respeito à característica do sistema construtivo inovador de interagir com materiais, mão de obra e tecnologias tradicionais/regionais, além dos utilizados pelas construtoras ou incorporadoras.

Esse requisito também tem caráter facultativo (uma vez que não é exigido pelas normas atuais) e o atendimento aos seus critérios concedem ao sistema construtivo a classificação de sistema construtivo inovador adaptável a tecnologias, materiais e mão de obra tradicionais.

Sistemas construtivos adaptáveis devem: permitir realização de manutenção recorrendo-se apenas a materiais, mão de obra e tecnologias equipamentos tradicionais/regionais; permitir a realização de reformas, modificações e ampliações recorrendo-se apenas a recursos tradicionais/ regionais; fornecer informações para realização de manutenção recorrendo-se apenas à materiais, equipamentos, mão de obra e tecnologias tradicionais/regionais; permitir interface com sistemas construtivos tradicionais/ regionais; oferecer informações e detalhes técnicos sobre interfaces entre o sistema construtivo inovador e tradicionais/regionais; fornecer informações que viabilizem a realização de modificações, reformas e ampliações; indicar materiais substituíveis e não substituíveis necessários à operação, uso e manutenção; indicar equipamentos substituíveis e não substituíveis necessários à operação, ao uso e à manutenção. 


\section{Considerações finais}

As inovações técnicas nos sistemas e componentes construtivos devem atender a diferentes aspectos de desempenho e econômicos. Além dos aspectos econômicos e comerciais é importante considerar os requisitos dos usuários, com foco na etapa de operação, uso e manutenção das edificações, sobretudo com as habitações de interesse social.

Sistemas construtivos inovadores podem e devem contribuir com a obtenção de maior manutenibilidade e melhoria no desempenho da edificação durante sua vida útil. A manutenibilidade deve ser considerada no processo de homologação de sistemas construtivos inovadores na construção, entre outros fatores: a facilidade de manutenção; viabilidade física e financeira de execução de serviços de manutenção; disponibilização de serviços de assistência técnica e capacitação de mão de obra regional para operar esses sistemas novos e flexibilização dos sistemas para que permitam reformas, reparos e ampliações, permitindo interfaces entre sistemas inovadores e convencionais (materiais, equipamentos e mão de obra).

A metodologia de avaliação da manutenibilidade de sistemas construtivos aqui apresentada leva em consideração os requisitos dos usuários e a relevância da etapa de operação, uso e manutenção. Essa consideração se dá através da proposição de instrumentos que avaliam inclusive a qualidade da informação fornecida por construtores e incorporadores no âmbito da manutenção.

A proposta de adoção de novos requisitos relacionados à flexibilidade e adaptabilidade dos sistemas construtivos inovadores para que estes possam efetivamente atender a requisitos, necessidades e expectativas dos usuários ao longo do tempo de modo satisfatório é uma contribuição ao processo de homologação destes sistemas.

Outra contribuição consiste na sistematização de requisitos e instrumentos para avaliação de sistemas construtivos, contribuindo para o processo de homogeneização no sistema de homologação desempenhado pelas instituições técnicas avaliadoras vinculadas ao SiNAT que, atualmente desempenham seu papel independentemente uma das outras.

Mesmo diante das melhorias que as normas de Desempenho (ABNT, 2012) e Manutenção (ABNT, 2013) sofreram frente às revisões a que foram submetidas e a partir daí serem visíveis alguns avanços neste cenário, esses avanços ainda são muito sutis fazendo-se necessário um olhar crítico mais aprofundado para as questões relacionadas à manutenção e à fase de operação, uso e manutenção das edificações, assim como para os requisitos e expectativas dos usuários. 


\section{Referências}

ABNT - ASSOCIAÇÃO BRASILEIRA DE NORMAS TÉCNICAS. NBR 5674: manutenção de edificações: requisitos para o sistema de gestão de manutenção. Rio de Janeiro, 2012.

. NBR 14037: diretrizes para elaboração de manuais de uso, operação e manutenção das edificações: requisitos para elaboração e apresentação dos conteúdos. Rio de Janeiro, 2011. Janeiro, 2013

NBR 15575: edificações habitacionais: desempenho: partes 1 a 5. Rio de

AL-HAMAD, A.; ASSAF, S.; AL-SHIHAH, M. The effect of faulty design on building maintenance. Journal of Quality in Maintenance Engineering, v. 3, n. 1, p. 29-39,1997.

ARIS, R. B. Maintenance factors in building design. Dissertação (Mestrado) - Universiti Teknologi Malaysia. Malásia: Universiti Teknologi Malaysia, 2006.

BONIN, L. C. Considerações sobre a utilização do conceito de desempenho como instrumento para modernização tecnológica na construção de edificações. In: ENCONTRO NACIONAL DE TECNOLOGIA DO AMBIENTE CONSTRUÍDO E QUALIDADE NO PROCESSO CONSTRUTIVO - ENTAC, 7., 1998. Florianópolis. Anais... Florianópolis: ANTAC, 1998.

BRASIL. Ministério das Cidades. Programa Brasileiro de Qualidade e Produtividade do Habitat. Sistema Nacional de Avaliações - SINAT. Disponível em: <http://pbqp-h. cidades.gov.br/projetos_sinat.php>. Acesso em: 28 fev. 2012.

FERNANDES, C. Inovações tecnológicas na Caixa. In: SEMINÁRIO DE SISTEMAS INDUSTRIALIZADOS Ả BASE DE CIMENTO PARA HABITAÇÃO, 201 1, São Paulo. [S.I.]: Comunidade da Construção, 2011.

EL-HARAM, M. A.; HORNER, M. W. Factors affecting housing maintenance cost. Journal of Quality in Maintenance Engineering, v. 8, n. 2, p. 115-23, 2002.

FERREIRA, A. B. H. Novo dicionário da língua portuguesa. 2. ed. Rio de Janeiro: Nova Fronteira, 1986.

GONÇALVES, O. M. et al. Normas técnicas para avaliação de sistemas construtivos inovadores para habitações. In: BONIN, H.; BONIN L. C. (Eds.). Normalização e certificação na construção habitacional. Porto Alegre: ANTAC, 2003. p. 42-53. (Coleção Habitare, 3)

KEMPTON, J. Modern methods of construction and RSL asset management. Structural Survey, v. 28, n. 2, p. 121-31, 2010.

KEMPTON, J.; SYMS, P. Modern methods of construction. implications for housing asset management in the RSL sector. Structural Survey, v. 27, n. 1, p. 36-45, 2009.

KIM, S. S. et al. Development of a housing performance evaluation model for multi-family residential buildings in Korea. Building and Environment, n. 40, p. 1103-16, 2004.

KLEIN, D. L.; KLEIN, G. M. B.; LIMA, R. C. A. Sistemas construtivos inovadores: procedimentos de avaliação. In: II SEMINÁRIO DE PATOLOGIA DAS EDIFICAÇÕES NOVOS MATERIAIS E TECNOLOGIAS EMERGENTES, 2004, Porto Alegre. Anais... Porto Alegre: UFRGS, 2004.

LUKKA, K. The constructive research approach. In: OJALA, L.; HLMOLA, O.-P. (Eds.). Case study research in logistics. Hilmola: Turku School of Economics and Business Administration, 2003. p. 83-101.

MITIDIERI FILHO, C. V. Avaliação de desempenho de componentes e elementos construtivos inovadores destinados a habitações: proposição específicas a avaliação do desempenho estrutural. São Paulo: EPUSP, 1998. 


\section{Avaliação da manutenibilidade em sistemas construtivos inovadores}

MITIDIERI FILHO, C. V.; CLETO, F.; WEBER, M. S. Desenvolvimento e implementação do Sistema Nacional de Avaliações Técnicas de Produtos Inovadores (SINAT). In: Simpósio Brasileiro de Gestão e Economia da Construção - SIBRAGEC, 5., 2007, Campinas. Anais... [S.n.t.].

MORAES, O. B.; SANTANA, M. J. A. Tecnologia, habitação e desenvolvimento sustentável. In: ENCONTRO NACIONAL SOBRE EDIFICAÇÕES E COMUNIDADES SUSTENTÁVEIS - ENECS, 3., 2003, São Carlos. Anais... [S.n.t.].

MOSSEL, H. J.; JANSEN, S. J. T. Maintenance services in social housing: what do residents find important? Structural Survey, v. 28, n. 3, p. 215-29, 2010.

MOUBRAY, J. Introduction to reliability-centered maintenance. 2000. Disponível em: <http://www.maitenanceresources.com>. Acesso: 3 dez. 2009.

OECD - ORGANIZAÇÃO PARA COOPERAÇÃO ECONÔMICA E DESENVOLVIMENTO. Manual de Oslo: diretrizes para coleta e interpretação de dados sobre inovação tecnológica. Organização para cooperação e desenvolvimento econômico. São Paulo: Finep; 1997.

PARLAMENTARY OFFICE OF SCIENCE AND TECHNOLOGY. Modern methods of house building. Postnote, n. 209, Dec 2003.

REZENDE, M. A. P.; BARROS, M. M. S. B.; ABIKO, A. K. Barreiras e facilitadores da inovação tecnológica na produção de habitações populares. In: ENCONTRO NACIONAL DE TECNOLOGIA DO AMBIENTE CONSTRUÍDO - ENTAC, 9., 2002, Foz do Iguaçu. Anais... Porto Alegre: ANTAC, 2002.

ROSA, E. B. Indicadores de desempenho e sistema ABC: o uso de Indicadores para uma gestão eficaz do custeio e das atividades de manutenção. 2006. 530p. Tese (Doutorado em engenharia de produção) - Escola Politécnica, Universidade de São Paulo. São Paulo: USP, 2006.

SALERMO, L. S. et al. Aplicação de ferramentas da mentalidade enxuta (Lean Thinking) em processo de manutenção predial. In: SIMPÓSIO BRASILEIRO DE GESTÃO E ECONOMIA DA CONSTRUÇÃO, 4. ENCONTRO LATINO-AMERICANO DE GESTÃO E ECONOMIA DA CONSTRUÇÃO, 4., 2005, Porto Alegre. Anais... Porto Alegre: ANTAC, 2005.

SANCHES, I. D. A.; FABRICIO, M. M.; BUZZAR, M. A. Instrumento para avaliação de sistemas construtivos inovadores: padronização do processo de homologação com foco em manutenibilidade 201?.

SEELEY, I. H. Building maintenance. London: Macmillan, 1982.

TOLEDO, R.; ABREU, A. F.; JUNGLES, A. E. A difusão de inovações tecnológicas na indústria da construção civil. Florianópolis: Centro Tecnológico da Universidade Federal de Santa Catarina, 2010.

TOLEDO, R.; JUNGLES, A. E. Identificação de fatores que interferem no processo de inovação tecnológica na construção civil. Florianópolis: Centro Tecnológico da Universidade Federal de Santa Catarina, 2010.

VALENÇA, M. M.; BONATES, M. F. The trajectory of social housing policy in Brazil: from the National Housing Bank to the Ministry of the Cities. Habitat International, v. 34, n. 2, p. 165-73, Apr. 2010.

WAEYENBERGH, G.; PINTELON, L. A framework for maintenance concept development. International Journal of Production Economics, v. 77, n. 3, p. 299-313, Apr. 2002. 



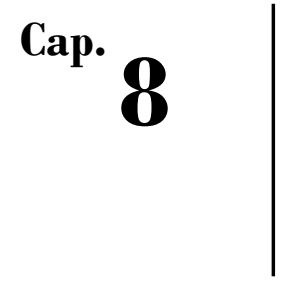

' O usuário, de acordo com a NBR 15575 (ABNT, 2013), é o proprietário, titular de direitos ou pessoa que ocupa a edificação. Neste trabalho, o termo usuário será usado com o significado de e de forma alternativa ao - termo morador, independentemente de deter a posse ou titularidade da edificação residencial.

2 ASSOCIAÇÃO BRASILEIRA DE NORMAS TÉCNICAS - ABNT.

\section{Contribuição ao estudo sobre uso e manutenção de sistemas construtivos inovadores: Light steel framing e paredes de concreto com formas de PVC incorporadas}

\author{
Claudia de Andrade Oliveira \\ Luciano Ferreti
}

\section{Introdução}

O princípio de que se deve projetar e construir uma edificação considerando padrões e/ou condições possíveis, viáveis e necessárias de uso e manutenção está entre os fundamentos do campo disciplinar da avaliação de desempenho.

O uso, especialmente de edificações residenciais, tem influências culturais, sociais, climáticas, ambientais e econômicas. $O$ uso da edificação inclui desde atividades rotineiras como limpeza, passando pela forma como os usuários $^{1}$ movimentam esquadrias, utilizam as instalações sanitárias, de gás e elétricas, até os carregamentos (estáticos ou dinâmicos) impostos à estrutura devidos aos costumes e/ou às ações extemporâneas praticadas pelos usuários. As condições locais (clima, interferências externas) combinadas aos padrões de uso podem potencializar o aparecimento de falhas nas edificações.

A manutenção predial, por sua vez, conceituada como o "conjunto de atividades a serem realizadas para conservar ou recuperar a capacidade funcional da edificação e seus sistemas constituintes, a fim de atender às necessidades e segurança dos seus usuários" (ABNT $\left.{ }^{2}, 2013\right)$, é influenciada pelas soluções de projeto e pela qualidade dos materiais e da construção.

De importância inquestionável em edificações industriais, a relevância da manutenção em outras tipologias funcionais de edificações parece ainda não ser plenamente 
${ }^{3}$ A primeira edição da norma de desempenho NBR 15575 foi publicada em maio de 2008. A versão atual vigente da norma, na sua quarta edição, foi publicada em fevereiro de 2013. reconhecida. Há tempos, como observa Bonin (1988), a "manutenção é um assunto negligenciado dentro dos estudos tecnológicos". O autor continua:

"pode-se apontar como uma das principais causas deste descaso [...] a própria forma como normalmente é considerado o processo produtivo da edificação, restrito às atividades dos técnicos intervenientes do processo excluindo quase totalmente a participação dos usuários do edifício construído" (BONIN, 1988).

Mais recentemente, as pesquisas seguem apontando a falta de um olhar mais atento dos projetistas e construtores no sentido do estabelecimento de uma melhor comunicação entre as partes e na observância de detalhes que favoreçam os serviços de manutenção e previnam as falhas nas edificações (SANCHES; FABRICIO, 2009; DARDENGO, 2010). Ao mesmo tempo, as pesquisas demonstram que a manutenção predial ainda requer gestão mais eficiente, além do melhor preparo e maior valorização dos profissionais atuantes na área (VELLOSO NETO, 2006).

Embora as dificuldades enfrentadas pelo usuário com relação à manutenção estejam parcialmente relacionadas ao projeto e à construção, a falta de manutenção, propriamente dita, tem sido um dos principais responsáveis pela deterioração e obsolescência precoces do imóvel, transformando-se em um dos maiores desafios para a permanência dos usuários nessas edificações, especialmente nas habitações de interesse social.

A análise de desempenho das habitações sociais mostra que a inexistência ou ineficiência de manutenção responde por, aproximadamente, $60 \%$ das falhas identificadas em edifícios habitacionais construídos por meio de mutirão associativo (FERRETI; OLIVEIRA, 2010). Nesses casos, a falta de manutenção adequada está diretamente associada: (a) ao esconhecimento do grau de risco e/ou perigo por parte dos usuários caso a falha não seja corrigida; (b) à falta de orientação técnica apropriada para a correção das falhas; (c) à falta de orientação técnica para novas obras que não foram consideradas no programa de necessidades e, principalmente, (d) à carência de recursos financeiros dos usuários.

A manutenção predial tem sido vista sob uma nova perspectiva desde a divulgação, em $2008^{3}$, da primeira edição da norma de desempenho brasileira - ABNT 
15575 -, momento em que formalmente foi estabelecida a dependência entre a durabilidade, a vida útil e o uso e manutenção da edificação.

\section{[...] durabilidade}

capacidade da edificação ou de seus sistemas de desempenho suas funções, ao longo do tempo e sob condições de uso e manutenção especificadas no manual de uso, operação e manutenção [...] (ABNT, 2013)

\section{[...] vida útil (VU)}

período de tempo em que um edifício e/ou seus sistemas se prestam às atividades para as quais foram projetados e construídos, com atendimento dos níveis de desempenho previstos nesta Norma, considerando a periodicidade e a correta execução dos processos de manutenção especificados no respectivo manual de uso, operação e manutenção (a vida útil não pode ser confundida com o prazo de garantia legal ou contratual) [...] (ABNT, 2013)

E com as reedições das normas dedicadas à manutenção predial NBR 14037 (ABNT, 2011 b) e NBR 5674 (ABNT, 2012), o papel do usuário no uso e manutenção dos edifícios continua sendo evidenciado. Se por um lado a assunção dessas responsabilidades transfere ao usuário o ônus de usar e manter corretamente o edifício, por outro lado os agentes do processo de produção devem assumir a sua responsabilidade de projetar e construir edifícios com o compromisso de viabilizar o uso, a operação e a manutenção em condições factíveis do ponto de vista técnico e financeiro.

Para os sistemas construtivos inovadores, há agravamentos naturais em razão da incerteza do seu desempenho ao longo do tempo, como também do desconhecimento e falta de documentação das intervenções do usuário na edificação, considerando as diversas condições de uso. As inovações tecnológicas na produção habitacional ainda carecem de aprofundamento sobre o uso e manutenção de modo a assegurar o desempenho ao longo da sua vida útil da edificação.

Pesquisadores (SILVA; RANASINGHE, 2010; SUSILAWATI, 2009; OLUBODUN, 2001) têm apontado que a manutenção de edificações deve ser tratada como uma questão onde estão envolvidas múltiplas variáveis. Entre as variáveis citadas estão a disponibilidade e oferta de recursos e mão de obra, a dificuldade de realização dos serviços, a capacidade do usuário de gerenciar os serviços de manutenção e a percepção do usuário quanto à necessidade e urgência de implementação desses serviços.

Dessa forma, alguns autores (SILVA; RANASINGHE, 2010; SUSILAWATI, 2009; LSTIBUREK, 2006) usam ou recomendam a análise de risco para orientar estratégias de intervenção nas edificações, considerando as múltiplas variáveis e os vários níveis de ação.

Nesta abordagem, a análise de risco implica a identificação e o reconhecimento, por parte de especialistas, de falhas da edificação que possam trazer consequências indesejáveis aos usuários, quer sejam aquelas consequências que reduzam o nível de segurança do edifício, quer sejam aquelas que reduzam 
ou impeçam as condições de habitabilidade e/ou operacionalização dos sistemas da edificação, ou mesmo aquelas que contribuam para o desperdício de recursos (água, energia).

O risco é identificado tanto em situações ou eventos normais como naqueles de caráter anormal ou de emergência. $\bigcirc$ risco não está necessariamente relacionado a uma falha que caracteriza condição de perigo iminente, no entanto, a permanência da falha pode resultar na depreciação do valor do imóvel e no aumento exponencial do custo para a manutenção futura.

As especificações contidas nos códigos de construção e normas técnicas vigentes que estão relacionadas a requisitos de segurança em edificações, refletem o julgamento baseado na análise de risco. Tipicamente esse julgamento é feito com base em parâmetros fixos e não considera uma análise sistêmica que permita definir os vários níveis de risco aceitáveis, tendo em vista que a percepção de risco pode variar de acordo com os indivíduos e com a situação. Além disso, os fatores de risco considerados no projeto podem ser alterados conforme a interação do usuário com a edificação e conforme a dinâmica do uso do ambiente e as condições de exposição do edifício. Nesses casos, a análise de risco é útil para auxiliar as tomadas de decisão buscando um equilíbrio entre os níveis de segurança toleráveis e os recursos disponíveis (físicos e financeiros) com o objetivo de restabelecer ou melhorar o desempenho global do edifício (GUIMARÃES, 2003; McDOWEE; LEMER, 1991).

Uma vez conhecidos, interpretados e documentados os cenários que levam ao risco, o processo produtivo pode ser realimentado com expectativas de meIhoria incremental do desempenho das edificações.

Portanto, conhecer em profundidade o impacto das tecnologias inovadoras ao longo da vida útil da edificação e reconhecer as formas de preservar o seu desempenho por meio da manutenção preventiva e corretiva são aspectos importantes que requerem empenho e investimentos do meio técnico e produtivo.

Cabem também esforços para o conhecimento e documentação de como se dá a interação do usuário com os sistemas inovadores e quais são as principais interferências ou modificações que o usuário introduz nesses sistemas para adequá-los às suas necessidades e expectativas.

É dentro deste escopo que se justifica a pesquisa e que se estabelecem os objetivos deste trabalho.

\section{Objetivo}

Interpretar aspectos relevantes relacionados ao uso e manutenção dos sistemas construtivos analisados sob a perspectiva do usuário e identificar falhas e limitações desses sistemas nas reais condições de uso. 


\section{Método}

O método proposto para a concretização do objetivo é de natureza exploratória e está baseado em estudos de caso.

O estudo de caso pode ser interpretado, segundo a literatura especializada (YIN, 2005), como uma estratégia de pesquisa e não como um método per si. Essa estratégia permite a investigação de fenômenos no seu estado natural, a partir de uma definição criteriosa da abordagem da pesquisa (pessoas, grupo, organizações), da lógica do planejamento, dos múltiplos métodos de coleta de dados, do tratamento e análise de dados.

Os fenômenos a serem investigados são: (a) a forma com se dá a interação do usuário com o sistema construtivo, e (b) os modos de falha dos sistemas inovadores em edificações habitacionais.

Para tanto, foram elaborados questionários, roteiros de entrevistas e roteiros de inspeção dos edifícios visitados.

Para os levantamentos de campo foram adaptados procedimentos da norma ISO 15686-7 (Building and constructed assets - service life planning - Part 7: Performance evaluation for feedback of service life data from practice). $O$ roteiro de inspeção das edificações foi elaborado tomando com referência a norma de inspeção predial de São Paulo do Instituto Brasileiro de Avaliações e Perícias de Engenharia de São Paulo - IBAPE (2011).

Em cada conjunto visitado foram aplicados questionários aos moradores, entrevistas com o profissional de manutenção e com o síndico ou responsável pelo conjunto residencial. Algumas entrevistas espontâneas foram realizadas com moradores que se dispuseram a conversar com os pesquisadores.

A aplicação dos instrumentos de pesquisa (questionários, roteiro de inspeção e roteiro de entrevistas) foi feita de acordo com as seguintes abordagens:

- Roteiro de inspeção predial com o objetivo de identificar falhas dos sistemas (partes) da edificação, que podem: (a) comprometer os procedimentos da manutenção ou (b) reduzir a vida útil de projeto (VUP) pela deterioração precoce dos materiais ou componentes;

- Questionário orientado aos moradores e as entrevistas realizadas com profissionais da manutenção, síndicos e moradores, com os objetivos de: (a) identificar as principais dificuldades e limitações no uso e manutenção da edificação e (b) registrar como o morador reconhece a sua interferência e responsabilidade perante o uso e a manutenção desses sistemas.

A equipe de visita aos conjuntos foi composta por dois ou três pesquisadores, sendo um deles, ao menos, profissional com experiência de, aproximadamente, 20 anos em projetos e em execução de obras. 


\section{Forma de análise dos resultados}

Foram caracterizadas falhas detectáveis na vistoria ou falhas previsíveis com base nas evidências e relatos dos entrevistados. Foi utilizado como base de referência o método de Análise de Modos de Falha e Efeitos - FMEA (Failure Mode and Effects Analysis), cuja validade foi demonstrada por Silva, Fonseca e Brito (2006) no planejamento de atividades de manutenção de edificações, além da possibilidade de aplicação às fases de concepção, projeto e construção de obras.

$\mathrm{Na}$ detecção das falhas foram documentados os seguintes aspectos:

a. vinculação da falha a um dos sistemas da edificação: fundação (1), estrutura (2), cobertura (3), vedação (4), vãos (5), revestimentos (6), pavimentos (7), instalações eletromecânicas (8), instalações hidrossanitárias (9), espaço\&função (10);

b. identificação da falha;

c. interpretação da falha incluindo, quando possível, o mecanismo de ocorrência, a origem e a interação e impacto nos demais elementos, componentes e sistemas da edificação e no ambiente interno e externo;

d. indicação dos efeitos e consequências das falhas, com base na análise dos prejuízos gerados, nos requisitos de segurança (estrutural, ao fogo e ao uso), habitabilidade (estanqueidade, conforto, acessibilidade, funcionalidade), manutenção, durabilidade;

e. classificação da severidade dos efeitos e consequências das falhas segundo uma escala de valores.

A frequência de ocorrência das falhas, uma das etapas na aplicação do método FMEA, não foi estimada por se tratar de uma pesquisa de estudos de caso isolados, em razão de limitações de tempo e recursos.

A conceituação de falha é adotada a partir do exposto na parte 1 da norma de desempenho (ABNT, 2013): "ocorrência que prejudica a utilização do sistema ou do elemento, resultando em desempenho inferior ao requerido".

Para o propósito dessa pesquisa, a esse conceito acrescenta-se o entendimento de que a ocorrência também pode prejudicar a qualidade do ambiente, trazendo riscos ao morador, notadamente aqueles riscos que comprometem a segurança, a saúde e o bem-estar do morador.

Cabe destacar que essas falhas, em parte, podem ser resultantes de vícios construtivos, de inadequações dos projetos e de não conformidade com documentos legais e normativos. Nesses casos, o estudo foi de utilidade para o reconhecimento das práticas de produção dessas tipologias construtivas.

No entanto, os modos de ocorrência e as consequências de diversas falhas, observadas in loco, sugerem possíveis indicadores da deterioração 
precoce dos materiais e componentes construtivos, com impacto nas futuras ações de manutenção predial.

\section{Estudos de caso}

A seleção dos casos foi feita com base nas condições de acesso aos dados (projetos e demais informações técnicas), possibilidade de realização de visitas e entrevistas com usuários e os agentes envolvidos com a realização dos empreendimentos.

Os sistemas do estudo foram selecionados entre aqueles aprovados ou considerados de interesse pelo Programa Brasileiro de Qualidade e Produtividade no Habitat - PBQP-H, destacando-se os sistemas Light Steel Framing (LSF) - Diretriz SiNAT 003 (BRASIL, 20125) e o de paredes de concreto estruturais com formas de PVC incorporadas (poli (cloreto de vinila) - Diretriz SiNAT 004 (BRASIL, 2010).

A seleção dos estudos de caso foi feita com base nos seguintes critérios: (a) disponibilidade de acesso às informações de projeto, histórico da construção e demais informações técnicas e (b) disponibilidade de acesso às edificações já habitadas, aos moradores, síndicos ou representantes dos moradores e demais agentes envolvidos com a realização dos empreendimentos.

Os três empreendimentos selecionados para a pesquisa são conjuntos habitacionais localizados em cidades do Estado de São Paulo. Um deles construído por meio de financiamento público e destinado a habitações de interesse social. Um segundo empreendimento voltado à população de baixa renda e produzido com financiamento público e privado. O terceiro caso, orientado à população de renda média-alta e construído com financiamento privado.

À época do desenvolvimento do projeto e da construção dos conjuntos residenciais investigados, as correspondentes diretrizes SiNAT dos sistemas construtivos ainda não haviam sido divulgadas. No entanto, os agentes envolvidos com a produção dos empreendimentos que obtiveram financiamento público declararam que os respectivos sistemas haviam sido chancelados por institutos de avaliação técnica e, consequentemente, aprovados para receber o crédito financeiro.

Na sequência, serão apresentadas informações gerais dos conjuntos estudados verificadas no período da
${ }^{4}$ SiNAT: Sistema Nacional de Avaliação Técnica.

${ }^{5}$ Edição revisada divulgada em dezembro de 2012. A edição original foi publicada em abril de 2010. 
realização dos levantamentos em campo. As informações estão relacionadas ao número de unidades habitacionais, às áreas construídas, ao período de ocupação e ao número de respondentes dos questionários distribuídos aos moradores.

\section{Ligth Steel Framing (LSF)}

O sistema LSF foi investigado em situações distintas: condomínio de sobrados (Figura 1A) e condomínio vertical de edifícios de 4 pavimentos, incluindo o térreo (Figura 1B).

O condomínio de sobrados compunha-se de 33 residências ocupadas por, aproximadamente, dez anos, além de três casas desocupadas. A área construída típica é de, aproximadamente, $150 \mathrm{~m}^{2}$. Foram distribuídos aos moradores 32 formulários e recebidos 11 formulários respondidos, representando 34\% das residências ocupadas do condomínio.

O condomínio vertical, composto por 13 blocos e com 16 apartamentos cada, sendo quatro apartamentos por andar, perfaz um total de 208 unidades habitacionais. A área útil do apartamento é de, aproximadamente, $44 \mathrm{~m}^{2}$. À época da pesquisa, cinco blocos estavam ocupados há cerca de seis anos. Cabe destacar que esses edifícios estavam esparsamente ocupados, fato que inviabilizou a aplicação dos questionários dirigidos aos moradores desse condomínio. Os outros oito blocos estavam em fase de acabamento.

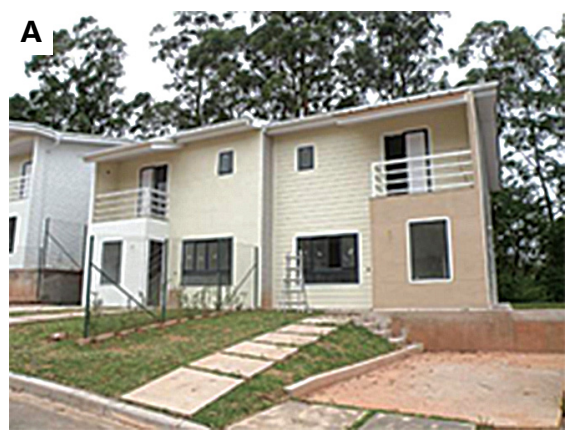

(A) Sobrados; (B) Edifício de quatro pavimentos.

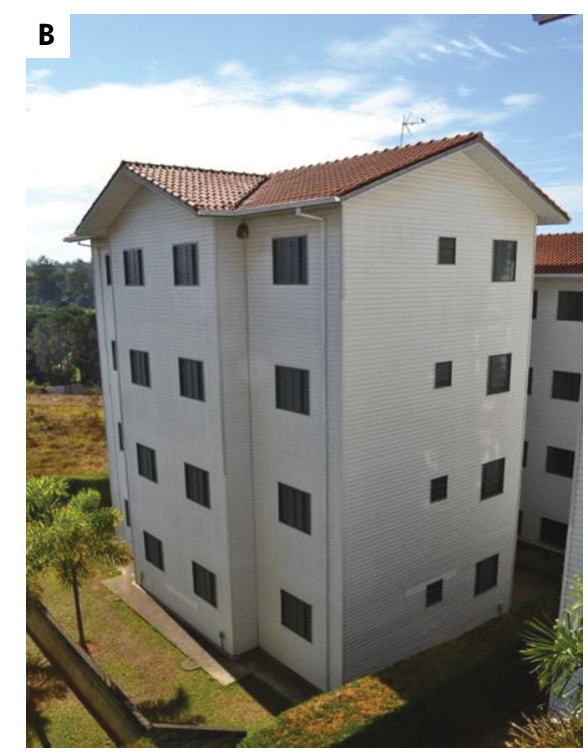

Figura 1. Estudos de caso em LSF 


\section{Paredes de concreto estruturais com formas de PVC}

sistema concreto-PVC foi estudado em um condomínio composto por 45 casas térreas (Figura 2A) e 106 sobrados (Figura 2B). O conjunto estava ocupado há, aproximadamente, um ano e 8 meses.

As casas têm área de $65,90 \mathrm{~m}^{2}$ e os sobrados de $54,86 \mathrm{~m}^{2}$. Foram distribuídos entre os moradores das casas 20 formulários e recebidos 10 formulários respondidos o que representa $22 \%$ das casas do conjunto.

Aos moradores dos sobrados, foram distribuídos 25 formulários e recebidos 18 formulários respondidos, com representatividade de, aproximadamente, $17 \%$ das unidades habitacionais do condomínio.

\section{Apresentação e discussão dos resultados}

Os resultados são apresentados em duas partes.

A primeira apresenta, para todos os estudos de caso, os resultados das vistorias na forma de fichas de ocorrências. São identificadas e interpretadas as falhas e, na sequência, quando cabível, são feitos comentários sobre as consequências dessas ocorrências no desempenho e na manutenção da edificação.

Na segunda parte são apresentados os resultados dos questionários aplicados aos moradores do condomínio de sobrados construídos com LSF e do condomínio de casas e sobrados construídos com o sistema concreto PVC. Como iá esclarecido, em razão da esparsa ocupação do condomínio vertical de LSF, não foi possível receber respostas dos moradores.

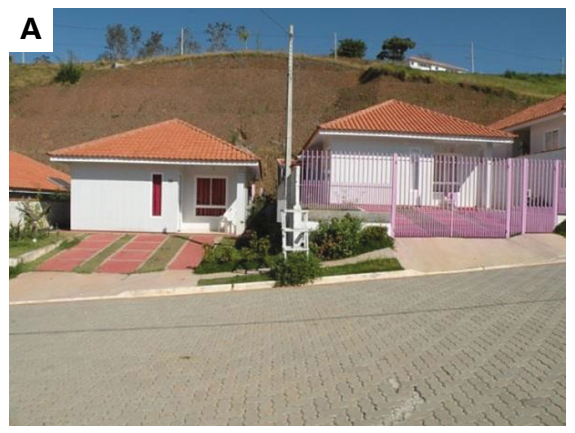

(A) Casas térreas; (B) Sobrados.

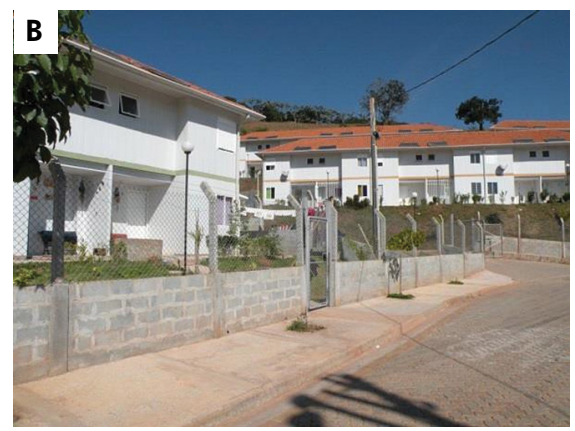

Figura 2. Estudos de caso em paredes de concreto estruturais com forma de PVC 


\section{Fichas de ocorrências}

As fichas de ocorrências ilustram algumas das diversas falhas detectadas nas edificações estudadas. Foram selecionadas as falhas mais relevantes para a discussão proposta neste trabalho. Os quadros de 1 a 7 apresentam as fichas de ocorrências do sistema construtivo LSF relacionadas a alguns dos sistemas da edificação: estrutura (Quadros 1 e 2); vedação (Quadro 3), revestimento (Quadros 4, 5 e 6) e eletromecânico (Quadro 7).

Os quadros de 8 a 13 apresentam as fichas do sistema construtivo Concreto+PVC relacionadas a alguns dos sistemas da edificação: vedação (Quadros 8, 9 e 10); vãos (Quadro 11), revestimento (Quadro 12) e hidrossanitário (Quadro 13). Não se pretende uma exaustiva discussão das causas dessas falhas, mas sim uma análise qualitativa das formas de ocorrência, das variáveis envolvidas e das consequências trazidas ao desempenho da edificação e aos moradores. 
Quadro 1. Ocorrência LSF 2.1 - Sistema construtivo Light Steel Framing

\begin{tabular}{|l|l|}
\hline Estudo de caso (LSF) & Sobrado em Light Steel Framing (LSF) \\
\hline Sistema & Estrutura \\
\hline Ocorrência (LSF 2.1) & Vibração na estrutura \\
\hline Registro fotográfico & \\
\hline
\end{tabular}

Interpretação da ocorrência

A ocorrência foi registrada a partir da declaração de um morador entrevistado sobre a sua sensação de desconforto e insegurança com a vibração da laje, quando do uso de equipamento de ginástica apoiado no piso do dormitório. Cabe destacar que: (a) a verificação da segurança e da estabilidade da estrutura para os estados limites últimos é compulsória para todo e qualquer projeto e, portanto, o projeto da estrutura ora apresentada assim foi verificado e (b) a percepção da vibração de um piso não implica, necessariamente, a perda de estabilidade ou de segurança da estrutura. $O$ efeito das vibrações em pisos resultantes das atividades humanas não é um assunto recente. Mas é certo que nos últimos anos, em razão do melhor conhecimento do comportamento em uso de estruturas mais esbeltas e leves o assunto tem despertado maior interesse de projetistas e pesquisadores. As cargas dinâmicas comumente consideradas no projeto de edifícios residenciais são as transientes (ato de caminhar ou de correr) e periódicas (atividades rítmicas como a dança ou ginástica). $\bigcirc$ estudo da vibração em pisos é um tema complexo e depende de uma série de fatores tais como "as características e a natureza das excitações dinâmicas, os critérios de aceitação para conforto humano em função do uso e ocupação, a razão de amortecimento modal e os pesos efetivos do piso" (FAKURY, 2007). Há procedimentos descritos por Smith, Hicks e Devine (2009) para a avaliação da resposta do piso aos carregamentos dinâmicos para estruturas em LSF. Dada a impossibilidade de acesso pleno ao projeto completo e memorial de cálculo deste estudo de caso, não é possível tecer maiores comentários sobre o assunto. No entanto, é de interesse para o desempenho do sistema construtivo em LSF uma análise estrutural mais detalhada para conhecer a resposta da estrutura quando submetida às cargas dinâmicas transientes e periódicas (como, por exemplo, a que foi citada nesta ocorrência) induzidas por atividades humanas. A exemplo do que tem sido pesquisado sobre ações dinâmicas em pisos mistos aço-concreto (MELLO, 2009), essas investigações podem colaborar para a verificação em projeto dos estados limites de serviço relacionados ao conforto humano e aos limites de vibração toleráveis pelos moradores, considerando-se a variação temporal e espacial de carregamentos dinâmicos nas estruturas de LSF.

\begin{tabular}{|l|c|c|c|c|c|c|}
\hline $\begin{array}{l}\text { Severidade da } \\
\text { ocorrência }\end{array}$ & $\begin{array}{c}\text { Sem } \\
\text { problemas } \\
\text { excepcionais }\end{array}$ & $\begin{array}{c}\text { Desconforto ou } \\
\text { comprometimento } \\
\text { segurança no uso }\end{array}$ & $\begin{array}{c}\text { Interrupção } \\
\text { no uso do } \\
\text { edifício }\end{array}$ & $\begin{array}{c}\text { Risco à } \\
\text { saúde }\end{array}$ & $\begin{array}{c}\text { Risco de } \\
\text { ferimento }\end{array}$ & $\begin{array}{c}\text { Risco } \\
\text { de vida }\end{array}$ \\
\cline { 2 - 8 } & $($ ) & $(X)$ & () & () & $($ ) & $($ ) \\
\hline
\end{tabular}


Quadro 2. Ocorrência LSF 2.2 - Sistema construtivo Light Steel Framing

\begin{tabular}{|l|l|}
\hline Estudo de caso (LSF) & Edifício de múltiplos andares em Light Steel Framing (LSF) \\
\hline Sistema & Estrutura \\
\hline Ocorrência (LSF 2.2) & $\begin{array}{l}\text { Deterioração/apodrecimento da laje de apoio de reservatórios } \\
\text { sobre placas de OSB. }\end{array}$ \\
\hline
\end{tabular}

Registro fotográfico
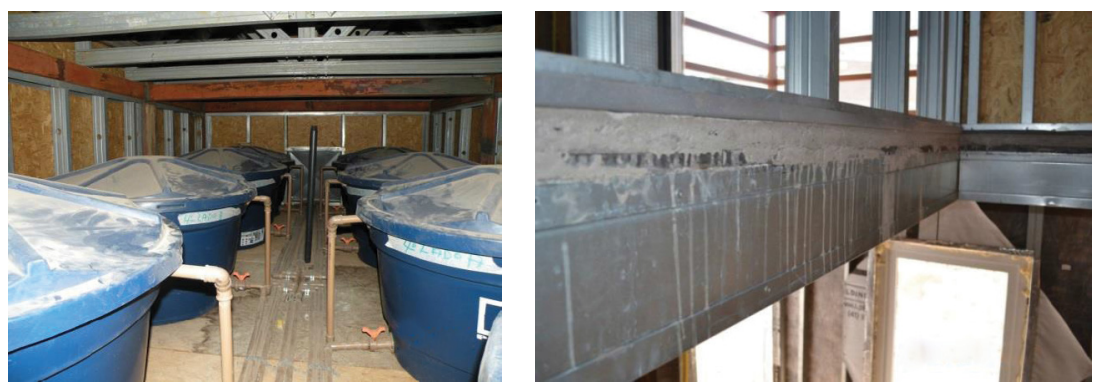

Interpretação da ocorrência

A execução da laje técnica neste edifício foi montada apenas com placas de OSB de aplicação em paredes com espaço máximo de $60 \mathrm{~cm}$, sem camada de revestimento.

Segundo o fabricante e distribuidor, as placas adequadas para tal aplicação são as destinadas para pisos e lajes secas (também estrutural) fixadas em perfis espaçados a, no máximo, $60 \mathrm{~cm}$.

○adrão $18 \mathrm{~mm}$ dessas placas - espessura $18,3 \mathrm{~mm}$ - possui a opção de bordas com encaixe macho-fêmea. Essas placas suportam carga distribuída de até $650 \mathrm{~kg} / \mathrm{m}^{2}$.

Por meio da análise visual, o arranjo físico e o carregamento da laje indicada nesta ocorrência - 8 reservatórios d'água de 310 L cada - parece estar dentro dos limites indicados.

No entanto, a água acumulada na laje, proveniente de possíveis vazamentos ou das operações de limpeza e manutenção, acabam por deteriorar as placas de OSB que, na ausência de procedimentos de vistoria frequente e manutenção periódica, poderão perder suas propriedades estruturais tornando-se um fator de risco para a segurança do usuário e do edifício.

Porém, neste caso de estudo, a manutenção pode ser prejudicada no futuro, devido à dificuldade operacional de efetuar a troca das placas de OSB deterioradas. A dificuldade é resultado do arranjo estrutural da laje seca (construção plataforma - ver detalhe da Figura 3A) usado neste caso, como também em grande número de edificações em LSF.

Ver detalhes na Figura 3 e comentários a seguir.

\begin{tabular}{|l|c|c|c|c|c|c|}
\hline \multirow{2}{*}{$\begin{array}{l}\text { Severidade da } \\
\text { ocorrência }\end{array}$} & $\begin{array}{c}\text { Sem } \\
\text { problemas } \\
\text { excepcionais }\end{array}$ & $\begin{array}{c}\text { Desconforto ou } \\
\text { comprometimento } \\
\text { segurança no uso }\end{array}$ & $\begin{array}{c}\text { Interrupção } \\
\text { no uso do } \\
\text { edifício }\end{array}$ & $\begin{array}{c}\text { Risco à } \\
\text { saúde }\end{array}$ & $\begin{array}{c}\text { Risco de } \\
\text { ferimento }\end{array}$ & $\begin{array}{c}\text { Risco } \\
\text { de vida }\end{array}$ \\
\cline { 2 - 7 } & $($ ) & $($ ) & $(X)$ & $(X)$ & $(X)$ & $($ ) \\
\hline
\end{tabular}


Os arranjos estruturais ilustrados na Figura 3A e Figura 3B são utilizados para a construção de lajes secas no sistema LSF. Por razões construtivas, apresentadas na sequência, o segundo arranjo é preterido em favor do primeiro.

Segundo alguns construtores entrevistados durante a pesquisa, o detalhe da Figura $3 \mathrm{~A}$ reduz o consumo de perfis metálicos respondendo por uma economia em torno de $10 \%$ do consumo de aço para a montagem da laje, além da redução de cerca de $40 \%$ do tempo de instalação.

Conforme Grubb, Gorgolewski e Lawson (2001), trata-se de arranjo típico da construção plataforma (platform construction) e que tem relação com a concepção do projeto estrutural. A parede é apoiada diretamente no piso e a transferência de cargas se dá pela placa. A condição permite que o piso atue como diafragma. Os autores apontam outra vantagem construtiva. A facilidade de montagem dos quadros das paredes que são aprumados em cada pavimento, não havendo desvios de prumo acumulados do(s) pavimento(s) inferior(es).
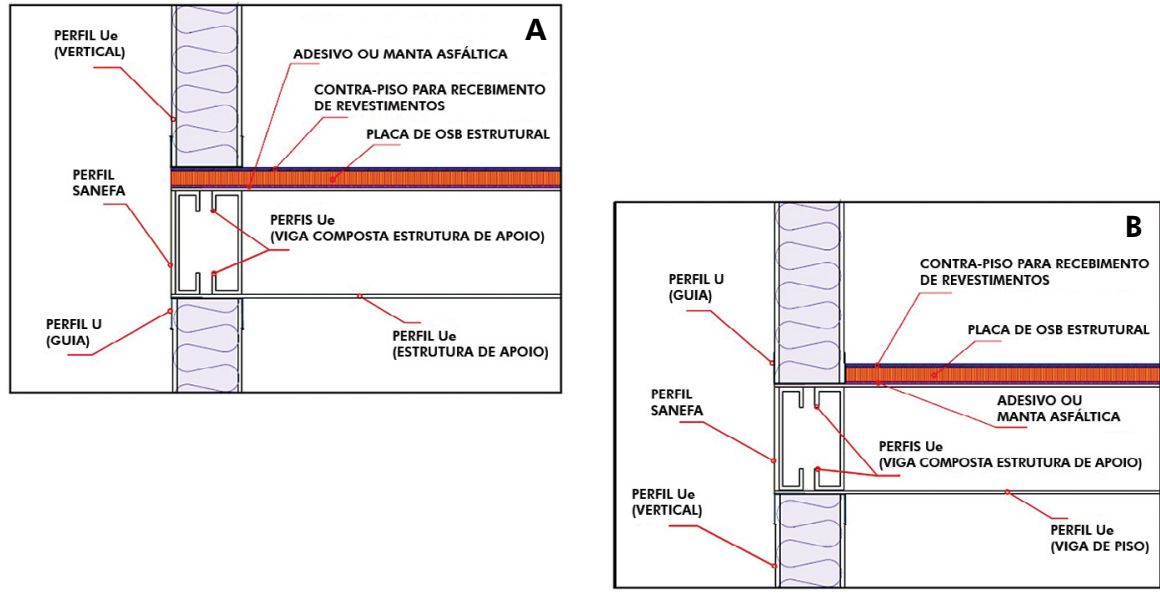

Figura 3. Detalhes genéricos de montagem das paredes: placa de OSB do piso apoiada na estrutura (A) e placa de OSB do piso faceando os montantes das paredes (B). Adaptação livre dos autores a partir de detalhes dos projetos arquitetônicos consultados. Desenho sem escala

A eventual substituição da placa de OSB na laje apresentada no Quadro 2 segundo os entrevistados, deve ser feita de maneira artesanal com o seccionamento e substituição parcial do OSB sob a parede, visto que não são previstos métodos de movimentação vertical dos quadros das paredes para a retirada das placas. Adicionalmente, naquele caso (Quadro 2), há aumento do custo de manutenção em razão da necessidade do manejo dos reservatórios em espaço reduzido e condições de difícil manobra. Tais operações tendem a ser mais simples em residências unifamiliares com um único reservatório de água elevado (Figura 4). 

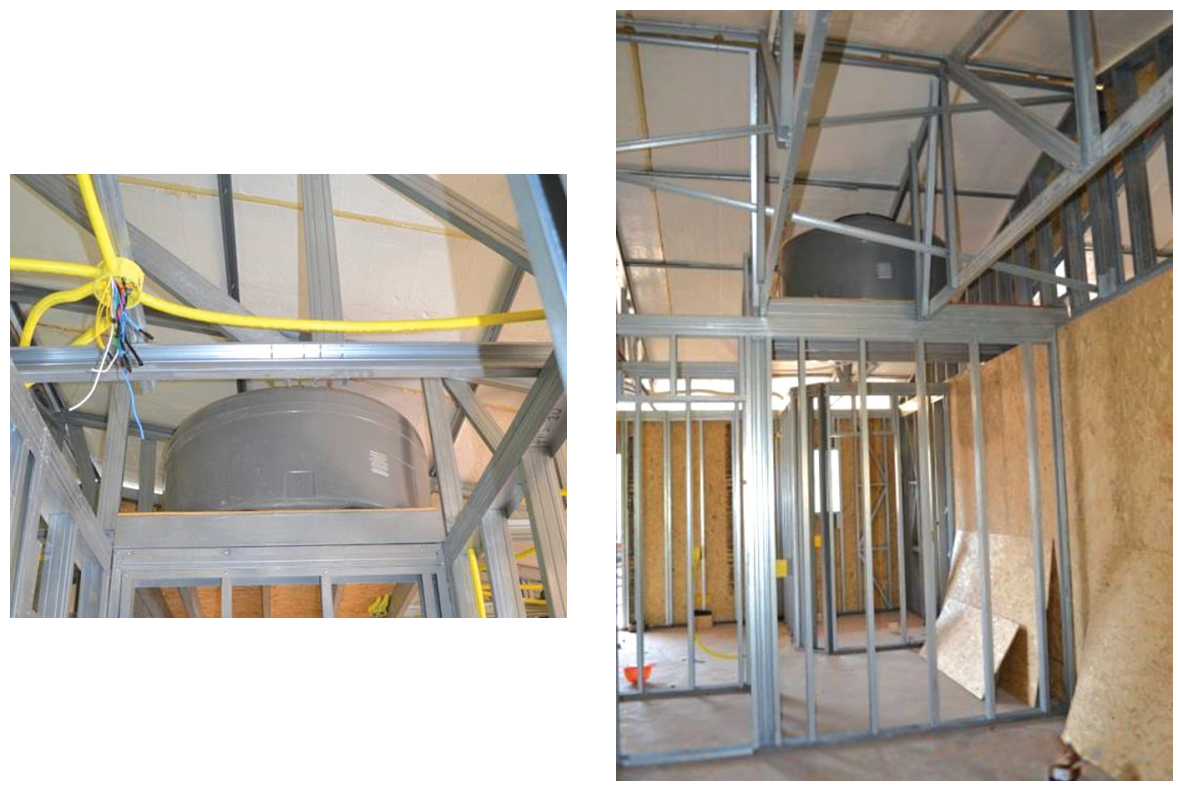

Figura 4. Posicionamento de reservatório elevado de água em sobrado construído com LSF

A manutenção de lajes secas deve ser criteriosamente estudada para evitar danos permanentes e/ou perda de estabilidade local dos elementos estruturais. 
Quadro 3. Ocorrência LSF 4.1 - Sistema construtivo Light Steel Framing

\begin{tabular}{|l|l|}
\hline Estudo de caso (LSF) & Edifício de múltiplos andares em Light Steel Framing (LSF) \\
\hline Sistema & Vedação \\
\hline Ocorrência (LSF 4.1) & $\begin{array}{l}\text { Deterioração das placas de gesso acartonado em parede de divisa } \\
\text { entre dormitório e banheiro, na face voltada para o dormitório. }\end{array}$ \\
\hline Registro fotográfico &
\end{tabular}

Interpretação da ocorrência

As evidências e o relato dos entrevistados sugerem que a água infiltrada no piso do banheiro do andar superior e no piso do banheiro contíguo provocou a deterioração das placas de gesso acartonado. A partir das inspeções visuais - destacada a impossibilidade de vistoria do andar superior e de acesso ao detalhamento de projeto - pode-se concluir que ocorrência se deve ao fato de que, provavelmente, a impermeabilização nos banheiros não foi executada para atender os requisitos de estanqueidade à água de banho ou de limpeza. Para a análise da ocorrência devem ser aclarados alguns conceitos vinculados às áreas molhadas e molháveis e as práticas de projeto associadas.

De acordo com a norma de desempenho NBR15575 parte 3 (ABNT, 2013b):

"Áreas molhadas: áreas da edificação cuja condição de uso e de exposição pode resultar na formação de lâmina d'água pelo uso normal a que o ambiente se destina (por exemplo, banheiro com chuveiro, área de serviço e áreas descobertas)."

"Áreas molháveis: áreas da edificação que recebem respingos de água decorrentes da sua condição de uso e exposição e que não resulte na formação de lâmina d'água pelo uso normal a que o ambiente se destina (por exemplo, banheiro sem chuveiro, lavabo, cozinha e sacada coberta)."

"Requisito - Estanqueidade de sistemas de pisos de áreas molháveis da habitação: Áreas molháveis não são estanques e, portanto, o critério de estanqueidade não é aplicável. Esta informação deve constar no manual de uso, operação e manutenção."

Com base nesses conceitos, atualmente é prática comum - para qualquer sistema construtivo - especificar a impermeabilização apenas nas áreas molhadas, Além disso, para os sistemas com paredes secas (drywall), conforme detalhes construtivos correntes para áreas molháveis ou molhadas, a base dos painéis de gesso acartonado não fica protegida do contato com a placa de OSB (oriented strand board) do piso.

No entanto, a prática mostra que as infiltrações de água são recorrentes e que dificultam e encarecem a manutenção. Soluções que minimizam o risco de umedecimento e deterioração desses componentes devem ser adotadas (ver exemplo na Figura 5).

\begin{tabular}{|l|c|c|c|c|c|c|}
\hline \multirow{2}{*}{$\begin{array}{l}\text { Severidade } \\
\text { da ocorrência }\end{array}$} & $\begin{array}{c}\text { Sem } \\
\text { problemas } \\
\text { excepcionais }\end{array}$ & $\begin{array}{c}\text { Desconforto ou } \\
\text { comprometimento } \\
\text { segurança no uso }\end{array}$ & $\begin{array}{c}\text { Interrupção } \\
\text { no uso do } \\
\text { edifício }\end{array}$ & $\begin{array}{c}\text { Risco à } \\
\text { saúde }\end{array}$ & $\begin{array}{c}\text { Risco de } \\
\text { ferimento }\end{array}$ & $\begin{array}{c}\text { Risco } \\
\text { de vida }\end{array}$ \\
\cline { 2 - 8 } & () & () & $(X)$ & $(X)$ & $($ ) & $($ ) \\
\hline
\end{tabular}


Dada à suscetibilidade à ação da água, especialmente do painel de gesso acartonado e da placa de OSB, a edição revisada da Diretriz SiNAT 003 (BRASIL, 2012) incluiu recomendações específicas para prevenir o umedecimento e, por conseguinte, a deterioração precoce dos materiais (item 1.2 Restrições de uso):

"para vedações que delimitem áreas molháveis e molhadas, a impermeabilização deverá ser constituída por mantas ou membranas apropriadas para esta finalidade, na interface entre a base dos quadros estruturais e o piso e nas laterais das paredes até a altura mínima de 20 cm" (Id. 2012).

Soluções genéricas para atender essas recomendações estão ilustradas na Figura 5:

As soluções apontadas na Figura 5 introduzem detalhes da: (a) impermeabilização completa do piso das áreas molhadas e também das áreas molháveis e impermeabilização das paredes na área do chuveiro e (b) junta na base dos painéis de gesso acartonado para evitar o contato direto com a água originária de possíveis vazamentos de tubulações embutidas nas paredes ou da penetração da água de possíveis falhas no sistema de impermeabilização.

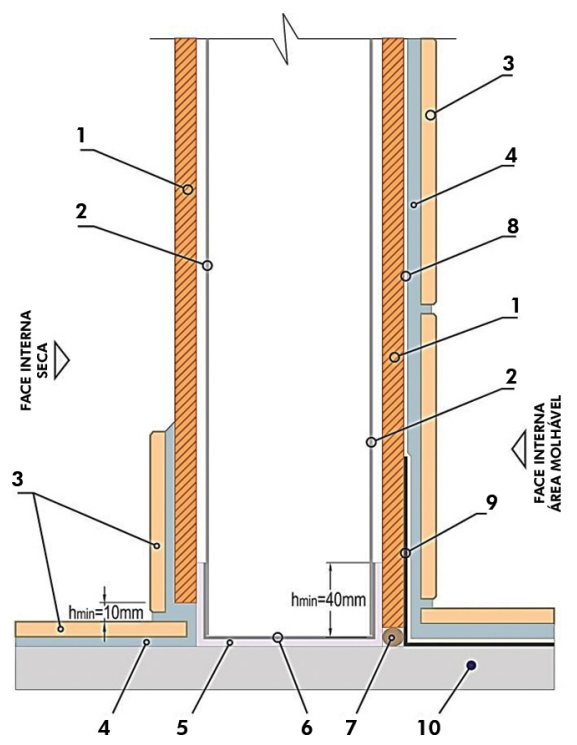

Legenda

1. Painel de gesso acartonado;

2. Montante Light Steel Framing;

3. Revestimento cerâmico;

4. Argamassa;

5. Banda acústica;

6. Guia Light Steel Framing;

7. Cordão de polipropileno expandido e selante flexível;

8. Impermeabilização;

9. Tela de poliéster para reforço da impermeabilização;

10. Laje/substrato

*Em áreas molháveis, a impermeabilização deve ser feita, no mínimo, com $40 \mathrm{~cm}$ de altura na borda inferior de todo o perímetro das paredes.

**Em áreas molhadas, a impermeabilização deve ser feita em toda a altura das paredes.

Figura 5. Corte esquemático: parede interna entre área seca e área molhável ou molhada. Adaptado pelos autores a partir de detalhes construtivos dos projetos dos empreendimentos estudados. Desenho sem escala 
Quadro 4. Ocorrência LSF 6.2 - Sistema construtivo Light Steel Framing

\begin{tabular}{|c|c|c|c|c|c|c|}
\hline \multicolumn{2}{|c|}{ Estudo de caso (LSF) } & \multicolumn{5}{|c|}{ Edifício de múltiplos andares em Light Steel Framing (LSF) } \\
\hline \multicolumn{2}{|l|}{ Sistema } & \multicolumn{5}{|l|}{ Revestimento } \\
\hline \multicolumn{2}{|c|}{ Ocorrência (LSF 6.2) } & \multicolumn{5}{|c|}{$\begin{array}{l}\text { Deformação do revestimento de PVC (siding Vinílico) da } \\
\text { fachada Leste (LE) do Bloco "E", sob a ação indireta do fogo. }\end{array}$} \\
\hline \multicolumn{7}{|c|}{ Registro fotográfico } \\
\hline \multicolumn{7}{|c|}{$=\mid \begin{array}{l}1+2 \\
5=2\end{array}$} \\
\hline \multicolumn{7}{|c|}{ Interpretação da ocorrência } \\
\hline \multicolumn{7}{|c|}{ 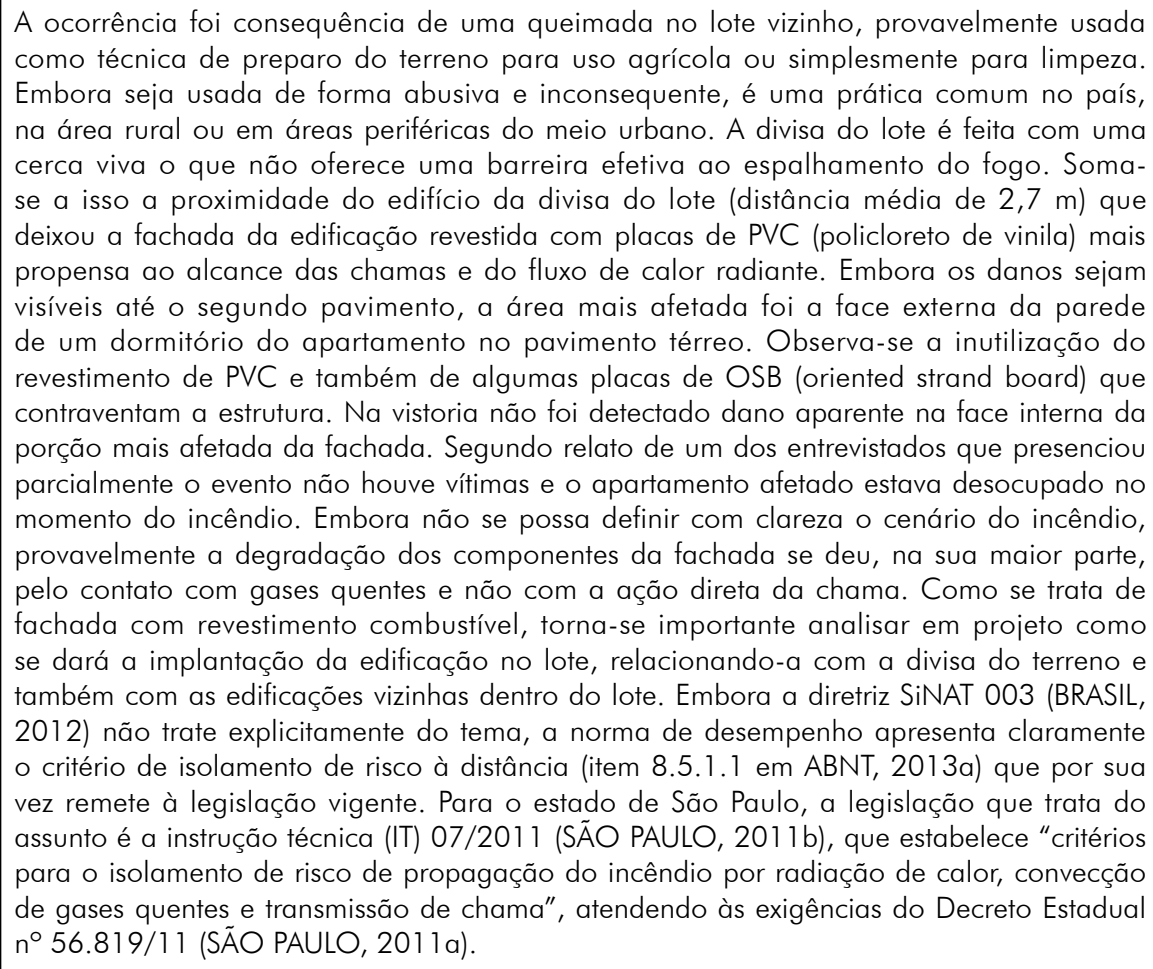 } \\
\hline \multirow[t]{2}{*}{$\begin{array}{l}\text { Severidade } \\
\text { da ocorrência }\end{array}$} & $\begin{array}{c}\text { Sem } \\
\text { problemas } \\
\text { excepcionais }\end{array}$ & $\begin{array}{l}\text { Desconforto ou } \\
\text { comprometimento } \\
\text { segurança no uso }\end{array}$ & $\begin{array}{l}\text { Interrupção } \\
\text { no uso do } \\
\text { edifício }\end{array}$ & & $\begin{array}{l}\text { Risco de } \\
\text { ferimento }\end{array}$ & \\
\hline & & & $(X)$ & $(X)$ & $(X)$ & \\
\hline
\end{tabular}


Quadro 5. Ocorrência LSF 6.3 - Sistema construtivo Light Steel Framing

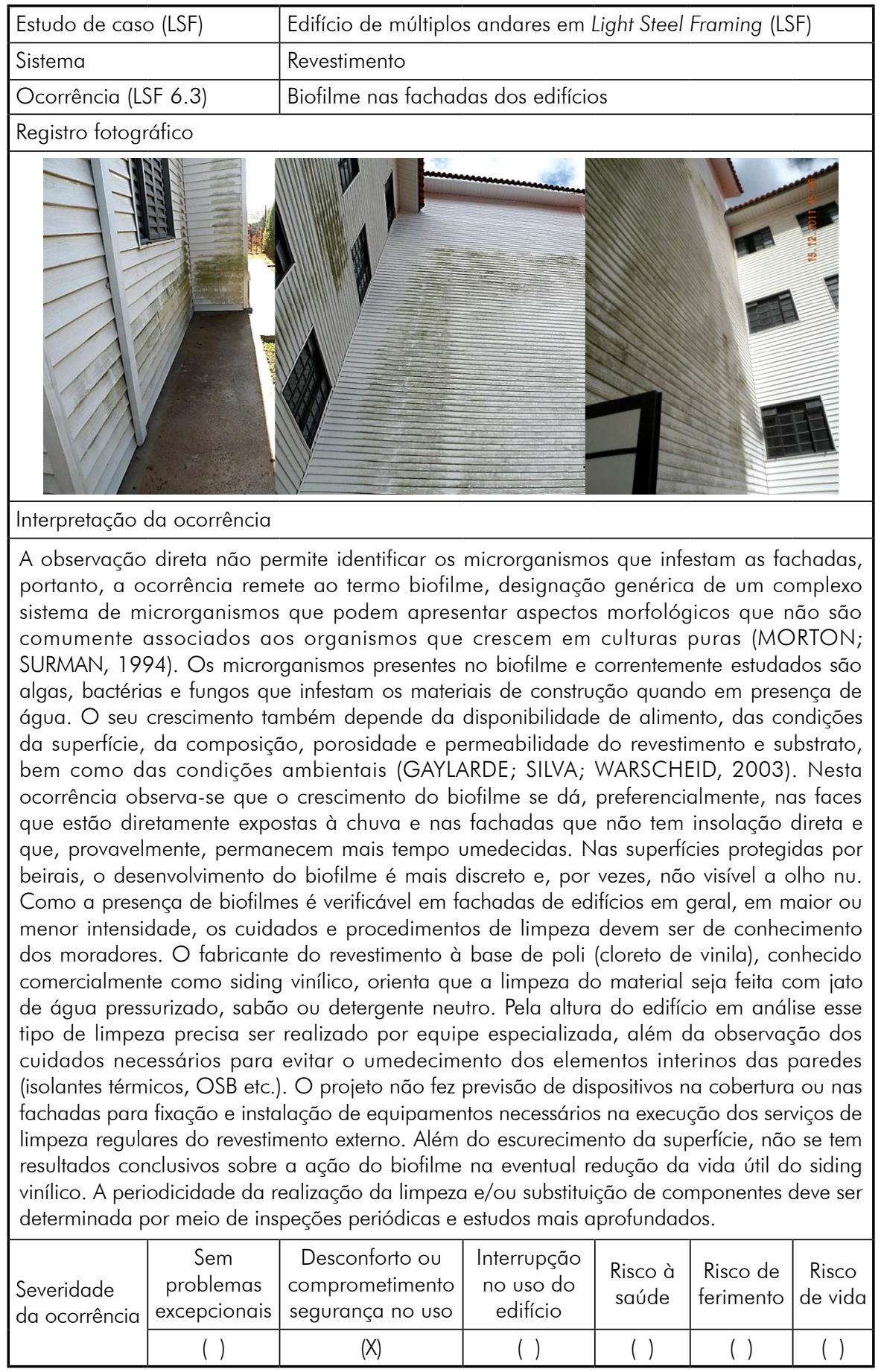


Quadro 6. Ocorrência LSF 6.4 - Sistema construtivo Light Steel Framing

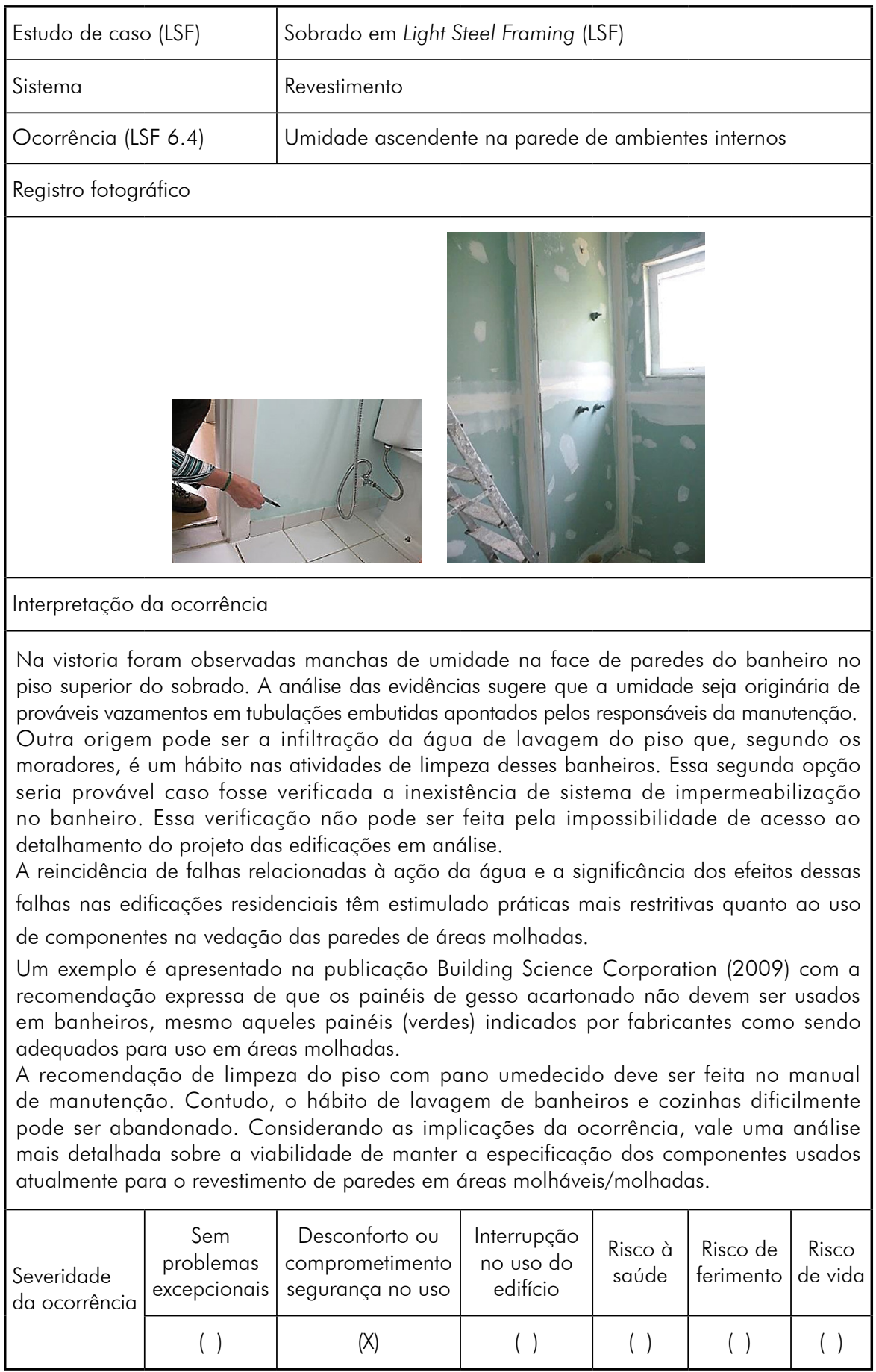


Quadro 7. Ocorrência LSF 8.1 - Sistema construtivo Light Steel Framing

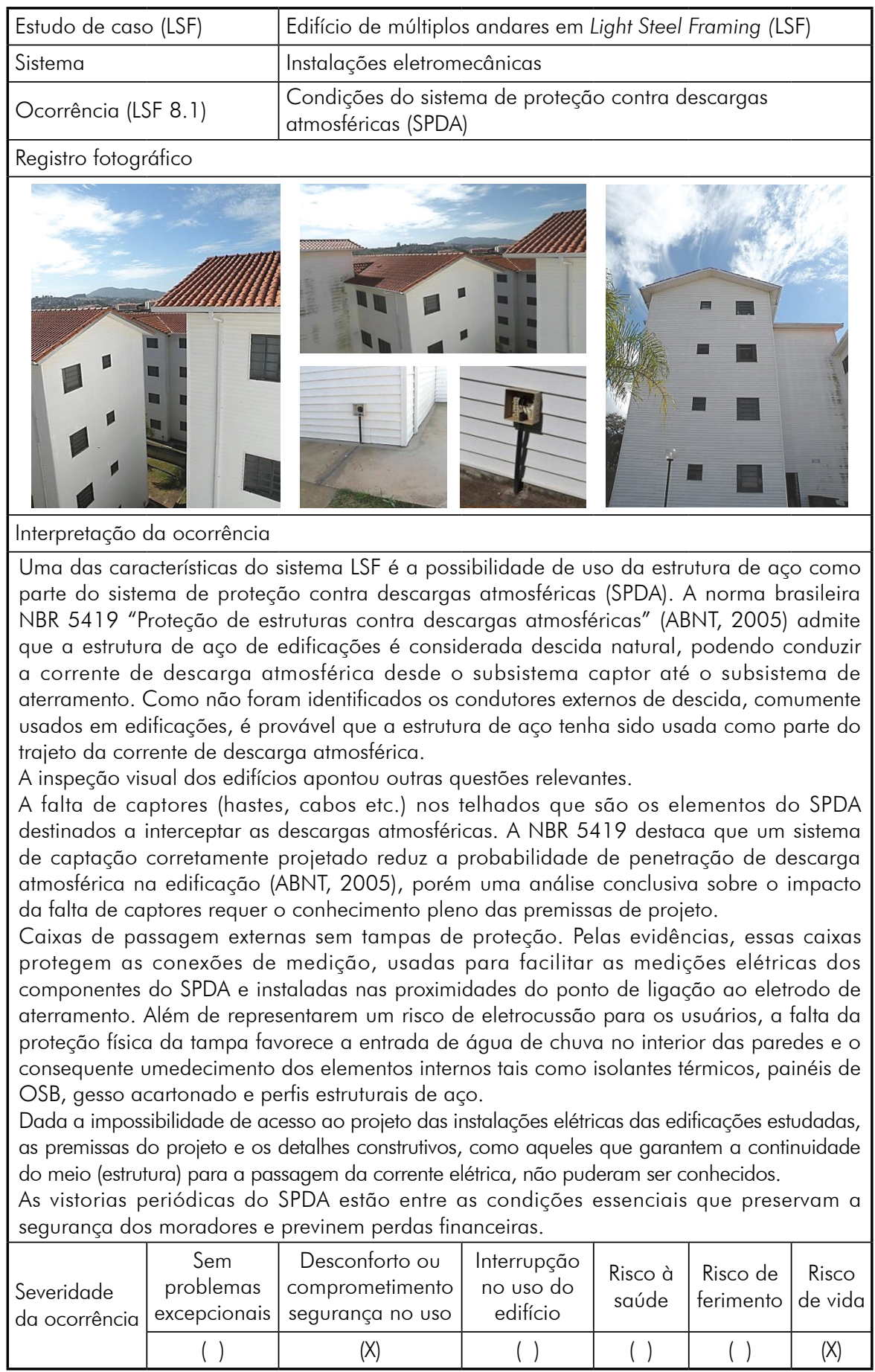


Quadro 8. Ocorrência PVC 4.1 - Sistema construtivo Paredes de concreto estruturais com forma de PVC

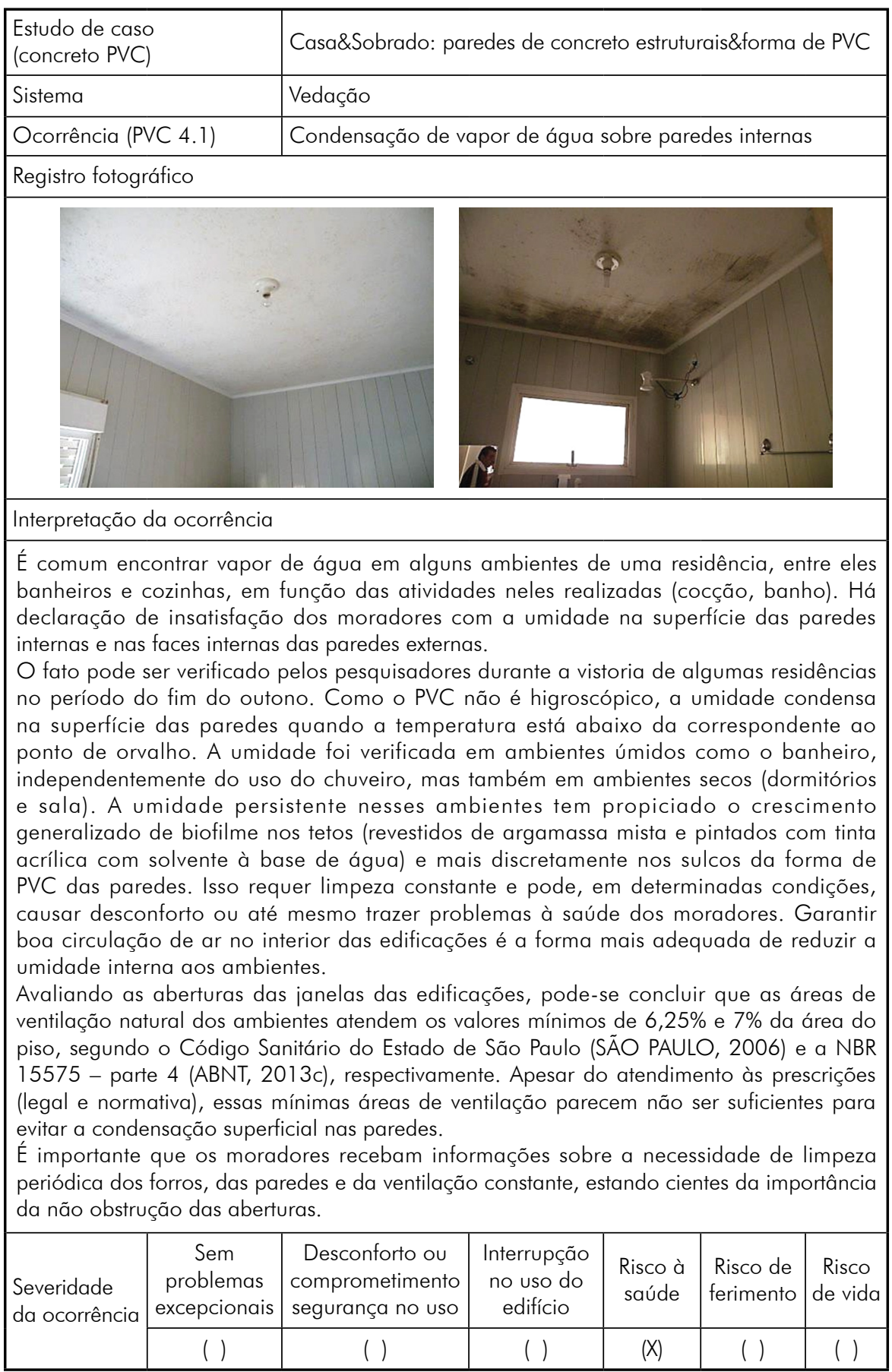


Quadro 9. Ocorrência PVC 4.2 - Sistema construtivo Paredes de concreto estruturais com forma de PVC

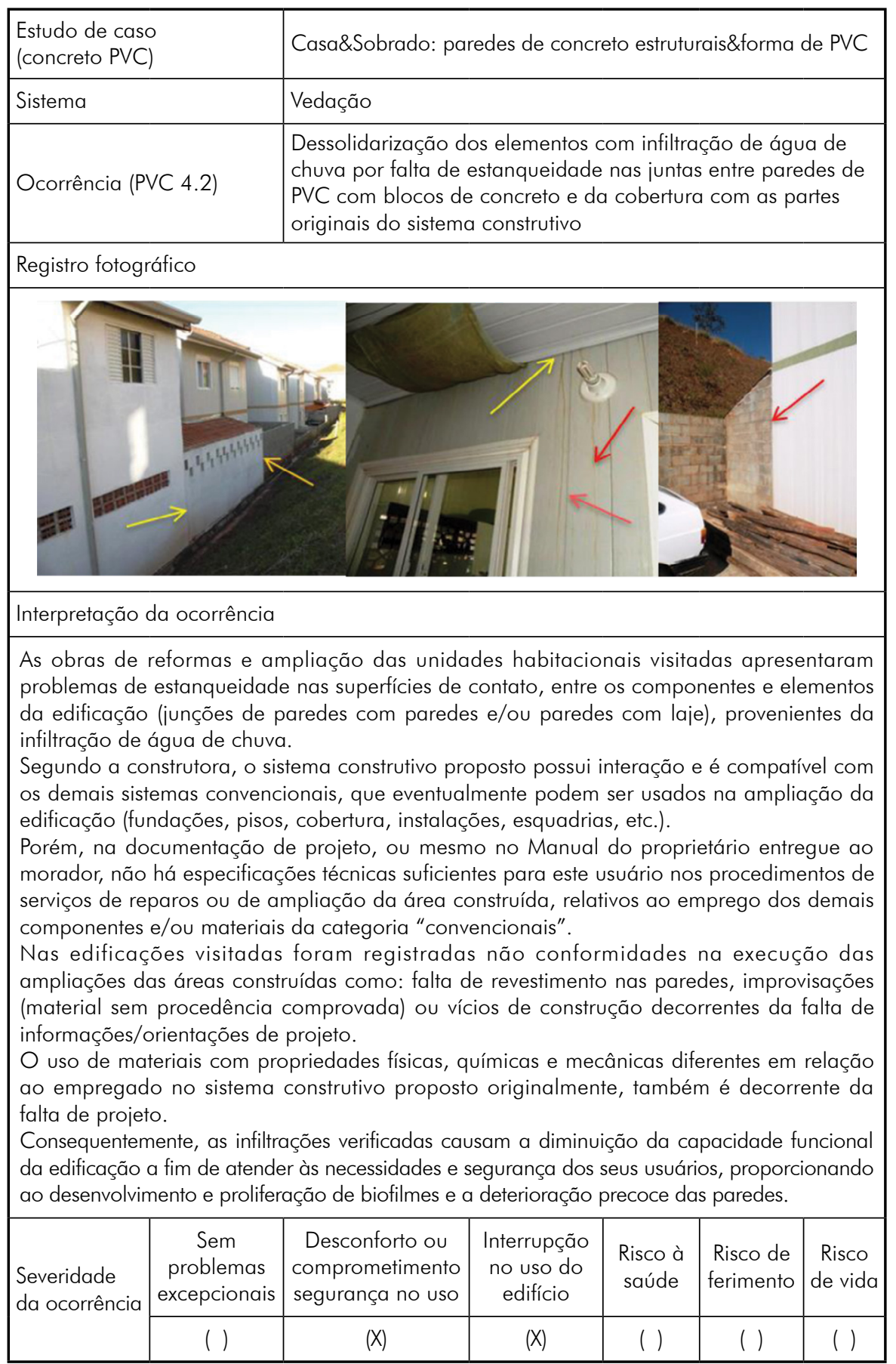


Quadro 10. Ocorrência PVC 4.3 - Sistema construtivo Paredes de concreto estruturais com forma de PVC

\begin{tabular}{|l|l|}
\hline $\begin{array}{l}\text { Estudo de caso } \\
\text { (concreto PVC) }\end{array}$ & Casa\&Sobrado: paredes de concreto estruturais\&forma de PVC \\
\hline Sistema & Vedação \\
\hline Ocorrência (PVC 4.3) & $\begin{array}{l}\text { Falta de especificação para os métodos e limites de fixação de } \\
\text { cargas suspensas nas paredes }\end{array}$ \\
\hline
\end{tabular}

Registro fotográfico
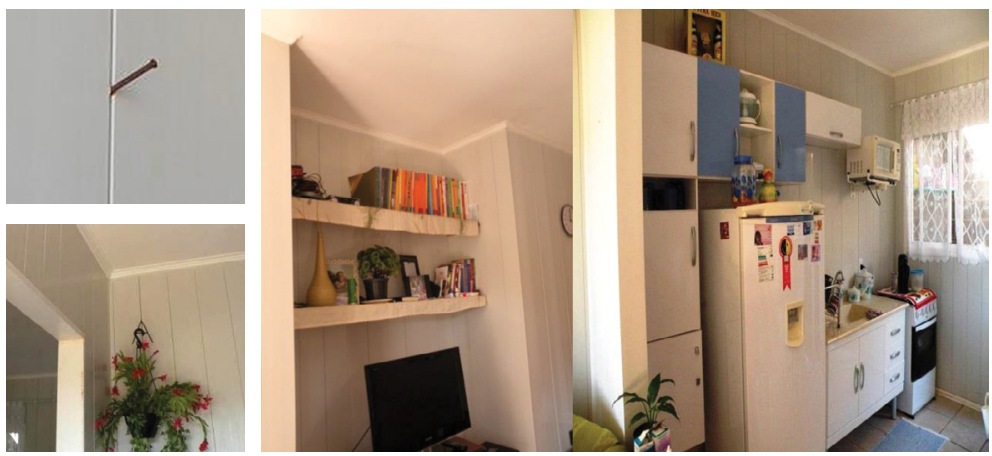

Interpretação da ocorrência

manual fornecido pela construtora orienta o usuário a fixar cargas suspensas apenas nos encontros das formas de PVC, mediante o uso de pregos. No entanto, o manual não faz referência ao limite específico de carga a ser fixada com o procedimento indicado ressaltante apenas que devem ser cargas leves, como também não faz menção a maneiras alternativas para o atendimento dos requisitos e critérios da NBR 15575 - parte 4 (ABNT, 2013c): o elemento vertical, do sistema de vedação, seja interno ou externo deve suportar até $0,4 \mathrm{kN}$ por ponto, considerando dispositivo de fixação padrão tipo mão-francesa. A norma indica como critérios de desempenho a não ocorrência de falhas que comprometam o estado-limite de serviço e os limites máximos de deslocamentos horizontais (instantâneo e residual).

Isso, em princípio, restringe a liberdade do morador de fazer furos em qualquer ponto da superfície da parede para fixar quaisquer objetos.

Mas prudentemente os moradores, segundo declarações espontâneas, fixam nas paredes objetos considerados leves, seguindo as orientações do manual. Para a fixação de prateleiras, armários, bancadas, fazem uso de parafusos e buchas ancorados no concreto. Nesse procedimento, frequentemente os furos são inutilizados por interceptarem armaduras (barras de aço dispostas verticalmente) existentes no interior das formas de PVC.

São recomendáveis orientações precisas sobre limites de carga, restrições de uso, formas e locais de fixação para evitar acidentes, perdas materiais ou mesmo a deterioração precoce dos elementos e componentes construtivos.

\begin{tabular}{|l|c|c|c|c|c|c|}
\hline \multirow{2}{*}{$\begin{array}{l}\text { Severidade } \\
\text { da ocorrência }\end{array}$} & $\begin{array}{c}\text { Sem } \\
\text { problemas } \\
\text { excepcionais }\end{array}$ & $\begin{array}{c}\text { Desconforto ou } \\
\text { comprometimento } \\
\text { segurança no uso }\end{array}$ & $\begin{array}{c}\text { Interrupção } \\
\text { no uso do } \\
\text { edifício }\end{array}$ & $\begin{array}{c}\text { Risco à } \\
\text { saúde }\end{array}$ & $\begin{array}{c}\text { Risco de } \\
\text { ferimento }\end{array}$ & \begin{tabular}{c} 
Risco de vida \\
\cline { 2 - 7 }
\end{tabular} \\
\cline { 2 - 7 } & $(\mathrm{X})$ & $(\mathrm{)}$ & $($ ) & $(X)$ & $($ ) \\
\hline
\end{tabular}


Quadro 11. Ocorrência PVC 5.2 - Sistema construtivo Paredes de concreto estruturais com forma de PVC

\begin{tabular}{|l|l|}
\hline $\begin{array}{l}\text { Estudo de caso } \\
\text { (concreto PVC) }\end{array}$ & Casa\&Sobrado: paredes de concreto estruturais\&forma de PVC \\
\hline Sistema & Vãos \\
\hline Ocorrência (PVC 5.2) & Facilidade de remoção das folhas das janelas \\
\hline Registro fotográfico
\end{tabular}

Interpretação da ocorrência

projeto das habitações não especifica as esquadrias e nem fornece os detalhes de fixação dos caixilhos dos tipos de janelas de PVC, utilizadas nestas construções. Embora a construtora informe no "memorial descritivo simples" que o sistema construtivo adotado possui acabamento comum nos vãos para receber as esquadrias de PVC, aço, alumínio, aço ou de madeira, a janela é tratada aqui como um elemento do sistema construtivo de concreto PVC.

As folhas das janelas do tipo "de correr" instaladas nas edificações são facilmente removíveis, leves e sem grade de proteção, características que, segundo a declaração dos próprios moradores, deixam a casa vulnerável a intrusões. A janela ilustrada nesta ocorrência está disposta na frente da casa, voltada para o leito viário, apresenta folgas e frestas entre as folhas e o marco que facilitam a remoção da folha manualmente.

Janelas de PVC vêm se apresentando como um dos materiais [componentes] com as características físicas, químicas e mecânicas que atendem os níveis mínimos de desempenho térmico e acústico, estanqueidade, instalação ágil, durabilidade e fácil manutenção.

Os problemas verificados nestas esquadrias provem da não conformidade do produto com os requisitos e critérios das normas específicas de janelas NBR 10821-2 (ABNT, 2011 a). A insuficiência de informações nos projetos, em especial no que diz respeito às especificações da drenagem, selantes, da ancoragem direta (marco e contramarco) nas paredes, não permite avaliar se as recomendações mínimas foram definidas em projeto com relação ao desempenho acústico, estanqueidade à água da chuva, resistência mecânica e segurança ao uso.

\begin{tabular}{|l|c|c|c|c|c|c|}
\hline \multirow{2}{*}{$\begin{array}{l}\text { Severidade } \\
\text { da ocorrência }\end{array}$} & $\begin{array}{c}\text { Sem } \\
\text { problemas } \\
\text { excepcionais }\end{array}$ & $\begin{array}{c}\text { Desconforto ou } \\
\text { comprometimento } \\
\text { segurança no uso }\end{array}$ & $\begin{array}{c}\text { Interrupção } \\
\text { no uso do } \\
\text { edifício }\end{array}$ & $\begin{array}{c}\text { Risco à } \\
\text { saúde }\end{array}$ & $\begin{array}{c}\text { Risco de } \\
\text { ferimento }\end{array}$ & $\begin{array}{c}\text { Risco } \\
\text { de vida }\end{array}$ \\
\cline { 2 - 7 } & $($ ) & $(X)$ & $($ ) & $(X)$ & $($ ) & ( ) \\
\hline
\end{tabular}


Quadro 12. Ocorrência PVC 6.1 - Sistema construtivo Paredes de concreto estruturais com forma de PVC

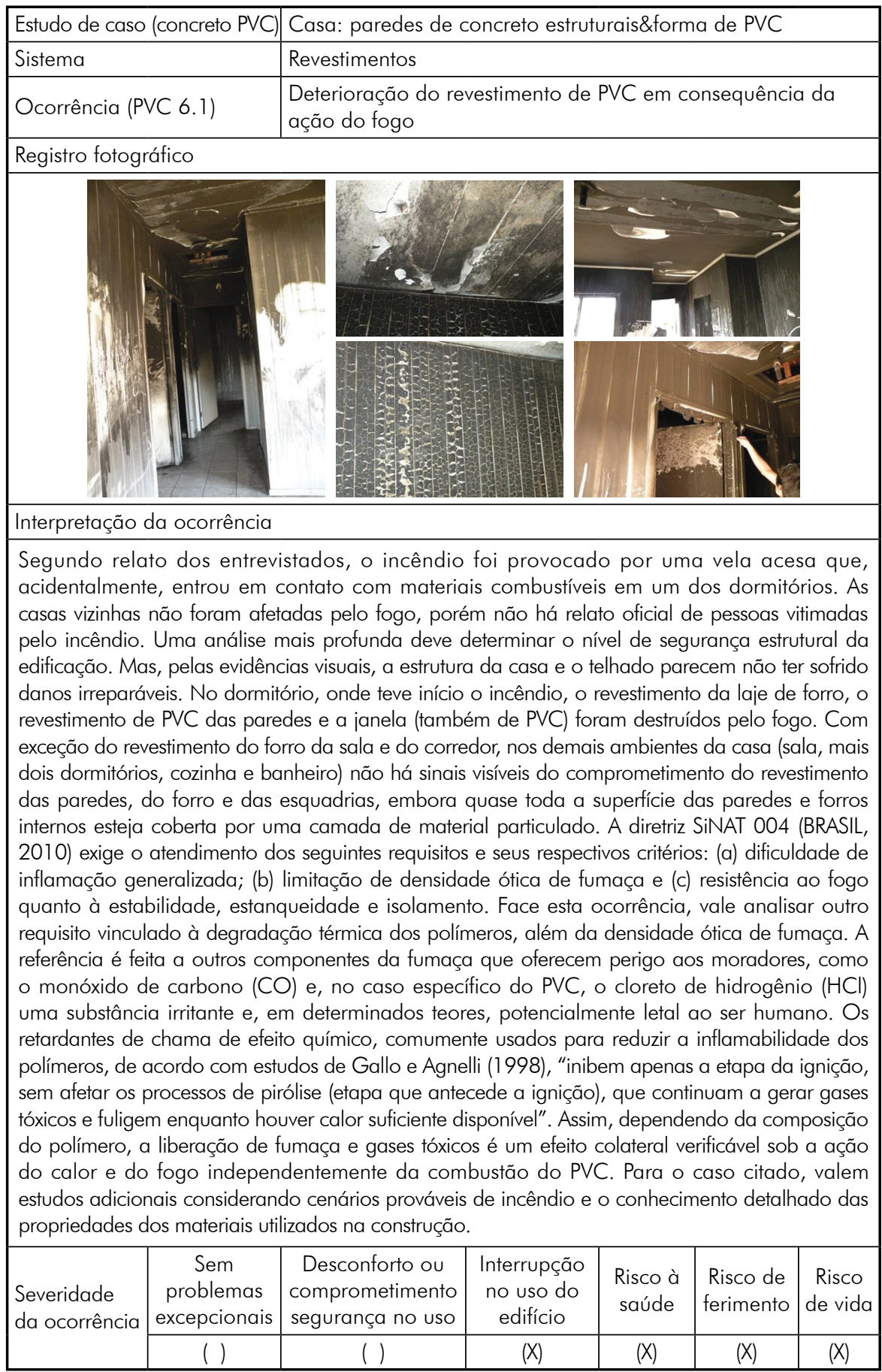


Quadro 13. Ocorrência PVC 9.1 - Sistema construtivo Paredes de concreto estruturais com forma de PVC






\section{Respostas dos moradores}

As figuras a seguir apresentam o nível de satisfação dos moradores com a qualidade e com a manutenção das edificações, bem como a frequência dos serviços de manutenção dos condomínios de sobrados de LSF, de casas de concreto PVC e de sobrados de concreto PVC, respectivamente. À apresentação das respostas, em termos percentuais dos respondentes, são feitos comentários considerando as observações e declarações espontâneas dos moradores no preenchimento dos questionários ou nas entrevistas.

\section{Condomínio de sobrados construídos com o sistema Light Steel Framing (LSF)}

O condomínio de sobradas de LSF, apesar de estar ocupado há, aproximadamente, 10 anos, apresenta grande percentual de moradores com alto nível de satisfação com a qualidade das edificações e com a manutenção (Figura 6). A maior parte dos moradores são proprietários dos imóveis.

Por se tratar de investimento privado, a aquisição dos imóveis se deu por livre escolha dos moradores, sendo que alguns deles já conheciam o sistema construtivo. Portanto, os moradores reconhecem com clareza as diferenças e limitações do sistema construtivo se comparado à construção convencional.

No entanto, há indícios de que alguns hábitos de limpeza, como o uso de água para lavagem dos banheiros, têm resultado no umedecimento das paredes (gesso acartonado) (Quadro 6). Com relação a outro hábito comum de fixação de cargas suspensas nas paredes, tais como elementos decorativos, luminárias, persianas, entre outros, os moradores têm consciência de que devem

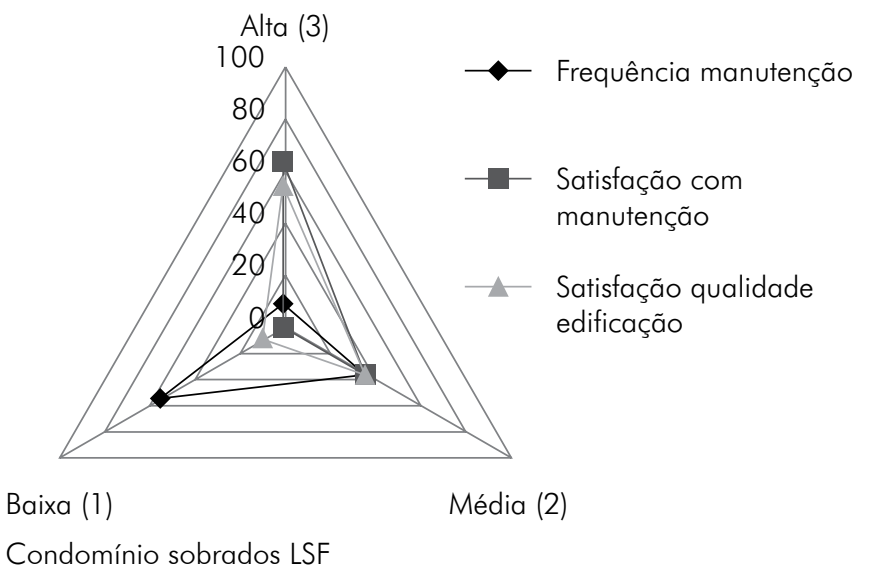

Figura 6. Respostas dos moradores do condomínio de sobrados construídas com o sistema de Ligtht Steel Framing (LSF) 
adotar cuidados especiais para evitar acidentes. Entre esses cuidados são incluídos a busca por dispositivos de fixação e suportes apropriados e a procura de auxílio profissional especializado.

Embora não tenham sido apontados com frequência, outros hábitos podem gerar desconforto e sensação de insegurança nos usuários. Exemplo disso foi a declaração espontânea de um morador sobre as vibrações na estrutura produzidas pelo uso de um equipamento de ginástica (ver Quadro 1). Como já apontado, trata-se de uma necessidade do morador que geralmente é desconsiderada, mas que merece atenção por parte dos projetistas e construtores.

A frequência dos serviços de manutenção é considerada baixa pelos moradores dos sobrados em LSF. Entre os serviços recorrentes estão os reparos nas instalações hidráulicas e cobertura para eliminar vazamentos e infiltrações de água, repinturas de fachadas e reparos regulares nas junções entre as placas de gesso acartonado para eliminar as fissuras e descolamento das fitas adesivas.

Atualmente os moradores são assistidos por técnicos de manutenção que, progressivamente, têm adquirindo experiência e melhorando a qualidade dos serviços ofertados. Isso explica as declarações de alguns moradores sobre a dificuldade de execução de reparos ou mesmo alterações quando da aquisição do imóvel. Mas vários declararam que a mão de obra ainda é despreparada. Para serviços mais especializados, os moradores ainda contam com a orientação e serviços da empresa construtora do conjunto de casas.

\section{Condomínio de casas construídas com o sistema de paredes de concreto estruturais e forma de PVC}

Para o conjunto de 45 casas de concreto PVC, foram obtidos níveis de satisfação dos moradores entre médio e alto para a manutenção e qualidade da edificação (Figura 7). Quando consultados, os moradores em geral declararam que as residências atendiam a suas expectativas e necessidades atuais. Um único morador, entre os respondentes, declarou estar insatisfeito com a edificação, provavelmente pelo fato de que não houve oportunidade para os futuros moradores opinarem sobre os sistemas e tipologias construtivas. A decisão foi tomada por agentes públicos de promoção e provisão de habitações de interesse social.

Alguns moradores que construíram mais um dormitório, garagem ou expandiram a área de serviço declararam-se satisfeitos com as possibilidades de ampliação da casa, mesmo que feita com métodos construtivos tradicionais (estrutura de concreto, alvenaria de blocos cerâmicos ou blocos de concreto e telhado com estrutura de madeira).

A maioria dos respondentes consegue reconhecer, com algumas limitações, as diferenças entre o sistema concreto PVC e os sistemas convencionais construtivos. Declararam que têm dificuldade em fixar cargas suspensas nas 
paredes. Alegaram que as paredes são muito resistentes à furação com equipamentos convencionais o que tem inibido a fixação de objetos mais pesados nas paredes (ver Quadro 10). A não necessidade de repintura da casa (paredes internas e externas) foi apontada por um morador com sendo uma vantagem do sistema.

Considerando o tempo de ocupação inferior a dois anos (1 ano e 8 meses) à época das entrevistas com os moradores e vistorias nos imóveis, era previsível que a maioria dos moradores declarassem que a frequência de manutenção é baixa, como de fato demonstra a ilustração da Figura 7.

No entanto, vários moradores apontaram que já enfrentaram problemas com o mau funcionamento das instalações elétricas e um morador declarou que tem problemas com a condensação de umidade nas paredes de ambientes secos, como os dormitórios (Quadro 8).

\section{Condomínio de sobrados construídos com o sistema de paredes de concreto estruturais e forma de PVC}

Nesse conjunto foram registrados os menores níveis de satisfação dos usuários quando à qualidade e manutenção da edificação (Figura 8).

O nível de satisfação médio com a qualidade da edificação parece estar vinculado aos problemas apontados pelos moradores tais como: vazamento de água de chuva pelo telhado, entrada de água de chuva nos eletrodutos, mau funcionamento das instalações elétricas e de telefonia, fissuras nas lajes de piso do pavimento inferior e superior, entupimento de tubulação de esgoto e dificuldade de acesso ao tubo para reparo por estar embutido na

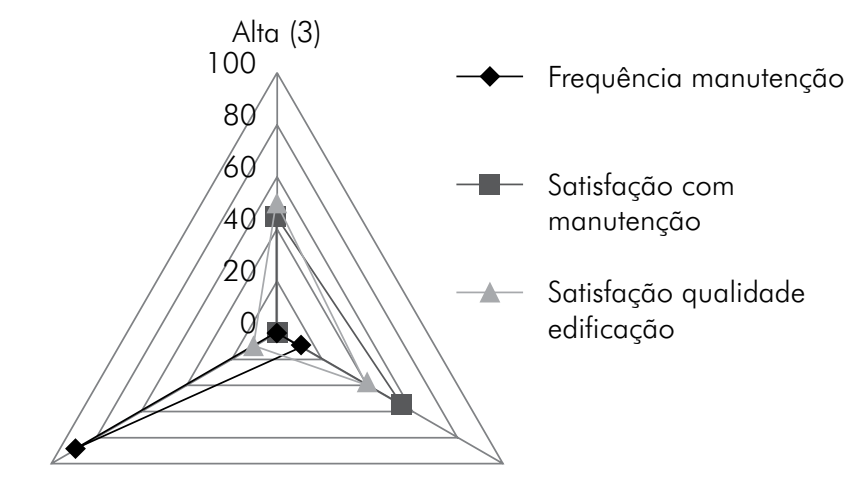

Baixa (1)

Média (2)

Condomínio casas concreto PVC

Figura 7. Respostas dos moradores do condomínio de casas construídas com o sistema de paredes de concreto estruturais e forma de PVC 
${ }^{6}$ Nesse conjunto, as unidades habitacionais são agrupadas. Há blocos de quatro ou seis sobrados geminados. parede de concreto (ver Quadro 13), falta de privacidade devido ao baixo nível de isolamento de som aéreo entre unidade habitacionais ${ }^{6}$, vulnerabilidade à intrusão na casa pela janela da sala (ver Quadro 11), cômodos muito pequenos, o que dificulta a distribuição de móveis e o deslocamento das pessoas. Mais da metade dos respondentes apontaram que enfrentam problemas com a condensação de umidade nos ambientes internos (dormitórios e sala) (ver Quadro 8).

Em parte, as falhas são resultantes das soluções adotadas em projeto e, em parte, também são decorrentes de vícios construtivos. Com exceção da condensação de umidade nos ambientes internos, os demais problemas podem ser verificáveis em edificações produzidas com outros sistemas construtivos.

Tendo em vista o tempo de ocupação dos imóveis, inferior a dois anos, a insatisfação com a manutenção do sistema construtivo também parece estar vinculada às falhas relatadas pelos moradores. Apesar de não encontrarem grandes dificuldades para a contratação de mão de obra, os moradores apontaram dificuldades para a recomposição do acabamento das paredes (ver Quadro 13). A despeito das falhas citadas, os moradores tendem a considerar a frequência de manutenção baixa.

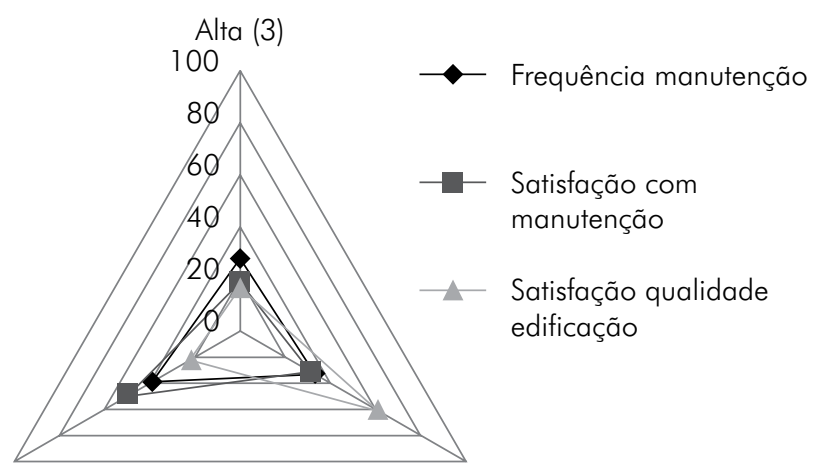

Baixa (1)

Média (2)

Condomínio sobrados concreto PVC

Figura 8. Respostas dos moradores do condomínio de sobrados construídos com o sistema de paredes de concreto estruturais e forma de PVC 
As alterações feitas pelos moradores foram: (a) acréscimo de um dormitório ${ }^{7}$ e (b) melhorias na área de serviço com o remanejamento das instalações e execução de teIhado. As reformas foram feitas com métodos construtivos tradicionais (estrutura de concreto, alvenaria de blocos cerâmicos ou blocos de concreto e telhado com estrutura de madeira). Porém, fissuras e destacamentos verificados entre o corpo original da casa e a ampliação podem resultar falhas de mais difícil correção nos sobrados do que nas casas térreas, ambos produzidos originalmente com o sistema concreto PVC.

Os moradores dos sobrados, à semelhança do posicionamento dos moradores das casas, reconhecem as peculiaridades do sistema e reconhecem algumas limitações. Declararam que têm dificuldade em fixar cargas suspensas nas paredes.

\section{Considerações finais}

Vários mecanismos das falhas descritas neste texto são de conhecimento e domínio de pesquisadores e profissionais da área da construção civil. No entanto, certas ocorrências ainda não são correntemente consideradas em projeto por não serem previsíveis. A imprevisibilidade está relacionada aos novos arranjos físicos, ao uso inovador de materiais já conhecidos, às novas formas de exposição e novas intervenções dos usuários. Sob essa perspectiva o caráter inovador dos sistemas estudados se reafirma.

A análise das ocorrências permitiu o conhecimento de aspectos críticos do funcionamento dos sistemas construtivos estudados, cuja significância foi validada com o posicionamento dos moradores e demais agentes entrevistados. Entre os aspectos levantados merecem destaque a ação direta e indireta da água sobre as estruturas, a ação do fogo e a interação de elementos e sistemas da edificação (instalações hidrossanitárias e estrutura; instalação elétrica de proteção (SPDA) e estrutura).

Do ponto de vista operacional, os moradores ainda enfrentam dificuldades para a aquisição de materiais apropriados para a manutenção e para a contratação de mão de obra qualificada. Esse resultado, de certa forma, já era esperado, mas há o agravamento gerado pelo desconhecimento dos impactos dos procedimentos comuns
${ }^{7} \bigcirc$ projeto arquitetônico prevê a possibilidade de ampliação futura de um dormitório no andar superior. 
de manutenção na funcionalidade e segurança do sistema (reparos nas lajes secas, lavagem de fachadas).

Dada à multiplicidade de temas vistos na pesquisa, que requerem diferenciados níveis de abordagem, é evidente a necessidade do aprofundamento desses estudos, notadamente quanto à relação custo-benefício das manutenções Porém, a releitura dos sistemas construtivos a partir dos resultados apresentados, contribui para a elaboração de certas diretrizes de uso e manutenção com destaque às limitações de uso, detalhes construtivos a serem preservados nas intervenções feitas e soluções complementares de projeto que visem a melhoria do nível de desempenho estrutural e funcional das edificações. 


\section{Referências}

ABNT - ASSOCIAÇÃO BRASILEIRA DE NORMAS TÉCNICAS. NBR 10821-2: esquadrias externas para edificações: parte 2 requisitos e classificação. Rio de Janeiro, 2011 a.

. NBR 14037: diretrizes para a elaboração de manuais de uso operação e manutenção das edificações - Requisitos para a elaboração e apresentação dos conteúdos. Rio de Janeiro, 2011 b.

. NBR 15575-1: edificações habitacionais - desempenho. Parte 1: Requisitos gerais. Rio de Janeiro, $2013 a$.

. NBR 15575-3: edificações habitacionais - desempenho. Parte 3: Requisitos para os sistemas de pisos. Rio de Janeiro, $2013 \mathrm{~b}$.

. NBR 15575-4: edificações habitacionais - desempenho. Parte 4: Requisitos para os sistemas de vedações verticais internas e externas - SWVIE. Rio de Janeiro, 2013c.

. NBR 15575-6: edificações habitacionais - desempenho. Parte 6: Requisitos para os sistemas hidrossanitários. Rio de Janeiro, $2013 d$.

NBR 5419: proteção de estruturas contra descargas atmosféricas. Rio de Janeiro, 2005.

. NBR 5674: manutenção de edificações - requisitos para o sistema de gestão

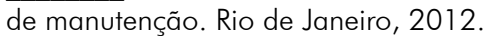

BONIN, C. L. Manutenção de edifícios: uma revisão conceitual. In: SEMINÁRIO SOBRE MANUTENCAO DE EDIFICIOS, Porto Alegre, 1988. Anais... Porto Alegre: UFRGS, 1988. p. 1-31.

BRASIL. Ministério das Cidades. Sistema Nacional de Avaliações Técnicas - SINAT. Diretriz SINAT No 003 - Sistemas construtivos estruturados em perfis leves de aço conformados a frio, com fechamentos em chapas delgadas (Sistemas leves tipo "Light Steel Framing"). Brasília, DF, 2012. Disponível em: <http://www.cidades.gov.br/pbqp-h/projetos_sinat. php>. Acesso em: 29 dez. 2013.

BRASIL. Ministério das Cidades. Sistema Nacional de Avaliações Técnicas - SINAT. Diretriz SINAT No 004 - Sistemas construtivos formados por paredes estruturais constituídas de painéis de PVC preenchidos com concreto (Sistemas de paredes com formas de PVC incorporadas). Brasília, DF, 2010. Disponível em: <http://www.cidades.gov.br/pbqp-h/ projetos_sinat.php>. Acesso em: 29 dez. 2013.

BUILDING SCIENCE CORPORATION. Informations Sheets. Info-306: interior water management. 2009. Available from: <http://www.buildingscience.com/ search? SearchableText=information + sheet $+306>$. Acesso em: 10 jan. 2014.

DARDENGO, C. F. R. I. Identificação de patologias e proposição de diretrizes de manutenção preventiva em edifícios residenciais multifamiliares da cidade de Viçosa -

MG. 2010. 162 f. Dissertação (Mestrado em Engenharia Civil) - Universidade Federal de Viçosa, Viçosa, 2010.

FAKURY, R. H. Sobre a revisão da norma brasileira de projeto de estruturas de aço e estruturas mistas de aço e concreto, a NBR 8800. REM: Revista Escola de Minas, v. 60, n. 2, p. 233-9, jun. 2007.

FERRETI, L.; OLIVEIRA, C. T. A. Análise do desempenho técnico-construtivo de habitações de interesse social. Cadernos do PROARQ (UFRJ), v. 15, p. 90-100, 2010.

GALLO, J. B.; AGNELLI., J. A. M. Aspectos do comportamento de polímeros em condições de incêndio. Polímeros, v. 8, n. 1, p. 23-38, mar. 1998. 
GAYLARDE, C. C.; SILVA, M. R.; WARSCHEID, T. Microbial impact on building materials: an overview. Materials and Structures, v. 36, n. 5, p. 342-52, June 2003

GRUBB, P. J.; GORGOLEWSKI, M. T.; LAWSON, R. M. Light steel framing in residential construction: building design using cold formed steel sections. Ascot: The Steel Construction Institute, 2001. (SCl Publication, P301).

GUIMARÃES, L. S. Gerenciamento de riscos e segurança de sistemas. São Paulo: i@ditora, 2003. IBAPE - INSTITUTO BRASILEIRO DE AVALIAÇÕES E PERÍCIAS DE ENGENHARIA DE SÃO PAULO. Norma de inspeção predial. São Paulo, 2011.

ISO - INTERNATIONAL STANDARDIZATION ORGANIZATION. ISO 15686-7: building and constructed assets - Service life planning - Part 7: Performance evaluation for feedback of service life data from practice. Geneva, 2006.

LSTIBUREK, J. BSD-144: increasing the durability of building constructions. Westford: Building Science Corporation, 2006. Disponível em: < http://www.buildingscience.com/ documents/digests/bsd-144-increasing-the-durability-of-building-constructions $>$. Acesso em: 10 jan. 2014.

McDOWELL, B. D.; LEMER, A. C. (Eds.). Uses of risk analysis achieve balance safety in building design and operations: studies in management of building technology. Washington, DC: National Academy Press, 1991.

MELLO, A. V. A. Análise do efeito da interação aço-concreto sobre a resposta dinâmica de pisos mistos. 2009. 210 f. Tese (Doutorado em Engenharia Civil) - Pontifícia Universidade Católica do Rio de Janeiro, Rio de Janeiro, 2010.

MORTON, L. H. G.; SURMAN, S. B. Biofilms in biodeterioration: a review. International Biodeterioration \& Biodegradation, v. 34, n. 3-4, p. 203-21, 1994.

OLUBODUN, F. A multivariate approach to the prediction of maintenance needs in public housing: the tenant dimension. Structural Survey, v. 19, n. 2, p. 133-41, 2001.

SANCHES, I. D. A.; FABRICIO, M. M. A importância do projeto na manutenção de HIS. In: SIMPÓSIO BRASILEIRO DE GESTÃO DA ECONOMIA DA CONSTRUÇÃO SIBRAGEC, 6., 2009, João Pessoa. Anais... Porto Alegre: ANTAC, 2009. p. 1-10.

SÃO PAULO (Estado). Código sanitário do Estado de São Paulo: Lei n ${ }^{\circ} 10.083$, de 23 de setembro de 1998 - Decreto n 12.342, de 27 de setembro de 1978 (Regulamento da promoção, preservação e recuperação da saúde no campo de competência da Secretaria do Estado da Saúde): normas técnicas, legislação estadual e federal básica e complementar. 6. ed. São Paulo: Edipro, 2006.

Decreto $n^{\circ} 56.819$, de 10 de março de 2011 . Instituiu o regulamento de segurança contra incêndio das edificações e áreas de risco para no Estado de São Paulo e dá providências correlatas. Diário Oficial do Estado, v. 121, n. 45, 11 mar. 2011 a.

. Polícia Militar do Estado de São Paulo. Corpo de Bombeiros. Instrução Técnica

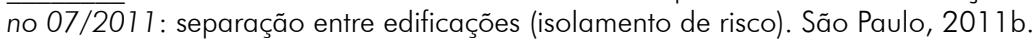

SILVA, S. R. C.; FONSECA, M.; BRITO, J. Metodologia FMEA e sua aplicação à construção de edifícios. In: ENCONTRO NACIONAL SOBRE QUALIDADE E INOVAÇÃO NA CONSTRUÇÃO - QIC2006, 2006, Lisboa. Anais... Lisboa: LNEC, 2006. p. 1-12. Disponível em: <http://www.fep.up.pt/disciplinas/pgi914/ref_topico3/fmea_ss_mf_ib_ qic2006.pdf>. Acesso em: 20 dez. 2012.

SILVA, N.; RANASINGHE, M. Maintainability risks of condominiums of Sri Lanka. Journal of Financial Management of Property and Construction, v. 15, n. 1, p. 41-60, 2010.

SMITH, A. L.; HICKS, S. J.; DEVINE, P. J. Design of floors for vibration: a new approach. Ascot: The Steel Construction Institute, 2009. (SCI Publication, P354). 
SUSILAWATI, C. Can risk management boost the supply of affordable housing development and management? International Journal of Housing Markets and Analysis. v. 2, n. 4, p. 392-402, 2009.

VELLOSO NETO, Z. F. Gerenciamento da manutenção de edifícios. 2006. 56 f.

Dissertação (Mestrado Profissional em Tecnologia em Construções de Edifícios) - Instituto de Pesquisas Tecnológicas do Estado de São Paulo, São Paulo, 2006.

YIN, R. K. Estudo de caso: planejamento e métodos. 3. ed. São Paulo: Bookman, 2005.

\section{Bibliografia}

ABNT - ASSOCIAÇÃO BRASILEIRA DE NORMAS TÉCNICAS. NBR 14432: exigências de resistência ao fogo de elementos construtivos de edificações - Procedimentos. Rio de Janeiro, 2001. 

Custos de manutenção efetivos e potenciais: um estudo em habitações de interesse social com sistema construtivo inovador

Maisa Beatriz M. Fausto da Silva Dimas de Assis Albuquerque Teixeira Alexsandra Rocha Meira Nelma Mirian Chagas de Araújo Gibson Rocha Meira

\section{Introdução}

O envelhecimento das construções no Brasil tem se tornado real e crescente, a exemplo do que já acontece há muito tempo em países desenvolvidos. Esse fato traz, intrinsecamente, a discussão sobre a importância e necessidade pujante de manutenção do patrimônio já construído.

De acordo com Freitas (2009), as edificações são construídas para durarem muitos anos, porém, no momento em que são entregues aos usuários, elas começam a sofrer vários tipos de degradação, tornando a manutenção necessária. Complementando, Seeley (1987) coloca que a manutenção inicia-se no dia em que os construtores saem da obra.

No entanto, tem se observado que, ao longo dos anos, em maior ou menor grau, as construções, ou partes delas, passam a apresentar desempenho insatisfatório, decorrente da falta ou deficiência da manutenção.

É certo que, atrelados a essa realidade de carência de manutenção, estão aspectos como a falta de planejamento, o improviso, a ausência de rigor técnico e a informalidade.

Detendo-se especificamente à questão da informalidade, na qual os próprios moradores, sozinhos ou com o auxílio de amigos e parentes, realizam a manutenção, Meijer (1993) a distingue da atividade de manutenção formal, realizada por profissionais contratados. 
Esse campo de atividade informal, conhecido também como do it yourself, cresce cada vez mais, fundamentando-se normalmente na ideia de reduzir custos sem deixar de realizar a manutenção das moradias. No cenário internacional, onde muitas vezes o custo da mão de obra para a realização dos serviços é elevado, há uma forte tendência a sua adoção.

Embora a informalidade esteja presente no campo da manutenção construtiva, é necessário deixar claro que essa forma de execução dos serviços normalmente distancia-se de aspectos técnicos, como análise do desempenho, durabilidade de materiais e sistemas construtivos, resultando muitas vezes em acidentes e prejuízos financeiros para os proprietários das construções.

No âmbito das habitações de interesse social (HIS), a manutenção é um tema ainda mais distante dessa realidade, uma vez que o poder aquisitivo dos moradores é limitado. Como consequência, quando se recorre à manutenção, essencialmente associa-se à informalidade.

Quando as HIS são construídas com algum sistema construtivo não convencional, a manutenção requer mais cautela ainda, uma vez que demanda conhecimento técnico mais aprofundado, ferramentas e mão de obra específica, e esse conhecimento prévio nem sempre é acessível aos usuários desse tipo de edificação.

Por outro lado, se as habitações passam por longos períodos de ausência de manutenção, os custos dessa natureza podem apresentar diferentes perfis ao longo da vida útil, em função da irregularidade com esse tipo de despesa (MEIRA, 2002). Na prática, quando as reservas dos proprietários são limitadas, a parcela destinada à manutenção da construção é frequentemente a que sofre redução orçamentária (ASHWORTH, 1996).

Com base nas considerações apresentadas, este capítulo foi desenvolvido buscando contextualizar os custos de manutenção de um conjunto de dez habitações de interesse social que utilizam sistema construtivo inovador. $O$ estudo dos custos está fundamentado em dois tipos de manutenções: aquela efetivamente realizada nas habitações, resultando no que aqui se denomina de custo efetivo, e aquela que foi identificada no momento da pesquisa, como necessária, mas não foi concretizada até o momento, resultando no custo potencial de manutenção.

Partindo-se desse entendimento dos custos de manutenção e das potenciais necessidades de realização desse tipo de serviço, cria-se um caminho aberto para a compreensão dos custos futuros em edificações com esse perfil, ou seja, habitações de interesse social construídas com sistema inovador.

\section{Manutenção das construções}

O termo manutenção teve sua origem histórica junto aos militares, com o significado de manter, nas unidades de combate, o efetivo e os equipamentos bélicos em condições de combate. Já na década de 1950, tanto nos Estados Unidos como na França, manutenção passou a ser um termo utilizado na indústria, no sentido de conservação (MONCHY, 1989 apud ANTUNES, 2004). 


\section{Custos de manutenção efetivos e potenciais: um estudo em habitações de interesse social com sistema construtivo inovador}

Mais recentemente, esse termo passou a fazer alusão a aspectos como desempenho, vida útil e necessidades dos usuários. Nesse sentido, no âmbito da Construção Civil, Gomide (2006) definiu manutenção como o conjunto de atividades e recursos que garantem o melhor desempenho da edificação, para atender às necessidades dos usuários, com confiabilidade e disponibilidade, ao menor custo possível. De forma complementar, a NBR 15575 (ABNT, 2013) relaciona manutenção a um conjunto de atividades a serem realizadas ao longo da vida total da edificação, para conservar ou recuperar a sua capacidade funcional e de seus sistemas constituintes de atender às necessidades e segurança dos seus usuários.

El-Haram e Horner (2002) ressaltam a existência de várias definições para a manutenção das construções. Entretanto, de forma objetiva, os autores associam manutenção à capacidade de manter a construção em condições apropriadas para uso. Em síntese, os objetivos da manutenção são (ALNER; FELLOWS, 1990): (a) garantir que as construções e suas partes estejam em condições seguras; (b) garantir que as construções estejam adequadas para uso; (c) garantir que as condições das construções atendam aos requisitos normativos; (d) manter o valor das construções; (e) manter ou melhorar a qualidade das construções.

\section{Custos de manutenção}

A partir de uma visão geral do processo construtivo, os custos totais de uma edificação não devem se limitar unicamente às despesas referentes à construção em si, mas abranger uma série de outras, identificadas ao longo de sua vida útil. Nesse sentido, têm-se as despesas relacionadas à concepção, produção e utilização. Nas duas primeiras categorias estão incluídas todas as despesas necessárias à criação do bem imóvel e, na última, aquelas que devem ser arcadas para que a habitação mantenha o desempenho satisfatório das suas funções, incluindo os custos de manutenção, administração e operação de equipamentos.

Os custos globais ou custos ao longo da vida útil (life cycle costs) apresentados por Stone (1980) englobam: (a) custos de construção; (b) custos de operação; (c) custos de manutenção; (d) custos de modernização ou adaptação; e (e) custos de demolição ou venda.

Examinando de forma mais específica os custos presentes na fase de uso das edificações, vê-se o quanto são relevantes as despesas com operação e manutenção, que juntas compõem os custos correntes (ALL-HAJJ; HORNER, 1997). Os custos operacionais são os decorrentes de limpeza, iluminação, operação de equipamentos e instalações, consumo de água, impostos, taxas de seguro e, para o caso de habitações coletivas sujeitas a regime condominial, acrescentam-se as despesas administrativas (ROSSO, 1990). Os custos de manutenção são aqueles necessários para manter a edificação em bom estado e em condições de uso (RICS, 1987 apud ALL-HAJJ; HORNER, 1997). 
Consoante El-Haram e Horner (2002), os custos de manutenção incluem todas as despesas necessárias para se manter a edificação acima dos padrões aceitáveis. Isso significa que os custos de manutenção compreendem reparos do dia-a-dia, atividades preventivas e melhorias. Os autores classificam esses custos em diretos e indiretos. Os custos diretos abrangem, por exemplo, materiais, mão de obra e ferramentas. Já os custos indiretos contemplam os custos gerenciais e administrativos, além dos custos gerais necessários à realização das tarefas com êxito.

Tanto os custos operacionais quanto os referentes à manutenção são bastante variados e dependem de uma série de fatores. Em relação aos custos de manutenção, El-Haram e Horner (2002) agrupam tais fatores em cinco classes distintas: (a) características das construções; (b) fatores relacionados aos próprios moradores; (c) características da manutenção; (d) aspectos relacionados à política pública; (e) outros. Para esse trabalho, realizado na Escócia, restrições orçamentárias e uso indevido da edificação foram fatores significativos.

Alguns desses fatores que interferem nos custos de manutenção também foram abordados por Meira (2002), que se reporta a autores diversos para justificar a influência, por exemplo, da localização (ROSSO, 1990; BROMILOW, 1985 apud CREMONINI, 1989; HAMMARLUND; JOSEPHSON, 1991 apud KOSKELA, 2000; INGUALDSEN, 1994 apud KOSKELA, 2000) e da idade da edificação (MARTEINSSON; JÓNSSON, 1999; ABRANTES; CALEJO, 1999; ANDERSEN, 1995).

Embora os custos de manutenção sofram diversos tipos de influências, em uma análise macro de toda a vida útil, Booty (2006, apud OLANREWAJU et al., 2011 ) afirma que $75 \%$ das despesas totais de uma edificação ao longo da vida útil são atribuídas à manutenção.

Diante da constatação da importância da manutenção, devido aos altos custos diretos e indiretos envolvidos e também por causa do impacto operacional que a manutenção pode exercer no desempenho, a concepção da manutenção deve ser feita de forma estruturada para cada caso (WAEYENBERGH; PINTELON, 2002). Nessa linha de pensamento, a NBR 5674 (ABNT, 2012) adverte que a manutenção não deve ser realizada improvisadamente e casualmente, mas fundamentada em procedimentos organizados e, ainda, com o controle dos custos.

A depender de aspectos diversos, o empirismo ainda prevalece no campo da manutenção. Isso dificulta, por exemplo, a compreensão do comportamento dos custos de manutenção em habitações de interesse social. Assim, pesquisas que abordam essa temática de custos de manutenção nesse tipo de habitação carecem de um maior aprofundamento.

Esse é, portanto, o caminho seguido no estudo abordado nesse capítulo, tornando-se ainda mais específico à medida que contempla habitações construídas com algum sistema construtivo não convencional. 


\section{Custos de manutenção efetivos e potenciais: um estudo em habitações}

de interesse social com sistema construtivo inovador

\section{Procedimentos metodológicos}

A pesquisa aqui apresentada foi desenvolvida a partir das etapas descritas a seguir:

\section{Pesquisa bibliográfica}

A etapa inicial consistiu no embasamento teórico da pesquisa, fundamentado em bibliografia nacional e internacional relacionada à temática de manutenção de edificações e de custos resultantes dessa atividade.

\section{Seleção das construções}

Com base em pesquisa realizada junto à Companhia de Habitação do Estado da Paraíba (CEHAP), foram investigadas possíveis habitações de interesse social (HIS) construídas com algum sistema inovador. Com esse perfil, identificou-se o Conjunto Habitacional Mariz I, localizado na cidade de João Pessoa. As moradias que compõem esse conjunto habitacional datam do final da década de 1990 e foram construídas utilizando paredes em placas de concreto, moldadas in loco.

\section{Visita preliminar}

Com o objetivo de conhecer a realidade das habitações, em termos de estrutura física, e ter uma visão geral da dinâmica de alterações construtivas realizadas ao longo dos anos, procedeu-se com uma visita inicial no local de estudo. Em função dessa visita, foram descartadas diversas habitações, por não manterem, na íntegra, o sistema construtivo empregado durante a execução da obra.

\section{Elaboração de formulário de entrevista}

Com o objetivo de auxiliar na condução da pesquisa de campo, elaborou-se um formulário de entrevista, no qual se buscou contemplar todos os possíveis elementos construtivos, passíveis de manutenção. Consequentemente, os possíveis serviços de manutenção foram abordados, visando, dessa forma, investigar os custos gerados pelos serviços realizados, ao longo dos anos de uso das habitações.

\section{Pesquisa de campo}

Dentre as moradias que mantiveram o mesmo sistema construtivo, foram selecionadas, de forma aleatória, dez unidades para a realização da pesquisa. Uma vez que nem todos os custos foram obtidos diretamente através das entrevistas com os moradores, foram realizadas medições in loco dos serviços realizados ao longo dos anos, bem como dos potenciais serviços de manutenção, ou seja, aqueles que não foram realizados, mas que, durante a pesquisa, foram considerados como necessários. 


\section{Montagem de planilhas orçamentárias}

A partir dos dados obtidos em campo foram montadas planilhas orçamentárias relativas aos serviços de manutenção realizados ao longo dos anos. Para a elaboração das planilhas tomou-se como referência os valores dos insumos atualizados e dos coeficientes de consumo de mão de obra e de materiais que compõem os custos unitários dos serviços da base do SINAPI (Sistema Nacional de Pesquisa de Custos e Índices da Construção Civil). O valor da mão de obra foi baseado em dados do SINTRICOM-JP (Sindicato dos Trabalhadores nas Indústrias da Construção e do Mobiliário de João Pessoa) e foram excluídos das composições de preços os encargos sociais, visando uma aproximação da realidade das técnicas de manutenção empregadas pelos moradores do estudo de caso. Os custos de insumos e mão de obra foram retroagidos, aplicando-se o INCC (Índice Nacional de Custo da Construção), para então se poder traçar a evolução dos custos ao longo do período estudado. Ressalta-se, no entanto, que os custos obtidos estão bem acima das despesas efetivamente realizadas com serviços de manutenção e não traduzem os valores reais, em moeda corrente, dos serviços executados pelos moradores. Essa diferença dos valores ocorre em função de fatores como técnicas empregadas para fazer os serviços (reparos em peças de concreto armado, utilizando argamassa de cimento e areia, sem o prévio tratamento da armadura exposta e em processo de corrosão), mão de obra utilizada (contratada, doada ou própria) e materiais utilizados (comprados ou doados). A opção pelo emprego dos coeficientes do SINAPI deve-se ao fato de que estes imprimem um padrão essencial aos custos dos serviços quantificados. A partir das composições de preços unitários dos serviços realizados foram elaboradas as planilhas orçamentárias das edificações pesquisadas. Concomitantemente a essas planilhas orçamentárias, também foram montadas aquelas referentes aos serviços não realizados, que se traduziam em potenciais necessidades de manutenção. Esses serviços foram quantificados dentro do mesmo modelo de planilha, baseando-se em dados do SINAPI. O padrão das composições permitiu o levantamento simultâneo dos serviços que foram executados e dos potenciais serviços de manutenção, em vários pontos das edificações pesquisadas.

\section{Análise dos dados}

Os dados obtidos no estudo foram analisados e interpretados, utilizando-se, para tanto, de recursos do software Excel. Para se proceder com a uniformização dos dados, todos os custos de manutenção apresentados estão expressos em $R \$ / \mathrm{m}^{2}$.

\section{Caracterização do objeto em estudo}

Entre os anos de 1998 e 2002, o órgão paraibano responsável pela construção de habitações de interesse social no estado, a CEHAP, construiu mais de sete mil moradias com sistema construtivo inovador e, dessas, 480 estão localizadas na cidade de João Pessoa. 


\section{Custos de manutenção efetivos e potenciais: um estudo em habitações}

de interesse social com sistema construtivo inovador

As moradias estudadas possuem $33,43 \mathrm{~m} 2$ de área construída, contendo 27 pilares em concreto armado, 124 placas de vedação, executadas em concreto pré-moldado, cujas paredes formadas receberam pintura à cal. As telhas da coberta são do tipo canal, as instalações hidrossanitárias e elétricas são aparentes e as esquadrias são de madeira, pintadas com esmalte sintético.

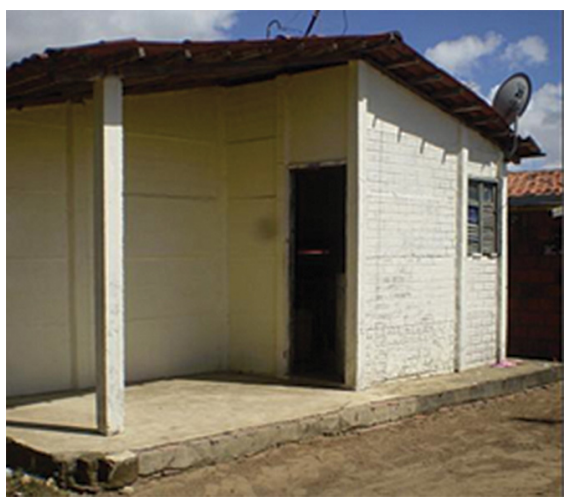

Fonte: Os autores.

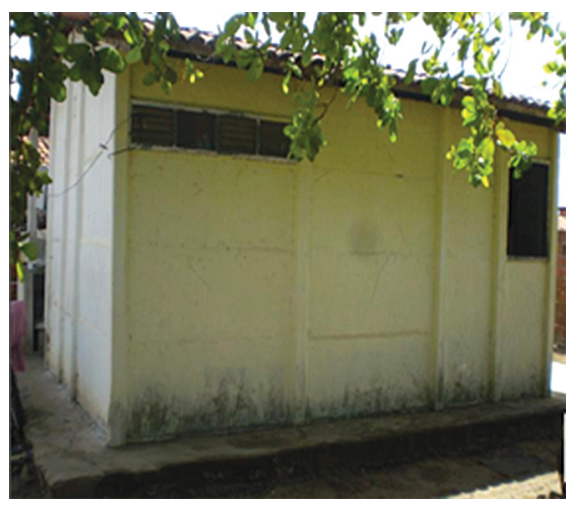

Fonte: Os autores.

Figura 1. Fachada frontal (casa 4)

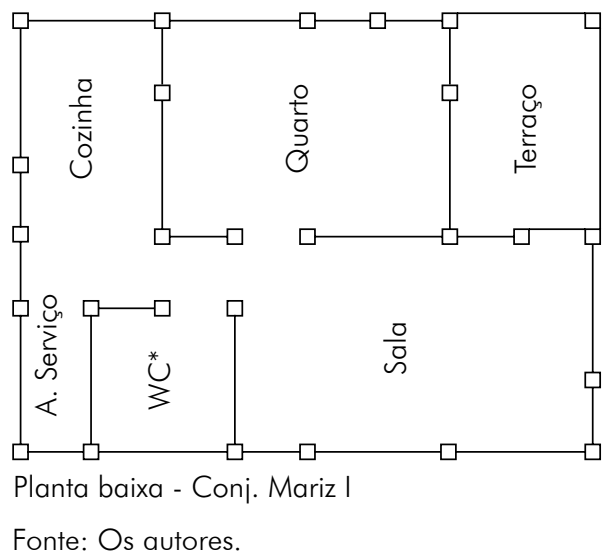

Figura 3. Modelo das moradias

\section{Resultados e análises}

A exposição dos resultados e das análises realizadas está apresentada em quatro itens: tratamento dos dados, custos efetivos, custos potenciais e custos efetivos $\mathrm{x}$ custos potenciais. 


\section{Tratamento dos dados}

Os quantitativos levantados só puderam ser convertidos em dados passíveis de análises mais detalhadas a partir da inserção destes na planilha de custos. Foram empregados os mesmos coeficientes de produtividade, no caso da mão de obra, e os mesmos consumos de materiais oriundos do SINAPI. A Tabela 1 apresenta um exemplo de composição elaborada na pesquisa.

Tabela 1. Exemplo de composição de preço unitário com insumos do SINAPI

\begin{tabular}{lccccc}
\hline \multicolumn{3}{c}{ Serviço: Piso cimentado áspero - 1:4 } & (sem junta de dilatação) & Unidade: $\mathrm{m} 2$ \\
\hline Cód. SINAPI & Insumos & Unidade & Consumo & Valor unitário (R\$) & Valor total (R\$) \\
\hline 73449 & $\begin{array}{c}\text { Argamassa de } \\
\text { cimento e areia - 1:4 } \\
\text { (preparo manual) }\end{array}$ & $\mathrm{kg}$ & 0,015 & 256,72 & 3,85 \\
4750 & Pedreiro & $\mathrm{h}$ & 0,850 & 4,59 & 3,90 \\
6111 & Servente & $\mathrm{h}$ & 0,850 & 3,41 & 2,90 \\
\hline & & Custo total de materiais - R\$ & 3,85 \\
& & Custo total de mão de obra - R\$ & 6,80 \\
& & Custo total - R\$ & 10,65 \\
\cline { 2 - 4 } & & &
\end{tabular}

Fonte: Os autores.

Visando adequar as composições às práticas de execução dos serviços realizados, em sua maioria, pelos próprios moradores, foram excluídos os coeficientes referentes aos encargos sociais e trabalhistas. Em função disso, houve uma redução dos preços dos serviços efetuados na manutenção das moradias, aproximando seus valores da realidade cotidiana daqueles habitantes.

Para que fossem realizadas as correções dos custos, ano a ano, foi efetuada a retroação dos valores dos insumos e senviços a partir do índice de correção do INCC (Ic). Os índices de correção de INCC foram calculados para cada ano, tomando como INCC anual a média anual desse índice (INCCanual = $\sum \mathrm{INCC}(\mathrm{Jan}$ a Dez)/12). Todas as correções tomaram como referencial abril/2013, ou seja, os valores de insumos e senviços foram retroagidos de abril/2013 para o ano em que foram efetuados os serviços realizados nas moradias estudadas. A Equação a seguir apresenta a fórmula utilizada para o cálculo dos Índices de Correção (Ic):

$$
\text { Equação 1: } \quad \frac{\text { IC }=\text { INCCanual(1) }}{\text { INCCabril/2013 }}
$$

A Tabela 2 apresenta os índices de correção encontrados, os quais foram utilizados nos cálculos dos custos. 


\section{Custos de manutenção efetivos e potenciais: um estudo em habitações}

de interesse social com sistema construtivo inovador

Tabela 2. Índices de correção (lc)

\begin{tabular}{cc}
\hline Ano & lc \\
\hline 1998 & 3,31 \\
1999 & 3,14 \\
2000 & 2,87 \\
2001 & 2,67 \\
2002 & 2,43 \\
2003 & 2,09 \\
2004 & 1,87 \\
2005 & 1,71 \\
\hline
\end{tabular}

\begin{tabular}{cc}
\hline Ano & lc \\
\hline 2006 & 1,63 \\
2007 & 1,54 \\
2008 & 1,41 \\
2009 & 1,32 \\
2010 & 1,24 \\
2011 & 1,16 \\
2012 & 1,06 \\
2013 & 1,03 \\
\hline
\end{tabular}

Fonte: Os autores.

\section{Custos Efetivos}

Em relação à manutenção corretiva ocorrida em habitações de interesse social, onde a informalidade e o improviso predominam, percebe-se que, se recebessem a devida atenção, o diagnóstico preciso do problema teria fundamental importância para o saneamento do defeito. Na maioria das vezes, a causa é indicada pelo morador ou profissional informal e nem sempre é a correta. A partir da identificação, o morador vislumbra a execução dos serviços de reparo com técnicas, ferramentas e materiais geralmente compatíveis com o seu poder aquisitivo e/ou a habilidade do executor. Fato corriqueiro em conjunturas que envolvem habitações de interesse social, é provável que a manutenção ocorra motivada pelas urgentes necessidades dos moradores, incomodados com o problema. $\bigcirc$ que se vê, de uma forma geral, são intervenções realizadas sem planejamento e previsão de custos, resultando, muitas vezes, em acréscimo significativo dos mesmos.

Em relação às manutenções realizadas ao longo dos anos de uso, nas dez casas pesquisadas, os custos totais por metro quadrado de área construída estão representados na Figura 4.

Pode-se observar na Figura 4 a representação do montante de todos os custos de manutenção efetivos referente a cada casa no período estudado (1998 a 2013), tendo como destaques as casas 1, 2, 7 e 8, as quais apresentam os maiores valores de custos (a casa 7 alcança o valor máximo, $R \$ 442,70 / m 2$ ). É possível também identificar os menores custos com manutenção, os quais são oriundos das casas 9 e 6 ( $R \$ 79,98 / \mathrm{m} 2$ e $R \$ 93,69 / \mathrm{m} 2$, respectivamente).

Numa análise estatística, a medida de posição está representada pela média amostral, calculada em $\mathrm{R} \$ 223,33 / \mathrm{m} 2$. Já em relação à dispersão dos valores, observa-se que a amplitude de $\mathrm{R} \$ 362,72 / \mathrm{m} 2$ denota uma diferença considerável entre os valores extremos.

A Figura 5 apresenta a contribuição de cada item de serviço de manutenção na soma dos custos efetivos totais das dez casas analisadas. 


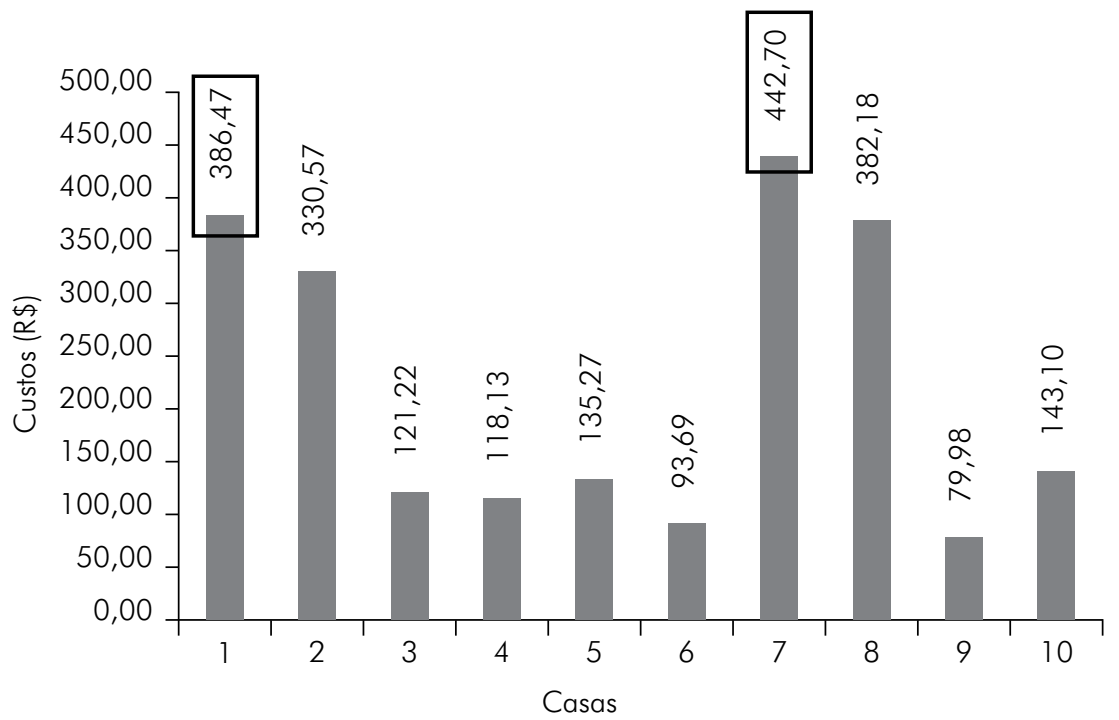

Fonte: Os autores.

Figura 4. Custos totais efetivos, por $\mathrm{m}^{2}$

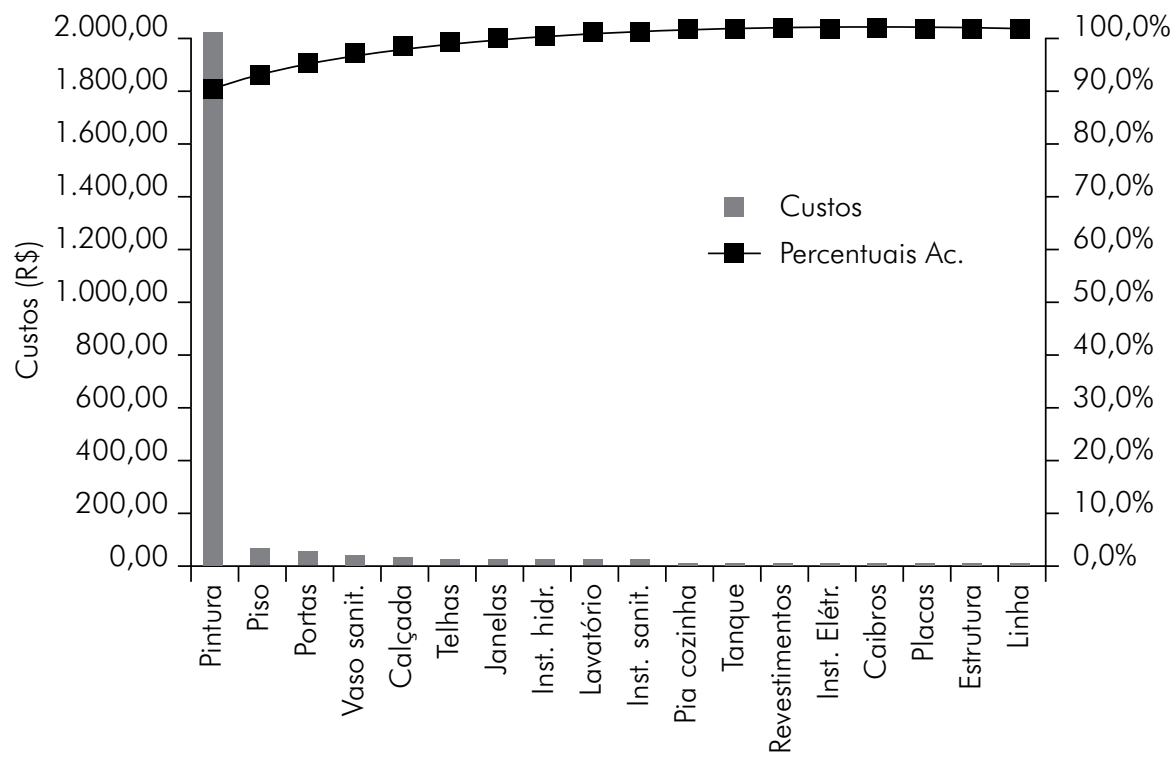

Itens de manutenção

Fonte: Os autores.

Figura 5. Custos totais efetivos por itens de manutenção, por $\mathrm{m}^{2}$ (Gráfico de Pareto) 


\section{Custos de manutenção efetivos e potenciais: um estudo em habitações de interesse social com sistema construtivo inovador}

Através do traçado do Gráfico de Pareto é possível observar que $22 \%$ dos itens de manutenção contribuem com $95 \%$ dos custos. Logo, é pertinente fazer referência aos itens pintura, piso, portas e vaso sanitário, já que os mesmos são os responsáveis por este percentual e totalizam $R \$ 2.121,30 / \mathrm{m}^{2}$.

Ainda em termos de custos efetivos, na Figura 6 é possível observar a evolução desses custos ao longo dos 15 anos analisados (1998 a 2012), além do ano de 2013, cujos montantes não foram contabilizados na íntegra.

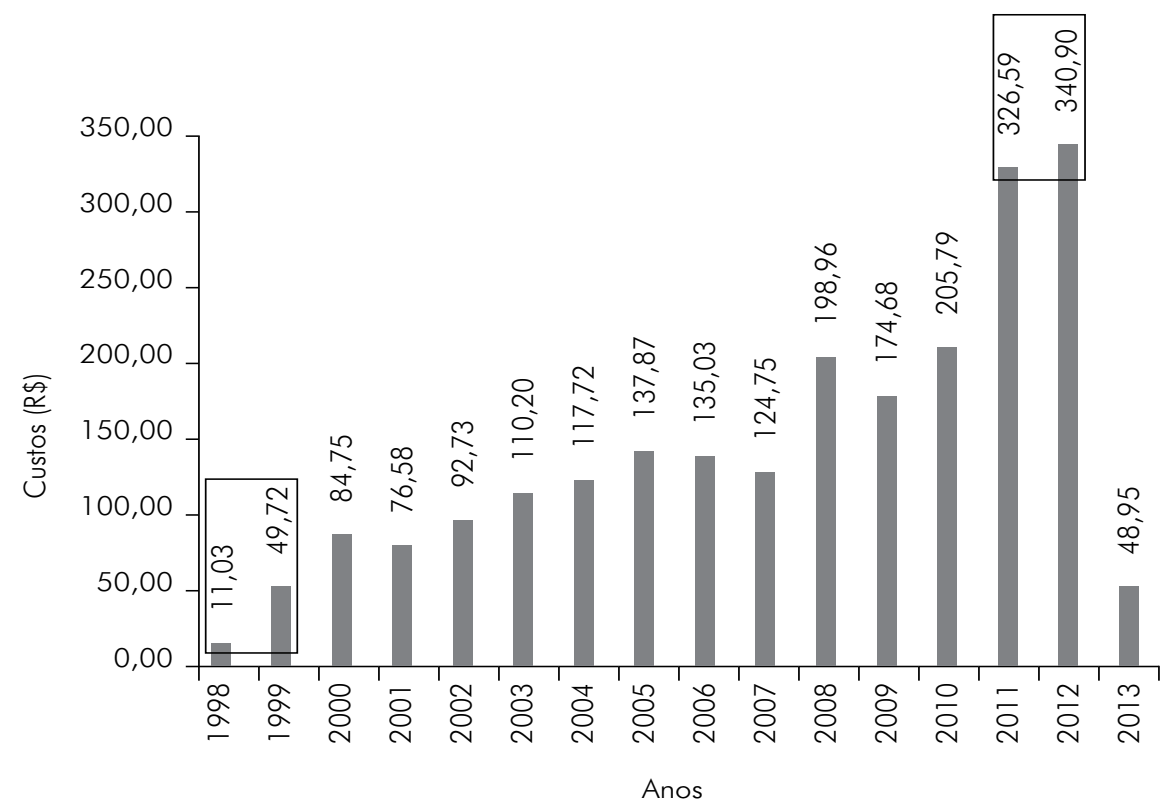

Fonte: Os autores.

Figura 6. Evolução dos custos efetivos (1998 a 2013), por m²

Na Figura 6, é perceptível que os montantes, de uma maneira geral, aumentam com o passar dos anos, tendo os seus maiores valores em 2011 e 2012 , com $R \$ 326,59 / \mathrm{m}^{2}$ e $R \$ 340,90 / \mathrm{m}^{2}$, respectivamente, e os menores

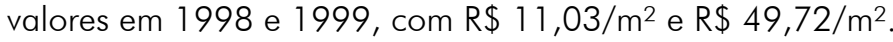

Com o objetivo de mensurar o volume anual de despesas de cada casa, obteve-se a média anual dos custos realizados, conforme se vê na Figura 7. Nesse ponto, é importante lembrar que os custos efetivos de 2013 estão exclusos desse somatório, pois os mesmos são relativos a um período de cinco meses desse ano. Tal exclusão se deu em função de um provável aumento, ao longo dos sete meses restantes de 2013, da quantidade de serviços de manutenção necessária de ser realizada e, desta forma, tornando as informações do período investigado insuficientes para participar do conjunto dos dados relativos a valores anuais absolutos. 


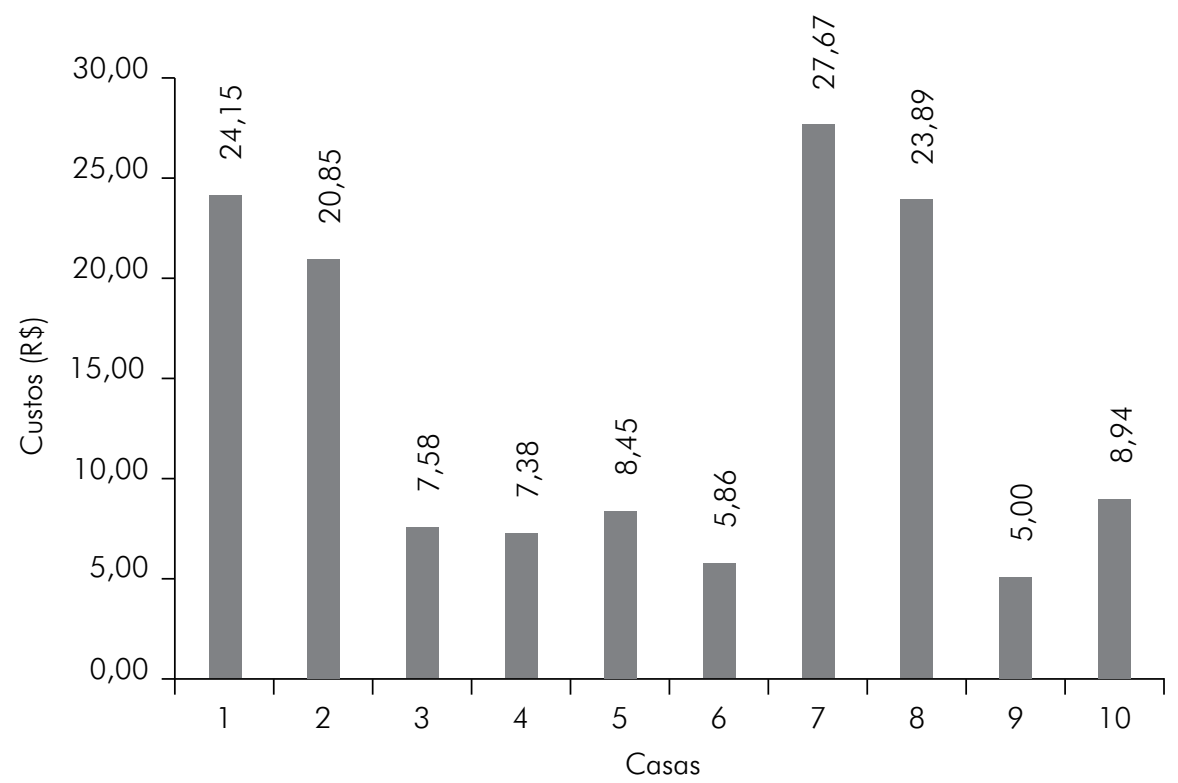

Fonte: Os autores.

Figura 7. Média anual dos custos efetivos, por $\mathrm{m}^{2}$

\section{Custos Potenciais}

A investigação in loco também trouxe à tona outras revelações para a pesquisa. Além de confirmar teses encontradas na literatura que apontam para $\circ$ aumento dos custos de manutenção ao longo do tempo, bem como para diferentes perfis de custos, provenientes ainda da fase de obra ou em função da irregularidade com que esse tipo de intervenção ocorre, os dados levantados evidenciam a procrastinação da manutenção, que somada a outros tipos de problemas, comprometem o desempenho da edificação.

Durante o estudo de campo foram analisados os serviços de manutenção realizados durante os anos de uso nas dez unidades escolhidas que mantinham as suas características originais, ou seja, conforme construídas. Nesse período da pesquisa, observou-se a deterioração de várias partes de cada casa, evidenciando, dessa forma, a necessidade de analisar também as manutenções potenciais e seus custos, ou seja, aquelas não realizadas até então, mas consideradas necessárias. Isso é percebido ao se detectar que um serviço precisa acontecer com uma periodicidade maior do que a realizada ou quando ele é executado, porém de forma insatisfatória.

Na Figura 8 é possível observar os custos potenciais para as dez casas estudadas, com suas estimativas calculadas para o ano de 2013. 


\section{Custos de manutenção efetivos e potenciais: um estudo em habitações de interesse social com sistema construtivo inovador}

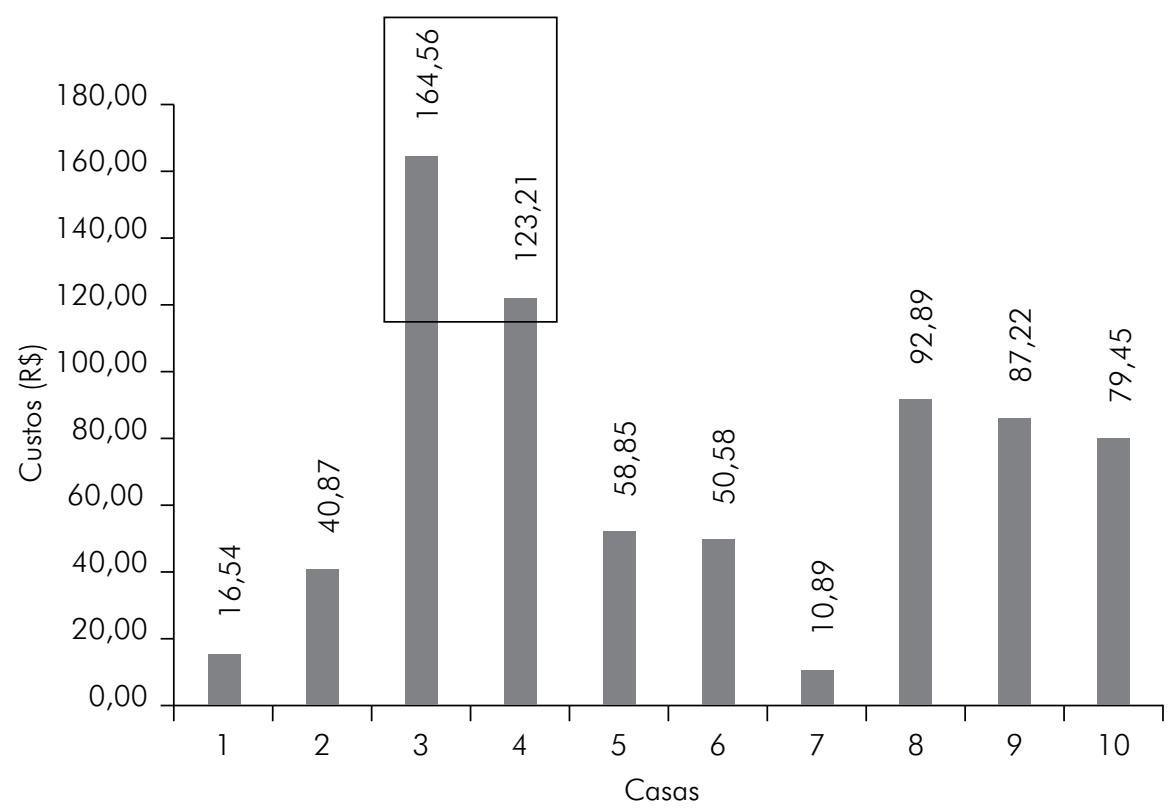

Fonte: Os autores.

Figura 8. Custos totais potenciais, por $\mathrm{m}^{2}$

Percebe-se, através da Figura 8, que as casas 3 e 4, segundo as despesas potenciais levantadas, são as que mais necessitam de intervenções de manutenção, sendo as respectivas estimativas de custos, em valores atuais (abril/2013), representadas por $R \$ 164,56 / \mathrm{m}^{2}$ e $R \$ 123,21 / \mathrm{m}^{2}$, respectivamente. Comparativamente, no gráfico dos custos totais efetivos (Figura 4), as mesmas casas estão entre as que apresentam os menores montantes com este tipo de despesa, ratificando os seus valores elevados nesta análise de custos potenciais. Analogamente, as casas 1, 2 e 7 ilustram exatamente 0 contrário, pois, nas discussões dos custos efetivos, as mesmas apresentaram os maiores valores em termos de custos (Figura 4), e aqui, analisando os potenciais, são as menores, com os valores $R \$ 16,54 / \mathrm{m}^{2}, \mathrm{R} \$ 10,89 / \mathrm{m}^{2}$ e $R \$ 40,87 / \mathrm{m}^{2}$, respectivamente.

O que se exibe na Figura 9 é a contribuição de cada item de serviço de manutenção na soma dos custos potenciais totais das dez casas do estudo de caso analisado.

Percebe-se que $27 \%$ dos itens de manutenção, representados pelos itens linhas, pintura, portas, calçada e piso, contribuem para $81 \%$ dos custos potenciais, que totalizam $R \$ 470,45 / \mathrm{m}^{2}$. 


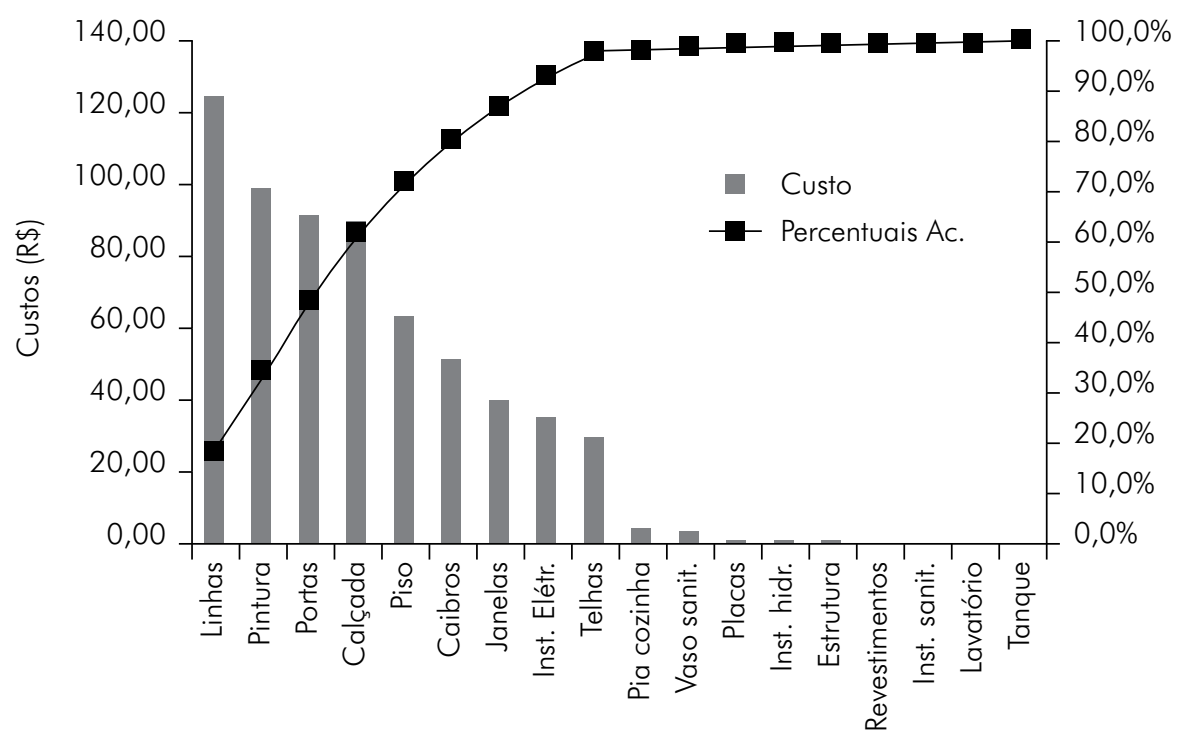

Itens de manutenção

Fonte: Os autores.

Figura 9. Custos totais potenciais por itens de manutenção, por $\mathrm{m}^{2}$ (Gráfico de Pareto)

\section{Custos Efetivos x Custos Potenciais}

Neste item, apresenta-se uma análise comparativa entre os custos das manutenções efetivamente realizadas e aqueles referentes às manutenções ainda não postas em prática, ou seja, as potenciais.

Ressalta-se que uma abordagem comparativa entre os custos efetivos e os potenciais não seria legítima, iá que o grupo dos custos efetivos refere-se a informações de quinze anos passados, ao tempo que os custos potenciais reportam-se ao presente, com base em abril/2013.

Assim, efetuando-se as ponderações entre os custos efetivos e potenciais, percebe-se que as moradias possuem comportamentos distintos com relação aos custos, como mostra a Figura 10.

Na Figura 10, observa-se que, durante os dezesseis anos de utilização, dentre as dez moradias pesquisadas, quatro apresentaram custo total de manutenção superior a $R \$ 300,00 / \mathrm{m}^{2}$, enquanto que três moradias apresentaram custo inferior a $R \$ 200,00 / \mathrm{m}^{2}$ e as outras três apresentaram custos entre $\mathrm{R} \$ 200,00 / \mathrm{m}^{2}$ e $\mathrm{R} \$ 300,00 / \mathrm{m}^{2}$.

A Figura 11 demonstra que os comportamentos dos custos efetivos e dos custos potenciais geram curvas distintas, onde um grande percentual dos custos efetivos se concentra num menor número de itens de serviços e o seu montante 


\section{Custos de manutenção efetivos e potenciais: um estudo em habitações}

de interesse social com sistema construtivo inovador

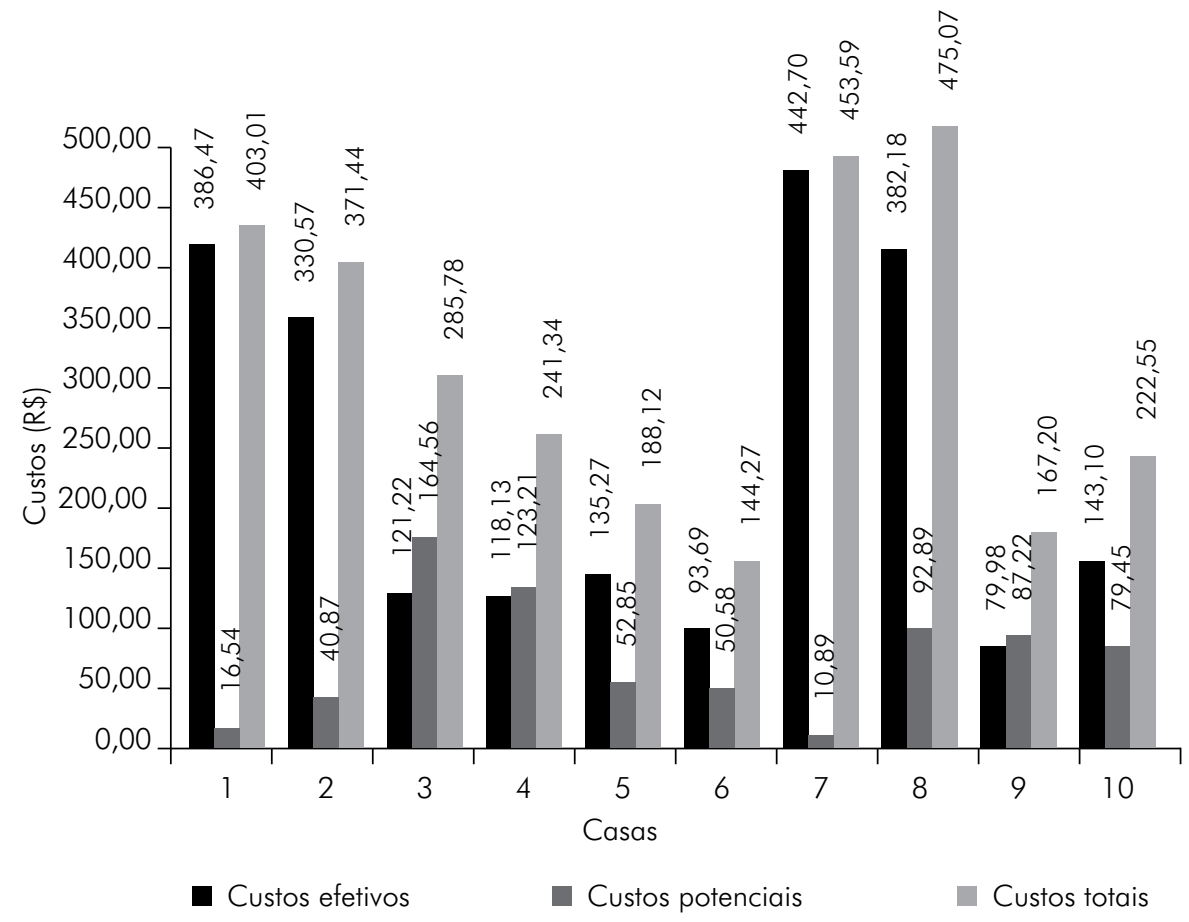

Fonte: Os autores.

Figura 10. Custos efetivos, potenciais e totais, por $\mathrm{m}^{2}$

excede consideravelmente o somatório dos custos potenciais. Estes, por sua vez, apresentam maior quantidade de itens de serviço de manutenção.

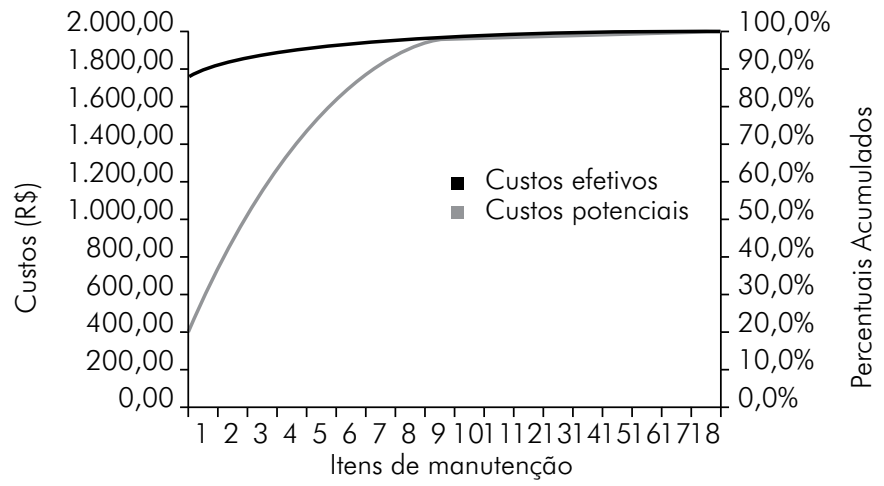

Fonte: Os autores.

Figura 11. Custos totais efetivos $x$ potenciais (percentuais acumulados) 
É importante ressaltar que algumas dificuldades podem ter contribuído para o adiamento da manutenção de vários itens das moradias que são objeto deste estudo. A relutância na consecução de reparos, por exemplo, nas placas de vedação pode estar associada às características das peças de concreto armado, que possuem espessura média de $3 \mathrm{~cm}$ e armadura fina e pouco densa, transformando qualquer intervenção em sua estrutura em risco de dano grave nesses elementos.

Por outro lado, alguns itens encontram motivação para a sua execução, justamente pela facilidade no acesso aos materiais e métodos. Um exemplo desta constatação são os serviços de pintura, bastantes presentes em todas as unidades pesquisadas.

Com efeito, os serviços de manutenção logram êxito quando melhoram o desempenho dos sistemas construtivos ao longo da vida útil e asseguram a sua importância quando vem à tona a queda no desempenho, com consequente aumento dos seus custos.

\section{Considerações finais}

A partir do estudo realizado nas dez habitações de interesse social localizadas na cidade de João Pessoa, constatou-se que a atividade de manutenção, prioritariamente, foi realizada informalmente e de maneira corretiva. É pertinente ressaltar que essa informalidade, associada ao fato de se tratarem de habitações destinadas à população de baixa renda, recebe o devido suporte das literaturas internacionais mencionadas no texto, uma vez que as mesmas justificam o seu uso como meio de reduzir custos.

Detendo-se especificamente aos custos de manutenção, conclui-se que os custos efetivos apresentam grande variabilidade entre as dez moradias estudadas. Entretanto, em termos percentuais, comprovou-se que $22 \%$ dos itens de manutenção contribuíram com $95 \%$ dos custos efetivos das dez moradias analisadas.

Observando o decorrer dos dezesseis anos de uso, verificou-se que os custos efetivos aumentaram ao longo do tempo, apresentando os seus maiores valores nos anos de 2011 e 2012, fato esse também respaldado pela literatura da área.

$\mathrm{Na}$ apreciação dos serviços de manutenção realizados pelos moradores ao longo dos anos, constata-se que 0 item pintura foi o destaque para a maioria das moradias pesquisadas, tornando-se o item mais representativo entre todos, em termos de custos de manutenção efetiva.

Sobre os custos potenciais, ficou evidenciado, de forma clara e até certo ponto prevista, que, na maioria das moradias, há uma tendência de inversão proporcional do montante anual destes, em relação aos custos reais. Em 75\% das casas onde a média anual dos custos efetivos ultrapassou o valor de $R \$$ $20,00 / m 2$, os custos potenciais seriam menores do que os efetivos. Na mesma 


\section{Custos de manutenção efetivos e potenciais: um estudo em habitações}

de interesse social com sistema construtivo inovador

análise, foi demonstrado que, entre as casas com média anual de custos efetivos abaixo de $R \$ 10,00 / \mathrm{m} 2$, 83\% delas teriam seus custos potenciais superiores aos realizados em mais de seis vezes.

Numa análise conjunta das manutenções realizadas e das potenciais, podese destacar que poucos itens foram responsáveis por valores consideráveis dos custos de manutenção realizados. Ao longo dos anos, isso certamente gerou lacunas, em termos de necessidade de manutenção em outros itens. Como consequência, observou-se que, de forma mais bem distribuída, muitos itens incrementaram os custos de manutenção potenciais, ou seja, aqueles que ainda não foram realizados, mas considerados necessários. 


\section{Referências}

ABNT - ASSOCIAÇÃO BRASILEIRA DE NORMAS TÉCNICAS. NBR 5674 : manutenção de edificações: requisitos para o sistema de gestão de manutenção. Rio de Janeiro, 2012. Janeiro, 2013.

NBR 15575: edificações habitacionais: desempenho: partes 1 a 5. Rio de ABRANTES, V.; CALEJO, R. Manutenção e reabilitação de edifícios. 1999. Disponível em: $<$ www.sotecnisol.pt/noticiais9.html>. Acesso em: 24 ago. 1999.

ALL-HAJJ, A.; HORNER, M. Modelling the running costs of buildings. Construction Management and Economics, v. 16, n. 4, p. 459-470, 1997.

ALNER, G. R.; FELLOWS, R. F. Maintenance of local authority school buildings in UK: a case study. In: INTERNATIONAL SYMPOSIUM ON PROPERTY MAINTENANCE MANAGEMENT AND MODERNIZATION - CIBW70, 1990, Singapore. Proceedings... Singapore: [s.n.], 1990. p. 90-9.

ANDERSEN, H. S. Explanation of decay and renewal in the housing market: what can Europe learn from American research? Netherlands Journal of Housing and the Built Environment, v. 10, n. 1, p. 65-85, 1995.

ANTUNES, G. B. S. Estudo da manutenção de edifícios: percepções dos projetistas e gerente/administradores. 2004. 228 f. Dissertação (Mestrado em Engenharia). Programa de Pós-Graduação em Engenharia Civil. Universidade Federal do Espírito Santo, Vitória, 2004.

ASHWORTH, A. Estimating the life expectancies of building components in life-cycle costing calculations. Structural Survey, v. 14, n. 2, p. 4-8, 1996.

CREMONINI, R. A. A avaliação de edificações em uso a partir de levantamentos de campo: subsídios para a programação da manutenção de edifícios e novos projetos. In: SIMPÓSIO NACIONAL DE TECNOLOGIA DA CONSTRUÇÃO CIVIL, 1989, São Paulo. Anais... São Paulo: USP, 1989. p. 137-47.

EL-HARAM, M. A.; HORNER, M. W. Factors affecting housing maintenance cost. Journal of Quality in Maintenance Engineering, v. 8, n. 2, p. 115-23, 2002.

FREITAS, C. R. Geração de indicadores visando a otimização da gestão da manutenção na Universidade Federal do Rio Grande do Sul. 2009. 69 f. Trabalho de Diplomação (Graduação em Engenharia Civil) - Departamento de Engenharia Civil, Universidade Federal do Rio Grande do Sul, Porto Alegre, 2009.

GOMIDE, T. L. F; PUJADAS, F. Z. A; FAGUNDES NETO, J. C. P. Técnicas de inspeção e manutenção predial. São Paulo: Pini, 2006.

KOSKELA, L. An exploration towards a production theory and its application to construction. 2000. 296p. Thesis (Doctorate in Technology) - Technical Research Centre of Finland, Espoo, 2000.

MARTEINSSON. B.; JÓNSSON, B. Overall survey buildings: performance and maintenance. In: DURABILITY OF BUILDING MATERIALS \& COMPONENTS, 8., 1999, Vancouver. Proceedings... Vancouver: NRS, 1999. p. 1634-44.

MEIJER, F. Maintenance and improvement activities of homeowners in the Netherlands. Netherlands Journal of Housing and Built Environment, v. 8, n. 3, p. 327-46, 1993.

MEIRA, A. R. Estudo das variáveis associadas ao estado de manutenção e a satisfação dos moradores de condomínios residenciais. 2002. 285 p. Tese (Doutorado em Engenharia de Produção) - Universidade Federal de Santa Catarina, Florianópolis, 2002. 


\section{Custos de manutenção efetivos e potenciais: um estudo em habitações}

de interesse social com sistema construtivo inovador

OLANREWAJU, A. A.; IDRUS, A.; KHAMIDI, M. F. Creating maintenance cost model for university buildings. International Journal of Social, Management Economics and Business Engineering, v 5, n. 12, p. 336-41, 2011.

ROSSO, T. Racionalização da construção. São Paulo: FAUUSP, 1990.

SEELEY, I. H. Building maintenance. London: Macmillan, 1987.

STONE, P. A. Building design evaluation- cost-in-use. London: E.\&F. N. Spon, 1980.

WAEYENBERGH, G.; PINTELON, L. A framework for maintenance concept development. International Journal of Production Economics, v. 77, n. 3, p. 299-313, 2002. 
